\title{
Unpaired Spin Densities from NMR Shifts ${ }^{\dagger}$ and Magnetic Anisotropies of Pseudotetrahedral Cobalt(II) and Nickel(II) Vinamidine Bis(chelates)
}

\author{
Rudolf Knorr, * Hermann Hauer, Alfons Weiss, Heinz Polzer, Friedrich Ruf, \\ Peter Löw, Peter Dvortsák, and Petra Böhrer \\ Department of Chemistry and Biochemistry, Ludwig-Maximilians-Universität, Butenandtstr. 5-13, \\ 81377 München, Germany; E-mail: rhk@cup.uni-muenchen.de
}

\section{Contents}

1. Table S1: $\delta^{\mathrm{MPC}}, \vartheta^{\mathrm{CON}}, \Delta \rho_{\mathrm{N}}$, and $\Delta \rho_{\mathrm{DFT}} \quad$ p S1

2. Figures S1-S4 of $\vartheta^{\mathrm{CON}}$ at Varied Temperatures $\quad$ p S8

3. Magnetic Susceptibility Measurements ( $\chi$ and $\Delta \chi$ ), with Figure S5 and Table S2 p S12

4. The NMR Problem of the Paramagnetic Bis( $N, N^{\prime}$-chelates) $1 \quad$ p S17

5. More about $\vartheta^{\mathrm{CON}}$ and $\Delta \rho_{\mathrm{N}} \quad$ p S18

6. Recording, Properties, and Assignments of Paramagnetic NMR Spectra p S19

7. DFT Computational Techniques and Results, Enlarged Version of Figure 4, Tables S3a,b_ p S20

8. Topological Averaging $\quad$ p S27

9. Syntheses of the Vinamidines and $\operatorname{Bis}\left(N, N^{\prime}\right.$-chelates $) \quad$ p S28

10. Almost Unimpeded $N$-Aryl Rotation in $\mathbf{7 N i}$ and $\mathbf{8 N i} \quad$ p S44

11. Tables S4-S46 of $\delta^{\mathrm{OBS}}, \delta^{\mathrm{DIA}}, \delta^{\mathrm{PARA}}, \delta^{\mathrm{MPC}}$, and $\vartheta^{\mathrm{CON}}$ at Varied Temperatures $\quad$ p S45

12. Appendix: Initializing Preparations $\quad$ p S91

13. References $\quad$ p S93

Note: Formulae, Charts, and literature references taken over from the Main Text are utilized with their unchanged numbers, whereas those cited here for the first time are denominated beginning with S. For convenience, the numbers of structural formulae begin with S35 in section 9. 


\section{Table S1}

Table S1. Metal-Centered Pseudocontact Shifts $\delta^{\mathrm{MPC}}$ (ppm at $298 \mathrm{~K}$ ), Reduced Contact Shifts $\vartheta^{\mathrm{CON}}$ (ppm at 298

$\mathrm{K})^{a}$, „Experimental“ Spin Densities $\Delta \rho_{\mathrm{N}}$ from Eqs $4 \mathrm{~b}$ and $4 \mathrm{c}$, Theoretical ${ }^{b}$ Spin Densities $\Delta \rho_{\mathrm{DFT}}$, and No. of the Correlation Lines in Figures S1-S4

\begin{tabular}{|c|c|c|c|c|c|c|c|c|c|c|}
\hline \multirow{3}{*}{$\begin{array}{l}\text { en- } \\
\text { try } \\
\text { S1.1 }\end{array}$} & \multirow{3}{*}{$\begin{array}{l}\text { nucleus } \\
\\
C^{1,3}\end{array}$} & \multirow{3}{*}{$\begin{array}{l}\text { cat- } \\
\text { ion } \\
\mathrm{Ni}\end{array}$} & \multirow{3}{*}{$\begin{array}{l}\delta^{\mathrm{MPC}} \\
298 \mathrm{~K} \\
-43.5\end{array}$} & \multirow{2}{*}{\multicolumn{2}{|c|}{$\begin{array}{c}\vartheta^{\mathrm{CON}} \\
298 \mathrm{~K}^{a}\end{array}$}} & \multirow{3}{*}{$\begin{array}{c}\Delta \rho_{\mathrm{N}} \\
\text { exp. } \\
-0.002162\end{array}$} & \multirow{3}{*}{$\begin{array}{l}\Delta \rho_{\mathrm{DFT}} \\
{[6-311 G} \\
(d, p)]^{b} \\
-0.00305\end{array}$} & \multirow{3}{*}{$\begin{array}{l}\Delta \rho_{\mathrm{DFT}} \\
{[6-311} \\
+G(2 d, p)]^{b} \\
-0.00373\end{array}$} & \multirow{3}{*}{$\begin{array}{l}\text { corr. } \\
\text { line } \\
\text { no. } \\
27\end{array}$} & \multirow{3}{*}{$\begin{array}{l}\text { valid for } \\
\text { complex } \\
\mathbf{6 N i}\end{array}$} \\
\hline & & & & & & & & & & \\
\hline & & & & $-435^{c, d}$ & \pm 20 & & & & & \\
\hline $\mathrm{S} 1.2$ & $C^{1,3}$ & $\mathrm{Ni}$ & -43.5 & $-555^{c, e}$ & \pm 25 & -0.002759 & $\begin{array}{l}-0.00380 \\
-0.00383\end{array}$ & $\begin{array}{l}-0.00460 \\
-0.00462\end{array}$ & 28 & $\begin{array}{l}12 \mathrm{Ni} \\
11,13 \mathrm{Ni}\end{array}$ \\
\hline S1.3 & $C^{1,3}$ & $\mathrm{Ni}$ & -43.5 & $-574^{c, f}$ & \pm 20 & -0.002853 & -0.00322 & -0.00387 & 29 & $15 \mathrm{Ni}$ \\
\hline S1.4 & $C^{1,3}$ & $\mathrm{Ni}$ & -43.5 & $-604^{c, g}$ & \pm 20 & -0.003002 & -0.00352 & -0.00422 & 30 & $24 \mathrm{Ni}$ \\
\hline S1.5 & $C^{1,3}$ & $\mathrm{Ni}$ & -43.5 & $-689^{c, g}$ & \pm 20 & -0.003425 & -0.00546 & -0.00603 & 31 & $19 \mathbf{N i}^{h}$ \\
\hline S1.6 & $C^{2}$ & $\mathrm{Ni}$ & -42.2 & +690 & \pm 5 & +0.003430 & +0.00296 & +0.00375 & 1 & $11,12,13 N i$ \\
\hline S1.7 & $C^{2}$ & $\mathrm{Ni}$ & -42.2 & +670 & \pm 4 & +0.003331 & +0.00235 & +0.00299 & - & $24 \mathrm{Ni}$ \\
\hline S1.8 & $C^{2}$ & $\mathrm{Ni}$ & -42.2 & +564 & \pm 1 & +0.002804 & +0.00237 & +0.00295 & - & $19 \mathbf{N i}^{h}$ \\
\hline S1.9 & $C^{2}$ & $\mathrm{Ni}$ & -42.2 & +549 & \pm 9 & +0.002729 & $\begin{array}{l}+0.00241 \\
+0.00224\end{array}$ & $\begin{array}{l}+0.00305 \\
+0.00284\end{array}$ & 3 & $\begin{array}{l}6 \mathrm{Ni} \\
15 \mathrm{Ni}\end{array}$ \\
\hline S1.10 & $\mathrm{N}-\mathrm{CH}_{3}$ & $\mathrm{Ni}$ & +16.65 & +242 & \pm 2 & +0.001203 & $\begin{array}{l}+0.00116 \\
+0.00101\end{array}$ & $\begin{array}{l}+0.00135 \\
+0.00133\end{array}$ & 9 & $\begin{array}{l}21 \mathrm{Ni} \\
14 \mathrm{Ni}\end{array}$ \\
\hline S1.11 & $N-i-C$ & Co & -30.1 & +263 & \pm 2 & +0.001037 & +0.00190 & +0.00183 & - & 6Co \\
\hline S1.12 & $N-i-C$ & Co & -30.1 & +251 & \pm 5 & +0.000989 & +0.00193 & +0.00185 & 48 & 11,12,13Co \\
\hline S1.13 & $N-i-C$ & Co & -30.1 & +238 & \pm 6 & +0.000938 & +0.00172 & +0.00162 & - & 10Co \\
\hline S1.14 & $N-i-\mathrm{C}$ & Co & -30.1 & +166 & \pm 4 & +0.000654 & +0.00197 & +0.00196 & - & 15Co \\
\hline S1.15 & $N-i-C$ & $\mathrm{Ni}$ & +21.7 & +260 & \pm 3 & +0.001292 & +0.00230 & +0.00201 & 47 & $6 \mathrm{Ni}$ \\
\hline S1.16 & $N-i-C$ & $\mathrm{Ni}$ & +21.7 & +245 & \pm 7 & +0.001218 & +0.00234 & +0.00200 & 49 & $11,12,13 \mathrm{Ni}$ \\
\hline S1.17 & $N-i-C$ & $\mathrm{Ni}$ & +21.7 & +221 & \pm 1 & +0.001099 & +0.00206 & +0.00170 & - & $10 \mathrm{Ni}$ \\
\hline S1.18 & $N-i-\mathrm{C}$ & $\mathrm{Ni}$ & +21.7 & +197 & - & +0.000979 & +0.00248 & +0.00225 & - & $15 \mathrm{Ni}$ \\
\hline S1.19 & $N-i-C$ & $\mathrm{Ni}$ & +21.7 & +158 & \pm 2 & +0.000785 & +0.00238 & +0.00212 & 53 & $24 \mathrm{Ni}$ \\
\hline $\mathrm{S} 1.20$ & $N-O-C$ & Co & -19.7 & +556 & $i$ & +0.002192 & +0.00193 & +0.00211 & 43 & $11,12,13 \mathrm{Co}$ \\
\hline
\end{tabular}




\begin{tabular}{|c|c|c|c|c|c|c|c|c|c|c|}
\hline \multirow{3}{*}{$\begin{array}{l}\text { en- } \\
\text { try } \\
\text { S1.21 }\end{array}$} & \multirow{3}{*}{$\begin{array}{l}\text { nucleus } \\
N-O-C\end{array}$} & \multirow{3}{*}{$\begin{array}{l}\text { cat- } \\
\text { ion } \\
\text { Co }\end{array}$} & \multirow{3}{*}{$\begin{array}{l}\delta^{\mathrm{MPC}} \\
298 \mathrm{~K} \\
-19.7\end{array}$} & \multirow{2}{*}{\multicolumn{2}{|c|}{$\begin{array}{c}\vartheta^{\mathrm{CON}} \\
298 \mathrm{~K}^{a}\end{array}$}} & \multirow{3}{*}{$\begin{array}{c}\Delta \rho_{\mathrm{N}} \\
\text { exp. } \\
+0.002141\end{array}$} & \multirow{3}{*}{$\begin{array}{l}\Delta \rho_{\mathrm{DFT}} \\
{[6-311 G} \\
(d, p)]^{b} \\
+0.00192\end{array}$} & \multirow{3}{*}{$\begin{array}{l}\Delta \rho_{\mathrm{DFT}} \\
{[6-311} \\
+G(2 d, p)]^{b} \\
+0.00211\end{array}$} & \multirow{3}{*}{$\begin{array}{l}\text { corr. } \\
\text { line } \\
\text { no. } \\
44\end{array}$} & \multirow{3}{*}{$\begin{array}{l}\text { valid for } \\
\text { complex } \\
\mathbf{1 0 C o}\end{array}$} \\
\hline & & & & & & & & & & \\
\hline & & & & +543 & $i$ & & & & & \\
\hline $\mathrm{S} 1.22$ & $\mathrm{~N}-\mathrm{O}-\mathrm{C}$ & Co & -19.7 & +528 & \pm 6 & +0.002081 & $\begin{array}{l}+0.00184 \\
+0.00277\end{array}$ & $\begin{array}{l}+0.00201 \\
+0.00302\end{array}$ & 45 & $\begin{array}{l}\text { 6Co } \\
\text { 19Co }\end{array}$ \\
\hline $\mathrm{S} 1.23$ & $\mathrm{~N}-\mathrm{O}-\mathrm{C}$ & Co & -19.7 & +511 & \pm 2 & +0.002014 & +0.00211 & +0.00227 & 46 & 15Co \\
\hline S1.24 & $\mathrm{N}-\mathrm{O}-\mathrm{C}$ & $\mathrm{Ni}$ & +13.6 & +513 & \pm 3 & +0.002550 & +0.00363 & +0.00405 & 46 & $19 \mathbf{N i}^{h}$ \\
\hline S1.25 & $\mathrm{N}-\mathrm{O}-\mathrm{C}$ & $\mathrm{Ni}$ & +13.6 & +470 & \pm 7 & +0.002336 & $\begin{array}{l}+0.00237 \\
+0.00255 \\
+0.00256\end{array}$ & $\begin{array}{l}+0.00265 \\
+0.00279 \\
+0.00281\end{array}$ & 4 & $\begin{array}{l}10-13 \mathrm{Ni} \\
15 \mathrm{Ni} \\
24 \mathrm{Ni}\end{array}$ \\
\hline S1.26 & $\mathrm{N}-\mathrm{O}-\mathrm{C}$ & $\mathrm{Ni}$ & +13.6 & +450 & \pm 1 & +0.002237 & +0.00227 & +0.00251 & 5 & $6 \mathrm{Ni}$ \\
\hline S1.27 & $N-O-\mathrm{H}$ & Co & -18.6 & -25.5 & $j$ & -0.000101 & -0.00013 & -0.00013 & - & 6Co \\
\hline S1.28 & $N-O-H$ & $\mathrm{Ni}$ & +13.4 & -29.0 & $j$ & -0.000144 & -0.00020 & -0.00022 & - & $6 \mathrm{Ni}$ \\
\hline $\mathrm{S} 1.29$ & $N-O-\mathrm{H}$ & $\mathrm{Ni}$ & +13.4 & -32.0 & \pm 1.0 & -0.000159 & -0.00020 & -0.00023 & 57 & $11,12,13 N i$ \\
\hline S1.30 & $N-O-\mathrm{H}$ & $\mathrm{Ni}$ & +13.4 & -33.6 & \pm 0.3 & -0.000167 & -0.00019 & -0.00021 & - & $16 \mathrm{Ni}$ \\
\hline S1.31 & $N-\mathrm{O}-\mathrm{H}$ & $\mathrm{Ni}$ & +13.4 & -34.4 & \pm 0.3 & -0.000171 & -0.00020 & -0.00023 & - & $15,25,27 \mathrm{Ni}$ \\
\hline S1.32 & $N-O-\mathrm{H}$ & $\mathrm{Ni}$ & +13.4 & -36.0 & \pm 1 & -0.000179 & -0.00020 & -0.00022 & 20 & $22-24,26,28 \mathrm{Ni}$ \\
\hline S1.33 & $N-\mathrm{O}-\mathrm{H}$ & $\mathrm{Ni}$ & +13.4 & -41.0 & $j$ & -0.000204 & -0.00028 & -0.00028 & 83 & $19 \mathbf{N i}^{h}$ \\
\hline S1.34 & $N-m-\mathrm{C}$ & Co & -8.35 & -77.0 & $i$ & -0.000304 & -0.00038 & -0.00044 & - & 6,11,12,13Co \\
\hline S1.35 & $N-m-\mathrm{C}$ & Co & -8.35 & -88.2 & $i$ & -0.000348 & -0.00041 & -0.00046 & - & 10Co \\
\hline S1.36 & $N-m-\mathrm{C}$ & Co & -8.35 & -116.3 & \pm 0.8 & -0.000458 & -0.00040 & -0.00044 & 64 & 15Co \\
\hline S1.37 & $N-m-C$ & Co & -8.35 & -163.7 & \pm 0.9 & -0.000645 & -0.00088 & -0.00084 & 24 & $19 \mathrm{Co}^{h}$ \\
\hline S1.38 & $N-m-\mathrm{C}$ & $\mathrm{Ni}$ & +5.92 & -87.2 & $i$ & -0.000433 & -0.00052 & -0.00060 & 22 & $6,11,12,13 \mathrm{Ni}$ \\
\hline S1.39 & $N-m-\mathrm{C}$ & $\mathrm{Ni}$ & +5.92 & -95.9 & \pm 0.1 & -0.000477 & -0.00055 & -0.00064 & - & $10 \mathrm{Ni}$ \\
\hline S1.40 & $N-m-C$ & $\mathrm{Ni}$ & +5.92 & -110 & \pm 1 & -0.000547 & -0.00052 & -0.00060 & 63 & $15 \mathrm{Ni}$ \\
\hline S1.41 & $N-m-\mathrm{C}$ & $\mathrm{Ni}$ & +5.92 & -116.1 & \pm 1.2 & -0.000577 & -0.00053 & -0.00062 & 64 & $24 \mathrm{Ni}$ \\
\hline $\mathrm{S} 1.42$ & $N-m-\mathrm{C}$ & $\mathrm{Ni}$ & +5.92 & -157 & \pm 1 & -0.000780 & -0.00101 & -0.00097 & 65 & $19 \mathbf{N i}^{h}$ \\
\hline S1.43 & $N-m-\mathrm{H}$ & Co & -4.83 & +17.8 & \pm 0.3 & +0.000070 & +0.00010 & +0.00010 & 18 & 10Co \\
\hline S1.44 & $N-m-\mathrm{H}$ & Co & -4.83 & +16.7 & \pm 0.3 & +0.000066 & +0.00010 & +0.00010 & 55 & 11,12,13Co \\
\hline S1.45 & $N-m-\mathrm{H}$ & Co & -4.83 & +16.0 & \pm 0.2 & +0.000063 & +0.00012 & +0.00013 & - & $19 \mathrm{Co}{ }^{h}$ \\
\hline S1.46 & $N-m-\mathrm{H}$ & Co & -4.83 & +14.7 & \pm 0.1 & +0.000058 & +0.00010 & +0.00010 & - & 15Co \\
\hline
\end{tabular}




\begin{tabular}{|c|c|c|c|c|c|c|c|c|c|c|}
\hline \multirow{3}{*}{$\begin{array}{l}\text { en- } \\
\text { try } \\
\text { S1.47 }\end{array}$} & \multirow{3}{*}{$\begin{array}{c}\text { nucleus } \\
N-m-\mathrm{H}\end{array}$} & \multirow{3}{*}{$\begin{array}{l}\text { cat- } \\
\text { ion } \\
\mathrm{Ni}\end{array}$} & \multirow{3}{*}{$\begin{array}{l}\delta^{\mathrm{MPC}} \\
298 \mathrm{~K} \\
+3.36\end{array}$} & \multirow{2}{*}{\multicolumn{2}{|c|}{$\begin{array}{c}\vartheta^{\mathrm{CON}} \\
298 \mathrm{~K}^{a}\end{array}$}} & \multirow{3}{*}{$\begin{array}{c}\Delta \rho_{\mathrm{N}} \\
\text { exp. } \\
+0.000092\end{array}$} & \multirow{3}{*}{$\begin{array}{l}\Delta \rho_{\text {DFT }} \\
{[6-311 G} \\
(d, p)]^{b} \\
+0.00016\end{array}$} & \multirow{3}{*}{$\begin{array}{l}\Delta \rho_{\mathrm{DFT}} \\
{[6-311} \\
+G(2 d, p)]^{b} \\
+0.00017\end{array}$} & \multirow{3}{*}{$\begin{array}{l}\text { corr. } \\
\text { line } \\
\text { no. } \\
-\end{array}$} & \multirow{3}{*}{$\begin{array}{l}\text { valid for } \\
\text { complex } \\
\text { 19Ni }^{h}\end{array}$} \\
\hline & & & & & & & & & & \\
\hline & & & & +18.5 & \pm 0.2 & & & & & \\
\hline $\mathrm{S} 1.48$ & $N-m-\mathrm{H}$ & $\mathrm{Ni}$ & +3.36 & +17.9 & \pm 0.2 & +0.000089 & +0.00014 & +0.00015 & 69 & $25-27 \mathrm{Ni}$ \\
\hline S1.49 & $N-m-\mathrm{H}$ & $\mathrm{Ni}$ & +3.36 & +17.4 & \pm 0.8 & +0.000086 & +0.00014 & +0.00015 & 18 & $\begin{array}{l}9,11,12,13,15 \\
23,24,28 \mathrm{Ni}\end{array}$ \\
\hline $\mathrm{S} 1.50$ & $N-m-\mathrm{H}$ & $\mathrm{Ni}$ & +3.36 & +16.3 & \pm 0.6 & +0.000081 & - & +0.00013 & - & $7,8 \mathrm{Ni}$ \\
\hline $\mathrm{S} 1.51$ & $N-p-\mathrm{C}$ & Co & -6.59 & +235 & \pm 4 & +0.000926 & +0.00115 & +0.00118 & 50 & $19 \mathrm{Co}^{h}$ \\
\hline $\mathrm{S} 1.52$ & $N-p-\mathrm{C}$ & Co & -6.59 & +187.2 & \pm 1.0 & +0.000738 & +0.00060 & +0.00068 & - & 15Co \\
\hline S1.53 & $N-p-C$ & Co & -6.59 & +182.6 & \pm 0.8 & +0.000720 & +0.00064 & +0.00073 & 51 & 10Co \\
\hline S1.54 & $N-p-\mathrm{C}$ & Co & -6.59 & +176 & \pm 2 & +0.000694 & +0.00060 & +0.00068 & 52 & 11,12,13Co \\
\hline S1.55 & $N-p-\mathrm{C}$ & Co & -6.59 & +163 & \pm 1 & +0.000643 & +0.00055 & +0.00063 & - & 6Co \\
\hline S1.56 & $N-p-\mathrm{C}$ & $\mathrm{Ni}$ & +4.65 & +223 & \pm 2 & +0.001109 & +0.00134 & +0.00141 & 10 & $19 \mathbf{N i}^{h}$ \\
\hline $\mathrm{S} 1.57$ & $N-p-\mathrm{C}$ & $\mathrm{Ni}$ & +4.65 & +176 & \pm 2 & +0.000875 & +0.00077 & +0.00089 & 52 & $24 \mathrm{Ni}$ \\
\hline $\mathrm{S} 1.58$ & $N-p-\mathrm{C}$ & $\mathrm{Ni}$ & +4.65 & +168 & \pm 2 & +0.000835 & +0.00076 & +0.00088 & - & $15 \mathrm{Ni}$ \\
\hline S1.59 & $N-p-\mathrm{C}$ & $\mathrm{Ni}$ & +4.65 & +165 & \pm 1 & +0.000820 & +0.00081 & +0.00096 & - & $10 \mathrm{Ni}$ \\
\hline S1.60 & $N-p-\mathrm{C}$ & $\mathrm{Ni}$ & +4.65 & +157 & $j$ & +0.000780 & +0.00076 & +0.00088 & 13 & $11,12,13 \mathrm{Ni}$ \\
\hline S1.61 & $N-p-\mathrm{C}$ & $\mathrm{Ni}$ & +4.65 & +148 & $j$ & +0.000736 & +0.00071 & +0.00083 & 14 & $6 \mathrm{Ni}$ \\
\hline S1.62 & $N-p-\mathrm{H}$ & Co & -3.89 & -23.0 & \pm 1.0 & -0.000091 & -0.00012 & -0.00013 & 77 & 6Co \\
\hline S1.63 & $N-p-\mathrm{H}$ & Co & -3.89 & -24.9 & $i$ & -0.000098 & -0.00012 & -0.00014 & 78 & 11,12,13Co \\
\hline S1.64 & $N-p-\mathrm{H}$ & Co & -3.89 & -31.9 & \pm 0.4 & -0.000126 & -0.00012 & -0.00014 & - & 15Co \\
\hline S1.65 & $N-p-\mathrm{H}$ & Co & -3.89 & -40.6 & $j$ & -0.000160 & -0.00024 & -0.00025 & 82 & $19 \mathrm{Co}^{h}$ \\
\hline S1.66 & $N-p-\mathrm{H}$ & $\mathrm{Ni}$ & +2.72 & -23.0 & \pm 1.0 & -0.000114 & -0.00015 & -0.00018 & 77 & $6,7,8 \mathrm{Ni}$ \\
\hline S1.67 & $N-p-\mathrm{H}$ & $\mathrm{Ni}$ & +2.72 & -24.2 & \pm 0.4 & -0.000120 & -0.00019 & -0.00020 & - & $20 \mathbf{N i}{ }^{h, k}$ \\
\hline S1.68 & $N-p-\mathrm{H}$ & $\mathrm{Ni}$ & +2.72 & -25.1 & $i$ & -0.000125 & -0.00016 & -0.00019 & 78 & $9,11,12,13 \mathrm{Ni}$ \\
\hline S1.69 & $N-p-\mathrm{H}$ & $\mathrm{Ni}$ & +2.72 & -28.5 & \pm 0.1 & -0.000142 & -0.00016 & -0.00018 & 79 & $16 \mathrm{Ni}$ \\
\hline $\mathrm{S} 1.70$ & $N-p-\mathrm{H}$ & $\mathrm{Ni}$ & +2.72 & -29.4 & \pm 0.2 & -0.000146 & -0.00016 & -0.00018 & - & $15 \mathrm{Ni}$ \\
\hline $\mathrm{S} 1.71$ & $N-p-\mathrm{H}$ & $\mathrm{Ni}$ & +2.72 & -29.6 & \pm 1.5 & -0.000147 & -0.00016 & -0.00018 & - & $22 \mathrm{Ni}$ \\
\hline $\mathrm{S} 1.72$ & $N-p-\mathrm{H}$ & $\mathrm{Ni}$ & +2.72 & -30.7 & $i$ & -0.000153 & -0.00016 & -0.00019 & 80 & $23-28 \mathrm{Ni}$ \\
\hline S1.73 & $N-p-\mathrm{H}$ & $\mathrm{Ni}$ & +2.72 & -38.45 & $j$ & -0.000191 & -0.00029 & -0.00033 & 81 & $19 \mathbf{N i}^{h}$ \\
\hline
\end{tabular}




\begin{tabular}{|c|c|c|c|c|c|c|c|c|c|c|}
\hline \multirow{3}{*}{$\begin{array}{l}\text { en- } \\
\text { try } \\
\text { S1.74 }\end{array}$} & \multirow{3}{*}{$\begin{array}{l}\text { nucleus } \\
N-p-\mathrm{H}\end{array}$} & \multirow{3}{*}{$\begin{array}{l}\text { cat- } \\
\text { ion } \\
\mathrm{Ni}\end{array}$} & \multirow{3}{*}{$\begin{array}{l}\delta^{\mathrm{MPC}} \\
298 \mathrm{~K} \\
+2.72\end{array}$} & \multirow{2}{*}{\multicolumn{2}{|c|}{$\begin{array}{c}\vartheta^{\mathrm{CON}} \\
298 \mathrm{~K}^{a}\end{array}$}} & \multirow{3}{*}{$\begin{array}{c}\Delta \rho_{\mathrm{N}} \\
\text { exp. } \\
-0.000196\end{array}$} & \multirow{3}{*}{$\begin{array}{l}\Delta \rho_{\mathrm{DFT}} \\
{[6-311 G} \\
(d, p)]^{b} \\
-0.00019\end{array}$} & \multirow{3}{*}{$\begin{array}{l}\Delta \rho_{\mathrm{DFT}} \\
{[6-311} \\
+G(2 d, p)]^{b} \\
-0.00026\end{array}$} & \multirow{3}{*}{$\begin{array}{l}\text { corr. } \\
\text { line } \\
\text { no. } \\
-\end{array}$} & \multirow{3}{*}{$\begin{array}{l}\text { valid for } \\
\text { complex } \\
\mathbf{2 0 N i}{ }^{h, l}\end{array}$} \\
\hline & & & & & & & & & & \\
\hline & & & & -39.5 & $j$ & & & & & \\
\hline S1.75 & $\mathrm{N}-\mathrm{m}-\mathrm{CH}_{3}$ & Co & -3.83 & +33.1 & \pm 0.2 & +0.000130 & +0.00017 & +0.00017 & 17 & 6Co \\
\hline S1.76 & $\mathrm{N}-\mathrm{m}-\mathrm{CH}_{3}$ & $\mathrm{Ni}$ & +2.65 & +32.6 & \pm 0.2 & +0.000162 & +0.00023 & +0.00025 & 17 & $6 \mathrm{Ni}$ \\
\hline S1.77 & $\mathrm{N}-\mathrm{m}-\mathrm{CH}_{3}$ & Co & -2.88 & -6.7 & \pm 0.3 & -0.000026 & -0.000036 & -0.000040 & 39 & 6Co \\
\hline S1.78 & $\mathrm{N}-\mathrm{m}-\mathrm{CH}_{3}$ & $\mathrm{Ni}$ & +1.96 & -7.9 & \pm 0.3 & -0.000039 & -0.000054 & -0.000063 & 40 & $6,7,8 \mathrm{Ni}$ \\
\hline S1.79 & $\mathrm{N}-\mathrm{m}-\mathrm{CH}_{3}$ & $\mathrm{Ni}$ & +1.96 & -9.59 & \pm 0.04 & -0.000048 & -0.000056 & -0.000064 & 76 & $16 \mathrm{Ni}$ \\
\hline S1.80 & $\mathrm{N}-\mathrm{m}-\mathrm{CH}_{3}$ & $\mathrm{Ni}$ & +1.96 & -10.1 & \pm 0.15 & -0.000050 & -0.000056 & -0.000064 & - & $22 \mathrm{Ni}$ \\
\hline S1.81 & $N-p-C_{3}$ & Co & -3.22 & -62.0 & \pm 0.3 & -0.000244 & -0.00026 & -0.00029 & 21 & 10Co \\
\hline S1.82 & $N-p-C_{3}$ & $\mathrm{Ni}$ & +2.24 & -61.8 & \pm 0.2 & -0.000307 & -0.00034 & -0.00038 & 21 & $10 \mathrm{Ni}$ \\
\hline S1.83 & $N-p-\mathrm{CH}_{3}$ & Co & -2.78 & +26.2 & \pm 0.2 & +0.000103 & +0.000115 & +0.00013 & 54 & 10Co \\
\hline S1.84 & $C^{\alpha^{\prime}}$ & Co & +13.9 & +873 & \pm 8 & +0.003441 & +0.00603 & +0.00582 & - & 15Co \\
\hline S1.85 & $C^{\alpha^{\prime}}$ & $\mathrm{Ni}$ & -9.30 & +898 & \pm 1 & +0.004464 & +0.00588 & +0.00586 & - & $19 \mathbf{N i}^{h}$ \\
\hline S1.86 & $C^{\alpha^{\prime}}$ & $\mathrm{Ni}$ & -9.30 & +665 & \pm 5 & +0.003306 & $\begin{array}{l}+0.00507 \\
+0.00489\end{array}$ & $\begin{array}{l}+0.00506 \\
+0.00491\end{array}$ & 2 & $\begin{array}{l}15 \mathrm{Ni} \\
24 \mathrm{Ni}\end{array}$ \\
\hline S1.87 & $\mathrm{H}^{\alpha^{\prime}}$ & Co & +20.6 & +458 & \pm 3 & +0.001805 & +0.00262 & +0.00256 & - & 11,12Co \\
\hline S1.88 & $\mathrm{H}^{\alpha^{\prime}}$ & Co & +20.6 & +449 & \pm 5 & +0.001770 & +0.00255 & +0.00248 & - & 6,10Co \\
\hline S1.89 & $\mathrm{H}^{\alpha^{\prime}}$ & $\mathrm{Ni}$ & -13.8 & +404 & \pm 8 & +0.002008 & +0.00236 & +0.00240 & - & $20 \mathbf{N i}^{h}$ \\
\hline S1.90 & $\mathrm{H}^{\alpha^{\prime}}$ & $\mathrm{Ni}$ & -13.8 & +386 & \pm 4 & +0.001919 & +0.00245 & +0.00247 & 6 & $11,12,13 \mathrm{Ni}$ \\
\hline S1.91 & $\mathrm{H}^{\alpha^{\prime}}$ & $\mathrm{Ni}$ & -13.8 & +379 & - & +0.001884 & +0.00238 & +0.00240 & - & $9 \mathrm{Ni}$ \\
\hline S1.92 & $\mathrm{H}^{\alpha^{\prime}}$ & $\mathrm{Ni}$ & -13.8 & +363 & \pm 9 & +0.001804 & +0.00238 & +0.00237 & 7 & $6,7 \mathrm{Ni}$ \\
\hline S1.93 & $C^{\beta^{\prime}}$ & Co & +6.09 & -85.5 & \pm 1.9 & -0.000337 & +0.000116 & +0.000116 & 61 & $19 \mathrm{Co}^{h}$ \\
\hline S1.94 & $C^{\beta^{\prime}}$ & $\mathrm{Ni}$ & -4.01 & -58.6 & \pm 0.6 & -0.000291 & +0.000123 & +0.000127 & 60 & $19 \mathbf{N i}^{h}$ \\
\hline S1.95 & $\mathrm{H}^{\beta^{\prime}}$ & Co & +8.26 & -52.3 & \pm 0.8 & -0.000206 & -0.000288 & -0.000306 & - & 15Co \\
\hline S1.96 & $\mathrm{H}^{\beta^{\prime}}$ & $\mathrm{Ni}$ & -5.50 & -44.6 & \pm 0.7 & -0.000222 & -0.00041 & -0.00046 & 58 & $23,24,28 \mathrm{Ni}$ \\
\hline S1.97 & $\mathrm{H}^{\beta^{\prime}}$ & $\mathrm{Ni}$ & -5.50 & -45.5 & \pm 0.8 & -0.000226 & $\begin{array}{l}-0.00038 \\
-0.00041\end{array}$ & $\begin{array}{l}-0.00042 \\
-0.00045\end{array}$ & 58 & $\begin{array}{l}16,22 \mathrm{Ni} \\
15,26 \mathrm{Ni}\end{array}$ \\
\hline S1.98 & $\mathrm{H}^{\beta^{\prime}}$ & $\mathrm{Ni}$ & -5.50 & -49.3 & \pm 0.6 & -0.000245 & -0.00041 & -0.00046 & 59 & $25,27 \mathrm{Ni}$ \\
\hline S1.99 & $\mathrm{H}^{\beta^{\prime}}$ & $\mathrm{Ni}$ & -5.50 & -50.5 & \pm 0.7 & -0.000251 & $\begin{array}{l}-0.00033 \\
-0.00038\end{array}$ & $\begin{array}{l}-0.00042 \\
-0.00043\end{array}$ & 59 & $\begin{array}{l}14 \mathrm{Ni} \\
21 \mathrm{Ni}\end{array}$ \\
\hline
\end{tabular}




\begin{tabular}{|c|c|c|c|c|c|c|c|c|c|c|}
\hline \multirow{3}{*}{$\begin{array}{l}\text { en- } \\
\text { try } \\
\text { S1.100 }\end{array}$} & \multirow[t]{2}{*}{ nucleus } & \multirow{3}{*}{$\begin{array}{l}\text { cat- } \\
\text { ion } \\
\text { Co }\end{array}$} & \multirow{3}{*}{$\begin{array}{l}\delta^{\mathrm{MPC}} \\
298 \mathrm{~K} \\
+5.50\end{array}$} & \multirow{2}{*}{\multicolumn{2}{|c|}{$\begin{array}{c}\vartheta^{\mathrm{CON}} \\
298 \mathrm{~K}^{a}\end{array}$}} & \multirow{3}{*}{$\begin{array}{c}\Delta \rho_{\mathrm{N}} \\
\text { exp. } \\
+0.000004\end{array}$} & \multirow{3}{*}{$\begin{array}{l}\Delta \rho_{\mathrm{DFT}} \\
{[6-311 G} \\
(d, p)]^{b} \\
-0.0000006\end{array}$} & \multirow{3}{*}{$\begin{array}{l}\Delta \rho_{\mathrm{DFT}} \\
{[6-311} \\
+G(2 d, p)]^{b} \\
-0.0000005\end{array}$} & \multirow{3}{*}{$\begin{array}{l}\text { corr. } \\
\text { line } \\
\text { no. } \\
-\end{array}$} & \multirow{3}{*}{$\begin{array}{l}\text { valid for } \\
\text { complex } \\
\text { 19Co }^{h}\end{array}$} \\
\hline & & & & & & & & & & \\
\hline & $\mathrm{H}^{\gamma^{\prime}}$ & & & +1.1 & \pm 0.7 & & & & & \\
\hline S1.101 & $\mathrm{H}^{\gamma^{\prime}}$ & $\mathrm{Ni}$ & -3.65 & +4.84 & \pm 0.12 & +0.000019 & -0.000007 & -0.000006 & - & $19 \mathbf{N i}^{h}$ \\
\hline S1.102 & $\mathrm{H}^{\gamma^{\prime}}$ & $\mathrm{Ni}$ & -3.65 & +4.20 & \pm 0.12 & +0.000017 & -0.000063 & -0.000061 & - & $20 \mathbf{N i}^{h}$ \\
\hline S1.103 & $\mathrm{C}^{\alpha} \quad\left(\mathrm{sp}^{3}\right)$ & Co & +20.3 & -224 & \pm 10 & -0.000883 & $\begin{array}{l}-0.00090 \\
-0.00093\end{array}$ & $\begin{array}{l}-0.00101 \\
-0.00101\end{array}$ & 25 & $\begin{array}{l}\text { 10,12,13Co } \\
11 \mathrm{Co}\end{array}$ \\
\hline S1.104 & $\mathrm{C}^{\alpha} \quad\left(\mathrm{sp}^{3}\right)$ & $\mathrm{Ni}$ & -13.4 & -227 & \pm 3 & -0.001128 & $\begin{array}{l}-0.00123 \\
-0.00127\end{array}$ & $\begin{array}{l}-0.00143 \\
-0.00147\end{array}$ & 25 & $\begin{array}{l}12,13 \mathrm{Ni} \\
11 \mathrm{Ni}\end{array}$ \\
\hline S1.105 & $\mathrm{C}^{\alpha}\left(\mathrm{sp}^{2}\right)$ & $\mathrm{Ni}$ & -13.9 & -263 & \pm 4 & -0.001307 & -0.00134 & -0.00155 & 26 & $24 \mathrm{Ni}$ \\
\hline S1.106 & $\mathrm{H}^{\alpha}$ & Co & +27.0 & -101 & \pm 4 & -0.000398 & $\begin{array}{l}-0.00044 \\
-0.00047\end{array}$ & $\begin{array}{l}-0.00049 \\
-0.00053\end{array}$ & 23 & $\begin{array}{l}\text { 15Co } \\
6 \mathrm{Co}\end{array}$ \\
\hline S1.107 & $\mathrm{H}^{\alpha}$ & Co & +27.0 & -118 & \pm 4 & -0.000465 & -0.00047 & -0.00053 & - & $19 \mathrm{Co}^{h}$ \\
\hline S1.108 & $\mathrm{H}^{\alpha}$ & $\mathrm{Ni}$ & -17.8 & -93 & \pm 2 & -0.000462 & -0.00064 & -0.00077 & 62 & $20 \mathbf{N i}^{h}$ \\
\hline S1.109 & $\mathrm{H}^{\alpha}$ & $\mathrm{Ni}$ & -17.8 & -105 & \pm 6 & -0.000522 & $\begin{array}{l}-0.00057 \\
-0.00060 \\
-0.00062 \\
-0.00064\end{array}$ & $\begin{array}{l}-0.00066 \\
-0.00070 \\
-0.00072 \\
-0.00075\end{array}$ & 23 & $\begin{array}{l}16 \mathrm{Ni} \\
15 \mathrm{Ni} \\
19 \mathrm{Ni} \\
6,7 \mathrm{Ni}\end{array}$ \\
\hline S1.110 & $\mathrm{H}^{\alpha}$ & $\mathrm{Ni}$ & -17.8 & -110.4 & \pm 0.4 & -0.000549 & -0.00059 & -0.00074 & 63 & $14 \mathrm{Ni}$ \\
\hline S1.111 & $C^{\beta}\left(\mathrm{sp}^{3}\right)$ & Co & +11.9 & +171 & \pm 3 & +0.000674 & +0.00088 & +0.00098 & - & 11Co \\
\hline S1.112 & $\mathrm{C}^{\beta} \quad\left(\mathrm{sp}^{3}\right)$ & Co & +11.9 & +168 & \pm 4 & +0.000662 & $\begin{array}{l}+0.00085 \\
+0.00082\end{array}$ & $\begin{array}{l}+0.00095 \\
+0.00092\end{array}$ & 12 & $\begin{array}{l}\text { 12Co } \\
13 \mathrm{Co}\end{array}$ \\
\hline S1.113 & $\mathrm{C}^{\beta} \quad\left(\mathrm{sp}^{3}\right)$ & $\mathrm{Ni}$ & -7.95 & +174 & \pm 3 & +0.000865 & $\begin{array}{l}+0.00107 \\
+0.00106 \\
+0.00102\end{array}$ & $\begin{array}{l}+0.00128 \\
+0.00128 \\
+0.00123\end{array}$ & 11 & $\begin{array}{l}12 \mathrm{Ni} \\
11 \mathrm{Ni} \\
13 \mathrm{Ni}\end{array}$ \\
\hline S1.114 & $C^{\beta} \quad\left(s^{2}\right)$ & $\mathrm{Ni}$ & -7.95 & +305 & \pm 4 & +0.001516 & +0.00183 & +0.00218 & 8 & $24 \mathrm{Ni}$ \\
\hline S1.115 & $\mathrm{H}^{\beta}$ & Co & +14.4 & +82 & \pm 2 & +0.000323 & +0.00035 & +0.00042 & 16 & 10Co \\
\hline S1.116 & $\mathrm{H}^{\beta}$ & $\mathrm{Ni}$ & -9.59 & +93.6 & \pm 0.9 & +0.000465 & +0.00054 & +0.00067 & 15 & $9 \mathrm{Ni}$ \\
\hline S1.117 & $C^{\gamma} \quad\left(\mathrm{sp}^{3}\right)$ & Co & +6.03 & +22.4 & \pm 0.6 & +0.000088 & +0.00012 & +0.00012 & 67 & 12Co \\
\hline S1.118 & $C^{\gamma}\left(\mathrm{sp}^{3}\right)$ & Co & +6.03 & +20.0 & \pm 0.4 & +0.000079 & +0.000104 & +0.000110 & 68 & $13 \mathrm{Co}$ \\
\hline S1.119 & $\mathrm{C}^{\gamma} \quad\left(\mathrm{sp}^{3}\right)$ & $\mathrm{Ni}$ & -4.03 & +23.0 & \pm 0.4 & +0.000114 & +0.00015 & +0.00017 & 66 & $12 \mathrm{Ni}$ \\
\hline S1.120 & $C^{\gamma} \quad\left(\mathrm{sp}^{3}\right)$ & $\mathrm{Ni}$ & -4.03 & +20.0 & \pm 0.2 & +0.000099 & +0.000121 & +0.000142 & 68 & $13 \mathrm{Ni}$ \\
\hline S1.121 & $C^{\gamma} \quad\left(\mathrm{sp}^{2}\right)$ & $\mathrm{Ni}$ & -4.21 & +22.8 & \pm 1.1 & +0.000113 & +0.00020 & +0.00025 & - & $24 \mathrm{Ni}$ \\
\hline S1.122 & $\mathrm{H}^{\gamma} \quad\left(\mathrm{CH}_{3}\right)$ & Co & +9.56 & +2.1 & \pm 0.2 & +0.000008 & +0.000016 & +0.000016 & 72 & 11Co \\
\hline
\end{tabular}




\begin{tabular}{|c|c|c|c|c|c|c|c|c|c|c|}
\hline \multirow{3}{*}{$\begin{array}{l}\text { en- } \\
\text { try } \\
\text { S1.123 }\end{array}$} & \multirow{3}{*}{$\begin{array}{l}\text { nucleus } \\
\mathrm{H}^{\gamma}\left(\mathrm{CH}_{3}\right)\end{array}$} & \multirow{3}{*}{$\begin{array}{l}\text { cat- } \\
\text { ion } \\
\mathrm{Ni}\end{array}$} & \multirow{3}{*}{$\begin{array}{l}\delta^{\mathrm{MPC}} \\
298 \mathrm{~K} \\
-6.38\end{array}$} & \multirow{2}{*}{\multicolumn{2}{|c|}{$\begin{array}{c}\vartheta^{\mathrm{CON}} \\
298 \mathrm{~K}^{a}\end{array}$}} & \multirow{3}{*}{$\begin{array}{c}\Delta \rho_{\mathrm{N}} \\
\exp . \\
+0.000018\end{array}$} & \multirow{3}{*}{$\begin{array}{l}\Delta \rho_{\mathrm{DFT}} \\
{[6-311 G} \\
(d, p)]^{b} \\
+0.000017\end{array}$} & \multirow{3}{*}{$\begin{array}{l}\Delta \rho_{\mathrm{DFT}} \\
{[6-311} \\
+G(2 d, p)]^{b} \\
+0.000020\end{array}$} & \multirow{3}{*}{$\begin{array}{l}\text { corr. } \\
\text { line } \\
\text { no. } \\
71\end{array}$} & \multirow{3}{*}{$\begin{array}{l}\text { valid for } \\
\text { complex } \\
\mathbf{1 1 N i}\end{array}$} \\
\hline & & & & & & & & & & \\
\hline & & & & +3.7 & \pm 0.3 & & & & & \\
\hline S1.124 & $\mathrm{H}^{\gamma} \quad\left(\mathrm{CH}_{2}\right)$ & Co & +10.70 & -3.7 & $j$ & -0.000013 & $\begin{array}{l}-0.000006 \\
-0.000007\end{array}$ & $\begin{array}{l}-0.000009 \\
-0.000010\end{array}$ & - & $\begin{array}{l}\text { 13Co } \\
12 \mathrm{Co}\end{array}$ \\
\hline S1.125 & $\mathrm{H}^{\gamma}\left(\mathrm{CH}_{2}\right)$ & $\mathrm{Ni}$ & -7.15 & -1.6 & \pm 0.2 & -0.000008 & $\begin{array}{l}-0.000013 \\
-0.000015\end{array}$ & $\begin{array}{l}-0.000018 \\
-0.000018\end{array}$ & 74 & $\begin{array}{l}13 \mathrm{Ni} \\
12 \mathrm{Ni}\end{array}$ \\
\hline S1.126 & $\mathrm{H}^{\gamma}$ (arom.) & $\mathrm{Ni}$ & -7.32 & -2.4 & $i$ & -0.000012 & $\begin{array}{l}-0.000013 \\
-0.000018\end{array}$ & $\begin{array}{l}-0.000017 \\
-0.000023\end{array}$ & 38 & $\begin{array}{l}24,26,28 \mathrm{Ni} \\
23 \mathrm{Ni}\end{array}$ \\
\hline S1.127 & $\mathrm{H}^{\gamma}$ (arom.) & $\mathrm{Ni}$ & -7.32 & -2.93 & $j$ & -0.000015 & -0.000016 & -0.000021 & - & $29 \mathrm{Ni}$ \\
\hline S1.128 & $\mathrm{H}^{\gamma}$ (arom.) & $\mathrm{Ni}$ & -7.32 & -3.7 & $j$ & -0.000018 & -0.000013 & -0.000017 & - & $21 \mathrm{Ni}$ \\
\hline S1.129 & $\mathrm{H}^{\gamma}$ (arom.) & $\mathrm{Ni}$ & -7.32 & -10.5 & $j$ & -0.000052 & $m$ & $m$ & 41 & $8 \mathrm{Ni}$ \\
\hline S1.130 & $\mathrm{C}^{\delta}($ anti) & Co & +4.94 & +0.7 & \pm 0.2 & +0.000003 & +0.000008 & +0.000009 & 73 & $12 \mathrm{Co}$ \\
\hline S1.131 & $\mathrm{C}^{\delta}($ anti) & $\mathrm{Ni}$ & -3.30 & +0.3 & \pm 0.3 & +0.000001 & -0.000004 & -0.000004 & 73 & $12 \mathrm{Ni}$ \\
\hline S1.132 & $\mathrm{C}^{\delta} \quad$ (syn) & Co & +5.55 & -1.3 & \pm 0.2 & -0.000005 & -0.0000007 & -0.0000014 & - & $13 \mathrm{Co}$ \\
\hline S1.133 & $\mathrm{C}^{\delta} \quad(\operatorname{syn})$ & $\mathrm{Ni}$ & -3.71 & -2.47 & \pm 0.02 & -0.000012 & -0.000021 & -0.000027 & - & $13 \mathrm{Ni}$ \\
\hline S1.134 & $\mathrm{C}^{\delta}$ (arom.) & $\mathrm{Ni}$ & -3.46 & +8.5 & \pm 0.4 & +0.000042 & +0.000006 & +0.000007 & 70 & $24 \mathrm{Ni}$ \\
\hline S1.135 & $\mathrm{H}^{\delta}$ (anti) & Co & +4.53 & +1.0 & \pm 0.2 & +0.000004 & +0.000007 & +0.000007 & - & 13Co \\
\hline S1.136 & $\mathrm{H}^{\delta}$ (anti) & Co & +4.18 & -0.4 & \pm 0.2 & -0.000002 & +0.000015 & +0.000017 & - & 12Co \\
\hline S1.137 & $\mathrm{H}^{\delta}$ (anti) & $\mathrm{Ni}$ & -2.80 & +3.9 & \pm 0.2 & +0.000019 & +0.000022 & +0.000027 & - & $12 \mathrm{Ni}$ \\
\hline S1.138 & $\mathrm{H}^{\delta}($ anti) & $\mathrm{Ni}$ & -3.04 & +1.95 & \pm 0.1 & +0.000010 & +0.000009 & +0.000011 & 34 & $13 \mathrm{Ni}$ \\
\hline S1.139 & $\mathrm{H}^{\delta}$ (arom.) & $\mathrm{Ni}$ & -2.87 & +5.6 & \pm 0.1 & +0.000028 & $\begin{array}{l}+0.000023 \\
+0.000032\end{array}$ & $\begin{array}{l}+0.000028 \\
+0.000040\end{array}$ & 32 & $\begin{array}{l}8 \mathrm{Ni} \\
25 \mathrm{Ni}\end{array}$ \\
\hline S1.140 & $\mathrm{H}^{\delta}$ (arom.) & $\mathrm{Ni}$ & -2.87 & +4.48 & \pm 0.08 & +0.000022 & +0.000019 & +0.000024 & 19 & $28 \mathrm{Ni}$ \\
\hline S1.141 & $\mathrm{H}^{\delta}$ (arom.) & $\mathrm{Ni}$ & -2.87 & +4.0 & \pm 0.4 & +0.000020 & $\begin{array}{l}+0.000023 \\
+0.000019\end{array}$ & $\begin{array}{l}+0.000028 \\
+0.000024\end{array}$ & - & $\begin{array}{l}22,23 \mathrm{Ni} \\
21,24 \mathrm{Ni}\end{array}$ \\
\hline S1.142 & $\mathrm{H}^{\delta}(3-\mathrm{H})$ & $\mathrm{Ni}$ & -2.87 & +3.37 & \pm 0.04 & +0.000017 & +0.000023 & +0.000028 & - & $29 \mathrm{Ni}$ \\
\hline S1.143 & $\mathrm{H}^{\delta} \quad(8-\mathrm{H})$ & $\mathrm{Ni}$ & -9.50 & $+0.2^{c, n}$ & $i$ & $+0.000001^{a}$ & -0.000006 & -0.000003 & 33 & $29 \mathrm{Ni}$ \\
\hline S1.144 & $\mathrm{H}^{\delta}\left(o-\mathrm{CH}_{3}\right)$ & $\mathrm{Ni}$ & -5.26 & +1.6 & \pm 0.3 & +0.000008 & +0.000008 & +0.000011 & - & $25 \mathrm{Ni}$ \\
\hline S1.145 & $\mathrm{H}^{\delta}\left(o-\mathrm{CH}_{3}\right)$ & $\mathrm{Ni}$ & -5.26 & +0.85 & \pm 0.1 & +0.000004 & +0.000010 & +0.000014 & - & $27 \mathrm{Ni}$ \\
\hline S1.146 & $\mathrm{C}^{\varepsilon} \quad\left(\mathrm{CH}_{3}\right)$ & Co & +3.13 & +0.85 & \pm 0.02 & +0.000003 & +0.000018 & +0.000017 & - & 13Co \\
\hline S1.147 & $\mathrm{C}^{\varepsilon}\left(\mathrm{CH}_{3}\right)$ & $\mathrm{Ni}$ & -2.10 & -1.3 & \pm 0.1 & -0.000006 & -0.000014 & -0.000015 & - & $13 \mathrm{Ni}$ \\
\hline
\end{tabular}




\begin{tabular}{|c|c|c|c|c|c|c|c|c|c|c|}
\hline \multirow{3}{*}{$\begin{array}{l}\text { en- } \\
\text { try } \\
\text { S1.148 }\end{array}$} & \multirow{3}{*}{$\begin{array}{l}\text { nucleus } \\
\mathrm{C}^{\varepsilon}\left(p-\mathrm{CH}_{3}\right)\end{array}$} & \multirow{3}{*}{$\begin{array}{l}\text { cat- } \\
\text { ion } \\
\mathrm{Ni}\end{array}$} & \multirow{3}{*}{$\begin{array}{r}\delta^{\mathrm{MPC}} \\
298 \mathrm{~K} \\
-1.99\end{array}$} & \multirow{2}{*}{\multicolumn{2}{|c|}{$\begin{array}{c}\vartheta^{\mathrm{CON}} \\
298 \mathrm{~K}^{a}\end{array}$}} & \multirow{3}{*}{$\begin{array}{c}\Delta \rho_{\mathrm{N}} \\
\text { exp. } \\
-0.000019\end{array}$} & \multirow{3}{*}{$\begin{array}{l}\Delta \rho_{\mathrm{DFT}} \\
{[6-311 G} \\
(d, p)]^{b} \\
-0.000010\end{array}$} & \multirow{3}{*}{$\begin{array}{l}\Delta \rho_{\mathrm{DFT}} \\
{[6-311} \\
+G(2 d, p)]^{b} \\
-0.000012\end{array}$} & \multirow{3}{*}{$\begin{array}{l}\text { corr. } \\
\text { line } \\
\text { no. } \\
75\end{array}$} & \multirow{3}{*}{$\begin{array}{l}\text { valid for } \\
\text { complex } \\
\mathbf{2 4 N i}\end{array}$} \\
\hline & & & & & & & & & & \\
\hline & & & & -3.9 & \pm 0.1 & & & & & \\
\hline S1.149 & $\mathrm{H}^{\varepsilon} \quad$ (axial) & Co & +4.49 & -1.5 & \pm 0.3 & -0.000006 & -0.0000001 & -0.0000001 & - & 12Co \\
\hline S1.150 & $\mathrm{H}^{\varepsilon} \quad$ (axial) & $\mathrm{Ni}$ & -3.00 & +0.33 & \pm 0.18 & +0.000002 & -0.0000007 & -0.0000007 & - & $12 \mathrm{Ni}$ \\
\hline S1.151 & $\mathrm{H}^{\varepsilon}$ (equat) & Co & +3.35 & -0.36 & \pm 0.20 & -0.000001 & +0.000002 & +0.000001 & - & 12Co \\
\hline S1.152 & $\mathrm{H}^{\varepsilon}$ (equat) & $\mathrm{Ni}$ & -2.24 & -0.45 & \pm 0.13 & -0.000002 & -0.000004 & -0.000005 & - & $12 \mathrm{Ni}$ \\
\hline S1.153 & $\mathrm{H}^{\varepsilon}\left(m-\mathrm{CH}_{3}\right)$ & $\mathrm{Ni}$ & -1.94 & +0.0 & \pm 0.1 & +0.0 & +0.0000001 & +0.0000004 & - & $26,27 \mathrm{Ni}$ \\
\hline S1.154 & $\mathrm{H}^{\varepsilon} \quad(4-\mathrm{H})$ & $\mathrm{Ni}$ & -2.30 & -1.14 & \pm 0.17 & -0.000006 & -0.000002 & -0.000002 & - & $29 \mathrm{Ni}$ \\
\hline S1.155 & $\mathrm{H}^{\varepsilon} \quad(p-\mathrm{H})$ & $\mathrm{Ni}$ & -2.30 & -1.2 & \pm 0.3 & -0.000006 & -0.000004 & -0.000004 & 37 & $22,23,26,27 \mathrm{Ni}$ \\
\hline S1.156 & $\mathrm{H}^{\varepsilon} \quad(p-\mathrm{H})$ & $\mathrm{Ni}$ & -2.30 & -1.75 & \pm 0.1 & -0.000009 & -0.000004 & -0.000004 & - & $21 \mathrm{Ni}$ \\
\hline S1.157 & $\mathrm{H}^{\varepsilon} \quad(p-\mathrm{H})$ & $\mathrm{Ni}$ & -2.30 & -12.0 & $j$ & -0.000060 & $m$ & $m$ & 42 & $8 \mathrm{Ni}$ \\
\hline S1.158 & $\mathrm{H}^{\varepsilon} \quad(7-\mathrm{H})$ & $\mathrm{Ni}$ & -1.46 & +0.70 & \pm 0.13 & +0.000003 & +0.000004 & +0.000005 & - & $29 \mathrm{Ni}$ \\
\hline S1.159 & $\mathrm{H}^{\varepsilon} \quad(5-\mathrm{H})$ & $\mathrm{Ni}$ & -1.83 & +0.36 & \pm 0.36 & +0.000002 & +0.000005 & +0.000006 & - & $29 \mathrm{Ni}$ \\
\hline S1.160 & $\mathrm{H}^{\zeta} \quad\left(\mathrm{CH}_{3}\right)$ & Co & +2.67 & -0.10 & \pm 0.10 & -0.0 & +0.0000006 & +0.0000005 & 36 & $13 \mathrm{Co}$ \\
\hline S1.161 & $\mathrm{H}^{\zeta}\left(p-\mathrm{CH}_{3}\right)$ & $\mathrm{Ni}$ & -1.62 & +2.1 & \pm 0.1 & +0.000010 & +0.000004 & +0.000004 & - & $24 \mathrm{Ni}$ \\
\hline S1.162 & $\mathrm{H}^{\zeta}\left(p-\mathrm{CH}_{3}\right)$ & $\mathrm{Ni}$ & -1.62 & +0.93 & \pm 0.02 & +0.000005 & +0.000003 & +0.000004 & 56 & $25 \mathrm{Ni}$ \\
\hline S1.163 & $\mathrm{H}^{\zeta}\left(\mathrm{CH}_{3}\right)$ & $\mathrm{Ni}$ & -1.79 & +0.18 & \pm 0.08 & +0.000001 & +0.000001 & +0.000001 & 35 & $13 \mathrm{Ni}$ \\
\hline S1.164 & $\mathrm{H}^{\zeta} \quad(6-\mathrm{H})$ & $\mathrm{Ni}$ & -1.31 & +0.56 & \pm 0.1 & +0.000003 & +0.000003 & +0.000004 & - & $29 \mathrm{Ni}$ \\
\hline S1.165 & $\mathrm{H}^{\eta}\left(o^{\prime}-\mathrm{H}\right)$ & $\mathrm{Ni}$ & -1.64 & +0.46 & \pm 0.03 & +0.000002 & -0.0000005 & -0.0000006 & - & $28 \mathrm{Ni}$ \\
\hline S1.166 & $\mathrm{H}^{9}\left(m^{\prime}-\mathrm{H}\right)$ & $\mathrm{Ni}$ & -0.85 & +0.53 & \pm 0.04 & +0.000003 & +0.0000002 & +0.0000003 & - & $28 \mathrm{Ni}$ \\
\hline S1.167 & $\mathrm{H}^{1}\left(p^{\prime}-\mathrm{H}\right)$ & $\mathrm{Ni}$ & -0.69 & -0.08 & \pm 0.05 & -0.0000004 & -0.0000006 & -0.0000007 & - & $28 \mathrm{Ni}$ \\
\hline
\end{tabular}

${ }^{a} \vartheta^{\mathrm{CON}}$ may contain a contribution of the ligand-centered pseudocontact shift $\vartheta^{\mathrm{LPC}}$. ${ }^{b}$ DFT calculations (UB3LYP) with the 6-311G(d,p) and the 6-311+G(2d,p) basis sets. ${ }^{c}$ Extrapolated to $1 / T=0 .{ }^{d}$ Slope -22000 K versus $1 / T$. ${ }^{e}$ Slope $-12000 \mathrm{~K}$ vs $1 / T$. ${ }^{f}$ Slope $-14000 \mathrm{~K}$ vs $1 / T$. ${ }^{g}$ Slope $-10000 \mathrm{~K}$ vs $1 / T$. ${ }^{h}$ All $N$-phenyl groups held perpendicular to the chelate ring. ${ }^{i}$ Positive slope of the correlation with $1 / T .{ }^{j}$ Negative slope of the correlation with $1 / T$. ${ }^{k}$ Uncongested $N$-phenyl group. ${ }^{l}$ Congested $N$-phenyl group. ${ }^{m}$ Not calculated in consideration of $\mathrm{C}^{2}$-phenyl rotation. ${ }^{n}$ Slope $+720 \mathrm{~K}$ vs $1 / T$. 


\section{Figures S1-S4 of $\vartheta^{\mathrm{CON}}$ at Varied Temperatures}

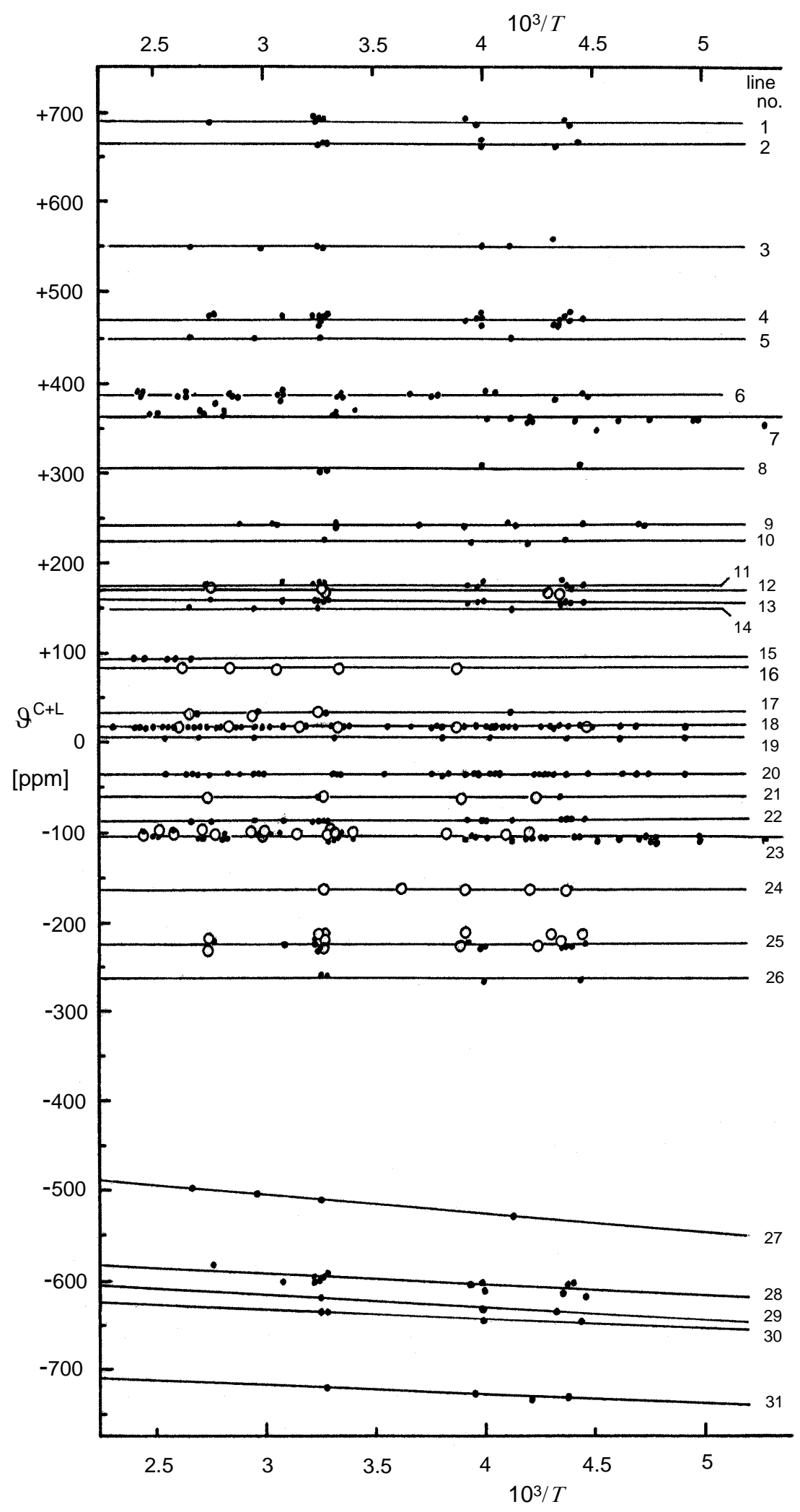

Figure S1. Correlation lines no. $1-31$ for reduced contact shifts $\vartheta^{\mathrm{CON}} \approx \vartheta^{\mathrm{C}+\mathrm{L}}\left({ }^{1} \mathrm{H}\right.$ and $\left.{ }^{13} \mathrm{C}\right)$ as a function of the reciprocal temperature. Open circles for $\mathbf{1 C o}$ and filled symbols for $\mathbf{1 N i}$. 


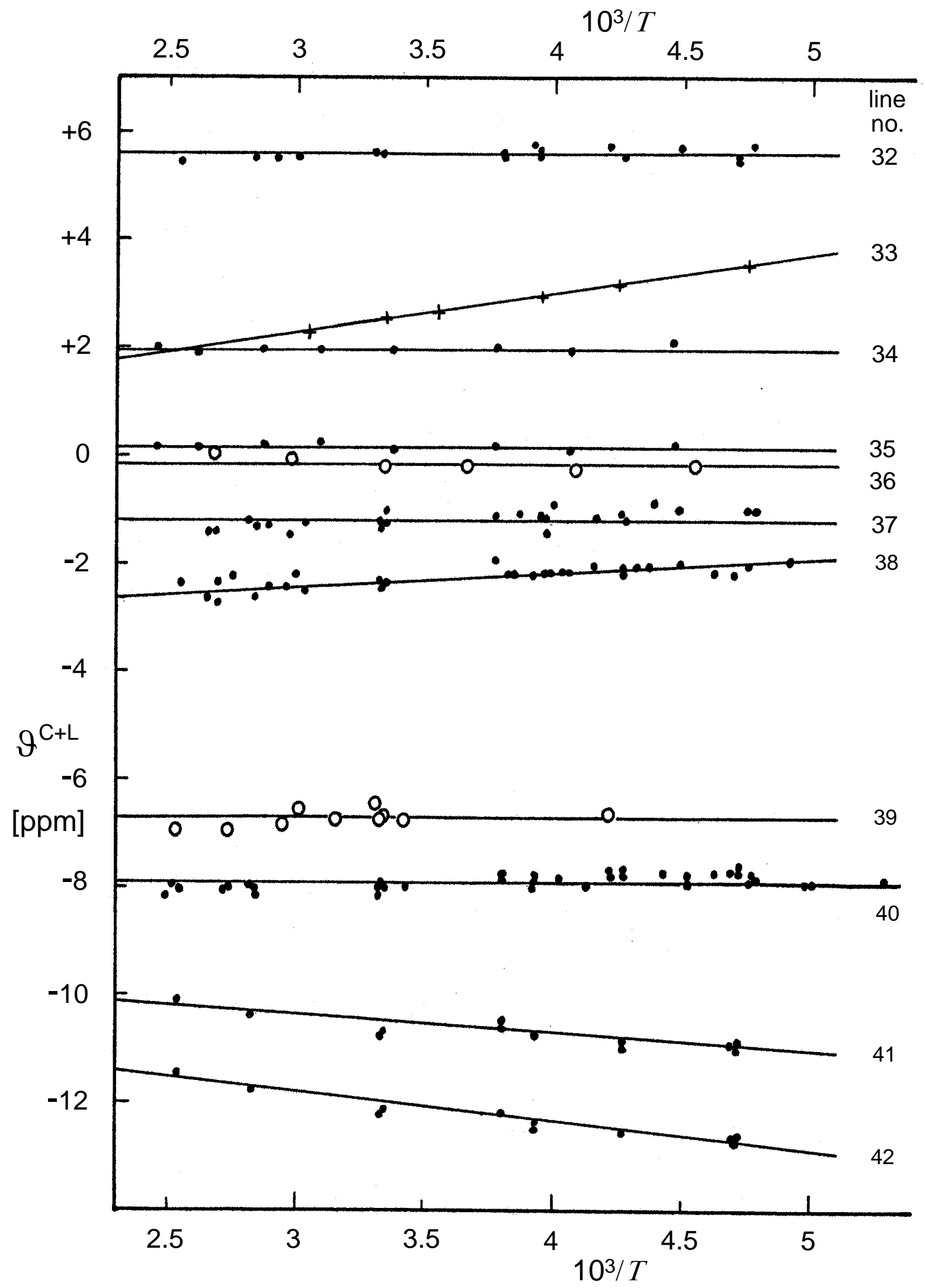

Figure S2. Correlation lines no. 32-42 for reduced contact shifts $\vartheta^{\mathrm{CON}} \approx \vartheta^{\mathrm{C}+\mathrm{L}}\left({ }^{1} \mathrm{H}\right.$ and $\left.{ }^{13} \mathrm{C}\right)$ as a function of the reciprocal temperature. Open circles for $\mathbf{1 C o}$ and filled symbols and + for $\mathbf{1 N i}$. 


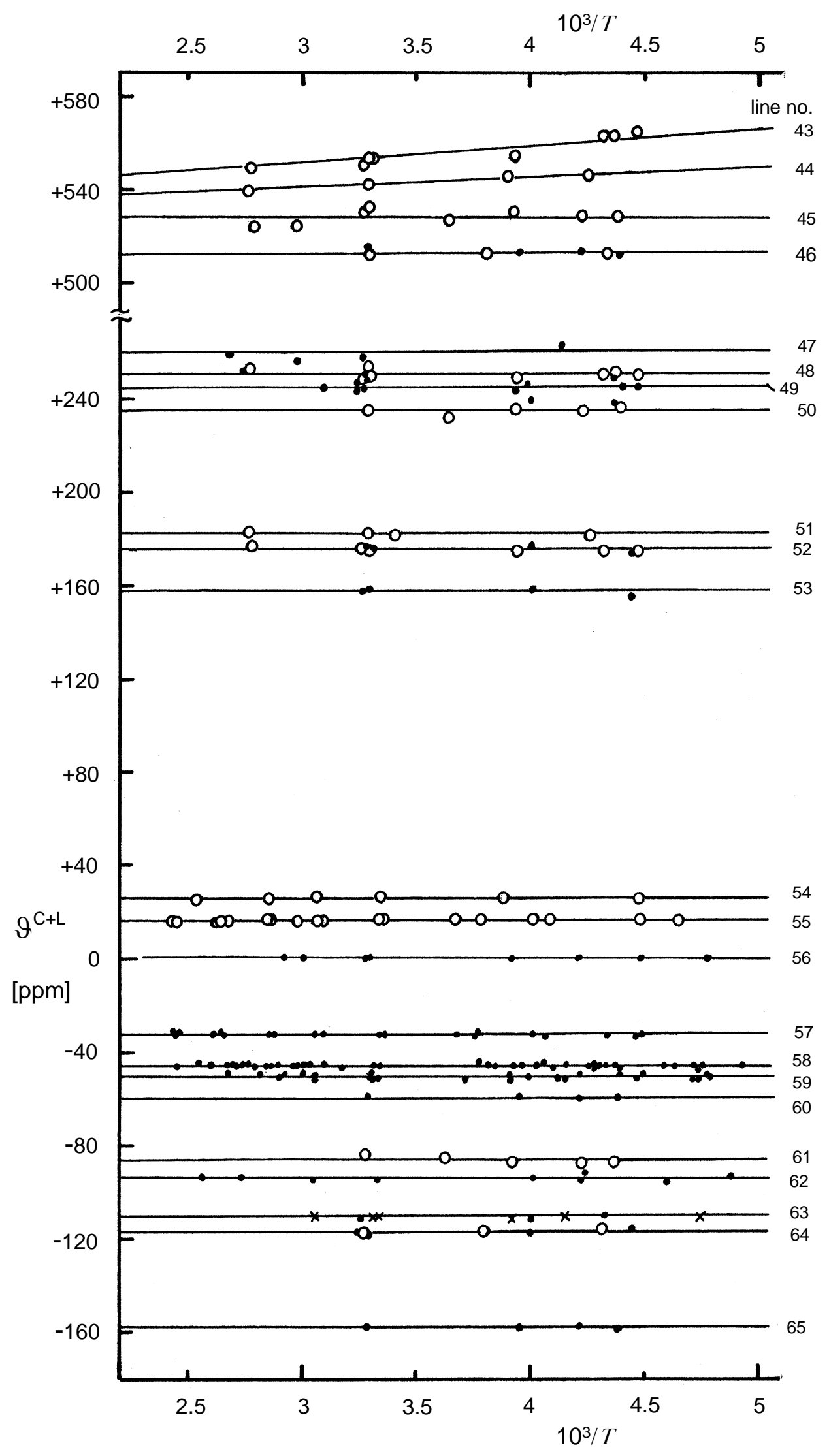

Figure S3. Correlation lines no. 43-65 for reduced contact shifts $\vartheta^{\mathrm{CON}} \approx \vartheta^{\mathrm{C}+\mathrm{L}}\left({ }^{1} \mathrm{H}\right.$ and $\left.{ }^{13} \mathrm{C}\right)$ as a function of the reciprocal temperature. Open circles for $\mathbf{1 C o}$ and filled symbols or $\times$ for $\mathbf{1 N i}$. 


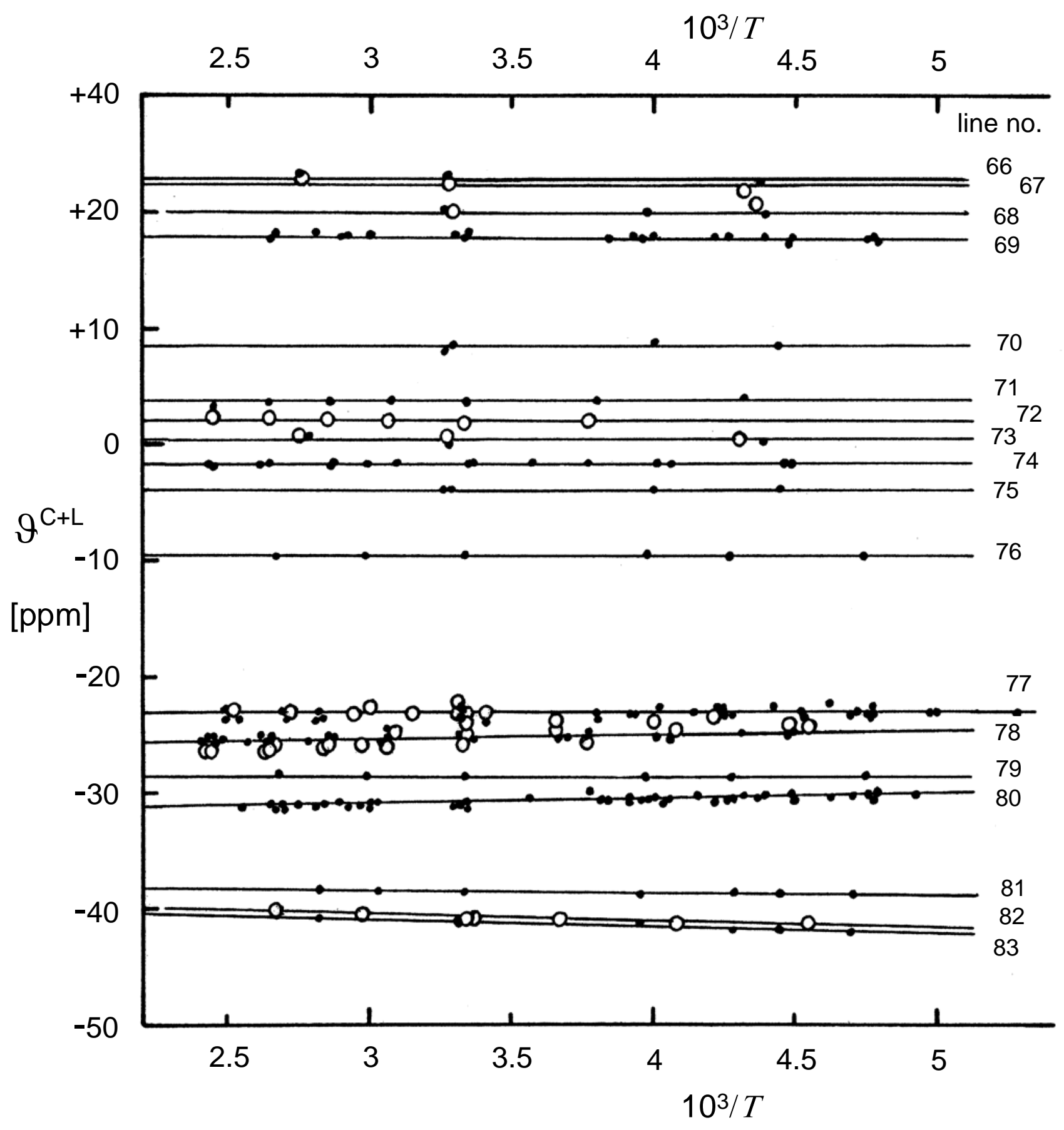

Figure S4. Correlation lines no. 66-83 for reduced contact shifts $\vartheta^{\mathrm{CON}} \approx \vartheta^{\mathrm{C}+\mathrm{L}}\left({ }^{1} \mathrm{H}\right.$ and $\left.{ }^{13} \mathrm{C}\right)$ as a function of the reciprocal temperature. Open circles for $\mathbf{1 C o}$ and filled symbols for $\mathbf{1 N i}$. 


\section{Magnetic Susceptibility Measurements $(\Delta \chi$ and $\chi$ ), with Figure S5 and Table S2}

The magnitudes of the nuclear quadrupole induced splittings $\left|\Delta \nu_{D}\right|$ of the deuterium NMR resonances of 4Co and $\mathbf{4 N i}$ are given by eq $8 .^{40,41}$ They depend on the angle $\phi$ between a C-D bond vector and the (as yet unknown) orientation of the unique magnetic axis. They were measured in $\mathrm{CH}_{2} \mathrm{Cl}_{2}$ solutions with $B_{0}=14.1$ tesla at the temperatures $T$ specified in Table 1 of the Main Text, and were analyzed by computer simulation of their lineshapes. Although most of the expected splittings were obscured by paramagnetic line broadening (which thwarted measurements above $300 \mathrm{~K}$ and below $230 \mathrm{~K}$ completely), the linewidths provided reasonable upper limits for the splittings to be expected from eq 8.

$$
\left|\Delta \nu_{\mathrm{D}}\right|=\left(e^{2} q Q / h\right) B_{0}^{2} \times\left|\left(3 \cos ^{2} \phi-1\right) \Delta \chi\right| \times\left(20 \mu_{0} k T\right)^{-1}
$$

The orientation of the unique magnetic axis may be established if $\left|\Delta \nu_{\mathrm{D}}\right|$ can be measured for at least two deuterium nuclei having substantially different angles $\phi$ which, however, should not change perceptibly on phenyl rotation. This holds true for the C-D bonds of $N$-para-D and of $\mathrm{D}^{\varepsilon}$, the deuterium NMR splittings of which were displayed in Table 1 . The quotients of these two splittings at $+27^{\circ} \mathrm{C}$ are $\left|\Delta v_{\mathrm{D}}(N-p a r a-\mathrm{D})\right| /\left|\Delta v_{\mathrm{D}}\left(\mathrm{D}^{\varepsilon}\right)\right|$ $=-(11.0 / 29.0)=-0.38(2)=\left[3 \cos ^{2} \phi(N-\right.$ para $\left.-\mathrm{D})-1\right] /\left[3 \cos ^{2} \phi\left(\mathrm{D}^{\varepsilon}\right)-1\right]$ for $4 \mathrm{Co}$ and $-(8.0 / 19.5)=-0.41(3)$ for $\mathbf{4 N i}$. The negative signs cannot be observed but were inferred, using the difference $\left|\phi(N-p-\mathrm{D})-\phi\left(\mathrm{D}^{\varepsilon}\right)\right|=$ $109(2)^{\circ}$ which is predetermined as the averaged value from crystal structures ${ }^{5,6}$ of $\mathbf{2}$ and $\mathbf{3 a} \mathbf{a} \mathbf{d}$ with the following consequences. Some elementary trigonometry reveals those negative quotients to be compatible only with $\phi\left(D^{\varepsilon}\right)$ $=+2( \pm 3)^{\circ}$ for $\mathbf{4 C o}$ and $+4( \pm 3)^{\circ}$ for $\mathbf{4 N i}$. If those quotients were positive, $\phi\left(\mathrm{D}^{\varepsilon}\right)$ could only be either $153^{\circ}$ or $27^{\circ}$, which would be incompatible with the structural axial symmetry. Considering that $\phi(N-p-\mathrm{D})$ in the crystalline model complexes ( $\mathbf{2}$ and $\mathbf{3 a}-\mathbf{d})$ might differ slightly from the value in solution, it can be concluded that the unique magnetic axis in solution coincides with the molecular $z$ axis $\left(M-C^{2}\right)$, so that $\phi\left(D^{\varepsilon}\right)=0$ for both 4 Co and 4Ni. In accord with $\phi(N-p-\mathrm{D})=109^{\circ}$, the $\left|\Delta \nu_{\mathrm{D}}\right|$ values of $\mathrm{D}^{\varepsilon}$ and $N$-para-D were found to be greater than those of $\mathrm{D}^{\gamma}, \mathrm{D}^{\delta}, N$-ortho-D and $N$-meta-D. The known ${ }^{44}$ temperature dependence of the $\delta^{\text {OBS }}$ values provided independent and unequivocal controls of the experimental temperatures $T$ at which $\left|\Delta v_{\mathrm{D}}\right|$ had been measured.

$$
|\Delta \chi|=20 \mu_{0} k T\left|\Delta v_{\mathrm{D}}\right| h\left(e^{2} q Q B_{0}^{2}\right)^{-1} \times\left|3 \cos ^{2} \phi-1\right|^{-1}
$$

The $\left|\Delta v_{\mathrm{D}}\right|$ values together with $\phi$ served to calculate the magnitudes $|\Delta \chi|$ of the anisotropies of the magnetic susceptibilities in SI units ${ }^{14-16}\left(\AA^{3} /\right.$ molecule) via eq S8a (rearranged from eq 8). The products $T \Delta \chi$ would be independent of the temperature if $\Delta \chi$ had Curie (1/T) behavior in Table 1 of the Main Text. This is not the case, however, because the $T|\Delta \chi|$ values increase with the reciprocal temperature, as shown in Figure S5 where the two correlation lines were chosen to conform to the functional form $\left(m_{1} / T+m_{2} / T^{2}\right)$ in accord with the general theory $^{35 e}$ and the explicit model calculations. ${ }^{22 e}$ 


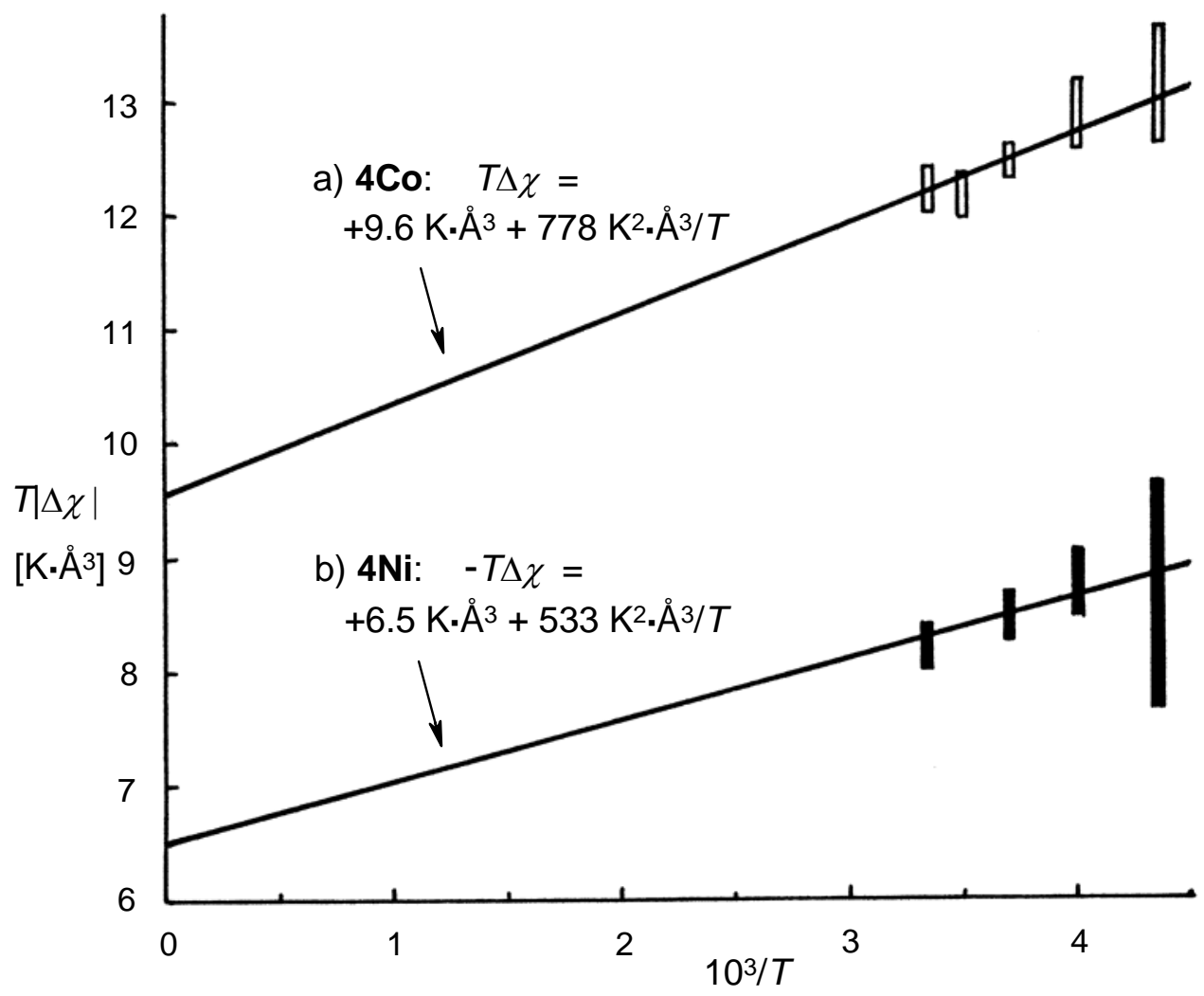

Figure S5. Dependence of $T \Delta \chi\left[K \cdot \AA^{3}\right]$ on the reciprocal temperature $\left[\mathrm{K}^{-1}\right]$ (a) for $\mathbf{4 C o}$, (b) for $\mathbf{4 N i}$.

The knowledge (eqs 9a,b) of this hyper-Curie ${ }^{38}$ temperature dependence (steeper slope) of the $\Delta \chi$ values of two model complexes (4Co and $\mathbf{4 N i}$ ), as opposed to the Curie-type behavior of the $\chi$ values mentioned in the Introduction, allows one to determine the metal-centered NMR shifts $\delta^{\mathrm{MCD}}$ (eq 6) for further bis(chelates) 1 whose geometry factors $G=\left(3 \cos ^{2} \theta-1\right) R^{-3}$ in eq 10a can be estimated with sufficient confidence. The results are listed in Table S2 which includes the terms $m_{1} G$ (in Kelvin) and $m_{2} G$ (in $\mathrm{K}^{2}$ ) from eqs $10 \mathrm{~b}, \mathrm{c}$ for computational convenience. It should be noticed that the analysis based on eqs $10 \mathrm{a}-\mathrm{c}$ would become inaccurate ${ }^{\mathrm{S} 1}$ for $R \leq$ $3 \AA$ because a magnetic dipole at the central metal ion had been assumed in deriving eq 6 .

Isotropic Magnetic Susceptibilities $\Delta \chi$ in solution were measured according to Evans ${ }^{17}$ and were corrected for diamagnetic contributions but not for a temperature independent paramagnetism. The resultant magnetic moments $\mu$ (eq 1) showed no systematic dependence on the temperature, until deterioration of the substance under investigation became perceptible. Measurements within superconducting coils ${ }^{\mathrm{S} 2 \mathrm{~S} 3}$ were not performed. 
Table S2. Calculation of Geometry Factors $G^{a}$ and of Metal (M) Ion Centered Pseudocontact Shifts $\delta^{\mathrm{MPC}}$ [ppm] (Eqs 10a-c) at $298 \mathrm{~K}$ from Polar Coordinates ${ }^{a}$ of the Nuclei in the Bis(chelate) Complexes 1.

\begin{tabular}{|c|c|c|c|c|c|c|c|c|c|}
\hline entry & nucleus & loc & M & $\theta$ & $R[\AA]$ & $G$ & $m_{1} G[\mathrm{~K}]$ & $m_{2} G\left[\mathrm{~K}^{2}\right]$ & $\delta^{\mathrm{MPC}}$ \\
\hline S2.1 & $C^{1,3}$ & - & $\mathrm{Ni}$ & 25.24 & 2.911 & +0.058965 & -0.010166 & -0.833765 & -43.5 \\
\hline S2.2 & $C^{2}$ & - & $\mathrm{Ni}$ & 0.0 & 3.270 & +0.057199 & -0.009861 & -0.808794 & -42.2 \\
\hline S2.3 & $N-\underline{C H}_{3}$ & - & $\mathrm{Ni}$ & 73.57 & 2.983 & -0.028632 & +0.004936 & +0.404856 & +21.1 \\
\hline S2.4 & $N-\underline{\mathrm{H}}_{3}$ & av & $\mathrm{Ni}$ & av & av & -0.022569 & +0.003891 & +0.319126 & +16.65 \\
\hline S2.5 & $N-i-C$ & - & Co & 72.60 & 2.977 & -0.027734 & -0.007061 & -0.572427 & -30.1 \\
\hline S2.6 & $N-i-C$ & - & $\mathrm{Ni}$ & 72.75 & 2.923 & -0.029478 & +0.005082 & +0.416819 & +21.7 \\
\hline S2.7 & $N-O-C$ & av & Co & $\mathrm{av}$ & av & -0.018133 & -0.004617 & -0.374265 & -19.7 \\
\hline S2.8 & $\mathrm{N}-\mathrm{O}-\mathrm{C}$ & $\mathrm{av}$ & $\mathrm{Ni}$ & av & av & -0.018478 & +0.003186 & +0.261279 & +13.6 \\
\hline S2.9 & $N-\mathrm{O}-\mathrm{C}$ & 90 & Co & 79.44 & 3.763 & -0.016876 & -0.004297 & -0.348324 & -18.3 \\
\hline $\mathrm{S} 2.10$ & $N-O-C$ & 90 & $\mathrm{Ni}$ & 79.91 & 3.705 & -0.017852 & +0.003078 & +0.252427 & +13.2 \\
\hline S2.11 & $N-O-\mathrm{H}$ & av & Co & av & av & -0.017128 & -0.004361 & -0.353522 & -18.6 \\
\hline $\mathrm{S} 2.12$ & $N-O-\mathrm{H}$ & $\mathrm{n}$ & $\mathrm{Ni}$ & 102.03 & 2.946 & -0.034014 & +0.005864 & +0.480958 & +25.4 \\
\hline S2.13 & $N-O-\mathrm{H}$ & d & $\mathrm{Ni}$ & 58.81 & 4.357 & -0.002363 & +0.000407 & +0.033413 & +1.74 \\
\hline S2.14 & $N-O-\mathrm{H}$ & av & $\mathrm{Ni}$ & av & av & -0.018189 & +0.003136 & +0.257192 & +13.4 \\
\hline S2.15 & $N-O-\mathrm{H}$ & 90 & Co & 76.98 & 3.765 & -0.015884 & -0.004044 & -0.327846 & -17.3 \\
\hline S2.16 & $N-O-\mathrm{H}$ & 90 & $\mathrm{Ni}$ & 77.24 & 3.719 & -0.016600 & +0.002862 & +0.234724 & +12.25 \\
\hline S2.17 & $N-m-C$ & $\mathrm{av}$ & Co & $\mathrm{av}$ & av & -0.007689 & -0.001958 & -0.158701 & -8.35 \\
\hline S2.18 & $N-m-C$ & av & $\mathrm{Ni}$ & $\mathrm{av}$ & av & -0.008027 & +0.001384 & +0.113502 & +5.92 \\
\hline S2.19 & $N-m-C$ & 90 & Co & 86.67 & 4.976 & -0.008034 & -0.002045 & -0.165825 & -8.73 \\
\hline S2.20 & $N-m-C$ & 90 & $\mathrm{Ni}$ & 87.51 & 4.908 & -0.008410 & +0.001450 & +0.118917 & +6.20 \\
\hline S2.21 & $N-m-\mathrm{H}$ & av & Co & av & av & -0.004444 & -0.001131 & -0.091724 & -4.83 \\
\hline S2.22 & $N-m-\mathrm{H}$ & $\mathrm{n}$ & $\mathrm{Ni}$ & 105.49 & 5.218 & -0.005533 & +0.000954 & +0.078237 & +4.08 \\
\hline $\mathrm{S} 2.23$ & $N-m-\mathrm{H}$ & $\mathrm{d}$ & $\mathrm{Ni}$ & 76.05 & 6.127 & -0.003590 & +0.000619 & +0.050763 & +2.65 \\
\hline S2.24 & $N-m-\mathrm{H}$ & av & $\mathrm{Ni}$ & av & av & -0.004562 & +0.000786 & +0.064507 & +3.36 \\
\hline S2.25 & $N-m-\mathrm{H}$ & 90 & Co & 88.70 & 5.757 & -0.005233 & -0.001332 & -0.108006 & -5.69 \\
\hline S2.26 & $N-m-\mathrm{H}$ & 90 & $\mathrm{Ni}$ & 89.58 & 5.691 & -0.005425 & +0.000935 & +0.076710 & +4.00 \\
\hline S2.27 & $N-p-\mathrm{C}$ & - & Co & 89.08 & 5.482 & -0.006065 & -0.001544 & -0.125186 & -6.59 \\
\hline $\mathrm{S} 2.28$ & $N-p-C$ & - & $\mathrm{Ni}$ & 90.04 & 5.411 & -0.006312 & +0.001088 & +0.089252 & +4.65 \\
\hline S2.29 & $N-p-\mathrm{H}$ & - & Co & 92.01 & 6.529 & -0.003580 & -0.000911 & -0.073886 & -3.89 \\
\hline S2.30 & $N-p-\mathrm{H}$ & - & $\mathrm{Ni}$ & 93.03 & 6.454 & -0.003687 & +0.000636 & +0.052134 & +2.72 \\
\hline S2.31 & $N-m-\underline{C H}_{3}$ & av & Co & $\mathrm{av}$ & av & -0.003524 & -0.000897 & -0.072735 & -3.83 \\
\hline S2.32 & $N-m-\underline{C H}_{3}$ & av & $\mathrm{Ni}$ & av & av & -0.003593 & +0.000619 & +0.050805 & +2.65 \\
\hline
\end{tabular}




\begin{tabular}{|c|c|c|c|c|c|c|c|c|c|}
\hline entry & nucleus & loc & M & $\theta$ & $R[\AA]$ & $G$ & $m_{1} G[\mathrm{~K}]$ & $m_{2} G\left[\mathrm{~K}^{2}\right]$ & $\delta^{\mathrm{MPC}}$ \\
\hline S2.33 & $N-m-\mathrm{CH}_{3}$ & av & Co & av & av & -0.002652 & -0.000675 & -0.054737 & -2.88 \\
\hline S2.34 & $N-m-\underline{C H}_{3}$ & av & $\mathrm{Ni}$ & av & av & -0.002663 & +0.000495 & +0.037655 & +1.96 \\
\hline S2.35 & $N-p-\underline{C} \mathrm{H}_{3}$ & - & Co & 92.92 & 6.945 & -0.002962 & -0.000754 & -0.061136 & -3.22 \\
\hline S2.36 & $N-p-\underline{\mathrm{CH}_{3}}$ & - & $\mathrm{Ni}$ & 94.04 & 6.870 & -0.003038 & +0.000524 & +0.042957 & +2.24 \\
\hline S2.37 & $N-p-\underline{\mathrm{H}}_{3}$ & av & Co & av & av & -0.002561 & -0.000652 & -0.052859 & -2.78 \\
\hline S2.38 & $N-p-\underline{\mathrm{H}}_{3}$ & av & $\mathrm{Ni}$ & av & av & -0.002400 & +0.000414 & +0.033936 & +1.77 \\
\hline S2.39 & $C^{\alpha^{\prime}}$ & - & Co & 35.07 & 4.285 & +0.012832 & +0.003267 & +0.264850 & +13.9 \\
\hline $\mathrm{S} 2.40$ & $C^{\alpha^{\prime}}$ & - & $\mathrm{Ni}$ & 35.19 & 4.301 & -0.012615 & -0.002175 & -0.178376 & -9.30 \\
\hline $\mathrm{S} 2.41$ & $\mathrm{H}^{\alpha^{\prime}}$ & - & Co & 33.12 & 3.879 & +0.018921 & +0.004817 & +0.390536 & +20.6 \\
\hline $\mathrm{S} 2.42$ & $\mathrm{H}^{\alpha^{\prime}}$ & - & $\mathrm{Ni}$ & 33.09 & 3.898 & +0.018670 & -0.003219 & -0.263994 & -13.8 \\
\hline S2.43 & $C^{\beta^{\prime}}$ & av & Co & av & av & +0.005606 & +0.001427 & +0.115708 & +6.09 \\
\hline S2.44 & $C^{\beta^{\prime}}$ & av & $\mathrm{Ni}$ & av & av & +0.005434 & -0.000937 & -0.076837 & -4.01 \\
\hline S2.45 & $\mathrm{H}^{\beta^{\prime}}$ & av & Co & $\mathrm{av}$ & av & +0.007603 & +0.001936 & +0.156926 & +8.26 \\
\hline $\mathrm{S} 2.46$ & $\mathrm{H}^{\beta^{\prime}}$ & av & $\mathrm{Ni}$ & av & av & +0.007465 & -0.001287 & -0.105555 & -5.50 \\
\hline S2.47 & $\mathrm{H}^{\gamma^{\prime}}$ & av & Co & av & av & +0.005062 & +0.001289 & +0.104480 & +5.50 \\
\hline S2.48 & $\mathrm{H}^{\gamma^{\prime}}$ & av & $\mathrm{Ni}$ & av & av & +0.004952 & -0.000854 & -0.070021 & -3.65 \\
\hline S2.49 & $\mathrm{C}^{\alpha}\left(\mathrm{sp}^{3}\right)$ & - & Co & 0.0 & 4.750 & +0.018662 & +0.004751 & +0.385176 & +20.3 \\
\hline $\mathrm{S} 2.50$ & $\mathrm{C}^{\alpha}\left(\mathrm{sp}^{3}\right)$ & - & $\mathrm{Ni}$ & 0.0 & 4.790 & +0.018198 & -0.003137 & -0.257320 & -13.4 \\
\hline S2.51 & $\mathrm{C}^{\alpha}\left(\mathrm{sp}^{2}\right)$ & - & $\mathrm{Ni}$ & 0.0 & 4.730 & +0.018899 & -0.003258 & -0.267232 & -13.9 \\
\hline S2.52 & $\mathrm{H}^{\alpha}$ & - & Co & 0.0 & 4.320 & +0.024807 & +0.006316 & +0.512022 & +27.0 \\
\hline $\mathrm{S} 2.53$ & $\mathrm{H}^{\alpha}$ & - & $\mathrm{Ni}$ & 0.0 & 4.360 & +0.024131 & -0.004160 & -0.341212 & -17.8 \\
\hline S2.54 & $\mathrm{C}^{\beta}\left(\mathrm{sp}^{3}\right)$ & - & Co & 15.42 & 5.460 & +0.010984 & +0.002797 & +0.226713 & +11.9 \\
\hline S2.55 & $C^{\beta}\left(\mathrm{sp}^{3}\right)$ & - & $\mathrm{Ni}$ & 15.31 & 5.498 & +0.010776 & -0.001858 & -0.152373 & -7.95 \\
\hline S2.56 & $\mathrm{C}^{\beta}\left(\mathrm{sp}^{2}\right)$ & - & $\mathrm{Ni}$ & 12.59 & 5.564 & +0.010783 & -0.001859 & -0.152472 & -7.95 \\
\hline S2.57 & $\mathrm{H}^{\beta}$ & - & Co & 11.36 & 5.216 & +0.013273 & +0.003379 & +0.273960 & +14.4 \\
\hline S2.58 & $\mathrm{H}^{\beta}$ & - & $\mathrm{Ni}$ & 11.28 & 5.255 & +0.012991 & -0.002240 & -0.183693 & -9.59 \\
\hline S2.59 & $C^{\gamma}\left(\mathrm{sp}^{3}\right)$ & - & Co & 12.05 & 6.957 & +0.005551 & +0.001413 & +0.114581 & +6.03 \\
\hline S2.60 & $C^{\gamma}\left(\mathrm{sp}^{3}\right)$ & - & $\mathrm{Ni}$ & 11.98 & 6.996 & +0.005463 & -0.000942 & -0.077245 & -4.03 \\
\hline S2.61 & $C^{\gamma}\left(\mathrm{sp}^{2}\right)$ & - & $\mathrm{Ni}$ & 10.07 & 6.937 & +0.005716 & -0.000985 & -0.080824 & -4.21 \\
\hline S2.62 & $\mathrm{H}^{\gamma}(t \mathrm{Bu})$ & av & Co & av & $\mathrm{av}$ & +0.008800 & +0.002240 & +0.181632 & +9.56 \\
\hline S2.63 & $\mathrm{H}^{\gamma}(t \mathrm{Bu})$ & av & $\mathrm{Ni}$ & av & av & +0.008656 & -0.001492 & -0.122396 & -6.38 \\
\hline S2.64 & $\mathrm{H}^{\gamma}(\operatorname{syn})^{b}$ & - & Co & 23.77 & 5.354 & +0.009856 & +0.002509 & +0.203424 & +10.70 \\
\hline S2.65 & $\mathrm{H}^{\gamma}(\text { syn })^{b}$ & - & $\mathrm{Ni}$ & 23.60 & 5.391 & +0.009696 & -0.001672 & -0.137101 & -7.15 \\
\hline S2.66 & $\mathrm{H}^{\gamma}\left(\mathrm{sp}^{2}\right)$ & - & $\mathrm{Ni}$ & 23.82 & 5.340 & +0.009921 & -0.001710 & -0.140283 & -7.32 \\
\hline
\end{tabular}




\begin{tabular}{|c|c|c|c|c|c|c|c|c|c|}
\hline entry & nucleus & $l o c$ & M & $\theta$ & $R[\AA]$ & $G$ & $m_{1} G[\mathrm{~K}]$ & $m_{2} G\left[\mathrm{~K}^{2}\right]$ & $\delta^{\mathrm{MPC}}$ \\
\hline S2.67 & $\mathrm{C}^{\delta}\left(\mathrm{sp}^{3}\right)^{c}$ & - & Co & 11.22 & 7.459 & +0.004546 & +0.001157 & +0.093829 & +4.94 \\
\hline S2.68 & $\mathrm{C}^{\delta}\left(\mathrm{sp}^{3}\right)^{c}$ & - & $\mathrm{Ni}$ & 11.16 & 7.499 & +0.004476 & -0.000772 & -0.063291 & -3.30 \\
\hline S2.69 & $\mathrm{C}^{\delta}\left(\mathrm{sp}^{3}\right)^{d}$ & - & Co & 0.0 & 7.317 & +0.005105 & +0.001300 & +0.105376 & +5.55 \\
\hline S2.70 & $\mathrm{C}^{\delta}\left(\mathrm{sp}^{3}\right)^{d}$ & - & $\mathrm{Ni}$ & 0.0 & 7.357 & +0.005023 & -0.000866 & -0.071025 & -3.71 \\
\hline S2.71 & $\mathrm{C}^{\delta}\left(\mathrm{sp}^{2}\right)^{e}$ & - & $\mathrm{Ni}$ & 0.0 & 7.530 & +0.004684 & -0.000808 & -0.066232 & -3.46 \\
\hline S2.72 & $\mathrm{H}^{\delta}(t)^{f}$ & - & Co & 19.09 & 7.583 & +0.003851 & +0.000980 & +0.079485 & +4.18 \\
\hline S2.73 & $\mathrm{H}^{\delta}(t)^{f}$ & - & $\mathrm{Ni}$ & 18.99 & 7.621 & +0.003801 & -0.000655 & -0.053746 & -2.80 \\
\hline S2.74 & $\mathrm{H}^{\delta}\left(\mathrm{CH}_{2}\right)^{d}$ & - & Co & 16.76 & 7.484 & +0.004176 & +0.001063 & +0.086194 & +4.53 \\
\hline S2.75 & $\mathrm{H}^{\delta}\left(\mathrm{CH}_{2}\right)^{d}$ & - & $\mathrm{Ni}$ & 16.67 & 7.523 & +0.004118 & -0.000710 & -0.058229 & -3.04 \\
\hline S2.76 & $\mathrm{H}^{\delta}(m-\mathrm{H})$ & - & $\mathrm{Ni}$ & 16.30 & 7.684 & +0.003887 & -0.000670 & -0.054962 & -2.87 \\
\hline S2.77 & $\mathrm{H}^{\delta}(o-\mathrm{Me})$ & av & $\mathrm{Ni}$ & av & av & +0.007124 & -0.001228 & -0.100733 & -5.26 \\
\hline S2.78 & $\mathrm{H}^{\delta}(8-\mathrm{H})^{g}$ & - & $\mathrm{Ni}$ & 33.67 & 4.374 & +0.012881 & -0.002221 & -0.182123 & -9.50 \\
\hline S2.79 & $\mathrm{C}^{\varepsilon}\left(\mathrm{sp}^{3}\right)^{d}$ & - & Co & 0.0 & 8.857 & +0.002876 & +0.000733 & +0.059413 & +3.13 \\
\hline $\mathrm{S} 2.80$ & $\mathrm{C}^{\varepsilon}\left(\mathrm{sp}^{3}\right)^{d}$ & - & $\mathrm{Ni}$ & 0.0 & 8.897 & +0.002840 & -0.000490 & -0.040158 & -2.10 \\
\hline $\mathrm{S} 2.81$ & $\mathrm{C}^{\varepsilon}(p-\mathrm{Me})$ & - & $\mathrm{Ni}$ & 0.0 & 9.050 & +0.002698 & -0.000465 & -0.038150 & -1.99 \\
\hline S2.82 & $\mathrm{H}^{\varepsilon}(\mathrm{ax})^{c}$ & $\mathrm{n}$ & Co & 19.63 & 7.382 & +0.004130 & +0.001052 & +0.085245 & +4.49 \\
\hline S2.83 & $\mathrm{H}^{\varepsilon}(\mathrm{ax})^{c}$ & $\mathrm{n}$ & $\mathrm{Ni}$ & 19.52 & 7.420 & +0.004076 & -0.000703 & -0.057635 & -3.00 \\
\hline S2.84 & $\mathrm{H}^{\varepsilon}(\mathrm{eq})^{c}$ & d & Co & 9.80 & 8.531 & +0.003081 & +0.000785 & +0.063598 & +3.35 \\
\hline S2.85 & $\mathrm{H}^{\varepsilon}(\mathrm{eq})^{c}$ & d & $\mathrm{Ni}$ & 9.75 & 8.570 & +0.003041 & -0.000524 & -0.043000 & -2.24 \\
\hline S2.86 & $\mathrm{H}^{\varepsilon}(m-\mathrm{Me})$ & - & $\mathrm{Ni}$ & av & av & +0.002632 & -0.000454 & -0.037216 & -1.94 \\
\hline S2.87 & $\mathrm{H}^{\varepsilon}(p-\mathrm{H})$ & - & $\mathrm{Ni}$ & 0.0 & 8.620 & +0.003123 & -0.000538 & -0.044159 & -2.30 \\
\hline S2.88 & $\mathrm{H}^{\varepsilon}(7-\mathrm{H})^{g}$ & - & $\mathrm{Ni}$ & 43.16 & 6.697 & +0.001985 & -0.000342 & -0.028068 & -1.46 \\
\hline S2.89 & $\mathrm{H}^{\varepsilon}(5-\mathrm{H})^{g}$ & - & $\mathrm{Ni}$ & 15.71 & 8.955 & +0.002479 & -0.000427 & -0.035053 & -1.83 \\
\hline S2.90 & $\mathrm{H}^{\zeta}\left(\mathrm{CH}_{3}\right)^{d}$ & - & Co & 6.36 & 9.277 & +0.002459 & +0.000626 & +0.050751 & +2.67 \\
\hline S2.91 & $\mathrm{H}^{\zeta}\left(\mathrm{CH}_{3}\right)^{d}$ & - & $\mathrm{Ni}$ & 6.33 & 9.371 & +0.002428 & -0.000419 & -0.034332 & -1.79 \\
\hline S2.92 & $\mathrm{H}^{\zeta}(p-\mathrm{Me})$ & - & $\mathrm{Ni}$ & 5.62 & 9.641 & +0.002200 & -0.000379 & -0.031108 & -1.62 \\
\hline S2.93 & $\mathrm{H}^{\zeta}(6-\mathrm{H})^{g}$ & - & $\mathrm{Ni}$ & 31.85 & 8.682 & +0.001780 & -0.000307 & -0.025169 & -1.31 \\
\hline S2.94 & $\mathrm{H}^{\eta}(o-\mathrm{H})^{h}$ & - & $\mathrm{Ni}$ & 13.27 & 9.396 & +0.002220 & -0.000383 & -0.031391 & -1.64 \\
\hline S2.95 & $\mathrm{H}^{9}(m-\mathrm{H})^{h}$ & - & $\mathrm{Ni}$ & 10.50 & 11.833 & +0.001147 & -0.000198 & -0.016219 & -0.85 \\
\hline S2.96 & $\mathrm{H}^{\mathrm{l}}(p-\mathrm{H})^{h}$ & - & $\mathrm{Ni}$ & 0.0 & 12.880 & +0.000936 & -0.000161 & -0.013235 & -0.69 \\
\hline
\end{tabular}

${ }^{a} \mathrm{M}=$ metal ion; "loc": av = average, $\mathrm{d}=$ more distant from $\mathrm{M}, \mathrm{n}=$ nearer to $\mathrm{M}, 90$ = orthogonal dihedral angle between $N$-aryl and chelate plane (otherwise always $45^{\circ}$ ); $\theta=$ polar angle $\mathrm{C}^{2}-\mathrm{M}$-nucleus [deg]; $R=$ distance M-nucleus; $G=\left(3 \cos ^{2} \theta-1\right) / R^{3} ; m_{1}(\mathrm{Co})=+0.2546 \mathrm{~K} \cdot \AA^{3} ; m_{1}(\mathrm{Ni})=-0.1724 \mathrm{~K} \cdot \AA^{3} ; m_{2}(\mathrm{Co})=+20.64 \mathrm{~K}^{2} \cdot \AA^{3}$; $m_{2}(\mathrm{Ni})=-14.14 \mathrm{~K}^{2} \cdot \AA^{3}$. ${ }^{b}$ Fixed $\mathrm{CH}_{2}$ in 12 and 13. ${ }^{c}$ 1-Adamantyl in 12. ${ }^{d}$ Bicyclo[2.2.2]octyl in 13. ${ }^{e} \mathrm{C}-$ para. ${ }^{f}$ tert-C $\underline{H}$ in 1-adamantyl of $\mathbf{1 2} .{ }^{g}$ In 1-naphthyl of $\mathbf{2 9 N i} .{ }^{h}$ In $p$-phenyl of $\mathbf{2 8 N i}$. 


\section{The NMR Problem of the Paramagnetic Bis( $N, N^{\prime}$-chelates) 1}

This section provides the background to equations 2-7. Full consistency with regard to the modern ${ }^{14-16}$ SI units was indispensable in order to arrive at numerically correct results which must be compatible with the values obtained from quantum chemical computation.

The through-bond "Fermi contact” shift component $\delta^{\mathrm{CON}}$ in eq S2a $\mathrm{a}^{30 \mathrm{f}, 57}$ is proportional to the hyperfine spinspin coupling constant $A_{\mathrm{s}}$ (given in energy units here). $A_{\mathrm{s}}$ refers to atomic s orbitals because only these have nonvanishing magnitudes at the observed nucleus $\left({ }^{1} \mathrm{H},{ }^{13} \mathrm{C}\right)$, the magnetogyric ratio of which is $\gamma_{\mathrm{N}}$. Except for Planck's constant $h$, all further symbols have been defined in the Introduction of the Main Text.

$$
\begin{aligned}
& \delta^{\mathrm{CON}}=g_{\mathrm{av}} \mu_{\mathrm{B}} S(S+1) A_{\mathrm{s}}\left(3 k T \gamma_{\mathrm{N}} h / 2 \pi\right)^{-1} \\
& A_{\mathrm{s}}=\mu_{\mathrm{o}} g_{\mathrm{av}} \mu_{\mathrm{B}} \gamma_{\mathrm{N}} h\left(\Delta \rho_{\mathrm{N}}\right)\left(6 \pi S a_{\mathrm{o}}{ }^{3}\right)^{-1}
\end{aligned}
$$

The expression for $A_{\mathrm{s}}$ in eq S2b was adapted from equivalent earlier formulations ${ }^{30 \mathrm{~g}, 30 \mathrm{~h}, 31 \mathrm{~d}}$ by the substitutions of $2 \mu_{0} / 3$ for $8 \pi / 3$ and of $\Delta \rho_{\mathrm{N}} /(2 S)$ for the unpaired one-electron spin density in contact with the observed nucleus. $\Delta \rho_{\mathrm{N}}$ is defined ${ }^{30 \mathrm{i}}$ as the local excess of spins having the energetically favored spatial orientation (named positive, “spin-up”, or magnetic moment $\uparrow$ aligned with the external field) minus those with the less stable alignment (called negative, “spin-down”, or magnetic moment $\downarrow$ ). This difference $\rho \uparrow-\rho_{\downarrow}=\Delta \rho_{\mathrm{N}}$ (named so here to avoid confusion with the electron density $\rho=\rho_{\uparrow}+\rho_{\downarrow}$ ) is gauged in "atomic units" as the unpaired spin portion that resides in the volume element ${ }^{27} a_{0}{ }^{3}=0.148185 \AA^{3}$ which is centered at the nucleus $\mathrm{N}^{30 \mathrm{a}, 30 \mathrm{~b}}$ Therefore, $a_{0}{ }^{3}$ was introduced in the denominator of eq S2b to balance the conversion of $\Delta \rho_{\mathrm{N}}$ from $\AA^{-3}$ to atomic units.

$$
\delta^{\mathrm{CON}}=\mu_{\mathrm{o}}{g_{\mathrm{av}}}^{2} \mu_{\mathrm{B}}^{2}(S+1)\left(9 k T a_{\mathrm{o}}^{3}\right)^{-1} \Delta \rho_{\mathrm{N}}
$$

Because $A_{\mathrm{s}}$ was frequently reported in $\mathrm{Hz}$ or radians/s or in gauss rather than in units of energy, we prefer to avoid this source of confusion ${ }^{30 a}$ altogether by the combination of eqs S2a and S2b to give eq 2, where $\delta^{\mathrm{CON}}$ is an experimental measure of $\Delta \rho_{\mathrm{N}}$, independent of the nuclear parameter $\gamma_{\mathrm{N}}$. But eq 2 might be suspected to be reasonably valid only for magnetically simple systems with properties closer to those of Co(II) than to those of pseudotetrahedral $\mathrm{Ni}(\mathrm{II})$ complexes. For the latter in particular, deviations from simple Curie-type $(1 / T)$ behavior may be expected. ${ }^{30 c, 35 a, 35 b}$ Clearly, the applicability of eq 2 to the bis $\left(N, N^{\prime}\right.$-chelate) complexes 1 Co and $\mathbf{1 N i}$ has to be assessed by explicit theoretical calculations. These have been carried out ${ }^{22}$ by Professor Bruce R. McGarvey at the University of Windsor (Canada), using the successful and widely accepted general equations ${ }^{35}$ set up by Kurland and McGarvey. The resulting theoretical Fermi contact parameters of 1Co and 1Ni were found $^{22 b}$ to be proportional to $1 / T$, thus establishing a necessary condition for computing spin densities via eq 2 .

The unpaired electron spin populations $\Delta \rho_{\mathrm{p}}$ residing in p-type atomic orbitals give rise to the ligand-centered pseudocontact (LPC) shift component $\delta^{\mathrm{LPC}}$ at a ligand atom nucleus under observation. (For symmetry reasons $^{51}$ spin in the ns atomic orbitals does not contribute significantly to pseudocontact NMR shifts.) Although physically akin to the metal-centered pseudocontact coupling (eq 6), this interaction cannot ${ }^{\mathrm{S} 1}$ be described by a comparatively simple approximation because of the very short distances $r_{\mathrm{i}}$ between the observed nucleus and the electron spin dispersed over the p orbitals ( $\sigma$ or $\pi$ bonding in part b of Chart 2). ${ }^{30 e}$ Instead, the 
$\Delta \rho_{\mathrm{p}}$ portions contained in small volume elements and the geometry factors $G_{i}^{\mathrm{L}}$ associated with them might be calculated and their products summed (or integrated) as in eq 7 over all contributing p orbitals. In addition to $r_{i}^{-3}$ (or further terms) ${ }^{\mathrm{S} 1}$ and a positive conversion ${ }^{14}$ factor, $G_{i}^{\mathrm{L}}$ should also contain a topological orientation function of the angles $\omega_{i}$ spanned between $r_{i}$ and the unique susceptibility axis, perhaps of the type $G_{i}^{\mathrm{L}}=\left(3 \cos ^{2} \omega_{i}-1\right) r_{i}^{-3}$ as suggested $^{22 \mathrm{~d}, 32}$ in a similar connection.

$$
\begin{gathered}
\delta^{\mathrm{LPC}}=+\Delta \chi_{\mathrm{L}} \Sigma_{i}\left[G_{i}^{\mathrm{L}}\left(\Delta \rho_{\mathrm{p}}\right)_{i}\right] \\
\Delta \chi_{\mathrm{L}}(\text { calcd })=d_{1} / T+d_{2} / T^{2}
\end{gathered}
$$

Equation 7 is an adaptation of the two-center model ${ }^{54}$ of $\delta^{\text {LPC }}$, simplified here for a one-level electronic system in axial symmetry. In accord with the one-center model, ${ }^{51}$ eq 7 contains a susceptibility anisotropy $\Delta \chi_{\mathrm{L}}$ which should resemble $^{38,51}$ (but perhaps ${ }^{22 e, 22 f, 35 d}$ not equal) the metal-centered $\Delta \chi$ (eq 6), for which a partial $1 / T^{2}$ (hyper-Curie) ${ }^{38}$ temperature dependence was derived in the Main Text (eqs 9a,b), in keeping with earlier predictions. $^{30 \mathrm{j}, 32,35 \mathrm{~d}}$ Indeed, explicit model calculations ${ }^{22 \mathrm{f}}$ of the parameters $\Delta \chi_{\mathrm{L}}$ for $\mathbf{1 C o}$ and $\mathbf{1 N i}$ revealed a marked hyper-Curie $^{38}$ behavior, which can be approximated ${ }^{47}$ as a quadratic function of the reciprocal temperature in eq S7a where the factors $d_{1}$ and $d_{2}$ have the same sign: plus for Co and minus for Ni, as calculated ${ }^{22 e}$ similarly for $\Delta \chi$ of eq 6. At room temperature, the Curie part $d_{1} / T$ and the hyper-Curie ${ }^{38}$ term $d_{2} / T^{2}$ contribute to the computed $^{22 \mathrm{f}} \Delta \chi_{\mathrm{L}}$ magnitudes in a ratio ${ }^{47}$ of roughly 56:44 for both Co and Ni(II). Hence it is clear that the $d_{2} / T^{2}$ term could be expected to make a sizeable contribution to $\delta^{\mathrm{LPC}}$.

\section{More about $\vartheta^{\mathrm{CON}}$ and $\Delta \rho_{\mathrm{N}}$}

After corrections of $\delta^{\mathrm{OBS}}$ (Tables S4-S46) for $\delta^{\mathrm{DIA}}$ (eq 5) and $\delta^{\mathrm{MPC}}$ (eq 10a), the resultant $\delta^{\mathrm{C}+\mathrm{L}}$ data of the bis(chelates) $6 \mathrm{Co}-29 \mathrm{Ni}$ were converted to the reduced shifts $\vartheta^{\mathrm{C}+\mathrm{L}} \approx \vartheta^{\mathrm{CON}}$ which were plotted in Figures S1-S4. The correlation lines served to recognize and discard spurious data, thus to arrive at an increased numerical reliability of the $\vartheta^{\mathrm{CON}}$ values (in ppm $=10^{-6}$ ) from which to calculate spin densities $\Delta \rho_{\mathrm{N}}$ via eqs $4 \mathrm{a}-\mathrm{C}$. For corresponding positions with numerically very similar $\vartheta^{\mathrm{CON}}$ values in structurally equivalent regions of different bis(chelates), the correlation lines were bundled to generate averaged $\vartheta^{\mathrm{CON}}$ values, so as to counterbalance further experimental irregularities (as might have been caused by large the linewidths or by unrecognized temperature fluctuations).

Are all of the alternating positive and negative peripheral $\Delta \rho_{\mathrm{N}}$ values in Table S1 generated predominantly by spin transmission through the $\pi$ systems of the chelate ring and of the two $N$-aryl rings? Our $\vartheta^{\text {CON }}$ data furnish evidence both for and against this notion, depending on the molecular position as follows. On the basis ${ }^{\mathrm{S}}$ of ESR coupling constants of $\pi$ radicals, we can expect that the $\vartheta^{\mathrm{CON}}$ ratio of ${ }^{13} \mathrm{C}^{\mathrm{i} /} \mathrm{H}^{\mathrm{i}}$ ( $\mathrm{C}^{\alpha} / \mathrm{H}^{\alpha}$, for example) should be +2.5 when ${ }^{13} \mathrm{C}^{\mathrm{i}} \mathrm{H}_{3}$ was substituted for ${ }^{1} \mathrm{H}^{\mathrm{i}}$ attached directly at a certain position of a $\pi$ scaffold, and that the $\vartheta^{\mathrm{CON}}$ ratio within that methyl group $\left(\mathrm{C}^{\alpha} / \mathrm{H}^{\beta}\right)$ should be -2.1 . These two criteria of methyl substitution may be combined to yield a third criterion, the $\mathrm{H}^{\beta} / \mathrm{H}^{\alpha} \quad \vartheta^{\mathrm{CON}}$ ratio $2.5 /(-2.1)=-1.19$ to be expected for the $\pi$ mechanism. For substituents at $\mathrm{C}^{2}$ of $\mathbf{3 0}$, the experimental ratios are +2.2 (lines 25 versus 23) by the first 
$\left(\mathrm{C}^{\alpha} / \mathrm{H}^{\alpha}\right)$ criterion for both $\mathrm{Co}(\mathrm{II})$ (entries S1.103 versus S1.106) and Ni(II) (S1.104 vs S1.109). The second criterion $\left(\mathrm{C}^{\alpha} / \mathrm{H}^{\beta}\right)$ yields -2.73 for $\mathrm{Co}(\mathrm{II})$ (S1.103 vs S1.115; lines 25 vs 16) and -2.43 for Ni(II) (S1.104 vs S1.116; lines 26 vs 15). Thus, $\pi$ spin density at $C^{2}$ appears to play an important role for spin transmission into the 2-substituents. In contrast, the experimental ratios for substitution at $C^{1,3}$ of $\mathbf{3 0}$ are roughly -17 by the $\mathrm{C}^{\alpha^{\prime}} / \mathrm{H}^{\beta^{\prime}}$ criterion (entries S1.84 vs S1.95, and S1.85 vs S1.99) and about -0.12 (instead of -1.19 ) by the $\mathrm{H}^{\beta^{\prime}} / \mathrm{H}^{\alpha^{\prime}}$ criterion (S1.95 vs S1.88, and S1.99 vs S1.90), suggesting a major positive non- $\pi$ contribution at both $\mathrm{C}^{\alpha^{\prime}}$ and $\mathrm{H}^{\alpha^{\prime}}$ by the anti route (cation- $N-\mathrm{C}^{1}-\alpha^{\prime}$ ). For the 2-aryl substituents restricted to approximately orthogonal conformations (31), any $\pi$ contribution appears to be small because the experimental $\mathrm{H}^{\beta} / \mathrm{H}^{\alpha}$ ratios are -0.35 (instead of -1.19) for the ortho positions of $\mathbf{2 7 N i / 2 6 N i ~ ( S 1 . 1 4 5 ~ a n d ~ S 1 . 1 2 6 ) , ~ z e r o ~ f o r ~ t h e ~ m e t a ~ p o s i t i o n s ~ o f ~}$ (27Ni or 26Ni)/25Ni (S1.153 and S1.139), and -0.78 for the para positions of $\mathbf{2 5 N i / 2 7 N i ~ ( l i n e s ~} 56$ and 37; S1.162 and S1.155).

With methyl groups at the meta position of the $N$-aryl $\pi$ system, the $\mathrm{C}^{\alpha} / \mathrm{H}^{\beta}$ ratios are -5.0 (instead of -2.1 ) for Co(II) (lines 17 vs 39; S1.75 vs S1.77) and -4.1 for $\mathrm{Ni}(\mathrm{II})$ (lines 17 vs 40 ; S1.76 vs S1.78), while $\mathrm{H}^{\beta} / \mathrm{H}^{\alpha}$ yields -0.40 (rather than -1.19 ) for Co(II) (lines 39 vs 55; S1.77 vs S1.44) and -0.45 for Ni(II) (lines 40 vs 18 ; S1.78 vs S1.49). Clean separation of $\pi$ from $\sigma$ transfer is obviously not an attribute of the $N$-aryl meta position. On the other hand, the experimental ratios for the para position of $N$-aryl are +2.45 by the $\mathrm{C}^{\alpha} / \mathrm{H}^{\alpha}$ criterion (lines 21 vs 78) for both $\mathrm{Co}(\mathrm{II})$ (entries S1.81 vs S1.63) and $\mathrm{Ni}(\mathrm{II})$ (entries S1.82 vs S1.68); in accord with -2.37 by $\mathrm{C}^{\alpha} / \mathrm{H}^{\beta}$ for Co(II) (S1.81 vs S1.83; lines 21 vs 54), this indicates a predominance of $\pi$ spin density at this most remote $N$ aryl position. The latter presupposition was the basis of an early analysis ${ }^{\mathrm{S} 5}$ of the $\delta^{\mathrm{PARA}}\left({ }^{1} \mathrm{H}\right)$ values, which was less convincing because the significant contribution of metal-centered pseudocontact shifts $\delta^{\mathrm{MPC}}$ to $\delta^{\mathrm{PARA}}$ was not known at that time.

\section{Recording, Properties, and Assignments of Paramagnetic NMR Spectra}

Most of the employed spectrometers and their parameters have been described previously. ${ }^{\mathrm{S} 6}$ The widely spread ${ }^{13} \mathrm{C}$ NMR spectra were usually taken at $B_{0}=1.88$ tesla with strong pulses $(7 \mu \mathrm{s})$ and high repetition rates (no relaxation delay). This was feasible because of the very efficient paramagnetic relaxation, which also suppressed nuclear Overhauser effects, so that the NMR integrals (with or without $\left\{{ }^{1} \mathrm{H}\right\}$ decoupling) of all types of ${ }^{13} \mathrm{C}$ nuclei could always be interpreted on the same footing. Spectrometer temperatures were measured before and after each run with a calibrated thermocouple located inside a dummy NMR test tube filled with solvent; they were checked at interpretation time for their accordance with $\vartheta^{\mathrm{CON}}$ values known to obey the Curie $(1 / T)$ law. For ${ }^{1} \mathrm{H}$ NMR measurements at $400 \mathrm{MHz}$ or at $200 \mathrm{MHz}$, the default parameters had to be adjusted by calling the Varian procedure setlimit('np',2048*1024,32,2).

Deuterium NMR spectra at $B_{0}=14.1$ tesla were measured with solutions containing 4Co (2.0 mg) or 4Ni (2.1 $\mathrm{mg})$ or $4 \mathrm{Zn}(3.5 \mathrm{mg})$ in dry $\mathrm{CH}_{2} \mathrm{Cl}_{2}(0.5 \mathrm{~mL})$ with $\mathrm{Cl}_{2} \mathrm{CD}-\mathrm{CDCl}_{2}(1.5 \mu \mathrm{L}$, as internal reference) and trifluoromethylbenzene (40 $\mu \mathrm{L}$, as ${ }^{19} \mathrm{~F}$ lock). In the spectra obtained in double-precision mode with $0.5 \mathrm{~Hz}$ of line 
broadening, the relevant ${ }^{2} \mathrm{H}$ NMR doublets caused by deuterium quadrupole interaction were analyzed for the frequency differences $\left|\Delta \nu_{\mathrm{D}}\right|$ by computer lineshape simulation.

In general, the NMR assignments relied primarily on the observation of similar ${ }^{1} \mathrm{H}$ or ${ }^{13} \mathrm{C}$ NMR shifts of comparable molecular regions, and such evidence could be supplemented on apt occasions by the measurement of signal intensities and of multiplet splittings $\left(J_{\mathrm{HH}}\right.$ or $\left.{ }^{1} J_{\mathrm{CH}}\right)$ of sufficiently narrow lines, or else by a consideration of the conspicuous linewidths of very broad resonances. Characteristic large linewidths (> 2 ppm at half height) at room temperature and $B_{0}=1.88$ tesla belong to $H^{\alpha^{\prime}}\left(>11 \mathrm{ppm}\right.$ for $\mathbf{1 C o}$ and $\mathbf{1 N i}$, compare Figure 1), $\mathrm{C}^{\alpha^{\prime}}$ (about 35 ppm for $\mathbf{1 C o}$ and $10 \mathrm{ppm}$ for $\mathbf{1 N i}$ ), $\mathrm{H}^{\alpha}$ and $\mathrm{H}^{\beta}$ (roughly $10 \mathrm{ppm}$ for 1Co), $N$-o-C (about $10 \mathrm{ppm}$ for $\mathbf{1 C o}$ and 1Ni), $N$-i-C (about 9 ppm for 1Co), and $N$-o-H (about 8 ppm for 1Co and 2 ppm for $\mathbf{1 N i}$ ).

The observed ${ }^{1} \mathrm{H}$ NMR shifts $\delta^{\mathrm{OBS}}$ do not depend on the concentrations (this excludes aggregation) or on the amount of free ligand present in the solution even at higher temperatures (this excludes ${ }^{\mathrm{S} 7}$ falsification by rapid ligand exchange). Therefore, even severely decomposed solutions can still give correct $\delta^{\mathrm{OBS}}$ values.

\section{DFT Computational Techniques and Results, Enlarged Version of Figure 4, Tables S3a,b}

The spin densities $\Delta \rho_{\mathrm{DFT}}$ were calculated for a single electronic state under conditions of tight convergence with the UB3LYP method of Gaussian $98^{\mathrm{S} 8}$ and Gaussian $03 ;^{\mathrm{S9}}$ these two programs generated practically equal $\Delta \rho_{\mathrm{DFT}}$ values (and HF energies) whereas their Mulliken spin densities differed appreciably. The results were accepted only when the nonprojected $S^{2}=S(S+1)$ values were 3.75-3.77 for Co(II) or 2.00-2.015 for Ni(II) bis(chelates), although considerably larger values should not necessarily ${ }^{\mathrm{S} 10}$ discredit the UB3LYP results. The results were discarded when they did not resemble those of sample calculations for similar parts of the same structural type of $\mathbf{1}$ for which the "stable” option of Gaussian had signalled the absence of an internal instability and thus had witnessed against a significant admixture of electronically excited states (which could have been expected $^{30 c, 35 a, 35 b}$ for pseudotetrahedral Ni(II) complexes in particular).

The considerable size of some of the bis(chelates) (such as 12Co and 12Ni with more than 410 electrons each) rendered it necessary to confine all runs to "single point” calculations (omitting structural optimization throughout) at "experimental” (X-ray) $)^{5,6}$ and partly idealized geometries: all hydrogen atoms $(\mathrm{C}-\mathrm{H}=1.09 \AA)$ and the carbon atoms of substituents at the $\mathrm{N}$ atoms and at $\mathrm{C}^{1,3}$ and $\mathrm{C}^{2}$ were placed at their idealized positions, as documented by the Gaussian "archives" for 12Co and 12Ni in the sequel. Unless noted otherwise, the twist angles were kept at $90^{\circ}$ between the two chelate planes and at $\varphi=45^{\circ}$ between the chelate and $N$-aryl planes. Two examples of the spin density values computed for a $60^{\circ}$ chelate twist are shown in entries S3a.8 and S3a.16 of Table S3a, while the dependence on $\varphi=0^{\circ}, 45^{\circ}$, and $90^{\circ}$ is depicted in Table S3b.

The general strategy consisted in computing an initial density functional for the singlet configuration of a Ni(II) bis(chelate) 1Ni, using the "guess=mix" keyword and usually the 6-31G(2d,p) basis set. This unrestricted functional was then used for computation of the triplet configuration, beginning with the same or a not too different basis set. The resultant functional served for runs with the larger valence triple- $\zeta$ 6-311G basis, which includes the Wachters ${ }^{\mathrm{S} 11}$ and $\mathrm{Hay}^{\mathrm{S} 12}$ sets for Co and Ni. All basis sets were specified globally for the whole bis(chelate). The Co(II) quartet state could often be obtained directly from the Ni(II) triplet functional, using the 6-31G(2d,p) 
or a larger basis set with the required geometrical changes (see the Gaussian Archives below). In general, the best choice was 6-311G(d,p), while the largest basis set used, 6-311+G(2d,p) with a diffuse function (“+”), worked slightly better for some ${ }^{13} \mathrm{C}$ nuclei (especially $\mathrm{C}^{2}, \mathrm{C}^{\alpha^{\prime}}, N-i-\mathrm{C}$, and several $N-p-\mathrm{C}$ ), as seen in Table S1. The augmented polarization functions (2d,p) in 6-311G(2d,p) provided $\Delta \rho_{\mathrm{DFT}}$ values (rows A in Table S3b) mostly in between those of 6-311+G(2d,p) in rows B and 6-311G(d,p) but usually closer to the latter. Complete omission of the polarization functions (6-311G) impaired most of the $\Delta \rho_{\mathrm{DFT}}$ results for 10Co (entry S3a.2) and 10Ni (S3a.11) but gave mixed results (not shown) for the bicyclo substituents at $C^{2}$ of both 13Co and 13Ni, whereas the gradient-corrected method UBLYP was decidedly much less suitable (S3a.7 and S3a.15), as had been noted previously ${ }^{59}$ for transition metal complexes. Compared with the Gaussian default grid, an "ultrafine" density grid did not change the $\Delta \rho_{\mathrm{DFT}}$ values of the observed nuclei appreciably (although the Mulliken spin densities were quite different). The correlation-consistent method “cc-pVDZ” worked less satisfactorily for the ligand atoms in a model calculation of $\mathbf{1 N i}\left(\right.$ all $\mathrm{R}^{\mathrm{i}}=\mathrm{H}$ ), as did also the "CCSD” method with participation of excited configurations. Tables S3a and S3b include $\Delta \rho_{\text {DFT }}$ values for the unsearched nuclei (Co, Ni, and nitrogen) and show that the computed absolute magnitudes are smaller for the Co(II) than for the Ni(II) bis(chelates), except for the metal cations, $\mathrm{C}^{2}$, and $\mathrm{H}^{\alpha^{\prime}}$. Despite their not too large $\Delta \rho_{\mathrm{DFT}}$ values, the resonances of $\mathrm{C}^{2}$ and $\mathrm{C}^{1,3}$ of Co(II) compounds could not be detected, presumably owing to their very large linewidths.

In a search for possible reasons of a non-Curie type behavior of $\vartheta^{\mathrm{CON}}$, a computational elongation (+10\%) of the four relatively weak $\mathrm{Ni}-\mathrm{N}$ bonds in $\mathbf{1 N i}$ (with all $\mathrm{R}^{\mathrm{i}}=\mathrm{H}$ ) with conservation of the ligand geometry was found to produce the largest changes of $\left|\Delta \rho_{\mathrm{DFT}}\right|$ at $\mathrm{C}^{1,3}(-72 \%)$ and at $\mathrm{R}^{\mathrm{N}}=\mathrm{H}(-70 \%)$, while it had smaller effects at $\mathrm{C}^{2}(-19 \%), \mathrm{H}^{\alpha}(-12 \%), \mathrm{H}^{\alpha^{\prime}}(+3 \%)$, and the Ni cation (-2\%). These stronger variations of $\left|\Delta \rho_{\mathrm{DFT}}\right|$ for the chelate ring members $\mathrm{C}^{1-3}$ indicate that increasingly larger twist amplitudes (as caused by heating ${ }^{52,53}$ ) might be apt to simulate (for $C^{1,3}$ in lines 27-31 of Figure S1) or to cancel (for $C^{2}$ in lines 1 and 3) parts of the (presumably) ${ }^{22 f}$ negative $d_{2} / T^{2}$ term expected from $\delta^{\mathrm{LPC}}$. On the other hand, more realistic (smaller) ${ }^{52,53}$ changes such as computing the bis(chelate) complex $10 \mathrm{Ni}$ in the geometry of $10 \mathrm{Co}$, or vice versa, produced only modest $\Delta \rho_{\mathrm{DFT}}$ variations (entries S3a.9 and S3a.17) in the chelate rings and rather small effects at the peripheral nuclei. 


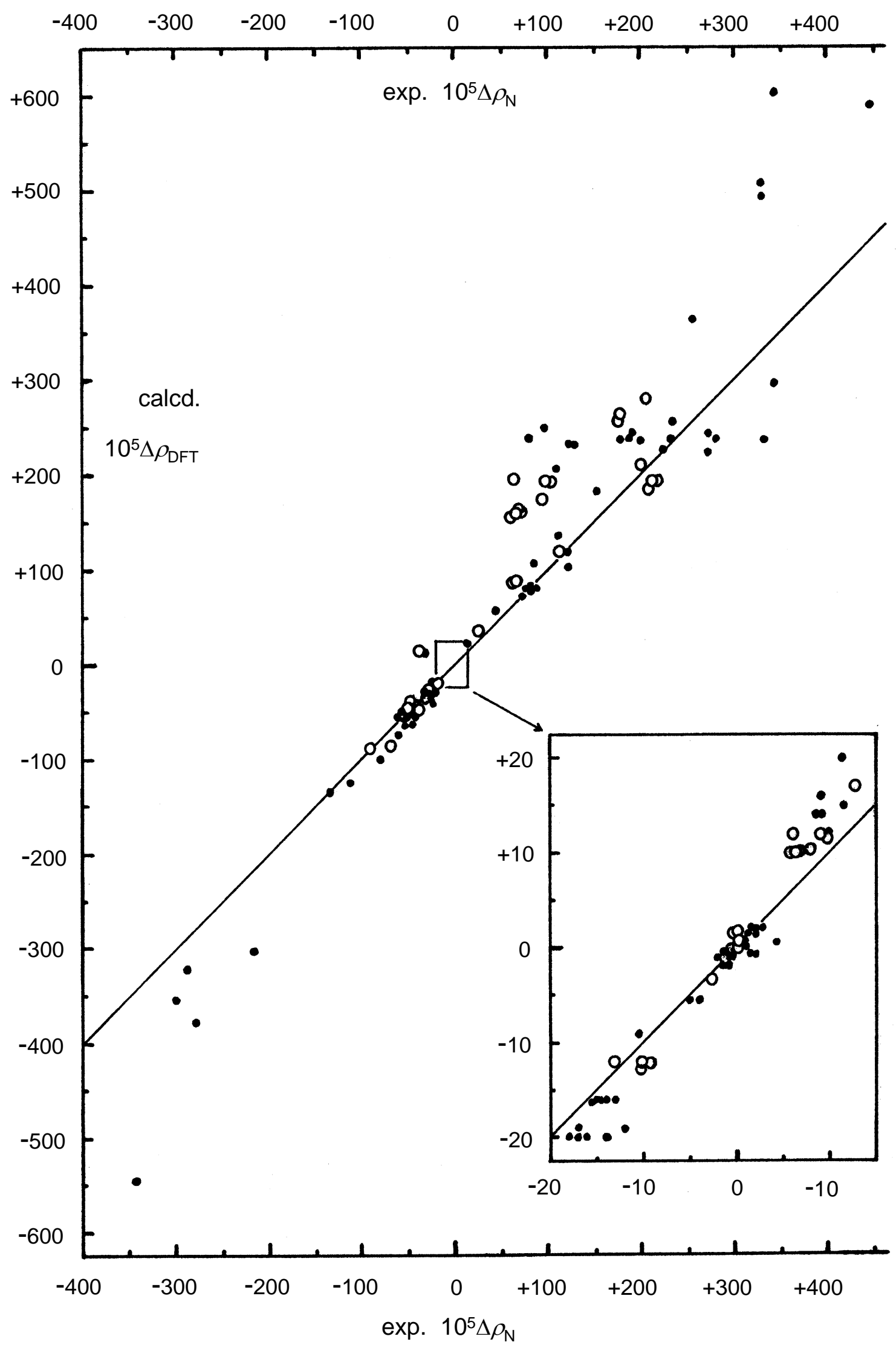

Figure 4. Distribution of ${ }^{1} \mathrm{H}$ and ${ }^{13} \mathrm{C}$ experimental $\left(\Delta \rho_{\mathrm{N}}\right)$ and computed spin densities $\left(\Delta \rho_{\mathrm{DFT}}\right.$ from UB3LYP/6311G(d,p)) about the desired 1:1 correlation line. Open circles for 1Co and filled symbols for $\mathbf{1 N i}$. 
The accompanying enlarged version of Figure 4 reveals both systematic and specific disagreements between $\Delta \rho_{\mathrm{DFT}}$ and $\Delta \rho_{\mathrm{N}}$. Nevertheless, the following three traits can be read from Table S1: (i) The Gaussian valence triple- $\zeta$ basis set 6-311G(d,p) without diffuse functions is preferable to $6-311+G(2 d, p)$ for most of the peripheral nuclei. (ii) With few serious exceptions concerning $C^{\beta^{\prime}}$ and $\mathrm{H}^{\gamma^{\prime}}$ (entries S1.93, S1.94, S1.101, and S1.102), the signs of the experimental $\Delta \rho_{\mathrm{N}}$ data were correctly reproduced, inclusive of $N-i-C$ (lines $47-49$ and 53; S1.11S1.19) which had been mentioned in the Main Text as providing the single violation of the sign alternation pattern displayed in 30. Further sign disagreements concern borderline cases with spin densities close to zero at $\mathrm{H}^{\gamma^{\prime}}$ of 19Co (S1.100), $\mathrm{C}^{\delta}$ of 12Ni (line 73; S1.131), $\mathrm{H}^{\delta}$ of 12Co (S1.136), 8-H of 29Ni (line 33; S1.143), $\mathrm{H}^{\varepsilon}$ of both 12Ni (S1.150) and 12Co (S1.151), $\mathrm{H}^{\zeta}$ of 13Co (line 36; S1.160), and $\mathrm{H}^{\eta}$ of 28Ni (S1.165). (iii) Both $\Delta \rho_{\mathrm{DFT}}$ and $\Delta \rho_{\mathrm{N}}$ are regularly smaller for the Co(II) bis(chelates) than for the isostructural Ni(II) compounds. Significant exceptions were observed for $\mathrm{C}^{\alpha^{\prime}}$ (S1.84 versus S1.86, line 2), $\mathrm{C}^{\beta^{\prime}}$ (lines 61 vs 60; S1.93 vs S1.94), and $\mathrm{H}^{\gamma}$ (S1.124 vs S1.125, line 74). Under the influence of positive spin density at the chelate center $\mathrm{C}^{2}$, the various 2substituents respond by developing $\Delta \rho_{\mathrm{N}}$ patterns in qualitative accord with $\Delta \rho_{\mathrm{DFT}}$ values for $\mathrm{C}^{\alpha}, \mathrm{H}^{\alpha}, \mathrm{C}^{\beta}, \mathrm{H}^{\beta}, \mathrm{C}^{\gamma}$, $\mathrm{H}^{\gamma}, \mathrm{H}^{\delta}$ (with exceptions), and $\mathrm{H}^{\varepsilon}$, but less so for $\mathrm{C}^{\delta}$ and $\mathrm{C}^{\varepsilon}$. The computed rise of $\Delta \rho_{\text {DFT }}$ at $\mathrm{C}^{2}$ by $23 \%$ on going from $\mathrm{R}^{\alpha}=\mathrm{H}$ in $\mathbf{6 N i}$ (entry S1.9; line 3) to $\mathrm{R}^{\alpha}=$ tert-alkyl in 11-13Ni (S1.6; line 1) agrees well with the experimental increase of $\Delta \rho_{\mathrm{N}}$ by 26\%; but the computed $5 \%$ increment of $\Delta \rho_{\mathrm{DFT}}$ at $\mathrm{C}^{2}$ from $\mathrm{R}^{\alpha}=\mathrm{H}$ in $15 \mathrm{Ni}$ (entry S1.9) to $\mathrm{R}^{\alpha}=p$-methylphenyl in $24 \mathrm{Ni}$ (S1.7) falls short of the experimental $22 \%$ increase of $\Delta \rho_{\mathrm{N}}$. It may be recalled that rigid rotational motions of nuclei about the $C^{2}-C^{\alpha}$ bond direction (the unique magnetic axis) will not change their polar coordinates and hence the $\vartheta^{\mathrm{MPC}}$ values (which are trustworthy, therefore).

The 1-naphthyl substituted 29Ni was chosen because of its axial chirality (as exploited in the Main Text $N$-aryl section) and because its 8-H should be positioned roughly on top of the adjacent $\mathrm{p}_{\pi}$ orbital of $\mathrm{C}^{2}$, namely, at 2.45 $\AA$ above $\mathrm{C}^{2}$ with the angle $\mathrm{H}-\mathrm{C}^{2}-\mathrm{C}^{\alpha}=81^{\circ}$. This distance might be short enough ${ }^{\mathrm{S} 13}$ to allow for spin density transfer from $\mathrm{p}_{\pi}\left(\mathrm{C}^{2}\right)$ to 8-H by 8-H/C $\mathrm{C}^{2}$ orbital overlap. Such a "short-circuited" spin transfer and its corresponding $\vartheta^{\mathrm{CON}}(8-\mathrm{H})$ should be independent of the temperature, provided that torsional motions do not reduce this unusual orbital overlap. However, extrapolation of the positive reduced shifts (crosses on line 33, or Table S46) toward $1 / T=0$ afforded a value close to zero, and the positive experimental contribution was not reflected by the computed negative spin density (entry S1.143). A possible interpretation might explain this with a $1 / T^{2}$ dependent, positive ligand-centered pseudocontact contribution $\delta^{\mathrm{LPC}}$ at $8-\mathrm{H}$ as follows. The (presumably) ${ }^{22 \mathrm{f}}$ negative $\Delta \chi_{\mathrm{L}}$ in eq 7 interacts with the positive $\Delta \rho_{\pi}$ which resides in the $\mathrm{p}_{\pi}$ orbital lobe centered at $\mathrm{C}^{2}$, yet $\delta^{\mathrm{LPC}}$ and $\vartheta^{\mathrm{LPC}}$ will be positive because the geometry factors $G_{i}^{\mathrm{L}}$ of eq 7 should be negative for $\omega_{1} \approx 80^{\circ}$. The vanishing extrapolated reduced shift might then be explained as the sum of a remaining positive Curie portion of $\vartheta^{\mathrm{LPC}}$ plus $\vartheta^{\mathrm{CON}} \approx-1 \mathrm{ppm}$ (from the negative $\Delta \rho_{\mathrm{DFT}}$ value in entry S1.143 via eq 4c). Related effects were not encountered for the o-methyl protons of $25 \mathrm{Ni}$ and $\mathbf{2 7 N i}$ (S1.144 and S1.145), perhaps owing to methyl rotation and hence smaller averaged $G_{i}^{\mathrm{L}}$ factors. 
Table S3a. UB3LYP Spin Densities $10^{3} \Delta \rho_{\mathrm{DFT}}$ as a Function of the Basis Sets and of Geometrical Changes, Compared with the Experimental Values $10^{3} \Delta \rho_{\mathrm{N}}$ of 9Ni, 10Co, and 10Ni

\begin{tabular}{|c|c|c|c|c|c|c|c|c|c|c|c|c|c|c|c|c|c|}
\hline entry & & basis set ${ }^{a}$ & & & & & spin de & nsities 1 & $0^{3} \Delta \rho_{\mathrm{DFT}}$ & or (exp.) & $10^{3} \Delta \rho_{\mathrm{N}}$ & & & & & & \\
\hline no. & no. & or exp. & cation & nitrogen & $C(1,3)$ & $C(2)$ & $\mathrm{H}\left(\alpha^{\prime}\right)$ & $\mathrm{C}(\alpha)$ & $\mathrm{H}(\beta)$ & $N-i-C$ & $\mathrm{~N}-\mathrm{O}-\mathrm{C}$ & $N-m-\mathrm{C}$ & $N-p-\mathrm{C}$ & $N-p-\underline{C} \mathrm{H}_{3}$ & $N-O-\mathrm{H}$ & $N-m-\mathrm{H}$ & $N-p-\mathrm{CH}_{3}$ \\
\hline S3a.1 & 10Co & exp. & - & - & - & - & +1.758 & -0.883 & +0.323 & +0.938 & +2.141 & -0.348 & +0.720 & -0.244 & - & +0.070 & +0.103 \\
\hline S3a.2 & 10Co & $\mathrm{G}(-)$ & -436.2 & +84.26 & -0.24 & +5.37 & +2.51 & -1.05 & +0.38 & +1.53 & +2.00 & -0.50 & +0.72 & -0.29 & -0.16 & +0.11 & +0.12 \\
\hline S3a.3 & 10Co & $G(d, p)$ & -432.8 & +83.98 & +0.36 & +4.85 & +2.54 & -0.90 & +0.35 & +1.72 & +1.92 & & +0.64 & & -0.14 & +0.10 & +0.115 \\
\hline S3a.4 & 10Co & $+\mathrm{G}(\mathrm{d}, \mathrm{p})$ & -410.8 & +79.81 & -0.08 & +5.22 & +2.44 & -1.02 & +0.41 & +1.69 & +2.05 & -0.45 & +0.68 & -0.29 & -0.15 & +0.10 & +0.13 \\
\hline S3a.5 & 10Co & G(2d,p) & -430.3 & +83.99 & +0.13 & +5.07 & +2.56 & -0.89 & +0.36 & +1.71 & +1.99 & -0.46 & +0.69 & -0.27 & -0.14 & +0.10 & +0.12 \\
\hline S3a.6 & 10Co & $+\mathrm{G}(2 \mathrm{~d}, \mathrm{p})$ & -413.0 & +80.08 & -0.22 & +5.38 & +2.47 & -1.01 & +0.42 & +1.62 & +2.11 & -0.43 & +0.73 & -0.29 & -0.15 & +0.10 & +0.13 \\
\hline S3a.7 & 10Co & $\mathrm{G}(2 \mathrm{~d}, \mathrm{p})^{b}$ & -330.7 & +94.14 & +1.47 & +6.52 & +3.73 & -1.12 & +0.59 & +2.60 & +2.38 & -0.34 & +0.72 & -0.34 & -0.14 & +0.12 & +0.174 \\
\hline S3a.8 & 10Co & $+\mathrm{G}(2 \mathrm{~d}, \mathrm{p})^{c}$ & -420.8 & +83.21 & +0.018 & +4.20 & +2.23 & -0.95 & +0.38 & +1.11 & +2.18 & -0.34 & +0.75 & -0.27 & -0.13 & +0.09 & +0.12 \\
\hline S3a.9 & 10Co & $+\mathrm{G}(2 \mathrm{~d}, \mathrm{p})^{d}$ & -415.8 & +86.09 & +0.25 & +4.87 & +2.50 & -1.04 & +0.45 & +1.38 & +2.44 & -0.50 & +0.77 & -0.31 & -0.16 & +0.11 & +0.14 \\
\hline S3a.10 & $10 \mathrm{Ni}$ & exp. & - & - & -3.20 & - & +1.884 & - & $+0.465^{e}$ & +1.099 & +2.366 & -0.477 & +0.820 & -0.307 & $-0.156^{e}$ & $+0.086^{e}$ & - \\
\hline S3a.11 & $10 \mathrm{Ni}$ & $\mathrm{G}(-)$ & -339.7 & +96.28 & -4.62 & +3.69 & +2.41 & -1.64 & +0.567 & +1.79 & +2.52 & -0.66 & +0.91 & -0.37 & -0.23 & +0.15 & +0.153 \\
\hline S3a.12 & $10 \mathrm{Ni}$ & $G(d, p)$ & -336.5 & +95.32 & -3.78 & +3.03 & +2.38 & -1.44 & +0.542 & +2.06 & +2.37 & -0.55 & +0.81 & -0.34 & -0.21 & +0.14 & +0.152 \\
\hline S3a.13 & $10 \mathrm{Ni}$ & $\mathrm{G}(2 \mathrm{~d}, \mathrm{p})$ & -334.6 & +95.12 & -4.04 & +3.28 & +2.41 & -1.47 & +0.57 & +1.97 & +2.47 & -0.59 & +0.90 & -0.35 & -0.22 & +0.14 & +0.16 \\
\hline S3a.14 & $10 \mathrm{Ni}$ & $+\mathrm{G}(2 \mathrm{~d}, \mathrm{p})$ & -325.1 & +93.55 & -4.60 & +3.86 & +2.38 & -1.68 & +0.67 & +1.70 & +2.64 & -0.64 & +0.96 & -0.38 & -0.23 & +0.15 & +0.18 \\
\hline S3a.15 & $10 \mathrm{Ni}$ & $\mathrm{G}(2 \mathrm{~d}, \mathrm{p})^{b}$ & -248.0 & +100.2 & -3.50 & +3.75 & +3.23 & -2.05 & +1.01 & +2.71 & +2.92 & -0.47 & +0.94 & -0.44 & -0.24 & +0.17 & +0.241 \\
\hline S3a.16 & $10 \mathrm{Ni}$ & $+\mathrm{G}(2 \mathrm{~d}, \mathrm{p})^{c}$ & -333.7 & +98.64 & -4.27 & +4.15 & +2.43 & -1.76 & +0.73 & +0.83 & +2.95 & -0.45 & +0.91 & -0.35 & -0.22 & +0.14 & +0.15 \\
\hline S3a.17 & $10 \mathrm{Ni}$ & $+\mathrm{G}(2 \mathrm{~d}, \mathrm{p})^{f}$ & -319.2 & +85.78 & -5.15 & +3.65 & +2.32 & -1.65 & +0.67 & +2.15 & +2.54 & -0.59 & +0.92 & -0.37 & -0.23 & +0.14 & +0.17 \\
\hline
\end{tabular}

${ }^{a}$ Abbreviated as the portion $\mathrm{x}$ of the triple- $\zeta$ basis set 6-311x. ${ }^{b}$ UBLYP method. ${ }^{c}$ Chelate interplanar twist angle $60^{\circ}$ (instead of $90^{\circ}$ ). ${ }^{d}$ Computed with the geometrical parameters of $\mathbf{1 0 N i} .{ }^{e}$ From $\vartheta^{\mathrm{CON}}$ of $\mathbf{9 N i}$ (instead of 10Ni). ${ }^{f}$ Computed with the geometrical parameters of $10 \mathrm{Co}$. 
Table S3b. UB3LYP Spin Densities $10^{3} \Delta \rho_{\mathrm{DFT}}$ as a Function of the Chelate/ $N$-Phenyl Interplanar Angle $\varphi$ and the Substituents $\mathrm{R}^{1}$ and $\mathrm{R}^{3}$

\begin{tabular}{|c|c|c|c|c|c|c|c|c|c|c|c|c|c|c|c|c|c|c|c|}
\hline \multirow{2}{*}{$\begin{array}{c}\text { entry } \\
\text { no. }\end{array}$} & \multirow{2}{*}{$\begin{array}{c}\text { cpd. } \\
\text { no. }\end{array}$} & \multirow{2}{*}{$\begin{array}{c}\varphi \\
\text { deg }\end{array}$} & \multicolumn{7}{|c|}{ basis } & \multicolumn{10}{|c|}{ computed spin densities $10^{3} \Delta \rho_{\mathrm{DFT}}$} \\
\hline & & & set $^{a}$ & cation & nitrogen & $\mathrm{C}(1,3)$ & $\mathrm{C}(2)$ & $\mathrm{H}(\alpha)$ & $\alpha^{\prime}$ & $\beta$ & $\gamma^{\prime}$ & $N-\mathrm{i}-\mathrm{C}$ & $N-\mathrm{o}-\mathrm{C}$ & $N-m-\mathrm{C}$ & $N-p-\mathrm{C}$ & $N-\mathrm{o}-\mathrm{H}$ & $N-m-\mathrm{R}$ & $N-m-\underline{H}_{3}$ & $N-p-\mathrm{H}$ \\
\hline \multirow[t]{2}{*}{ S3b.1 } & $6^{\prime} \mathrm{Co}^{b}$ & $0^{\circ}$ & A & -423.6 & +84.09 & +1.22 & +4.72 & -0.42 & +2.57 & - & - & +1.11 & +3.11 & -0.23 & +0.85 & -0.03 & +0.12 & - & -0.08 \\
\hline & & & B & -410.0 & +83.05 & +1.04 & +4.77 & -0.46 & +2.56 & - & - & +1.01 & +3.07 & -0.25 & +0.89 & -0.05 & +0.12 & - & -0.09 \\
\hline \multirow[t]{2}{*}{ S3b.2 } & $6^{\prime} \mathrm{Co}^{b}$ & $45^{\circ}$ & A & -430.4 & +83.33 & +0.33 & +4.96 & -0.48 & +2.59 & - & - & +1.94 & +1.95 & -0.39 & +0.63 & -0.14 & +0.10 & - & -0.13 \\
\hline & & & B & -412.6 & +79.93 & +0.05 & +5.21 & -0.53 & +2.48 & - & - & +1.88 & +2.05 & -0.42 & +0.66 & -0.14 & +0.10 & - & -0.14 \\
\hline \multirow[t]{2}{*}{ S3b.3 } & 6Co & $45^{\circ}$ & A & -429.4 & +83.16 & +0.37 & +4.96 & -0.48 & +2.58 & - & - & & +1.91 & & & & +0.17 & -0.037 & -0.12 \\
\hline & & & B & -412.7 & +79.86 & +0.12 & +5.17 & & +2.48 & - & - & & +2.01 & & & & & & -0.13 \\
\hline \multirow[t]{2}{*}{ S3b.4 } & $6^{\prime} \mathrm{Co}^{b}$ & $90^{\circ}$ & A & -426.8 & +81.24 & -0.94 & +5.17 & -0.53 & +2.58 & - & - & & +2.20 & & & & & - & -0.17 \\
\hline & & & B & -410.1 & +77.70 & -1.22 & +5.45 & -0.59 & +2.47 & - & - & +1.67 & +2.45 & -0.46 & & -0.18 & & - & -0.17 \\
\hline \multirow[t]{2}{*}{ S3b.5 } & 19Co & $90^{\circ}$ & A & -420.3 & +80.47 & -2.30 & +4.09 & -0.48 & +6.38 & +0.111 & +0.001 & +0.30 & +2.86 & -0.89 & +1.22 & -0.24 & +0.13 & - & -0.25 \\
\hline & & & B & -406.2 & +77.27 & -2.41 & +4.28 & -0.53 & +6.11 & +0.127 & -0.001 & +0.27 & +3.02 & -0.84 & +1.18 & -0.23 & +0.13 & - & -0.25 \\
\hline \multirow[t]{2}{*}{ S3b.6 } & $\mathbf{6}^{\prime} \mathbf{N i}^{b}$ & $0^{\circ}$ & A & -331.2 & +96.10 & -2.59 & +2.44 & -0.62 & +2.38 & - & - & +1.70 & +2.83 & -0.44 & +0.90 & -0.17 & +0.13 & - & -0.14 \\
\hline & & & B & -323.7 & +95.67 & -2.80 & +2.72 & -0.68 & +2.40 & - & - & +1.51 & +2.84 & -0.51 & +0.96 & -0.19 & +0.14 & - & -0.16 \\
\hline \multirow[t]{2}{*}{ S3b.7 } & $\mathbf{6}^{\prime} \mathbf{N i}^{b}$ & $45^{\circ}$ & A & -335.1 & +95.51 & -3.32 & +2.62 & -0.66 & +2.40 & - & - & +2.30 & +2.42 & -0.54 & +0.82 & -0.21 & +0.14 & 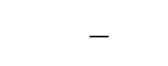 & -0.17 \\
\hline & & & B & -325.4 & +93.89 & -3.78 & +3.08 & -0.76 & +2.37 & - & - & +2.08 & +2.56 & -0.58 & +0.86 & -0.22 & +0.14 & 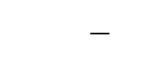 & -0.18 \\
\hline \multirow[t]{2}{*}{ S3b.8 } & $6 \mathrm{Ni}$ & $45^{\circ}$ & A & -334.7 & +95.55 & -3.31 & +2.64 & -0.67 & +2.40 & - & - & +2.21 & +2.37 & & & -0.21 & +0.24 & & -0.16 \\
\hline & & & B & -325.3 & +93.76 & -3.73 & +3.05 & -0.75 & +2.37 & - & - & +2.01 & +2.51 & -0.62 & +0.83 & -0.22 & +0.25 & -0.062 & -0.18 \\
\hline \multirow[t]{2}{*}{ S3b.9 } & $\mathbf{6}^{\prime} \mathbf{N i}^{b}$ & $90^{\circ}$ & A & -330.0 & +91.98 & -4.60 & +2.93 & -0.71 & +2.40 & - & - & +2.01 & +2.98 & -0.54 & +1.00 & -0.21 & +0.12 & - & -0.20 \\
\hline & & & B & -322.1 & +90.76 & -4.99 & +3.45 & -0.82 & +2.38 & - & - & +1.77 & +3.35 & -0.48 & +0.98 & -0.21 & +0.12 & - & -0.20 \\
\hline \multirow[t]{2}{*}{ S3b.10 } & $19 \mathrm{Ni}$ & $90^{\circ}$ & A & -324.0 & +91.14 & -5.66 & +2.57 & -0.65 & +5.97 & +0.124 & -0.005 & +0.30 & +3.78 & -1.02 & +1.44 & -0.28 & +0.16 & - & -0.30 \\
\hline & & & B & -316.6 & +89.77 & -6.03 & +2.95 & -0.72 & +5.86 & +0.127 & -0.006 & +0.22 & +4.05 & -0.97 & +1.41 & -0.28 & +0.17 & - & -0.33 \\
\hline \multirow[t]{2}{*}{ S3b.11 } & $20 \mathrm{Ni}$ & $90^{\circ}$ & A & -327.5 & $+88.87^{c}$ & $-4.42^{c}$ & +2.67 & -0.68 & $+2.41^{c}$ & - & - & $+2.16^{c}$ & $+2.83^{c}$ & $-0.56^{c}$ & $+1.00^{c}$ & $-0.21^{c}$ & $+0.12^{c}$ & - & $-0.20^{c}$ \\
\hline & & & B & -319.7 & $+87.73^{c}$ & $-4.78^{c}$ & +3.13 & -0.77 & $+2.40^{c}$ & - & - & $+1.93^{c}$ & $+3.17^{c}$ & $-0.50^{c}$ & $+0.98^{c}$ & $-0.21^{c}$ & $+0.12^{c}$ & - & $-0.20^{c}$ \\
\hline \multirow[t]{2}{*}{ S3b.12 } & $20 \mathrm{Ni}$ & $90^{\circ}$ & A & -327.5 & $+94.31^{d}$ & $-5.99^{d}$ & +2.67 & -0.68 & $+5.22^{d}$ & +0.75 & -0.062 & $+0.74^{d}$ & $+3.54^{d}$ & $-0.83^{d}$ & $+1.29^{d}$ & $-0.25^{d}$ & $+0.16^{d}$ & - & $-0.27^{d}$ \\
\hline & & & B & -319.7 & $+92.67^{d}$ & $-6.44^{d}$ & +3.13 & -0.77 & $+5.12^{d}$ & +0.72 & -0.061 & $+0.54^{d}$ & $+3.87^{d}$ & $-0.77^{d}$ & $+1.25^{d}$ & $-0.25^{d}$ & $+0.16^{d}$ & - & $-0.26^{d}$ \\
\hline
\end{tabular}

${ }^{a} \mathrm{~A}=6-311 \mathrm{G}(2 \mathrm{~d}, \mathrm{p}), \mathrm{B}=6-311+\mathrm{G}(2 \mathrm{~d}, \mathrm{p}) .{ }^{b} 6^{\prime}=6$ minus all $m-\mathrm{CH}_{3}$ groups. ${ }^{c}$ Uncongested side: $\mathrm{C}(1), \mathrm{H}\left(\alpha^{\prime}\right)$, and appertaining $N$-aryl nuclei. ${ }^{d}$ Congested side: $\mathrm{C}(3), \mathrm{C}\left(\alpha^{\prime}\right), \mathrm{C}\left(\beta^{\prime}\right), \mathrm{H}\left(\gamma^{\prime}\right)$, and appertaining $N$-aryl nuclei. 


\section{Gaussian Archive of 12Co:}

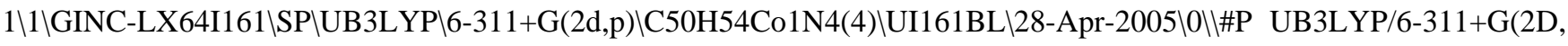
P) $\mathrm{SCF}=($ TIGHT,MAXCYCLE=200) POP=REGULAR GFINPUT GUESS= READ IOP(6/82=1) \\CoAdg3Q2.com = Quartett 109 Atome pop=regular gfinput $\backslash \backslash 0,4 \backslash X \backslash C o, 1,8 . \backslash \mathrm{X}, 2,2 ., 1,90 . \mid \mathrm{N}, 2,1.97,3,48.5,1,0 ., 0 \backslash \mathrm{C}, 4,1.307,2,121.5,3,0 ., 0 \backslash \mathrm{C}, 2,3.23$,

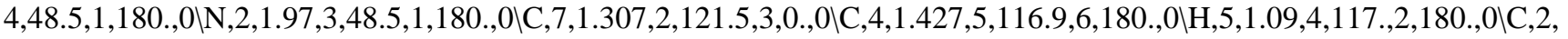

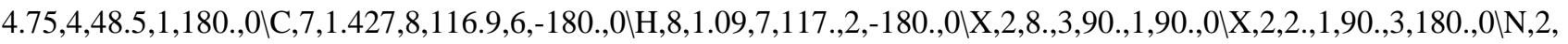

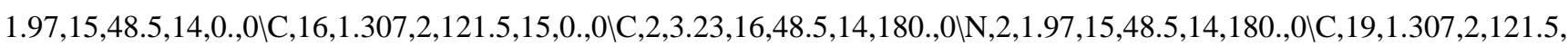

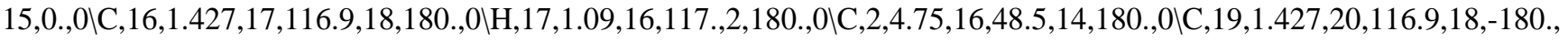

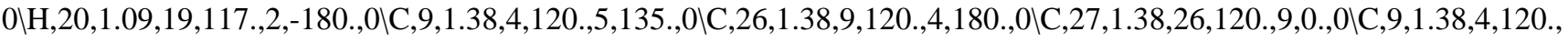

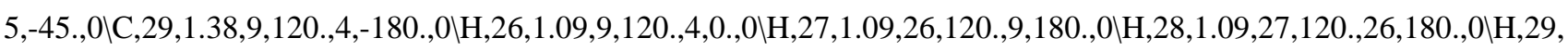

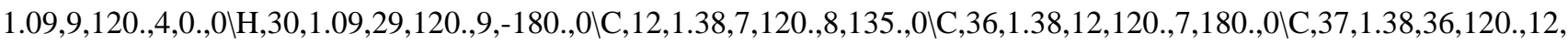

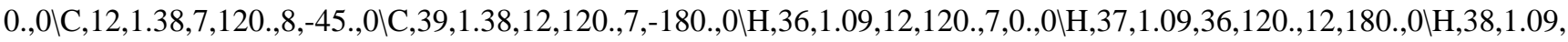

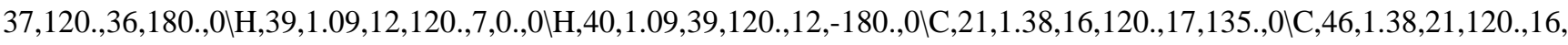

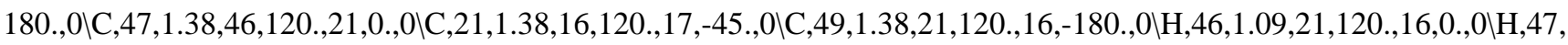

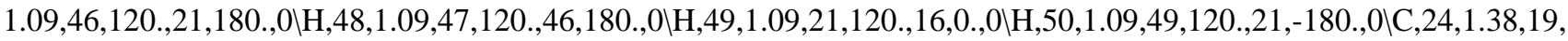

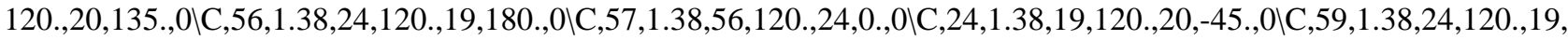

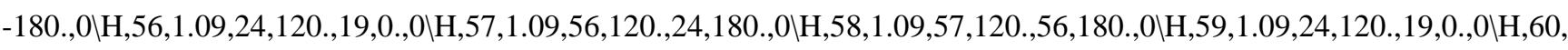

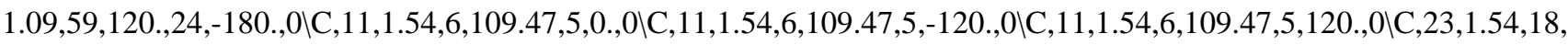

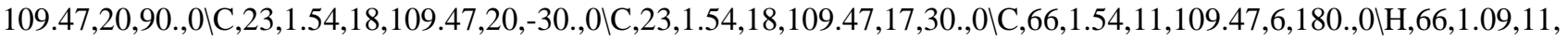

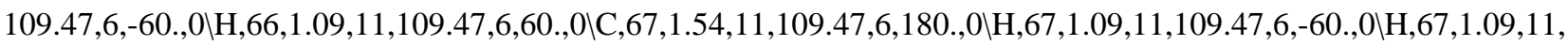

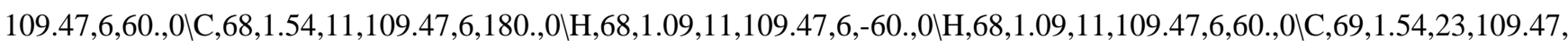

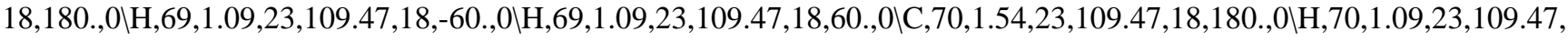

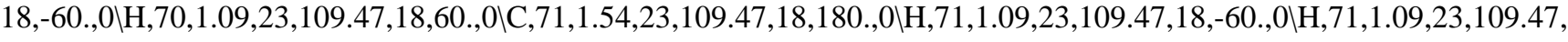

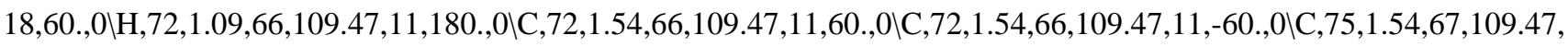

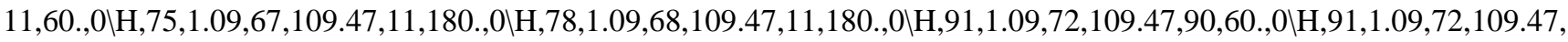

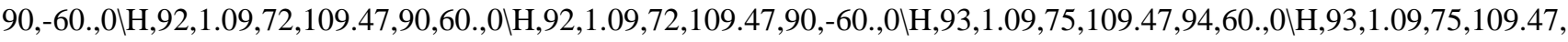

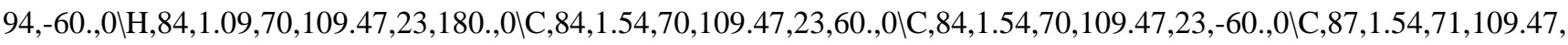

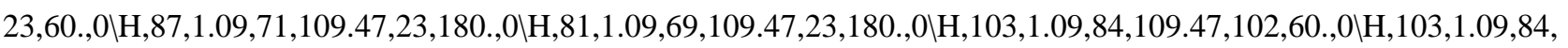

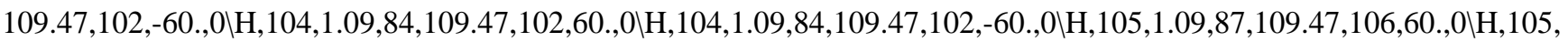
1.09,87,109.47,106,-60.,0॥\Version=IA64-Linux-G03RevB.01 \State=4-A \HF=-3540.284327\S2=3.765487\S2-1=0.IS2A= 3.750097\RMSD=2.809e-09\Dipole=-0.0023288,0.0032243,0.0461526\PG=C01 [X(C50 H54Co1N4)]।@

\section{Gaussian Archive of 12Ni:}

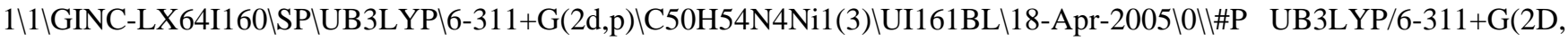
P) $\mathrm{SCF}=($ TIGHT,MAXCYCLE=200) POP=REGULAR GFINPUT GUESS= READ IOP(6/82=1)\\iAdg3T2.com = Triplett 109 Atome pop=regular gfinput $\backslash \backslash 0,3 \backslash X \backslash N i, 1,8 . \backslash X, 2,2 ., 1,90 . \backslash N, 2,1.95,3,47.5,1,0 ., 0 \backslash \mathrm{C}, 4,1.33,2,124 ., 3,0 ., 0 \backslash \mathrm{C}, 2,3.27,4$,

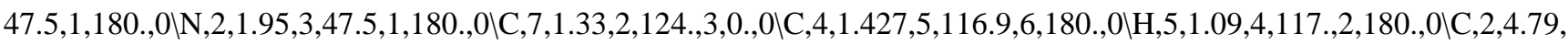

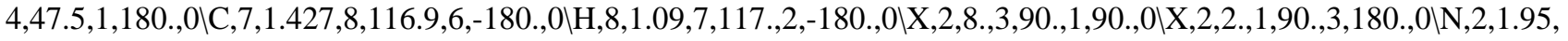

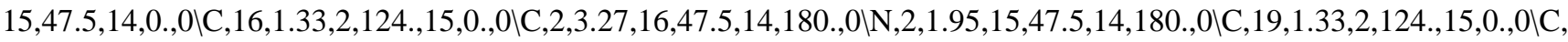

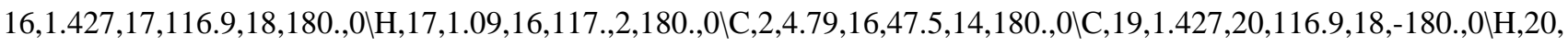

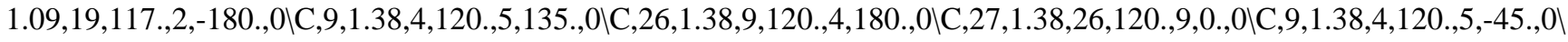

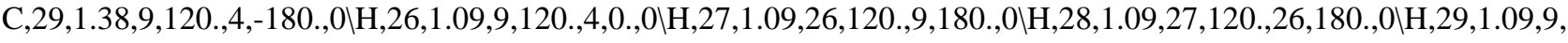




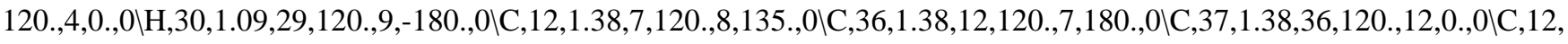

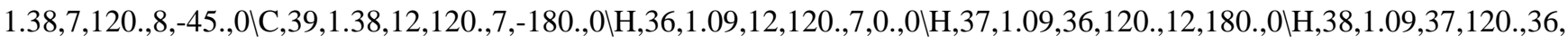

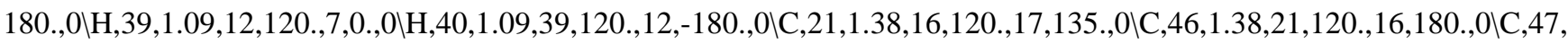

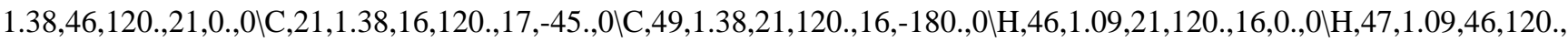

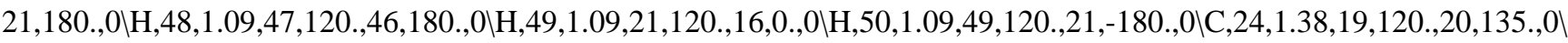

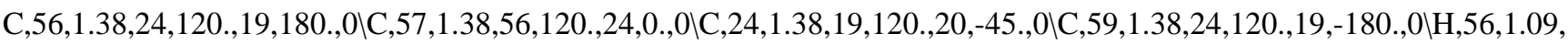

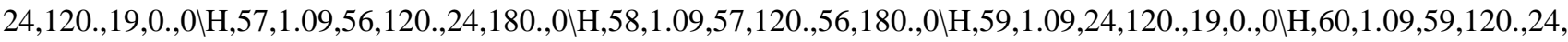

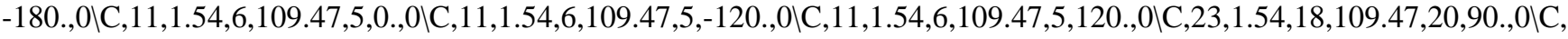

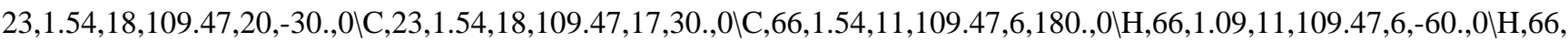

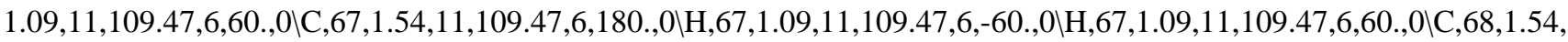

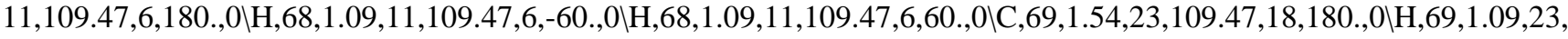

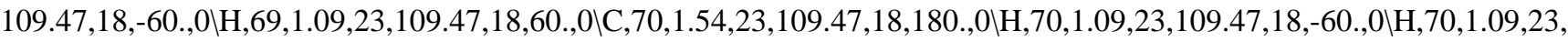

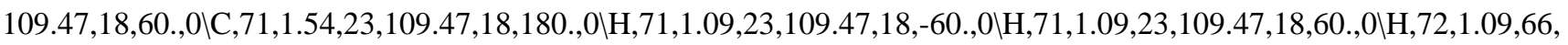

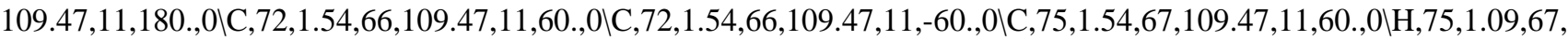

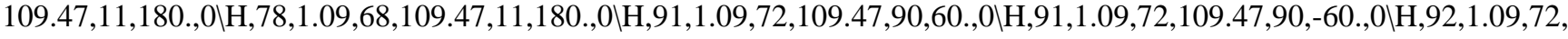

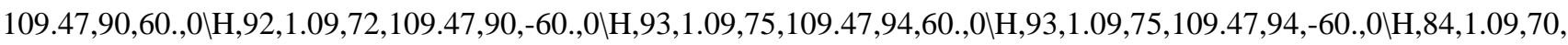

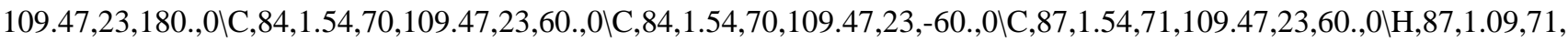

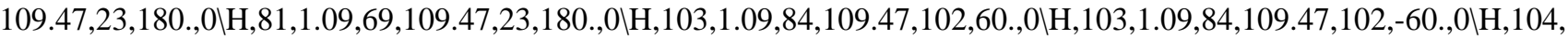
1.09,84,109.47,102,60.,0\H,104,1.09,84,109.47,102,-60.,0\H,105,1.09,87,109.47,106,60.,0\H,105,1.09,87,109.47,106,-60.,

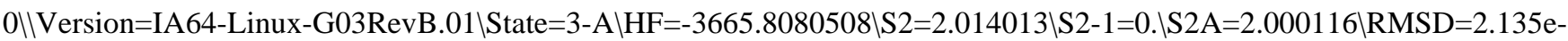
09\Dipole=-0.0007696, 0.0029679,0.0426335\PG=C01 [X(C50H54N4Ni1)]\\@

\section{Topological Averaging}

Intramolecular rotations will change the polar coordinates $\theta$ and $R$ (eqs 6 and 10a) of the participating nuclei, except for nuclei positioned at or rotating about the molecular $z\left(\mathrm{C}^{2}-\mathrm{R}^{\alpha}\right)$ axis (as in 10, 12, 13, and 21-29) or for nuclei in or at the rotation independent $p$ positions of the $N$-aryl groups. For example, protons of methyl groups whose $\mathrm{C}-\mathrm{C}$ bonds are not positioned in the $\mathrm{z}$ axis (as in $\mathbf{6}, \mathbf{7}, \mathbf{1 5}$, and 19) do change their polar coordinates on $\mathrm{C}-\mathrm{C}$ rotation, as do the methyl carbon atoms of the tert-butyl substituents at $\mathrm{C}^{1}$ or $\mathrm{C}^{3}$ in $\mathbf{1 9}$ and $\mathbf{2 0}$. In these cases, the geometry factors $G=\left(3 \cos ^{2} \theta-1\right) R^{-3}$ of four conformations with dihedral angles (12 values) differing by $60^{\circ}$ had to be averaged with equal weights, as appropriate for an almost free rotation. The same task of averaging was less straightforward for nuclei in and at the ortho and meta positions of the $N$-aryl groups: As outlined in the $N$-aryl section of the Main Text, the most stable $N$-aryl conformation was assumed to have dihedral angles of roughly $+45^{\circ}$ and $-135^{\circ}$, measured between an $\mathrm{Ni}-\mathrm{N}$ bond and the adjacent two $\mathrm{C}$ (ipso) $\mathrm{C}($ ortho) bonds of an aryl ring. Because the corresponding pairs of nuclear positions (near and distant ortho or meta as shown in 6-10) exhibited common NMR absorptions in most cases, this assumption requires some kind of averaging of these positions. Such topological averaging was simulated by taking one half of the sum of the two appertaining geometry factors $G$ (eq 6) as the averaged value for calculating a $\delta^{\mathrm{MCD}}$ shift (eq 10a-c) in Table S2 (entries marked with $l o c=a v$ ). These $G$ factors deviate by less than $24 \%$ from those of the $90^{\circ}$ conformation (entries marked with $l o c=90$ ) which is easily attainable and typifies the effective $D_{2 d}{ }^{2}$ symmetry. Numerical 
examples of such averaging are given in entries S2.12-14 and S2.22-24 of Table S2.

The angular dependence of $\Delta \rho_{\mathrm{DFT}}$ of methyl groups attached to $\mathrm{sp}^{2}$-hybridized carbon centers was determined by DFT computation in two conformations having dihedral angles $0^{\circ}$ and $90^{\circ}$ with respect to the $\mathrm{sp}^{2}$ plane. In keeping with an almost free rotation, the results (3 plus 3 values) were averaged with equal weights.

\section{Syntheses of the Vinamidines and $\operatorname{Bis}\left(N, N^{\prime}\right.$-chelates)}

The vinamidine ligands $\mathbf{6 H}$ and $\mathbf{7 H}$ were prepared simply via acid-catalyzed $\mathrm{C}-\mathrm{N}$ condensation of arylamines with malonaldehyde tetraethylacetal (the commercially available 1,1,3,3-tetraethoxypropane). The arylamines 3,5-dimethylaniline (for $\mathbf{6 H}$ ) and 3-methylaniline (for $\mathbf{7 H}$ ) were chosen because their incorporation led to metal complexes having increased solubility. In the same fashion, the 2-methylated vinamidines $\mathbf{9 H}$ and $\mathbf{1 0 H}$ were obtained from 2-methyl-1,1,3,3-tetraalkoxypropanes. ${ }^{\text {S14 }}$ The less volatile phenylmalonaldehyde, generated from phenylacetaldehyde dimethylacetal by a Vilsmeier-Haack-Arnold ${ }^{\mathrm{S} 15, \mathrm{~S} 16}$ formylation but with 2.5 equiv. of $\mathrm{POCl}_{3}$ in place of $\mathrm{COCl}_{2}$, was used for the preparation of vinamidine $\mathbf{8 H}$ by condensation with 3-methylaniline. However, the deuterated phenylmalonaldehyde (S44) was synthesized more conveniently from $\left[\mathrm{D}_{8}\right]$ toluene via the enamine route as follows (Scheme S1).

\section{Scheme S1}
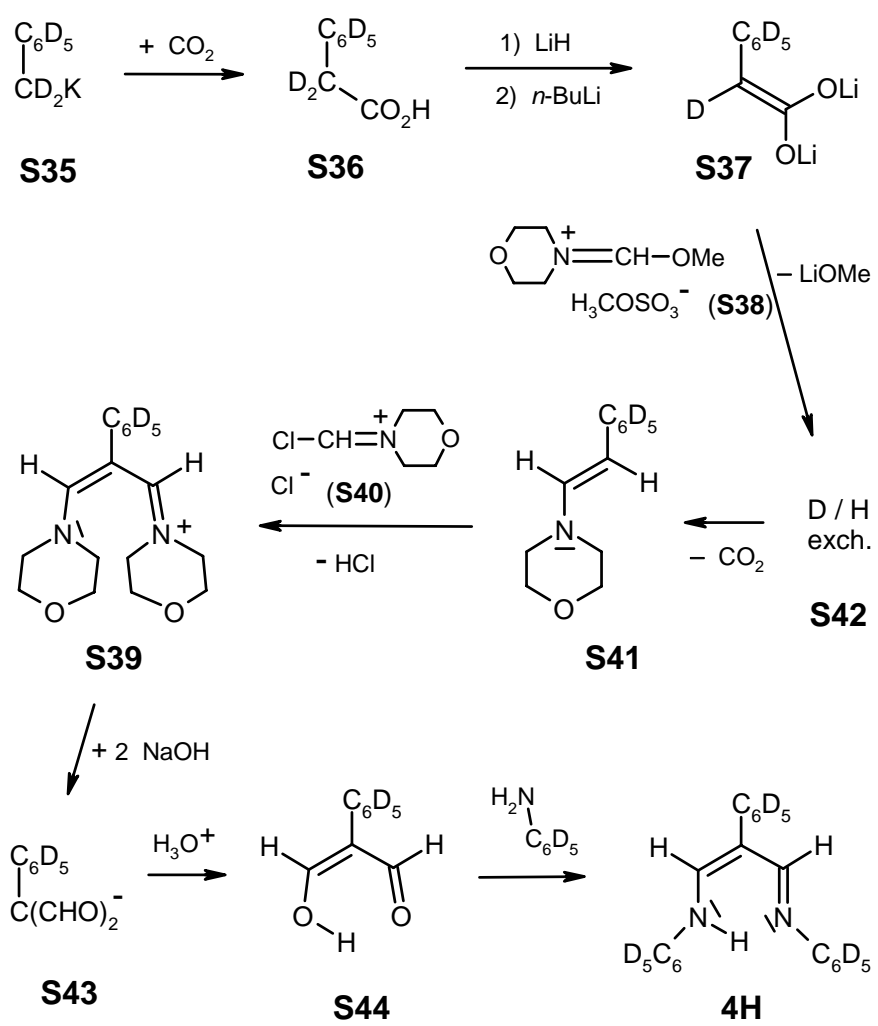

$\left[\mathrm{D}_{7}\right]$ Benzylpotassium (S35), prepared from $\left[\mathrm{D}_{8}\right]$ toluene with $n$-butyllithium (n-BuLi) and potassium tert-butoxide (KOtBu) in pentane, ${ }^{\mathrm{S} 17-\mathrm{S} 19}$ was carboxylated to give $41 \%$ of ( $\alpha, \alpha, 2,3,4,5,6$-heptadeuterio)phenylacetic acid (S36). The enediolate S37 of S36 was then iminomethylated with 4-(methoxymethylene)morpholinium methyl sulfate (S38), a domesticated Vilsmeier reagent, ${ }^{69}$ which furnished the enamine $\mathbf{S 4 1}$ in very poor yield and highly 
contaminated. The subsequent iminomethylation of enamine S41 with the activated Vilsmeier reagent 4-(chloromethylene)morpholinium chloride ${ }^{70}$ (S40) gave the vinamidinium salt S39, which was purified and then hydrolyzed to yield the deuterated phenylmalonaldehyde S44 (5\% over three steps). Condensation with 2,3,4,5,6pentadeuterioaniline afforded $72 \%$ of vinamidine $\mathbf{4 H}$. This and the other vinamidines derived from substituted malonaldehydes furnished M(II) bis(chelates) which are insensitive to non-acidic water and thus were easily prepared with M(II) acetate tetrahydrates in hot alkaline ethanol.

\section{Scheme S2}
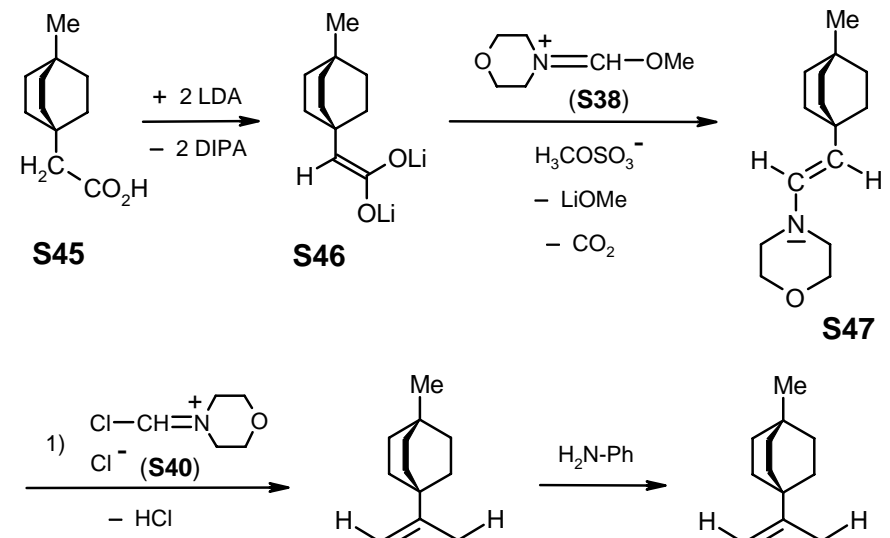

2) $\mathrm{NaOH}$

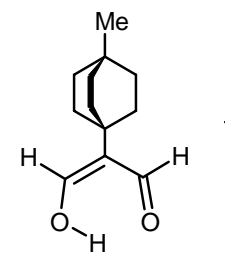

S48

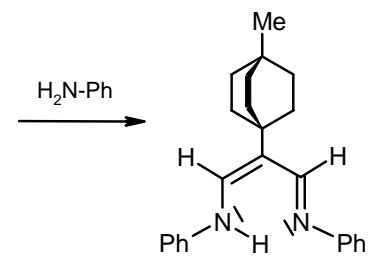

13H

The known tert-butyl- and 1-adamantylmalonaldehydes, required for the preparation of $\mathbf{1 1 H}$ and $\mathbf{1 2 H}$, had been obtained $\mathrm{d}^{70, \mathrm{~S} 20}$ in a similar way from the enediolates of tert-butyl and 1-adamantylacetic acids, respectively. The novel enediolate S46, generated similarly (Scheme S2) from 4-methyl-1-bicyclo[2.2.2]octylacetic acid (S45) with two equivalents of lithium diisopropylamide (LDA), was iminomethylated with reagent $\mathbf{S 3 8}$ to give the enamine S47. A second iminomethylation with reagent $\mathbf{S 4 0}$ and a subsequent very mild hydrolysis reaction produced the spectroscopically pure malonaldehyde S48 in only 19\% yield, perhaps attributable to a hardly avoidable loss of material as reported earlier for alternative syntheses of tert-butyl- ${ }^{\mathrm{S} 1}$ and 1-adamantyl malonaldehydes. ${ }^{\text {S22 }}$ For fear of such losses, the constitution of $\mathbf{S 4 8}$ was verified not by purification but by C-N condensation with aniline, affording the vinamidine $\mathbf{1 3 H}$ in $91 \%$ yield.

\section{Scheme S3}

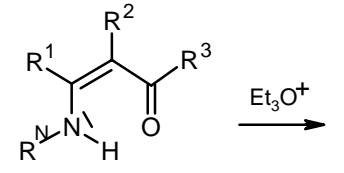

S49

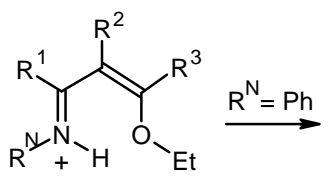

S50<smiles>[R]c1nc2ccccc2c([R])c1[R]</smiles>

S51

Vinamidine formation by a twofold $\mathrm{C}-\mathrm{N}$ condensation of anilines is also possible for acetylacetone with acid catalysis in the second stage, providing vinamidines $\mathbf{1 5} \mathbf{H}^{4,18}$ and $\mathbf{1 6} \mathbf{H}$; but this simple protocol cannot be extended to the majority of 2-substituted 1,3-diketones beyond the first stage which affords enaminoketones S49 
$\left(\mathrm{R}^{2} \neq \mathrm{H}\right)$. Activation of $\mathbf{S 4 9}$ with triethyloxonium tetrafluoroborate (Scheme S3) to give S50 had allowed to incorporate ${ }^{4}$ a second equivalent of $\mathrm{R}^{\mathrm{N}} \mathrm{NH}_{2}$, and this technique has been utilized ${ }^{\mathrm{S} 6}$ for the syntheses of the $N$ methyl vinamidines $\mathbf{1 4 H}$ and $\mathbf{2 1 H}$. However, aryl substituents $\mathrm{R}^{\mathrm{N}}$ in $\mathbf{S 4 9}$ and S50 under these conditions prefer the cyclization to give quinolines (S51) if none of the other substituents $\left(\mathrm{R}^{1-3}\right)$ is hydrogen (see 21-29) or if $\mathrm{R}^{1}\left(\mathrm{R}^{3}\right)$ are bulky groups (see $\mathbf{1 9}$ and 20). ${ }^{\mathrm{S} 6}$ This obstacle to synthesizing highly substituted vinamidines, such as needed in this work, had been circumvented ${ }^{63,71}$ by $\mathrm{C}-\mathrm{C}$ (rather than $\mathrm{C}-\mathrm{N}$ ) bond formation and is detailed in the sequel for two novel examples.

The Schiff base S52a of mesitylacetone (Scheme S4) had been obtained ${ }^{\mathrm{S} 23}$ as an inseparable mixture of the (E) and $(Z)$ configurational isomers. Deprotonation of this mixture with methyllithium (MeLi) and LDA as a catalyst in diethyl ether was very slow at $-25^{\circ} \mathrm{C}$ but occurred readily at room temperature, affording the mixture ${ }^{\mathrm{s} 23}$ of 1 azaallyllithium isomers S53a. Unfortunately, the subsequent $\alpha$-iminoalkylation with the iminoester $N$-(1-ethoxyethylidene)aniline $^{\mathrm{S} 24}$ (S54) yielded a product mixture from which the vinamidine $\mathbf{2 5 H}$ could be isolated only in a moderately contaminated form. It should be mentioned that the $N$-lithio vinamidine $25 \mathrm{Li}$ is the primary product before work-up because residual MeLi or LDA or 1-azaallyllithium S53a can deprotonate 25H. Therefore, the controlled addition of a second equivalent of MeLi was required for total conversion of the Schiff base S52a and was monitored by a prompt evolution of methane, measured at a gas buret so as to allow to interrupt the addition as soon as MeLi was no longer immediately consumed by the proton donors. Formation of the bis(chelate) 25Ni was accomplished by prolonged heating of $25 \mathbf{L i}$ in THF with dry bis(tetraethylammonium) tetrabromonickelate(II), ${ }^{\mathrm{S} 5, \mathrm{~S} 26}$ not unexpectedly with a yield of only $2 \%$.

\section{Scheme S4}
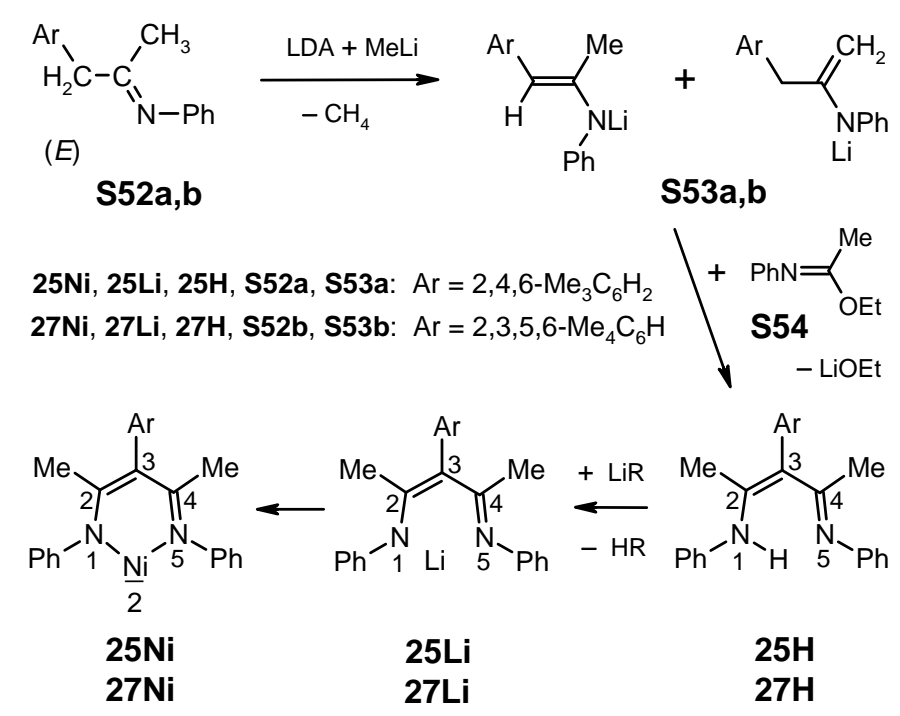

Similar synthetic problems were encountered with the Schiff base S52b of durylacetone (Scheme S4), obtained $^{\text {S23 }}$ as an $(E) /(Z)=75 / 25$ mixture. Whereas previous examples ${ }^{71}$ of sterically less shielded arylacetone imines had always furnished products deriving from $\mathrm{CH}_{2}$ deprotonation alone, formation of the 1-azaallyllithium isomers S53b and subsequent $\alpha$-iminoalkylation with reagent S54 produced a highly contaminated sample of vinamidine $\mathbf{2 7 H}$ which was converted to the bis(chelate) $27 \mathrm{Ni}$ directly. Although $27 \mathrm{Ni}$ was obtained in only $5 \%$ 
yield with respect to Schiff base S52b, a purified aliquot was cleaved back to $\mathbf{2 7 H}$, which was then recrystallized and characterized. All other bis(chelates) of this type (19Ni-24Ni, 19Co, 26Ni, 28Ni, and 29Ni) were prepared from $\mathrm{known}^{71}$ vinamidine ligands in $20-87 \%$ yields.

General Procedures for Preparation of the Bis(chelate) M(II) Complexes. A1: In Ethanol. A solution of metallic sodium (69 $\mathrm{mg}, 3.0 \mathrm{mmol})$ in ethanol $(5 \mathrm{ml})$ was poured onto a vinamidine $(2.5 \mathrm{mmol})$, followed by a solution of an $\mathrm{M}(\mathrm{II})$ (Co or $\mathrm{Ni}$ ) acetate tetrahydrate $\left(\mathrm{C}_{4} \mathrm{H}_{6} \mathrm{O}_{4} \mathrm{M} \cdot 4 \mathrm{H}_{2} \mathrm{O}, \approx 375 \mathrm{mg}, 1.5 \mathrm{mmol}\right)$ in ethanol $(5 \mathrm{~mL})$. The mixture was refluxed $(0.17-16 \mathrm{~h})$ and then cooled; the required period of heating may be estimated by observing the rate of initial color development. The dark, crystalline precipitate was washed on a coarse filter with distd. water until free of ethanol, whereupon it will no longer be wetted by water, so that basic Ni salts could be removed by washing with $0.5 \mathrm{M} \mathrm{HCl}$ or aqueous (1\%) acetic acid. After further rinsing with distd. water (till free of acid) and finally with ethanol, the bis(chelate) was dried in a desiccator over solid $\mathrm{KOH}$ to remove the last traces of acetic acid. Thereafter, it may be recrystallized from ethyl acetate or precipitated from a filtered solution in boiling ethyl acetate by slow addition of dry ethanol. - Variant A2: The protocol A1 was changed by employment of a doubled amount of sodium in ethanol to react with a vinamidinium perchlorate (in place of a vinamidine).

B1: Aprotic. A vinamidine (3.0 mmol) in anhydrous THF or diethyl ether (30 mL) was stirred under dry nitrogen gas in a flask, equipped with a pressure-equalizing dropping funnel that was connected to a gas buret. Ethereal methyllithium solution was added dropwise from the funnel until the evolution of methane ceased. Dry bis(tetraethylammonium) tetrabromometalate(II) $\left(\mathrm{C}_{16} \mathrm{H}_{40} \mathrm{Br}_{4} \mathrm{~N}_{2} \mathrm{M}, 1.8 \mathrm{mmol}\right)^{\mathrm{S} 27}$ was added to the mixture. Depending on the rate of color development, the mixture was stirred at room temperature or refluxed unter $\mathrm{N}_{2}$ gas for at least $12 \mathrm{~h}$. After evaporation to dryness, the dark-colored residue was extracted with anhydrous ethyl acetate or benzene or hot hexane. The filtered extracts were concentrated to yield the crude bis(chelate). Hexane or dry ethyl acetate are recommended as solvents for recrystallization or for precipitation by the slow addition of dry ethanol to the boiling solution. - Variant B2: The suspension of a vinamidinium perchlorate (in place of a vinamidine) was treated according to protocol B1, employing a doubled amount of methyllithium.

\section{$N$-[2-(Pentadeuteriophenyl)-3-(pentadeuteriophenylimino)-1-propen-1-yl]-2,3,4,5,6-pentadeuterioben-} zenamine (4H). The labeled phenylmalonaldehyde S44 (159 mg, $1.04 \mathrm{mmol}$ ) and 2,3,4,5,6-pentadeuterioaniline $(0.199 \mathrm{~mL}, 2.18 \mathrm{mmol})$ in anhydrous methanol $(1.58 \mathrm{~mL})$ were refluxed unter argon for $2.5 \mathrm{~h}$. The vinamidine 4H was the only product (236 mg, 72\%), as judged from ${ }^{1} \mathrm{H} \mathrm{NMR}_{\text {in }} \mathrm{CDCl}_{3}(\delta 8.02$ for $=\mathrm{CHN}$, no aromatic $\mathrm{H}$, no impurity signals), and a fraction recrystallized from ethanol had mp 120-123 ${ }^{\circ} \mathrm{C}$ (ref S28: $137-139{ }^{\circ} \mathrm{C}$; ref S29: $130{ }^{\circ} \mathrm{C}$, both for the unlabeled vinamidine).

\section{Bis $\{N$-[2-(pentadeuteriophenyl)-3-(pentadeuteriophenylimino)-1-propen-1-yl]-2,3,4,5,6-pentadeuterio-}

benzenaminato- $N, N$ \}cobalt(II) (4Co). The crude vinamidine $4 \mathbf{H}$ (190 mg, $0.61 \mathrm{mmol})$ in alkaline anhydrous ethanol (3.5 mL) was treated according to procedure A1 (4 h reflux): yield $120 \mathrm{mg}$ (58\%), mp 251-259 ${ }^{\circ} \mathrm{C}$. One recrystallization form anhydrous ethyl acetate (3 mL) afforded a dark brown powder (29 mg), mp $256-258{ }^{\circ} \mathrm{C}$ (ref S30: $258{ }^{\circ} \mathrm{C}$; ref S31: $256-258{ }^{\circ} \mathrm{C}$, both for the unlabeled compound); ${ }^{2} \mathrm{H}$ NMR $\left(\mathrm{CH}_{2} \mathrm{Cl}_{2}, 92.12 \mathrm{MHz},+27\right.$ $\left.{ }^{\circ} \mathrm{C}\right) \delta 18.41\left(\mathrm{~d},\left|\Delta v_{\mathrm{D}}\right|=7.2 \mathrm{~Hz}, 8\right.$ meta-D), $16.39\left(\mathrm{~d},\left|\Delta v_{\mathrm{D}}\right|<5 \mathrm{~Hz}, 4 \mathrm{D}^{\delta}\right), 8.75\left(\mathrm{~s}, 4 \mathrm{D}^{\gamma}\right), 0.80\left(\mathrm{~d},\left|\Delta v_{\mathrm{D}}\right|=29.0 \mathrm{~Hz}, 2\right.$ 
$\left.\mathrm{D}^{\varepsilon}\right),-20.81\left(\mathrm{~d},\left|\Delta v_{\mathrm{D}}\right|=11.0 \mathrm{~Hz}, 4\right.$ para-D), -32.57 (br s, 8 ortho-D).

$\operatorname{Bis}\{N$-[2-(pentadeuteriophenyl)-3-(pentadeuteriophenylimino)-1-propen-1-yl]-2,3,4,5,6-pentadeuterio-

benzenaminato- $\boldsymbol{N}, \boldsymbol{N}$ \}nickel(II) (4Ni). The vinamidine $\mathbf{4 H}$ (85 mg, $0.27 \mathrm{mmol}$ ) was subjected to procedure A1 (4 h reflux), precipitating a brown powder which was recrystallized from anhydrous ethyl acetate (5 mL): Dark blue, sparkling small needles; $31 \mathrm{mg}$ (33\%); mp 262.5-264 ${ }^{\circ} \mathrm{C}$ (ref S30: $264{ }^{\circ} \mathrm{C}$, ref S31: $276-278{ }^{\circ} \mathrm{C}$, both for the unlabeled compound); ${ }^{2} \mathrm{H}$ NMR $\left(\mathrm{CH}_{2} \mathrm{Cl}_{2}, 92.12 \mathrm{MHz},+27{ }^{\circ} \mathrm{C}\right) \delta 27.16$ (d, 8 meta-D), $10.09\left(4 \mathrm{D}^{\delta}\right),-6.94$ (d, $\left.\left|\Delta v_{\mathrm{D}}\right|=19.5 \mathrm{~Hz}, 2 \mathrm{D}^{\varepsilon}\right),-9.73$ (8 ortho-D), -10.44 (4 D $),-13.87$ (d, $\left|\Delta v_{\mathrm{D}}\right|=8.0 \mathrm{~Hz}, 4$ para-D).

Bis $\{N$-[2-(pentadeuteriophenyl)-3-(pentadeuteriophenylimino)-1-propen-1-yl]-2,3,4,5,6-pentadeuterio-

benzenaminato- $\boldsymbol{N}, \boldsymbol{N}$ \}zinc(II) (4Zn). The basic solution of vinamidine $\mathbf{4 H}$ (68 $\mathrm{mg}, 0.22 \mathrm{mmol}$ ) in anhydrous ethanol $(1.3 \mathrm{~mL})$ was treated according to procedure A1 (4 h reflux). The precipitate was recrystallized from anhydrous ethyl acetate (8 mL) to afford fine yellow needles: yield $43 \mathrm{mg}(58 \%), \mathrm{mp} 259-261{ }^{\circ} \mathrm{C}$ (ref S32: no data for the unlabeled compound); ${ }^{2} \mathrm{H}$ NMR $\left(\mathrm{CH}_{2} \mathrm{Cl}_{2}, 92.12 \mathrm{MHz}\right) \delta 7.10$ (6 D), 7.26 (5 D), 7.43 (2 D), 7.47 (2 D).

$\operatorname{Bis}\{N$-[3-(3,5-dimethylphenylimino)-1-propen-1-yl]-3,5-dimethylbenzenaminato- $N$, $N\}$ cobalt(II) (6Co). Procedure A1 applied to the known ${ }^{\mathrm{S} 33}$ vinamidine $\mathbf{6 H}$ afforded glistening, purple-colored flakes (81\%): mp 168$169^{\circ} \mathrm{C}$ (ethyl acetate/ethanol 1:1); IR (KBr) 2920, 1572, 1505, 1453, and $1310 \mathrm{~cm}^{-1}$; UV-vis (dioxane) $\lambda_{\max } 252$ nm (lg $\varepsilon=4.40), 398$ (4.63), 515 (3.45); ${ }^{1} \mathrm{H}$ NMR Table S4; ${ }^{13} \mathrm{C}$ NMR Table S5; Anal. Calcd for $\mathrm{C}_{38} \mathrm{H}_{42} \mathrm{~N}_{4} \mathrm{Co}$ (613.7): C, 74.37; H, 6.90; N, 9.13. Found: C, 74.63; H, 6.90; N, 9.14. Molecular mass 609 (osmom. in benzene).

$\operatorname{Bis}\left\{N\right.$-[3-(3,5-dimethylphenylimino)-1-propen-1-yl]-3,5-dimethylbenzenaminato- $\left.N, N^{\prime}\right\}$ nickel(II) (6Ni). Sparkling black needles were obtained from procedure A1 (3 h reflux) with the known ${ }^{\mathrm{S} 33}$ vinamidine $\mathbf{6 H}$ after three recrystallizations from ethyl acetate/ethanol (1:1): Crude yield 65\%; mp 189-190.5 ${ }^{\circ} \mathrm{C}$; IR (KBr) 2910, 1576, 1505, 1445, 1308, and $1292 \mathrm{~cm}^{-1}$; UV-vis (dioxane or benzene) $\lambda_{\max } 394 \mathrm{~nm}(\lg \varepsilon=4.54)$; ${ }^{1} \mathrm{H}$ NMR Table S6; ${ }^{13} \mathrm{C}$ NMR Table S7; Anal. Calcd for $\mathrm{C}_{38} \mathrm{H}_{42} \mathrm{~N}_{4} \mathrm{Ni}$ (613.5): C, 74.40; H, 6.90; N, 9.13. Found: C, 74.44; H, 6.89; N, 9.27. Molecular mass 611 (osmom. in benzene).

Bis $\left\{N\right.$-[3-(3,5-dimethylphenylimino)-1-propen-1-yl]-3,5-dimethylbenzenaminato- $\left.N, N^{\prime}\right\} \operatorname{copper(II)\quad (6Cu).~}$ Copper diacetate hydrate reacted with the known ${ }^{\mathrm{S} 33}$ vinamidine $\mathbf{6 H}$ in precedure A1 to afford glistening, black needles (39\%) after recrystallization from ethyl acetate/ethanol (1:1): mp 187-189 ${ }^{\circ} \mathrm{C}$; IR (KBr) 2915, 1579, 1510, 1463, 1318, and $1300 \mathrm{~cm}^{-1}$; UV-vis (dioxane) $\lambda_{\max } 251 \mathrm{~nm}$ (lg $\varepsilon=4.38$ ), 328 (4.31), 407 (4.66), 543 (3.53), 700 (vbr, 3.45); no NMR resonances found; Anal. Calcd for $\mathrm{C}_{38} \mathrm{H}_{42} \mathrm{~N}_{4} \mathrm{Cu}$ (618.3): C, 73.82; $\mathrm{H}, 6.85 ; \mathrm{N}$, 9.06. Found: C, 73.66; H, 6.98; N, 9.21.

$\mathbf{N}$-[3-(3-Methylphenylimino)-1-propen-1-yl]-3-methylbenzenamine (7H). Prepared as described for $\mathbf{6 H}$ but with 3-methylaniline to give $77 \%$ of the yellow 7H-hydrogen perchlorate: mp 219-220 ${ }^{\circ} \mathrm{C}$ (ethanol); IR (KBr) $3230(\mathrm{NH}), 2910,1628,1575,1338,1268,1215,1120,1105$, and $1087 \mathrm{~cm}^{-1}$; Anal. Calcd for $\mathrm{C}_{17} \mathrm{H}_{19} \mathrm{~N}_{2} \mathrm{ClO}_{4}$ (350.8): C, 58.21; H, 5.46; N, 7.99. Found: C, 58.28; H, 5.44; N, 7.81.

The crude free base $\mathbf{7 H}$, obtained from $\mathbf{7} \mathbf{H} \cdot \mathrm{HClO}_{4}$ by treatment with excess $2 \mathrm{M} \mathrm{NaOH}$ and extraction with $\mathrm{CH}_{2} \mathrm{Cl}_{2}$, had mp $71-75{ }^{\circ} \mathrm{C}$ (no data in ref S34); ${ }^{1} \mathrm{H}$ NMR $\left(\mathrm{CDCl}_{3}\right) \delta 2.32\left(\mathrm{~s}, 2 \mathrm{CH}_{3}\right), 5.07\left(\mathrm{t},{ }^{3} \mathrm{~J}=6.5 \mathrm{~Hz}, 2-\mathrm{H}\right)$, 6.95 (m, 8 aromat. H), 7.55 (d, $\left.{ }^{3} J=6.5 \mathrm{~Hz}, 1-/ 3-\mathrm{H}\right), 11.0$ (br, NH). 
Bis $\left\{N\right.$-[3-(3-methylphenylimino)-1-propen-1-yl]-3-methylbenzenaminato- $\left.N, N^{\prime}\right\}$ nickel(II) (7Ni). After preparation from $\mathbf{7} \mathbf{H} \cdot \mathrm{HClO}_{4}$ by procedure A2, this known ${ }^{\mathrm{S} 34}$ bis(chelate) was fully characterized because several of its ${ }^{1} \mathrm{H}$ NMR isotropic shifts $\left(\delta^{\mathrm{PARA}}\right)$ differed strongly from those reported. ${ }^{12, \mathrm{~S} 7}$ Yield 66\%; mp $170-171{ }^{\circ} \mathrm{C}$ (ethyl acetate, no mp in lit.); IR (KBr) 3020, 2910, 1568, 1515, 1480, 1455, 1440, 1350, 1312, and $690 \mathrm{~cm}^{-1}$; UV-vis (dioxane) $\lambda_{\max } 245 \mathrm{~nm}$ (lg $\left.\varepsilon=4.39\right), 394$ (4.54) [ref S28: $\left(\mathrm{CH}_{3} \mathrm{OH}\right) 248$ (4.49), 396 (4.46), 530 (3.49)]; ${ }^{1} \mathrm{H}$ NMR Table S8; Anal. Calcd for $\mathrm{C}_{34} \mathrm{H}_{34} \mathrm{~N}_{4} \mathrm{Ni}$ (557.4): C, 73.27; H, 6.15; N, 10.05. Found: C, 73.21; H, 5.95; N, 10.22. Molecular mass 543 (osmom. in benzene).

$\mathrm{N}$-[3-(3-Methylphenylimino)-2-phenyl-1-propen-1-yl]-3-methylbenzenamine $\mathbf{( 8 H )}$. Phenylmalonaldehy$\mathrm{de}^{\mathrm{S} 35}$, 3-methylaniline (2.5 equiv), and perchloric acid (2.5 equiv) were refluxed in ethanol for $2 \mathrm{~h}$, affording $38 \%$ of crude $\mathbf{8} \mathbf{H} \cdot \mathrm{HClO}_{4}$ with mp $156-159{ }^{\circ} \mathrm{C}$. This material was converted to vinamidine $\mathbf{8 H}$ with excess $2 \mathrm{M}$ $\mathrm{NaOH} / \mathrm{CH}_{2} \mathrm{Cl}_{2}$ : mp 128-129 ${ }^{\circ} \mathrm{C}$ (ethanol); IR (KBr) 3040, 2900, 1638, 1602, 1582, 1542, 1489, 1290, 1163, 775, 768, 752, and $698 \mathrm{~cm}^{-1}$; UV-vis $\left(\mathrm{CHCl}_{3}\right) \lambda_{\max } 293 \mathrm{~nm}(\lg \varepsilon=4.28), 406$ (4.37); UV-vis $\left(\mathrm{CH}_{3} \mathrm{OH}\right) \lambda_{\max } 245$ nm (lg $\varepsilon=4.22), 287$ (4.26), 395 (4.37); ${ }^{1} \mathrm{H}$ NMR $\left(\mathrm{CDCl}_{3}\right) \delta 2.33$ (s, $\left.2 \mathrm{CH}_{3}\right), 6.90$ (m, 5 aromat. H), 7.27 (mc, 8 aromat. H), 7.97 (s, 1-/3-H); Anal. Calcd for $\mathrm{C}_{23} \mathrm{H}_{22} \mathrm{~N}_{2}$ (326.4): C, 84.63; H, 6.79; N, 8.58. Found: C, 84.40; $\mathrm{H}$, 6.73; N, 8.60.

Bis $\{N$-[3-(3-methylphenylimino)-2-phenyl-1-propen-1-yl]-3-methylbenzenaminato- $N, N$ \}nickel(II) (8Ni). Prepared by procedure A1: yield 76 \%; mp 181-183 ${ }^{\circ} \mathrm{C}$ (ethyl acetate/methanol); IR (KBr) 3020, 2910, 1580, 1460, 1440, 1365, 1305, 783, 765, 701, and $695 \mathrm{~cm}^{-1}$; UV-vis (dioxane) $\lambda_{\max } 300 \mathrm{~nm}$ (lg $\left.\varepsilon=4.64\right), 411$ (4.47); ${ }^{1} \mathrm{H}$ NMR Table S9; Anal. Calcd for $\mathrm{C}_{46} \mathrm{H}_{42} \mathrm{~N}_{4} \mathrm{Ni}$ (709.6): C, 77.86; H, 5.97; N, 7.90. Found: C, 77.73; H, 6.05; N, 8.13. Molecular mass 707 (osmom. in benzene).

$N$-(2-Methyl-3-phenylimino-1-propen-1-yl)benzenamine (9H). A mixture of 2-methyl-1,1,3,3-tetraalkoxypropanes $^{\mathrm{S} 14}$ (20 mmol) was heated to reflux (2 h) with anilinium chloride (50 mmol) in anhydrous ethanol (50 $\mathrm{mL}$ ), depositing $4.30 \mathrm{~g}(79 \%)$ of $\mathbf{8 H} \cdot \mathrm{HCl}^{\mathrm{S} 36, \mathrm{~S} 37}$ from the cooled solution. This salt was shaken with diethyl ether and excess $2 \mathrm{M} \mathrm{NaOH}$ until dissolved; the ethereal layer was washed until neutral, dried, and concentrated to furnish the vinamidine 9H: $\mathrm{mp} 139-141^{\circ} \mathrm{C}$ (ethanol; ref S38: $136-138^{\circ} \mathrm{C}$; ref S39: $\left.139{ }^{\circ} \mathrm{C}\right)$; $\mathrm{IR}(\mathrm{KBr}) 3190(\mathrm{~N}-$ H), 3040, 1635, 1596, 1545, 1493, 1480, 1307, 1271, 1249, 761, 741, and $684 \mathrm{~cm}^{-1} ;{ }^{1} \mathrm{H} \mathrm{NMR}\left(\mathrm{CDCl}_{3}\right) \delta 2.02$ (s, $\mathrm{CH}_{3}$ ), 7.17 (mc, 10 aromat. H), 7.62 (s, 1-/3-H); Anal. Calcd for $\mathrm{C}_{16} \mathrm{H}_{16} \mathrm{~N}_{2}$ (236.3): C, 81.32; H, 6.83; N, 11.85. Found: C, 81.61; H, 6.86; N, 11.78.

Bis[N-(2-methyl-3-phenylimino-1-propen-1-yl)benzenaminato- $\left.N, N^{\prime}\right]$ nickel(II) (9Ni). This known ${ }^{\mathrm{S} 3}$ but insufficiently characterized bis(chelate) was obtained in 25\% yield from vinamidine $\mathbf{9 H}$ (1.58 g, $6.68 \mathrm{mmol}$ ) by a literature procedure ${ }^{\mathrm{S} 26}$ as metallic sparkling, blue-violet flakes after recrystallization from xylene or (better) chlorobenzene: $\operatorname{mp} 291-292{ }^{\circ} \mathrm{C}$ dec (ref S38: > $300{ }^{\circ} \mathrm{C}$ ); IR (KBr) 1590, 1460, 1440, 1390, 760, and $690 \mathrm{~cm}^{-1}$; UV-vis $\left(\mathrm{CHCl}_{3}\right) \quad \lambda_{\max } 412 \mathrm{~nm}(\lg \varepsilon=4.34) ;{ }^{1} \mathrm{H}$ NMR Table S10; Anal. Calcd for $\mathrm{C}_{32} \mathrm{H}_{30} \mathrm{~N}_{4} \mathrm{Ni}$ (529.3): C, 72.61; H, 5.71; N, 10.58. Found: C, 72.60; H, 5.78; N, 10.56.

$\mathrm{N}$-[2-Methyl-3-(4-methylphenylimino)-1-propen-1-yl]-4-methylbenzenamine (10H). A mixture of 2-methyl-1,1,3,3-tetraalkoxypropanes ${ }^{\mathrm{S} 14}(8.01 \mathrm{mmol})$ in ethanol $(10 \mathrm{~mL})$ was added dropwise to a solution of $p$ toluidine (1.71 g, $16.0 \mathrm{mmol})$ and aqueous perchloric acid (70\%, $1.95 \mathrm{~mL}, 21.5 \mathrm{mmol})$ in ethanol (20 mL). The 
solution slowly deposited yellow crystals in the course of days at room temperature and was finally refluxed for 3 h. The crystals $\left(\mathbf{1 0 H} \cdot \mathrm{HClO}_{4}\right)$ were washed with ethanol and dried: Total yield $2.15 \mathrm{~g}$ (74\%); mp up to 281.5$282{ }^{\circ} \mathrm{C}$ (ethanol); IR (KBr) 3700-2800 (vbr, N-H), 1620, 1578, 1520, 1322, 1293, 1200, 1087, and $814 \mathrm{~cm}^{-1}$; Anal. Calcd for $\mathrm{C}_{18} \mathrm{H}_{21} \mathrm{~N}_{2} \mathrm{ClO}_{4}$ (364.8): C, 59.26; H, 5.80; N, 7.68. Found: C, 59.30; H, 5.90; N, 7.93.

The free base $10 \mathrm{H}$ was obtained by shaking $\mathbf{1 0 H} \cdot \mathrm{HClO}_{4}$ with $\mathrm{CH}_{2} \mathrm{Cl}_{2}$ and excess $2 \mathrm{M} \mathrm{NaOH}$ until dissolved, followed by concentration of the washed and dried $\mathrm{CH}_{2} \mathrm{Cl}_{2}$ layer. This yellow vinamidine was fully characterized because its mp was significantly higher than the literature value: mp 171-173 ${ }^{\circ} \mathrm{C}$ (ethanol; ref S39: $165{ }^{\circ} \mathrm{C}$ ); IR $(\mathrm{KBr}) 3190(\mathrm{~N}-\mathrm{H}), 3018,2915,1651,1645,1561,1519,1505,1302,1277,1257$, and $805 \mathrm{~cm}^{-1}$; ${ }^{1} \mathrm{H}$ NMR $\left(\mathrm{CDCl}_{3}\right) \delta 2.02\left(\mathrm{~s}, \mathrm{CH}_{3}\right), 2.33$ (s, 2 p- $\left.\mathrm{CH}_{3}\right), 7.02\left(\mathrm{mc}, 2 \mathrm{C}_{6} \mathrm{H}_{4}\right), 7.55$ (s, 1-/3-H); ${ }^{13} \mathrm{C} \mathrm{NMR}\left(\mathrm{CDCl}_{3}\right) \delta 20.80(\mathrm{q}, 2-$ $\mathrm{CH}_{3}$ and 2 p- $\mathrm{CH}_{3}$ ), 113.5 (very weak s, C-2), 117.6 (d, 4 o-C), 129.7 (d, 4 m-C), 132.3 (s, 2 p-C), 144.4 (weak s, 2 i-C), 149.6 (br d, C-1/-3); Anal. Calcd for $\mathrm{C}_{18} \mathrm{H}_{20} \mathrm{~N}_{2}$ (264.4): C, 81.78; H, 7.63; N, 10.60. Found: C, 81.65; H, 7.69; N, 10.37 .

\section{$\operatorname{Bis}\{N$-[2-methyl-3-(4-methylphenylimino)-1-propen-1-yl]-4-methylbenzenaminato- $N, N\}$ cobalt(II)}

(10Co). The conversion of $\mathbf{1 0 H} \cdot \mathrm{HClO}_{4}(350 \mathrm{mg}, 0.96 \mathrm{mmol}$ ) according to procedure A2 had to be carried out under an atmosphere of dry $\mathrm{N}_{2}$ gas. After $10 \mathrm{~min}$ at reflux, the mixture was chilled in ice under $\mathrm{N}_{2}$ gas for $2 \mathrm{~h}$, affording $185 \mathrm{mg}$ (66\%) of glistening, dark blue rodlets: mp 164.5-165 ${ }^{\circ} \mathrm{C}$ (ethanol); IR (KBr) 2923, 1669, 1608, 1517, 1407, 1312, 1302, and $816 \mathrm{~cm}^{-1}$; UV-vis (dioxane) $\lambda_{\max } 255 \mathrm{~nm}$ (lg $\left.\varepsilon=4.36\right), 419$ (4.59), 555 (3.41); ${ }^{1} \mathrm{H}$ NMR Table S11; ${ }^{13} \mathrm{C}$ NMR Table S12; Anal. Calcd for $\mathrm{C}_{36} \mathrm{H}_{38} \mathrm{~N}_{4} \mathrm{Co}$ (585.7): C, 73.83; H, 6.54; N, 9.57. Found: C, 74.11; H, 6.74; N, 9.64.

\section{Bis $\{N$-[2-methyl-3-(4-methylphenylimino)-1-propen-1-yl]-4-methylbenzenaminato- $N, N\}$ nickel(II)}

(10Ni). Procedure A2 was used to convert $\mathbf{1 0 H} \cdot \mathrm{HClO}_{4}(350 \mathrm{mg}, 0.96 \mathrm{mmol}$ ) to $\mathbf{1 0 N i}$ within $10 \mathrm{~min}$ in refluxing ethanol. The cooled mixture deposited long black needles: yield $180 \mathrm{mg}$ (64\%); mp 197-200 ${ }^{\circ} \mathrm{C}$ without dec (ethanol); IR (KBr) 2935, 1608, 1524, 1313, 1303, and $818 \mathrm{~cm}^{-1}$; UV-vis (dioxane) $\lambda_{\max } 244 \mathrm{~nm}(\lg \varepsilon=4.52$ ); no ${ }^{1} \mathrm{H}$ NMR; ${ }^{13} \mathrm{C}$ NMR Table S13; Anal. Calcd for $\mathrm{C}_{36} \mathrm{H}_{38} \mathrm{~N}_{4} \mathrm{Ni}$ (585.4): C, 73.86; H, 6.54; N, 9.57. Found: C, 73.61; H, 6.46; N, 9.83.

$\operatorname{Bis}\{N$-[2-methyl-3-(4-methylphenylimino)-1-propen-1-yl]-4-methylbenzenaminato- $N, N\}$ zinc(II) (10Zn). Following procedure A1 (30 min reflux), $\mathbf{1 0 H}$ (264 mg, $1.00 \mathrm{mmol}$ ) was converted to brick-red needles: $\mathrm{mp}$ 153.5-154.5 ${ }^{\circ} \mathrm{C}$ (dry ethanol); IR (KBr) 2918, 1599, 1465 (br), 1314, and $1303 \mathrm{~cm}^{-1}$; UV-vis (dioxane) $\lambda_{\max } 258$ nm (lg $\varepsilon=4.26)$, sh 300 (3.85), 445 (4.76); ${ }^{1} \mathrm{H}$ NMR $\left(\mathrm{CDCl}_{3}\right) \delta 2.01$ (s, 2-CH $), 2.18$ (s, 2 p- $\left.\mathrm{CH}_{3}\right), 6.82$ (mc, arom. AA'BB' system); Anal. Calcd for $\mathrm{C}_{36} \mathrm{H}_{38} \mathrm{~N}_{4} \mathrm{Zn}$ (592.1): C, 73.03; H, 6.47; N, 9.46. Found: C, 73.06; H, 6.60; N, 9.97.

$N$-(2-tert-Butyl-3-phenylimino-1-propen-1-yl)benzenamine (11H). The solution of tert-butylmalonaldehy$\mathrm{de}^{70}$ (240 mg, $1.87 \mathrm{mmol}$ ) and aniline $(0.400 \mathrm{~mL}, 4.39 \mathrm{mmol})$ in ethanol (3 mL) was kept at room temperature overnight, slowly depositing yellow crystals (360 mg, 69\%) of pure $\mathbf{1 1 H}$ : mp 100.5-101.5 ${ }^{\circ} \mathrm{C}$ (dry ethanol); IR $(\mathrm{KBr})$ 2945, 1650, 1603, 1545, 1505, 1291, 1076, 753, and $690 \mathrm{~cm}^{-1}$; UV-vis (dioxane) $\lambda_{\max } 254 \mathrm{~nm}(\lg \varepsilon=$ 4.18), 388 (4.38); ${ }^{1} \mathrm{H}$ NMR $\left(\mathrm{CDCl}_{3}\right) \delta 1.25$ (s, $\left.3 \mathrm{CH}_{3}\right), 7.17$ (mc, $\left.2 \mathrm{C}_{6} \mathrm{H}_{5}\right), 7.85$ (s, 1-/3-H); ${ }^{13} \mathrm{C} \mathrm{NMR}\left(\mathrm{CDCl}_{3}\right) \delta$ 31.2 (q, $3 \mathrm{CH}_{3}$ ), 33.0 (s, C- $\alpha$ ), 114.8 (s, C-2), 117.9 (d, 4 o-C), 122.9 (d, 2 p-C), 129.1 (d, 4 m-C), 147.0 (d, C- 
1/-3), again 147.0 (s, 2 i-C); Anal. Calcd for $\mathrm{C}_{19} \mathrm{H}_{22} \mathrm{~N}_{2}$ (278.4): C, 81.97; H, 7.97; N, 10.06. Found: C, 82.04; $\mathrm{H}$, 8.01; N, 10.21 .

Bis[ $N$-(2-tert-butyl-3-phenylimino-1-propen-1-yl)benzenaminato- $\left.N, N^{\prime}\right]$ cobalt(II) (11Co). Employing the vinamidine 11H (420 mg, $1.51 \mathrm{mmol}$ ), procedure A1 (5 h reflux) afforded $400 \mathrm{mg}$ (86\%) of pure 11Co as a dark powder: mp 152-153 ${ }^{\circ} \mathrm{C}$ (ethanol); IR (KBr) 2950, 1579, 1475, 1441, 1373, 1360, 1312, 758, and $692 \mathrm{~cm}^{-1}$; UV-vis (dioxane) $\lambda_{\max } 254 \mathrm{~nm}(\lg \varepsilon=4.25), 541$ (3.39); ${ }^{1} \mathrm{H}$ NMR Table S14; ${ }^{13} \mathrm{C}$ NMR Table S15; Anal. Calcd for $\mathrm{C}_{38} \mathrm{H}_{42} \mathrm{~N}_{4} \mathrm{Co}$ (613.7): C, 74.37; H, 6.90; N, 9.13. Found: C, 74.41; H, 6.86; N, 9.15.

Bis[ $N$-(2-tert-butyl-3-phenylimino-1-propen-1-yl)benzenaminato- $\left.N, N^{\prime}\right]$ nickel(II) (11Ni). Procedure A1 (5 h reflux) was used to convert the vinamidine $\mathbf{1 1 H}$ (280 $\mathrm{mg}, 1.01 \mathrm{mmol}$ ) to the very stable, dark red bis(chelate) 11Ni: yield 190 mg (61\%); mp 145-146 C (ethanol); IR (KBr) 2955, 1582, 1441, 1371, 1359, 1309, 1215, 1190, 760, and $694 \mathrm{~cm}^{-1}$; UV-vis (dioxane) $\lambda_{\max } 240 \mathrm{~nm}(\lg \varepsilon=4.30), 405$ (4.48); ${ }^{1} \mathrm{H}$ NMR Table S16; ${ }^{13} \mathrm{C}$ NMR Table S17; Anal. Calcd for $\mathrm{C}_{38} \mathrm{H}_{42} \mathrm{~N}_{4} \mathrm{Ni}$ (613.5): C, 74.40; H, 6.90; N, 9.13. Found: C, 73.88; H, 6.89; N, 9.16.

$\mathrm{N}$-[2-(1-Adamantyl)-3-phenylimino-1-propen-1-yl]benzenamine (12H). A solution of adamantyl-1-malonaldehyde $^{70}$ (185 mg, $0.90 \mathrm{mmol}$ ) and aniline $(0.30 \mathrm{~mL}, 3.29 \mathrm{mmol})$ in ethanol $(5 \mathrm{~mL})$ began to deposit yellow crystals after $30 \mathrm{~min}$. After one night at room temperature, the precipitate was collected and dried to yield 260 mg (81\%) of fine yellow lancets: $\mathrm{mp} 183.5-185{ }^{\circ} \mathrm{C}$ (dry ethanol); IR (KBr) 2907, 2843, 1651, 1603, 1545, 1303, 1293, 1167, 1038, 765, 743, and $695 \mathrm{~cm}^{-1}$; UV-vis $\left(\mathrm{CH}_{2} \mathrm{Cl}_{2}\right) \quad \lambda_{\max } 254 \mathrm{~nm}(\lg \varepsilon=4.16), 390(4.38) ;{ }^{1} \mathrm{H}$ NMR $\left(\mathrm{CDCl}_{3}\right) \delta$ 1.73, 1.80 and 1.85 (3 pseudo-s, $6 \mathrm{CH}_{2}$ ), 2.05 (br, $3 \mathrm{H}-\delta$ ), 7.20 (mc, $2 \mathrm{C}_{6} \mathrm{H}_{5}$ ), 7.80 (s, 1-/3-H); ${ }^{13} \mathrm{C} \mathrm{NMR}\left(\mathrm{CDCl}_{3}\right) \delta 28.8\left(\mathrm{~d},{ }^{1} J=132.9 \mathrm{~Hz}, 3 \mathrm{CH}-\gamma\right), 34.4(\mathrm{C}-\alpha), 36.6\left(\mathrm{t},{ }^{1} \mathrm{~J}=126.0 \mathrm{~Hz}, 3 \mathrm{CH}_{2}-\delta\right), 42.9\left(\mathrm{t},{ }^{1} \mathrm{~J}=\right.$ 126.0 Hz, $\left.3 \mathrm{CH}_{2}-\beta\right), 115.0$ (C-2), 117.9 (dt, $\left.{ }^{1} J=158.4 \mathrm{~Hz}, 4 \mathrm{o}-\mathrm{C}\right), 122.8$ (dt, ${ }^{1} J=162.4 \mathrm{~Hz},{ }^{3} \mathrm{~J}=7.1 \mathrm{~Hz}, 2 \mathrm{p}-\mathrm{C}$ ), 129.1 (dd, ${ }^{1} \mathrm{~J}=159.2 \mathrm{~Hz},{ }^{3} \mathrm{~J}=7.5 \mathrm{~Hz}, 4 \mathrm{~m}-\mathrm{C}$ ), 147.1 (2 ipso-C), again 147.1 (dd, ${ }^{1} \mathrm{~J}=159.4 \mathrm{~Hz},{ }^{3} \mathrm{~J}=8.0 \mathrm{~Hz}, \mathrm{C}-$ 1/-3); Anal. Calcd for $\mathrm{C}_{25} \mathrm{H}_{28} \mathrm{~N}_{2}$ (356.5): C, 84.23; H, 7.92; N, 7.86. Found: C, 84.29; H, 8.07; N, 7.84. The ${ }^{13} \mathrm{C}$ NMR assignments have been made from intensities and from signal multiplicities in ${ }^{1} \mathrm{H}$-coupled spectra. Differentiation of the C- $\beta$ and C- $\delta$ methylene groups was accomplished by comparison with literature $\mathrm{e}^{\mathrm{S40}}$ assignments.

Bis $\left\{N\right.$-[2-(1-adamantyl)-3-phenylimino-1-propen-1-yl]benzenaminato- $\left.N, N^{\prime}\right\}$ cobalt(II) (12Co). The vinamidine 12H (640 mg, $1.80 \mathrm{mmol}$ ) was treated according to procedure A1 (16 h reflux) to give $680 \mathrm{mg}$ (93\%) of crude 12Co as a black powder with mp $257-259{ }^{\circ} \mathrm{C}$ (dec). Recrystallization from ethyl acetate led to incorporation of 0.5 equiv of this solvent, which could not be removed in vacuo over $\mathrm{P}_{4} \mathrm{O}_{10}$ /paraffin wax and was detectable in the IR and NMR spectra: $\mathrm{mp}$ 270-272 ${ }^{\circ} \mathrm{C} \mathrm{dec;} \mathrm{IR} \mathrm{(KBr)} \mathrm{2901,} \mathrm{2846,} 1735$ (w, ethyl acetate), 1464, 1447, 1330, 1309, 1210, 762, and $693 \mathrm{~cm}^{-1}$; UV-vis (dioxane) $\lambda_{\max } 256 \mathrm{~nm}$ (lg $\varepsilon=4.38$ ), 410 (4.58), 540 (3.44); ${ }^{1} \mathrm{H}$ NMR $\left(\mathrm{Cl}_{2} \mathrm{CD}-\mathrm{CDCl}_{2}\right)$ Table S18, plus $\delta 1.24,2.00$, and 4.02 for ethyl acetate; ${ }^{13} \mathrm{C}$ NMR $\left(\mathrm{Cl}_{2} \mathrm{CD}-\mathrm{CDCl}_{2}\right)$ Table S19, plus $\delta 13.8,21.0$, 60.2, and 170.7 for ethyl acetate; Anal. Calcd for $\mathrm{C}_{50} \mathrm{H}_{54} \mathrm{~N}_{4} \mathrm{Co}^{\cdot 1} / 2 \mathrm{C}_{4} \mathrm{H}_{8} \mathrm{O}_{2}(769.9+$ 44.1): C, 76.73; H, 7.18; N, 6.88. Found: C, 76.96; H, 7.22; N, 6.40.

$\operatorname{Bis}\left\{N\right.$-[2-(1-adamantyl)-3-phenylimino-1-propen-1-yl]benzenaminato- $\left.N, N^{\prime}\right\}$ nickel(II) (12Ni). Transformation of the vinamidine $\mathbf{1 2 H}$ (340 $\mathrm{mg}, 0.95 \mathrm{mmol}$ ) required at least $16 \mathrm{~h}$ of refluxing in procedure A1. Recrystallization from ethyl acetate furnished pure $12 \mathrm{Ni}$ as a dark red powder (250 $\mathrm{mg}, 65 \%$ ) containing 0.5 equiv of this solvent, which could not be removed at 0.01 Torr $\left(25^{\circ} \mathrm{C}\right)$ over $\mathrm{P}_{4} \mathrm{O}_{10} /$ paraffin wax and was detectable in the 
IR and NMR spectra: mp 229-231 ${ }^{\circ} \mathrm{C}$ dec; IR (KBr) 2902, 2847, 1735 (w, ethyl acetate), 1463, 1447, 1325, 1309, 1210, 763, and $694 \mathrm{~cm}^{-1}$; UV-vis (dioxane) $\lambda_{\max } 240 \mathrm{~nm}$ (lg $\left.\varepsilon=4.41\right), 404$ (4.51); ${ }^{1} \mathrm{H}$ NMR $\left(\mathrm{Cl}_{2} \mathrm{CD}-\right.$ $\left.\mathrm{CDCl}_{2}\right)$ Table S20, plus $\delta 1.2,1.97$, and 4.2 for ethyl acetate; ${ }^{13} \mathrm{C} \mathrm{NMR}\left(\mathrm{Cl}_{2} \mathrm{CD}-\mathrm{CDCl}_{2}\right)$ Table S21, plus $\delta 14.1$, 21.3, 60.2, and 171.0 for ethyl acetate; Anal. Calcd for $\mathrm{C}_{50} \mathrm{H}_{54} \mathrm{~N}_{4} \mathrm{Ni}^{1} \frac{1}{2} \mathrm{C}_{4} \mathrm{H}_{8} \mathrm{O}_{2}(769.7+44.1)$ : C, 76.75; $\mathrm{H}, 7.18$; N, 6.88. Found: C, 76.95; H, 7.29; N, 6.93.

$N$-[2-(4-Methyl-1-bicyclo[2.2.2]octyl)-3-phenylimino-1-propen-1-yl]benzenamine (13H). Aniline (0.40 mL, $4.39 \mathrm{mmol})$ and (4-methyl-1-bicyclo[2.2.2]octyl)malonaldehyde (S48, $280 \mathrm{mg}, 1.44 \mathrm{mmol})$ in ethanol (2 mL) began to deposit yellow needles after $30 \mathrm{~min}$ at room temperature. After $16 \mathrm{~h}$, the precipitate was collected by suction and washed with little ethanol, then dried in vacuo to give $450 \mathrm{mg}$ (91\%, mp 159-163 ${ }^{\circ} \mathrm{C}$ ): $\mathrm{mp} 165-166$ ${ }^{\circ} \mathrm{C}$ (dry ethanol); IR (KBr) 2930, 2850, 1644, 1601, 1541, 1298, 753, and $693 \mathrm{~cm}^{-1}$; UV-vis (dioxane) $\lambda_{\max } 254$ $\mathrm{nm}(\lg \varepsilon=4.24), 390$ (4.38); ${ }^{1} \mathrm{H} \mathrm{NMR}\left(\mathrm{CDCl}_{3}\right) \delta 0.83\left(\mathrm{~s}, 4-\mathrm{CH}_{3}\right), 1.52$ (mc, $3 \mathrm{CH}_{2}-\delta$, assigned by comparison with 11H), 1.70 (mc, $3 \mathrm{CH}_{2}-\gamma$ ), 7.03 (mc, $4 \mathrm{o}-\mathrm{H}$ and 2 p-H), 7.27 (mc, $4 \mathrm{~m}-\mathrm{H}$ ), 7.77 (s, 1-/3-H), 12.45 (br s, NH); ${ }^{13} \mathrm{C}$ NMR $\left(\mathrm{CDCl}_{3}\right) \delta 27.8$ (s, 1 C- $\delta$ ), 28.2 (q, $\left.14-\mathrm{CH}_{3}\right), 32.5$ (t, $\left.3 \mathrm{CH}_{2}-\beta\right), 32.9(\mathrm{~s}, \mathrm{C}-\alpha), 33.6\left(\mathrm{t}, 3 \mathrm{CH}_{2}-\gamma\right), 114.0$ (s, C-2), 117.9 (d, 4 o-C), 122.9 (d, 2 p-C), 129.1 (d, 4 m-C), 147.1 (s, 2 ipso-C), 147.5 (d, C-1/-3); Anal. Calcd for $\mathrm{C}_{24} \mathrm{H}_{28} \mathrm{~N}_{2}$ (344.5): C, 83.68; H, 8.19; N, 8.13. Found: C, 83.66; H, 8.27; N, 8.30. The ${ }^{13} \mathrm{C}$ NMR assignments agree with those ${ }^{\mathrm{S} 41}$ for a related ester.

Bis $\left\{N\right.$-[2-(4-methyl-1-bicyclo[2.2.2] ]octyl)-3-phenylimino-1-propen-1-yl]benzenaminato- $\left.N, N^{\prime}\right\}$ cobalt(II) (13Co). Pure 13Co (36 mg, 74\%) was obtained ${ }^{\mathrm{S42}}$ as a dark red powder after treatment of the vinamidine $\mathbf{1 3 H}$ (44 mg, $0.13 \mathrm{mmol}$ ) according to procedure A1 (2 h at $60{ }^{\circ} \mathrm{C}$ ) under argon gas: mp 266-268 ${ }^{\circ} \mathrm{C}$; IR (KBr) 2940, 2854, 1580, 1465, 1447, 1312, 1212, 758, and $693 \mathrm{~cm}^{-1}$; UV-vis (dioxane) $\lambda_{\max } 254 \mathrm{~nm}$ (lg $\varepsilon=4.52$ ), 411 (4.63), 541 (3.43); ${ }^{1} \mathrm{H}$ NMR Table S22; ${ }^{13} \mathrm{C}$ NMR Table S23; Anal. Calcd for $\mathrm{C}_{48} \mathrm{H}_{54} \mathrm{~N}_{4} \mathrm{Co}$ (745.9): C, 77.29; H, 7.30; N, 7.51. Found: C, 77.07; H, 7.44; N, 7.66.

\section{$\operatorname{Bis}\left\{N\right.$-[2-(4-methyl-1-bicyclo[2.2.2] ]octyl)-3-phenylimino-1-propen-1-yl]benzenaminato- $\left.N, N^{\prime}\right\}$ nickel(II)}

(13Ni). Procedure A1 converted the vinamidine $\mathbf{1 3 H}$ (350 mg, $1.02 \mathrm{mmol}$ ) to black needles (320 mg, 86\%), which were recrystallized twice from ethyl acetate $(50 \mathrm{~mL})$ by precipitation with dry ethanol: $\mathrm{mp} 264-266{ }^{\circ} \mathrm{C}$; IR (KBr) 2935, 2850, 1463, 1445, 1307 (br), 1210, and $691 \mathrm{~cm}^{-1}$; UV-vis (dioxane) $\lambda_{\max } \operatorname{sh} 238 \mathrm{~nm}$ (lg $\varepsilon=4.49$ ), 404 (4.55); ${ }^{1} \mathrm{H}$ NMR Table S24; ${ }^{13} \mathrm{C}$ NMR Table S25; Anal. Calcd for $\mathrm{C}_{48} \mathrm{H}_{54} \mathrm{~N}_{4} \mathrm{Ni}$ (745.7): C, 77.31; H, 7.30; N, 7.51. Found: C, 77.38; H, 7.25; N, 7.85.

Bis[N-(1-methyl-3-methylimino-1-buten-1-yl)methanaminato- $\left.N, N^{\prime}\right]$ nickel(II) (14Ni). The vinamidine $14 \mathrm{H}^{4}$ and its Ni(II) bis(chelate) ${ }^{4, \mathrm{~S} 6}$ were prepared as published. ${ }^{1} \mathrm{H}$ NMR: Corrected values are in Table S26.

$N$-(1-Methyl-3-phenylimino-1-buten-1-yl)benzenamine (15H). Prepared from acetylacetone via the enaminoketone S49 $\left(\mathrm{R}^{\mathrm{N}}=\right.$ phenyl, $\mathrm{R}^{1}=\mathrm{R}^{3}=$ methyl, $\mathrm{R}^{2}=\mathrm{H}$ ) as described for $\mathbf{1 6 H}$ : yield 73\%; mp 50-51 ${ }^{\circ} \mathrm{C}$ (ref 4 : 49-50.5 ${ }^{\circ} \mathrm{C}$; ref 18: 50-52 $\left.{ }^{\circ} \mathrm{C}\right)$; ${ }^{1} \mathrm{H}$ NMR $\left(\mathrm{CDCl}_{3}\right.$ or $\left.\mathrm{CCl}_{4}\right) \delta 1.93\left(\mathrm{~s}, 2 \mathrm{CH}_{3}\right), 4.75(\mathrm{~s}, 2-\mathrm{H}), 7.00\left(\mathrm{mc}^{2}, 2 \mathrm{C}_{6} \mathrm{H}_{5}\right)$, 12.4 (br, NH); ${ }^{13} \mathrm{C}$ NMR $\left(\mathrm{CDCl}_{3}\right) \delta 20.72$ (q, $2 \mathrm{CH}_{3}$ ), 97.27 (d, C-2), 122.34 (d, 4 o-C), 122.95 (d, 2 p-C), 128.52 (d, 4 m-C), 145.51 (s, 2 ipso-C), 159.03 (s, C-1/-3).

Bis[ $N$-(1-methyl-3-phenylimino-1-buten-1-yl)benzenaminato- $\left.N, N^{\prime}\right] \operatorname{cobalt(II)~(15Co).~The~method~of~}$ McGeachin ${ }^{4}$ was used to prepare $\mathbf{1 5 C o}$ from $\mathbf{1 5 H} \cdot \mathrm{HCl}^{63 a, 543}$ (10 mmol) in alkaline methanol at room temperature 
under $\mathrm{N}_{2}$ gas (15 min). The orange-brown powder (yield 79\%) was washed with dry methanol: $\mathrm{mp} 138-140{ }^{\circ} \mathrm{C}$ (ref 4: $143-145{ }^{\circ} \mathrm{C}$ ); ${ }^{1} \mathrm{H}$ NMR Table S27; ${ }^{13} \mathrm{C}$ NMR Table S28.

Bis[N-(1-methyl-3-phenylimino-1-buten-1-yl)benzenaminato- $\left.N, N^{\prime}\right]$ nickel(II) (15Ni). Prepared from 15H in THF by a literature procedure ${ }^{18}$ in 37\% yield: $\mathrm{mp} 162{ }^{\circ} \mathrm{C}$ dec (ethanol; ref 18: $162-163{ }^{\circ} \mathrm{C}$; ref 4: 167-168 $\left.{ }^{\circ} \mathrm{C}\right)$; IR (KBr) 3049, 2919, 1591, 1544, 1526, 1480, 1443, 1382 (br), 1268, 1192, 749, and $697 \mathrm{~cm}^{-1}$; UV-vis $\left(\mathrm{CCl}_{4}\right) \quad \lambda_{\max } 348 \mathrm{~nm}(\lg \varepsilon=4.37), 620$ (2.56); ${ }^{1} \mathrm{H}$ NMR Table S29; ${ }^{13} \mathrm{C}$ NMR Table S30; Anal. Calcd for $\mathrm{C}_{34} \mathrm{H}_{34} \mathrm{~N}_{4} \mathrm{Ni}$ (557.4): C, 73.27; H, 6.15; N, 10.05. Found: C, 73.17; H, 6.24; N, 10.33. - The ${ }^{1} \mathrm{H}$ NMR shifts agree with those reported in ref 18 , whereas the assignments for $\mathrm{CH}_{3}-\beta^{\prime}$ and $m-\mathrm{H}$ had inadvertently been interchanged on p 734 of ref 8 . The ${ }^{13} \mathrm{C}$ NMR shifts reported ${ }^{8}$ at $250 \mathrm{~K}$ disagree with ours but become compatible if it is assumed that the spectrum was taken at $243 \mathrm{~K}$.

$N$-[1-Methyl-3-(3,5-dimethylphenylimino)-1-buten-1-yl]-3,5-dimethylbenzenamine (16H). The mixture of 3,5-dimethylaniline (4.26 mL, $34 \mathrm{mmol})$ and acetylacetone (3.08 mL, $30 \mathrm{mmol})$ was kept at room temperature ${ }^{18}$ for 10 min to produce the enaminoketone $\mathbf{S 4 9}\left(R^{N}=3,5\right.$-dimethylphenyl, $R^{1}=R^{3}=$ methyl, $\left.R^{2}=H\right)$, which was heated to reflux with 3,5-dimethylanilinium chloride $(4.71 \mathrm{~g}, 29.9 \mathrm{mmol})$ in ethanol $(50 \mathrm{~mL})$ for $2 \mathrm{~h}$. After concentration to dryness, the oily residue could not be induced to crystallize, but the addition of $\mathrm{HClO}_{4}(70 \%)$ in aqueous ethanol afforded $19 \%$ of the well-crystallizing, yellow $\mathbf{1 6} \mathbf{H} \cdot \mathrm{HClO}_{4}$ : mp $177-178{ }^{\circ} \mathrm{C}$ dec (ethanol); IR $(\mathrm{KBr}) 3290$ (N-H), 3004, 2915, 1555, 1522 (br), 1306 (br), 1118, 1091 (br), and $1065 \mathrm{~cm}^{-1}$; UV-vis $\left(\mathrm{CH}_{3} \mathrm{OH}\right)$ $\lambda_{\max } 345 \mathrm{~nm}$ (lg $\varepsilon=4.39$ ); Anal. Calcd for $\mathrm{C}_{21} \mathrm{H}_{27} \mathrm{~N}_{2} \mathrm{ClO}_{4}$ (406.9): C, 61.99; H, 6.69; N, 6.88. Found: C, 62.12; H, 6.74; N, 6.83.

The pure vinamidine $\mathbf{1 6 H}$ was obtained from $\mathbf{1 6 H} \cdot \mathrm{HClO}_{4}$ with excess $2 \mathrm{M} \mathrm{NaOH} / \mathrm{CH}_{2} \mathrm{Cl}_{2}$. (The use of $\mathrm{Et}{ }_{2} \mathrm{O}$ in place of $\mathrm{CH}_{2} \mathrm{Cl}_{2}$ may cause long delays in the wetting of $\mathbf{1 5 H} \cdot \mathrm{HClO}_{4}$ and should be avoided.) $\mathrm{The} \mathrm{CH}_{2} \mathrm{Cl}_{2}$ layer was washed, dried, and concentrated, leaving again an oily residue that formed colorless crystals (73\%) on contact with ethanol: $\mathrm{mp}$ 90-91.5 ${ }^{\circ} \mathrm{C}$ (ref S44: no mp); IR (KBr) 2910, 1625, 1541 (br), 1312, 1268, 1142, and $847 \mathrm{~cm}^{-1}$; UV-vis $\left(\mathrm{CCl}_{4}\right.$ or dioxane) $\lambda_{\max } 344 \mathrm{~nm}(\lg \varepsilon=4.35) ;{ }^{1} \mathrm{H} \mathrm{NMR}\left(\mathrm{CCl}_{4}\right) \delta 1.92\left(\mathrm{~s}, 1-/ 3-\mathrm{CH}_{3}\right), 2.25(4 \mathrm{~m}$ $\mathrm{CH}_{3}$ ), 4.68 (s, 2-H), 6.47 (s, 4 o-H), 6.55 (s, 2 p-H), 12.33 (NH); Anal. Calcd for $\mathrm{C}_{21} \mathrm{H}_{26} \mathrm{~N}_{2}$ (306.5): C, 82.31; $\mathrm{H}$, 8.55; N, 9.14. Found: C, 82.39; H, 8.55; N, 9.14. The overall yield (14\%) was higher than that reported ${ }^{\mathrm{S} 44}$ quite $^{2}$ recently.

\section{Bis $\{N$-[1-methyl-3-(3,5-dimethylphenylimino)-1-buten-1-yl]-3,5-dimethylbenzenaminato-N,N’\}nickel(II)}

(16Ni). Procedure B2 (18 h reflux, extraction with hot hexane) applied to $\mathbf{1 6 H} \cdot \mathrm{HClO}_{4}(1.00 \mathrm{~g}, 2.46 \mathrm{mmol})$ furnished brown-yellow, glimmering platelets (640 mg, 78\%), while all solutions of 16Ni were dark green. Mp 237-238 ${ }^{\circ} \mathrm{C}$ dec (ethyl acetate); IR (KBr) 2906, 1520, 1443, 1384 (br), 1305, 1149, 1019, 844, 751, 741, and 690 $\mathrm{cm}^{-1}$; UV-vis $\left(\mathrm{CCl}_{4}\right.$ or $\left.\mathrm{CHCl}_{3}\right) \lambda_{\max } 352 \mathrm{~nm}$ (lg $\varepsilon=4.38$ ), sh 431 (3.70), 625 (2.51); UV-vis (dioxane) $\lambda_{\max } 356$ nm (lg $\varepsilon=4.37$ ) sh 432 (3.77), 630 (2.60); ${ }^{1} \mathrm{H}$ NMR Table S31; Anal. Calcd for $\mathrm{C}_{42} \mathrm{H}_{50} \mathrm{~N}_{4} \mathrm{Ni}$ (669.6): C, 75.34; H, 7.53; N, 8.37. Found: C, 75.51; H, 7.69; N, 8.56. Molecular mass 668 (osmom. in benzene).

$\mathrm{N}$-(1-tert-Butyl-4,4-dimethyl-3-phenylimino-1-penten-1-yl)benzenamine (19H). ${ }^{1} \mathrm{H}$ NMR (equilibrium mixture $^{71}$ at room temperature in $\left.\mathrm{CDCl}_{3}\right) \delta 1.08$ (s, $\left.6 \mathrm{CH}_{3}\right), 5.62$ (s, 2-H), 6.65 (m, 4 o-H), 7.08 (m, 4 m-H and 2 p$\mathrm{H}) ;{ }^{13} \mathrm{C} \mathrm{NMR}\left(\mathrm{Cl}_{2} \mathrm{CD}-\mathrm{CDCl}_{2}\right.$ at $\left.-35.5{ }^{\circ} \mathrm{C}\right) \delta 27.9$ (q, $6 \mathrm{CH}_{3}$ ), 36.3 (s, quart. 1-/3-C), 105.4 (C-2), 119.3 (d, 4 o- 
C), 122.7 (d, 2 p-C), 128.1 (d, 4 m-C), 144.2 (s, 2 ipso-C), 150.8 (s, C-1/-3). This ${ }^{13} \mathrm{C}$ NMR spectrum was obtained from a decomposing solution of $\mathbf{1 9 N i}$, which formed the kinetically controlled ${ }^{71}$ vinamidine tautomer $19 H$ first.

Bis[N-(1-tert-butyl-4,4-dimethyl-3-phenylimino-1-penten-1-yl)benzenaminato-N,N']cobalt(II) (19Co). A suspension of $\mathbf{1 9 H} \cdot \mathrm{HClO}_{4}{ }^{71}$ (2.00g, $\left.4.60 \mathrm{mmol}\right)$ in anhydrous $\mathrm{Et}_{2} \mathrm{O}(10 \mathrm{~mL})$ was combined with methyllithium (3 equiv) in $\mathrm{Et}_{2} \mathrm{O}$ and treated according to procedure $\mathrm{B} 2$ (48 $\mathrm{h}$ reflux under $\mathrm{N}_{2}$ gas). The filtered solution was concentrated to dryness, and the deep red residue was crystallized from $\mathrm{CCl}_{4} /$ ethanol (1:2), yielding $800 \mathrm{mg}$ (48\%) of almost pure 19Co. Solutions of this bis(chelate) in $\mathrm{CDCl}_{3}$ or in $\mathrm{Cl}_{2} \mathrm{CD}-\mathrm{CDCl}_{2}$ are not stable at ambient temperature. Further purification was accomplished by filtration of a solution of 19Co in hexane under $\mathrm{N}_{2}$ and precipitation with dry ethanol (3 times): mp 147-149.5 ${ }^{\circ} \mathrm{C}$; IR (KBr) 2963, 1505, 1377, 1358, and $699 \mathrm{~cm}^{-1}$; UV-vis (dioxane) $\lambda_{\max } 241 \mathrm{~nm}(\lg \varepsilon=4.40), 347$ (4.36), 390 (4.14); ${ }^{1} \mathrm{H}$ NMR Table S32; ${ }^{13} \mathrm{C}$ NMR Table S33; Anal. Calcd for $\mathrm{C}_{46} \mathrm{H}_{58} \mathrm{~N}_{4} \mathrm{Co}$ (725.9): C, 76.11; H, 8.05; N, 7.72. Found: C, 76.04; H, 8.07; N, 7.97.

\section{Bis[N-(1-tert-butyl-4,4-dimethyl-3-phenylimino-1-penten-1-yl)benzenaminato- $\left.N, N^{\prime}\right]$ nickel(II)}

(19Ni).

Procedure B2 (19 h reflux) converted $\mathbf{1 9 H} \cdot \mathrm{HClO}_{4}{ }^{71}$ (2.00g, $\left.4.60 \mathrm{mmol}\right)$ in anhydrous THF $(20 \mathrm{~mL})$ rather slowly to the dark blue bis(chelate) $\mathbf{1 9 N i}$, which was extracted with hot hexane under $\mathrm{N}_{2}$ gas from the solid product mixture: yield 1.22 g (73\%); mp 178-180 ${ }^{\circ} \mathrm{C}$ dec (hexane); IR (KBr) 2954, 1500, 1476, 1373, 1354, 1189, and $697 \mathrm{~cm}^{-1}$; UV-vis ( $\mathrm{CCl}_{4}$ or dioxane) $\lambda_{\max } 294 \mathrm{~nm}$ (lg $\left.\varepsilon=4.29\right), 388$ (4.08), 654 (2.58); ${ }^{1} \mathrm{H}$ NMR Table S34; ${ }^{13} \mathrm{C}$ NMR Table S35; Anal. Calcd for $\mathrm{C}_{46} \mathrm{H}_{58} \mathrm{~N}_{4} \mathrm{Ni}$ (725.7): C, 76.13; H, 8.06; N, 7.72. Found: C, 76.11; H, 8.04; N, 7.95. Molecular mass 693 (osmom. in benzene). A solution of $19 \mathrm{Ni}$ in $\mathrm{Cl}_{2} \mathrm{CD}-\mathrm{CDCl}_{2}$ decomposed within 20 min at room temperature.

Bis[N-(4,4-dimethyl-3-phenylimino-1-penten-1-yl)benzenaminato-N,N']nickel(II) (20Ni). This dark green bis(chelate) (1.19 g, 86\%) was obtained from $\mathbf{2 0 H} \cdot \mathrm{HClO}_{4}{ }^{71}(1.70 \mathrm{~g}, 4.49 \mathrm{mmol})$ in anhydrous THF (30 mL) by procedure B2 (18 h reflux, then benzene extraction): $\mathrm{mp} 151-152{ }^{\circ} \mathrm{C}$ dec (ethyl acetate/ethanol 1:2); $\mathrm{IR}(\mathrm{KBr})$ 2964, 1560, 1482, 1418, 1321, 1267, 757, and $701 \mathrm{~cm}^{-1}$; UV-vis $\left(\mathrm{CCl}_{4}\right) \quad \lambda_{\max } 379 \mathrm{~nm}(\lg \varepsilon=4.21), 635$ (2.36); UV-vis (dioxane) $\lambda_{\max } 381 \mathrm{~nm}(\lg \varepsilon=4.42), 627(2.71) ;{ }^{1} \mathrm{H}$ NMR Table S36; Anal. Calcd for $\mathrm{C}_{38} \mathrm{H}_{42} \mathrm{~N}_{4} \mathrm{Ni}$ (613.5): C, 74.40; H, 6.90; N, 9.13. Found: C, 74.20; H, 7.02; N, 8.94. - 20Ni is chiral, but its solution in L-(-)(1-phenylethyl)amine did not exhibit any diastereotopic splitting of the ${ }^{1} \mathrm{H}$ NMR signals.

Bis[N-(4,4-dimethyl-3-phenylimino-1-penten-1-yl)benzenaminato-N,N']zinc(II) (20Zn). This diamagnetic bis(chelate) was prepared to provide $\delta^{\text {DIA }}$ values, because the vinamidine $\mathbf{2 0 H}$ has the extended conformation. ${ }^{71}$ Procedure B2 (14 h reflux, then benzene extraction) with $\left(\mathrm{Et}_{4} \mathrm{~N}\right)_{2} \mathrm{ZnBr}_{4} \quad(873 \mathrm{mg}, 1.35 \mathrm{mmol})^{\mathrm{S45}}$ converted $\mathbf{2 0 H} \cdot \mathrm{HClO}_{4}{ }^{71}(1.04 \mathrm{~g}, 2.75 \mathrm{mmol})$ in anhydrous THF $(25 \mathrm{~mL})$ to the slowly crystallizing, bright-yellow 20Zn: yield 395 mg (47\%); mp 126-128 ${ }^{\circ} \mathrm{C}$ (ethanol); IR (KBr) 2960, 1563, 1483, 1428, 1330, 1272, 1102, 755, 740, and $701 \mathrm{~cm}^{-1}$; UV-vis $\left(\mathrm{CCl}_{4}\right) \quad \lambda_{\max } 401 \mathrm{~nm}(\lg \varepsilon=4.42) ;{ }^{1} \mathrm{H}$ NMR $\left(\mathrm{CS}_{2}\right.$ at $-40,-18$, and $\left.+27{ }^{\circ} \mathrm{C}\right) \delta 0.95$ (s, 3 $\mathrm{CH}_{3}$ ), 4.77 (d, $\left.{ }^{3} \mathrm{~J}=8 \mathrm{~Hz}, 2-\mathrm{H}\right), 6.27$ (m, $\left.4 \mathrm{o}-\mathrm{H}\right), 6.80$ (mc, 6 aromat. H), 7.20 (d, $\left.{ }^{3} \mathrm{~J}=8 \mathrm{~Hz}, 3-\mathrm{H}\right)$; Anal. Calcd for $\mathrm{C}_{38} \mathrm{H}_{42} \mathrm{~N}_{4} \mathrm{Zn}$ (620.2): C, 73.60; H, 6.83; N, 9.03. Found: C, 73.29; H, 6.84; N, 9.11.

Bis[N-(1-methyl-3-methylimino-2-pheny1-1-buten-1-yl)methanaminato-N,N']nickel(II) (21Ni). The vinamidine $\mathbf{2 1 H}$ and its bis(chelate) 21Ni have been published. ${ }^{4, \mathrm{~S} 6}{ }^{1} \mathrm{H}$ NMR Table S37. 


\section{Bis\{ $N$-[1-methyl-3-(3,5-dimethylphenylimino)-2-pheny1-1-buten-1-yl]-3,5-dimethylbenzenaminato-}

N,N’\}nickel(II) (22Ni). The vinamidine 22H ${ }^{71}$ (800 mg, $2.09 \mathrm{mmol}$ ), subjected to procedure B1 (19 h reflux, then benzene extraction), furnished yellow-green, easily hydrolyzing needles: yield $750 \mathrm{mg}$ (88\%); mp 301-302 ${ }^{\circ} \mathrm{C}$ dec (ethyl acetate); IR (KBr) 2913, 1600, 1586, 1533, 1434, 1366, 1347, 1151, 842, 701, and $694 \mathrm{~cm}^{-1}$; UVvis (dioxane) $\lambda_{\max } 361 \mathrm{~nm}(\lg \varepsilon=4.24), 632$ (2.86); ${ }^{1} \mathrm{H}$ NMR Table S38; Anal. Calcd for $\mathrm{C}_{54} \mathrm{H}_{58} \mathrm{~N}_{4} \mathrm{Ni}(812.8)$ : C, 78.92; H, 7.11; N, 8.62. Found: C, 78.95; H, 7.06; N, 6.86. Molecular mass 787 (osmom. in benzene).

Bis[N-(1-methyl-2-phenyl-3-phenylimino-1-buten-1-yl)benzenaminato-N,N']nickel(II) (23Ni). The vinamidine $23 \mathbf{H}^{71}$ (1.30 g, $3.98 \mathrm{mmol}$ ), treated according to procedure B1 (extraction with boiling hexane), afforded green-black crystals tending to decompose: yield $720 \mathrm{mg}$ (25\%); mp $180-182{ }^{\circ} \mathrm{C}$ dec (dry ethanol); $\mathrm{IR}(\mathrm{KBr})$ 2990, 1530, 1340 (br), 1203, 757, and $694 \mathrm{~cm}^{-1}$; UV-vis $\left(\mathrm{CHCl}_{3}\right.$ or dioxane) $\lambda_{\max } 368 \mathrm{~nm}$ (lg $\left.\varepsilon=4.24\right), 617$ (2.77); ${ }^{1} \mathrm{H}$ NMR Table S39; Anal. Calcd for $\mathrm{C}_{46} \mathrm{H}_{42} \mathrm{~N}_{4} \mathrm{Ni}$ (709.6): C, 77.86; H, 5.97; N, 7.90. Found: C, 77.92; H, 5.87; N, 8.11.

$\boldsymbol{N}$-[1-Methyl-2-(4-methylphenyl)-3-phenylimino-1-buten-1-yl]benzenamine $\quad(24 \mathrm{H}) . \quad{ }^{1} \mathrm{H} \quad \mathrm{NMR}\left(\mathrm{CCl}_{4}\right)$ as published; ${ }^{71}{ }^{13} \mathrm{C}$ NMR $\left(\mathrm{CDCl}_{3}\right) \delta 20.0$ (q, 1-/3- $\mathrm{CH}_{3}$ ), 21.2 (q, $\delta-\mathrm{CH}_{3}$ ), 109.4 (s, C-2), 122.8 (d, 4 N-o-C), 123.0 (d, 2 N-p-C), 128.6 (d, 4 N-m-C), 129.0 (d, 2 C- $\beta$ ), 131.8 (d, 2 C- $\gamma$ ), 135.7 (s, C- $\delta$ ), 138.7 (s, C- $\alpha$ ), 145.5 (s, 2 Nipso-C), 159.3 (s, C-1/-3).

Bis $\{N$-[1-methyl-2-(4-methylphenyl)-3-phenylimino-1-buten-1-yl]benzenaminato- $N, N\}$ nickel(II) (24Ni). According to procedure B1 (14 h reflux, then benzene extraction), the vinamidine $\mathbf{2 4 \mathbf { H } ^ { 7 1 }}$ (1.10 g, 3.23 mmol) furnished dark green crystals: yield $950 \mathrm{mg}$ (80\%); mp 226-228 ${ }^{\circ} \mathrm{C}$ dec (ethyl acetate/ethanol 1:1); IR (KBr) 3005, 1587, 1523, 1345, 1311, 1206, 759, and $693 \mathrm{~cm}^{-1}$; UV-vis $\left(\mathrm{CCl}_{4}\right.$ or dioxane) $\lambda_{\max } 375 \mathrm{~nm}(\lg \varepsilon=4.28)$, 625 (2.89); UV-vis $\left(\mathrm{CHCl}_{3}\right) \quad \lambda_{\max } 370 \mathrm{~nm}(\lg \varepsilon=4.30), 626(2.90) ;{ }^{1} \mathrm{H}$ NMR Table S40; ${ }^{13} \mathrm{C}$ NMR Table S41; Anal. Calcd for $\mathrm{C}_{48} \mathrm{H}_{46} \mathrm{~N}_{4} \mathrm{Ni}$ (737.6): C, 78.16; H, 6.29; N, 7.60. Found: C, 78.34; H, 6.47; N, 7.71.

$\mathrm{N}$-[1-Methyl-3-phenylimino-2-(2,4,6-trimethylphenyl)-1-buten-1-yl]benzenamine $(25 \mathrm{H})$. The mixture of 1-azaallyllithium constitutional isomers ${ }^{\mathrm{S} 3}$ S53a, generated from the Schiff bases S52a (8.00 g, $\left.31.8 \mathrm{mmol}\right)$ with methyllithium and 0.2 equiv of diisopropylamine in diethyl ether, was refluxed with ethyl $N$-phenylacetimidate ${ }^{\mathrm{S} 24}$ (S54, $6.83 \mathrm{~g}, 42 \mathrm{mmol}$ ) under $\mathrm{N}_{2}$ gas for $112 \mathrm{~h}$ and titrated with additional methyllithium during this period (protocol A of ref 71). After hydrolysis and extraction with diethyl ether, the combined extracts were washed until neutral, dried, and concentrated. Unconsumed starting material, reagents and sideproducts (such as $N, N^{\prime}-$ diphenylacetamidine) were removed by distillation up to $190{ }^{\circ} \mathrm{C} / 0.001$ Torr, leaving a brown residue (8.1 g) which could not be recrystallized and did not form a crystalline hydrogenperchlorate. Its ${ }^{1} \mathrm{H}$ NMR spectra showed little change after two distillations at 200-220 ${ }^{\circ} \mathrm{C}$ (bath temp.)/0.005 Torr), affording an oil which again did not crystallize with $\mathrm{HClO}_{4}$ in ethanol or 1-propanol: ${ }^{1} \mathrm{H} \mathrm{NMR}\left(\mathrm{CCl}_{4}\right) \delta 1.58\left(\mathrm{~s}, 1-/ 3-\mathrm{CH}_{3}\right), 2.13\left(\mathrm{~s}, \delta-\mathrm{CH}_{3}\right), 2.20(\mathrm{~s}, 2$ $\beta-\mathrm{CH}_{3}$ ), 6.97 (mc, $2 \mathrm{~N}-\mathrm{C}_{6} \mathrm{H}_{5}$ ), 13.68 (br, NH).

\section{Bis $\left\{N\right.$-[1-methyl-3-phenylimino-2-(2,4,6-trimethylphenyl)-1-buten-1-yl]benzenaminato- $\left.N, N^{\prime}\right\}$ nickel(II)}

(25Ni). The crude vinamidine 25H (6.16 g, less than $16.7 \mathrm{mmol}$ ) in THF, subjected to procedure B1 (36 h at 55 ${ }^{\circ} \mathrm{C}$, then extraction with hot hexane), afforded carmine-red needles 25Ni: yield $131 \mathrm{mg}(2 \%)$; mp 251-253 ${ }^{\circ} \mathrm{C}$ dec (hexane); IR (KBr) 2918, 1590, 1529, 1343, 1209, 697, and $691 \mathrm{~cm}^{-1}$; UV-vis $\left(\mathrm{CCl}_{4}\right.$ or dioxane) $\lambda_{\max } 277$ 
nm (lg $\varepsilon=4.42), 385$ (4.28), 608 (2.74); ${ }^{1} \mathrm{H}$ NMR Table S42; Anal. Calcd for $\mathrm{C}_{52} \mathrm{H}_{54} \mathrm{~N}_{4} \mathrm{Ni}$ (793.7): C, 78.69; H, 6.86; N, 7.06. Found: C, 78.40; H, 6.74; N, 7.02.

\section{Bis $\left\{N\right.$-[1-methyl-2-(3,5-dimethylphenyl)-3-phenylimino-1-buten-1-yl]benzenaminato- $\left.N, N^{\prime}\right\}$ nickel(II)}

(26Ni). Using procedure B1 (19 h reflux, then benzene extraction), the vinamidine $\mathbf{2 6 H}^{71}$ (1.09 $\left.\mathrm{g}, 3.07 \mathrm{mmol}\right)$ was converted to dark green flakes: yield $802 \mathrm{mg}$ (68\%); mp 228-230 ${ }^{\circ} \mathrm{C}$ dec (ethyl acetate/ethanol 1:2); IR $(\mathrm{KBr}) 3018,2914,1590,1531,1369,1348,1208$, and $700 \mathrm{~cm}^{-1}$; UV-vis $\left(\mathrm{CCl}_{4}\right.$ or dioxane) $\lambda_{\max } 374 \mathrm{~nm}(\lg \varepsilon=$ 4.30), 628 (2.91); ${ }^{1} \mathrm{H}$ NMR Table S43; Anal. Calcd for $\mathrm{C}_{50} \mathrm{H}_{50} \mathrm{~N}_{4} \mathrm{Ni}$ (765.7): C, 78.43; H, 6.58; N, 7.32. Found: C, 78.35; H, 6.62; N, 7.07. Molecular mass 758 (osmom. in benzene).

$N$-[1-Methyl-3-phenylimino-2-(2,3,5,6-tetramethylphenyl)-1-buten-1-yl]benzenamine $(27 H) . \quad T h e(E / Z)$ mixture $^{\mathrm{S} 23}$ S52b (3.17 g, $12.0 \mathrm{mmol}$ ) and diisopropylamine (0.20 equiv) in diethyl ether (23 mL) was titrated ${ }^{71}$ with methyllithium. After the addition of ethyl $N$-phenylacetimidate ${ }^{\mathrm{S} 24}$ (S54, $2.04 \mathrm{~g}, 12.5$ mmol), the mixture was refluxed under $\mathrm{N}_{2}$ gas for 5 days with intermediate titrations with additional methyllithium (protocol A of ref 71). After hydrolysis with iced water $(100 \mathrm{~mL})$ and extraction with diethyl ether, the combined extracts were washed until neutral, dried over $\mathrm{Na}_{2} \mathrm{SO}_{4}$, and concentrated to dryness. The crude material contained only little vinamidine 27H, which could not be precipitated with $\mathrm{HClO}_{4}$ in 1-propanol. Distillation of an aliquot at 180-200 ${ }^{\circ} \mathrm{C}$ (bath temp.)/0.03 Torr did not change the composition. Therefore, 27Ni was prepared from the crude material and then cleaved as follows.

The bis(chelate) $27 \mathrm{Ni}$ (220 mg, $0.268 \mathrm{mmol})$ in $\mathrm{CH}_{2} \mathrm{Cl}_{2}(20 \mathrm{~mL})$ was stirred for 3 days with $\mathrm{HClO}_{4}(0.7 \mathrm{~mL})$ in water $(1.0 \mathrm{~mL})$ and acetic acid $(0.5 \mathrm{~mL})$. The $\mathrm{CH}_{2} \mathrm{Cl}_{2}$ layer was separated from the weakly acidic (!), faintly green water phase, washed until neutral, dried over $\mathrm{Na}_{2} \mathrm{SO}_{4}$, and concentrated to yield $75 \mathrm{mg}$ (36\%) of the almost pure, pale brown powder 27H: $\mathrm{mp} 114-115{ }^{\circ} \mathrm{C}$ (from $1 \mathrm{~mL}$ of ethanol); IR (KBr) 2916, 1599, 1525, 1493, 1254, 1223, 746, and $698 \mathrm{~cm}^{-1}$; UV-vis (dioxane) $\lambda_{\max } 357 \mathrm{~nm}(\lg \varepsilon=4.28) ;{ }^{1} \mathrm{H} \mathrm{NMR}\left(\mathrm{CCl}_{4}\right) \delta 1.55$ (s, 1-/3- $\left.\mathrm{CH}_{3}\right), 2.17$ (2 $\gamma-\mathrm{CH}_{3}$ ), 2.23 (s, $2 \beta-\mathrm{CH}_{3}$ ), 7.02 (mc, $2 \mathrm{~N}-\mathrm{C}_{6} \mathrm{H}_{5}$ ), 13.6 (br, $\mathrm{NH}$ ); Anal. Calcd for $\mathrm{C}_{27} \mathrm{H}_{30} \mathrm{~N}_{2}$ (382.5): C, 84.77; H, 7.91; N, 7.32. Found: C, 84.56; H, 7.93; N, 7.23.

\section{Bis $\{N$-[1-methyl-3-phenylimino-2-(2,3,5,6-tetramethylphenyl)-1-buten-1-yl]benzenaminato- $N, N\}$ nickel-}

(II) (27Ni). The crude product obtained from $10.8 \mathrm{mmol}$ of the Schiff bases S52b, containing very little vinamidine 27H (see above), was dissolved in THF (40 mL) and titrated with methyllithium in $\mathrm{Et}_{2} \mathrm{O}$ according to procedure B1. After addition of solid, dry $\left(\mathrm{Et}_{2} \mathrm{NiBr}_{4}(5.00 \mathrm{~g}, 7.83 \mathrm{mmol})\right.$, the mixture was refluxed under $\mathrm{N}_{2}$ gas for 2 days, then concentrated in vacuo and dried in a desiccator. This deeply colored powder was extracted on a filter with dry benzene (5 times), leaving a gray powder which was discarded. The benzene extracts were concentrated, then precipitated with anhydrous ethanol ( $25 \mathrm{~mL}$ ), affording almost pure $\mathbf{2 7 N i}$ (220 $\mathrm{mg}, 5 \%$ rel. to S52b) in two fractions as dark blue needles: $\mathrm{mp} 309-311^{\circ} \mathrm{C}$ dec (ethyl acetate/dry ethanol); IR (KBr) 2921, 1534, 1372, 1345, 1212, and $698 \mathrm{~cm}^{-1}$; UV-vis $\left(\mathrm{CCl}_{4}\right.$ or dioxane) $\lambda_{\max } 387 \mathrm{~nm}(\lg \varepsilon=4.30)$, sh $608(2.76)$; ${ }^{1} \mathrm{H}$ NMR Table S44; Anal. Calcd for $\mathrm{C}_{54} \mathrm{H}_{58} \mathrm{~N}_{4} \mathrm{Ni}$ (821.8): C, 78.92; H, 7.11; N, 6.82. Found: C, 79.07; H, 7.09; N, 7.12.

Bis $\{N$-[2-(4-biphenylyl)-1-methyl-3-phenylimino-1-buten-1-yl]benzenaminato- $N$, $N$ \} $\}$ nickel(II) (28Ni). The vinamidine $28 \mathrm{H}^{71}$ (1.65 g, $\left.4.10 \mathrm{mmol}\right)$ and $\left(\mathrm{Et}_{4} \mathrm{~N}\right)_{2} \mathrm{NiBr}_{4}(1.60 \mathrm{~g}, 2.51 \mathrm{mmol})$ were dissolved in a solution of sodium (115 mg, $5.0 \mathrm{mmol})$ in anhydrous ethanol $(20 \mathrm{~mL})$. This mixture darkened slowly during three days of 
refluxing under $\mathrm{N}_{2}$ gas. The green precipitate (1.29 g) was separated by filtration from the supernatant ethanol, which contained no $\mathbf{2 8 N i}$ and was discarded. The precipitate was extracted under $\mathrm{N}_{2}$ with dry benzene (20 plus 3 $\times 10 \mathrm{~mL}$ ), and the extracts were concentrated in vacuo, then dissolved in ethyl acetate $(2 \mathrm{~mL})$ and precipitated with anhydrous ethanol $(20 \mathrm{~mL})$ to yield $380 \mathrm{mg}(17 \%)$ of a dark green powder: $\mathrm{mp} 139-141{ }^{\circ} \mathrm{C}$ (ethyl acetate/ethanol); mixed mp 124-127 ${ }^{\circ} \mathrm{C}$ with vinamidine $\mathbf{2 8 H}$ (ref 71: $143{ }^{\circ} \mathrm{C}$ for $\mathbf{2 8 H}$ ); Anal. Calcd for $\mathrm{C}_{58} \mathrm{H}_{50} \mathrm{~N}_{4} \mathrm{~N} \cdot 1 / 2 \mathrm{C}_{4} \mathrm{H}_{8} \mathrm{O}_{2}(861.8+44.1)$ : C, 79.56; H, 6.01; N, 6.19. Found: C, 79.76; H, 6.27; N, 6.33. This modification contained 0.5 equiv of ethyl acetate, which could not be removed at $<0.01$ Torr $\left(25{ }^{\circ} \mathrm{C}\right.$ ) as shown by a weak IR absorption at $1729 \mathrm{~cm}^{-1}$ and by the ${ }^{1} \mathrm{H}$ NMR spectra $(\delta 1.17,1.90$, and 3.99).

A modification free from ethyl acetate was obtained by short treatment with hot ethanol, forming dark blue needles or a dark brown powder with mp $213-216{ }^{\circ} \mathrm{C}$ (dec) and the same mp when mixed with the low-melting modification. In both forms, 28Ni had the same IR and ${ }^{1} \mathrm{H}$ NMR spectra: IR (KBr) 3019, 1594, 1530, 1488, 1372, 1350, 1212, 759, and $695 \mathrm{~cm}^{-1}$; UV-vis $\left(\mathrm{CCl}_{4}\right.$ or dioxane) $\lambda_{\max } 320 \mathrm{~nm}(\lg \varepsilon=4.33), 367$ (4.31), 626 (2.94); ${ }^{1} \mathrm{H}$ NMR Table S45; Anal. Calcd for $\mathrm{C}_{58} \mathrm{H}_{50} \mathrm{~N}_{4} \mathrm{Ni}$ (861.8): C, 80.84; H, 5.85; N, 6.50. Found: C, 81.12; H, 6.10; N, 6.76.

Bis $\left\{N\right.$-[1-methyl-2-(1-naphthyl)-3-phenylimino-1-buten-1-yl]benzenaminato- $\left.N, N^{\prime}\right\}$ nickel(II) (29Ni). According to procedure B1 (22 h reflux, then benzene extraction), vinamidine $\mathbf{2 9 H}^{\mathbf{7 1}}$ (1.30 g, $3.45 \mathrm{mmol}$ ) in THF (30 mL) was converted to dark green 29Ni: crude yield $1.01 \mathrm{~g} \mathrm{(72 \% );} \mathrm{mp} \mathrm{231-233}{ }^{\circ} \mathrm{C}$ dec (ethyl acetate/ethanol 1:2); IR (KBr) 3047, 1588, 1527, 1368, 1345, 1207, 780, and $693 \mathrm{~cm}^{-1}$; UV-vis (CCl ${ }_{4}$ or dioxane) $\lambda_{\max } 276 \mathrm{~nm}$ (lg $\varepsilon=4.59), 286$ (4.61), 296 (4.54), 371 (4.29), 620 (2.87); ${ }^{1} \mathrm{H}$ NMR Table S46; Anal. Calcd for $\mathrm{C}_{54} \mathrm{H}_{46} \mathrm{~N}_{4} \mathrm{Ni}$ (809.7): C, 80.10; H, 5.73; N, 6.92. Found: C, 79.81; H, 5.76; N, 6.99.

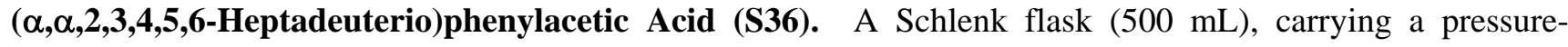
equalizing dropping funnel and a magnetic stirbar, was flushed with dry argon, then charged with dry potassium tert-butoxide (5.26 g, $47.0 \mathrm{mmol})$ and [ $\left.\mathrm{D}_{8}\right]$ toluene $(5.00 \mathrm{~mL}, 47.0 \mathrm{mmol})$ in dry pentane $(50 \mathrm{~mL})$. The flask was cooled in ice, and $n$-butyllithium $(39.1 \mathrm{~mL}, 46.9 \mathrm{mmol}$ ) was added slowly through the funnel with stirring under argon. The orange-colored suspension of $\left[\mathrm{D}_{7}\right]$ benzylpotassium (S35) was stirred overnight at room temperature (to attain the equilibrium composition), ${ }^{\mathrm{S} 19}$ then cooled in a bath of acetone which contained an excess of solid $\mathrm{CO}_{2}$. A slurry of solid $\mathrm{CO}_{2}(30 \mathrm{~g})$ in precooled, dry $\mathrm{Et}_{2} \mathrm{O}(20 \mathrm{~mL})$ was prepared and poured slowly into the reaction flask (violent foaming may be tempered by the addition of $\operatorname{dry} \mathrm{Et}_{2} \mathrm{O}$ ). The mixture was kept at room temperature overnight, then stirred with $2 \mathrm{M} \mathrm{NaOH}(90 \mathrm{~mL})$ and $\mathrm{Et}_{2} \mathrm{O}(150 \mathrm{~mL})$ until dissolved, and this $\mathrm{Et}_{2} \mathrm{O}$ layer was discarded. The alkaline aqueous phase was cooled in ice, covered with $\mathrm{Et}_{2} \mathrm{O}(50 \mathrm{~mL})$, and acidified carefully with conc. $\mathrm{HCl}$, then extracted with $\mathrm{Et}_{2} \mathrm{O}(150+80+80 \mathrm{~mL})$, which was washed until neutral, dried over $\mathrm{Na}_{2} \mathrm{SO}_{4}$, and concentrated to dryness. The residue was dried over $\mathrm{P}_{4} \mathrm{O}_{10}$ in a desiccator, affording a solid mass (5.15 g, 77\%) which was leached out with boiling hexane (75 mL). The filtered hot hexane solution was concentrated to $30 \mathrm{~mL}$ and cooled, precipitating pure $\mathbf{S 3 6}$ which was washed with very cold hexane and dried over $\mathrm{P}_{4} \mathrm{O}_{10}$ : yield $2.75 \mathrm{~g}$ (41\%); mp 66-68 ${ }^{\circ} \mathrm{C}$ (ref S46: $77-78{ }^{\circ} \mathrm{C}$ for unlabeled $\mathrm{PhCH}_{2} \mathrm{CO}_{2} \mathrm{H}$ ); ${ }^{1} \mathrm{H}$ NMR $\left(\mathrm{CDCl}_{3}\right) \delta 3.61\left(\mathrm{t} 1: 1: 1,{ }^{2} J_{\mathrm{CD}} \approx 1.8 \mathrm{~Hz}\right.$, trace of CHD- $\left.\alpha\right), 11.6(\mathrm{br}, \mathrm{OH}) ;{ }^{13} \mathrm{C} \mathrm{NMR}\left(\mathrm{CDCl}_{3}\right) \delta 40.4(\mathrm{qi} 1: 2: 3: 2: 1$, ${ }^{1} J_{\mathrm{CD}}=19 \mathrm{~Hz}, \mathrm{CD}_{2}-\alpha$ plus trace of CHD- $\alpha$ at 40.7$), 126.8$ (t 1:1:1, $\left.{ }^{1} J_{\mathrm{CD}}=24.3 \mathrm{~Hz}, p-\mathrm{C}\right), 128.1\left(\mathrm{t} 1: 1: 1,{ }^{1} J_{\mathrm{CD}}=24.4\right.$ 
Hz, 2 o-C), 128.9 (t 1:1:1, ${ }^{1} J_{\mathrm{CD}}=24.2 \mathrm{~Hz}, 2 \mathrm{~m}-\mathrm{C}$ ), 133.0 (s, $i-\mathrm{C}$ ), 178.2 (s, $\mathrm{CO}_{2} \mathrm{H}$ ). - The mother liquor contained $1.23 \mathrm{~g} \mathrm{S36}$ of $\mathrm{mp} 43-50{ }^{\circ} \mathrm{C}$. The use of pentane ${ }^{\mathrm{S} 17-\mathrm{S} 19}$ (rather than benzene ${ }^{\mathrm{S} 47}$ ) as a solvent was essential in this dedeuteration reaction of $\left[\mathrm{D}_{8}\right]$ toluene which is retarded by a kinetic isotope effect and hence not much faster than the deprotonation of benzene.

(Pentadeuteriophenyl)malonaldehyde (S44). In orientating experiments we noticed that double deprotonation of unlabeled phenylacetic acid at $-78{ }^{\circ} \mathrm{C}$ occurred more slowly than expected from the reported ${ }^{\mathrm{S} 48}$ procedure. However, this double deprotonation as well as the dedeuteration of $\mathbf{S 3 6}$ were fast at up to $+35^{\circ} \mathbf{C}$, as was shown by methylation test reactions. The following conditions ${ }^{\mathrm{S} 9}$ (but LiH instead of NaH, no LDA) led to the recovery of up to $50 \%$ of phenylacetic acid owing to fast proton or deuteron transfer from an intermediate (S42), as suggested by the total absence of deuterium from both olefinic positions in the enamine $\mathbf{S 4 1}$.

The labeled acid S36 (2.86 g, $20.0 \mathrm{mmol})$ in anhydrous THF (10 mL) was added dropwise with stirring to a slurry of lithium hydride (159 mg, $20.0 \mathrm{mmol}$ ) in THF (6 mL); this and all further manipulations down to hydrolysis were performed under a slow stream of dry argon. The immediate evolution of hydrogen gas was completed after 15 min under reflux. The resulting heavy white suspension was cooled in an icebath during the dropwise addition of $n$-butyllithium (20.0 mmol in $8.00 \mathrm{~mL}$ of hexane), producing a pale yellow slurry which was warmed to $+33^{\circ} \mathrm{C}$ internal temperature for $30 \mathrm{~min}$. At $-63{ }^{\circ} \mathrm{C}$, dry $N$-methylpyrrolidone $(13.5 \mathrm{~mL})$ in dry THF $(15 \mathrm{~mL})$ was added dropwise, keeping the internal temperature at below $-58{ }^{\circ} \mathrm{C}$, and the viscous $N$-(methoxymethylene)morpholinium methyl sulfate $(\mathbf{S 3 8}, 60.0 \mathrm{mmol})^{69}$ was introduced as fast as possible. The mixture, containing gummy pearls of coagulated S38, was kept in the cold bath during warmup to $-20{ }^{\circ} \mathrm{C}$, when stirring could be resumed upon the exothermic diminution or dissolution ${ }^{69}$ of the viscid precipitate. After further stirring (which may not always be possible due to precipitation of the viscid product) for $1 \mathrm{~h}$ at $+23^{\circ} \mathrm{C}$, solid sodium methoxide (3.24 g, $60 \mathrm{mmol}$ ) was added to the cooled mixture, which was stirred further for 5 min and then poured onto ice (75 g). Residual precipitate in the reaction flask was rinsed with distd. water into the iced fraction. This alkaline product mixture was extracted with $\mathrm{Et}_{2} \mathrm{O}(150+75+75 \mathrm{~mL})$. The combined $\mathrm{Et}_{2} \mathrm{O}$ extracts were washed until neutral, dried over $\mathrm{Na}_{2} \mathrm{SO}_{4}$, concentrated to dryness, and dried in vacuo over $\mathrm{KOH}$, yielding $2.30 \mathrm{~g}$ of crude material which contained heavily contaminated $N$-[2-(pentadeuteriophenyl)-1-ethenyl]morpholine (S41), as recognized from its two ${ }^{1} \mathrm{H}$ NMR olefinic doublets $\left({ }^{3} J_{\mathrm{HH}}=14 \mathrm{~Hz}\right) .{ }^{69}$ In view of its low stability, ${ }^{550}$ this enamine was not purified but was dissolved in dry $\mathrm{CH}_{2} \mathrm{Cl}_{2}(5.0 \mathrm{~mL})$ and added dropwise to an ice-cooled suspension of $N$ (chloromethylene)morpholinium chloride (S40, $10.0 \mathrm{mmol})^{70}$ in $\mathrm{CH}_{2} \mathrm{Cl}_{2}(10 \mathrm{~mL})$. After stirring for $2 \mathrm{~h}$ at room temperature, the large excess of reagent $\mathbf{S 4 0}$ was destroyed by dropwise addition of aqueous $\mathrm{HBF}_{4}(3.77 \mathrm{~mL}$, $30.0 \mathrm{mmol}$ ) with cooling in an icebath. The mixture was diluted with more $\mathrm{CH}_{2} \mathrm{Cl}_{2}(20 \mathrm{~mL})$, which dissolved the precipitated tetrafluoroborate of vinamidinium S39. The $\mathrm{CH}_{2} \mathrm{Cl}_{2}$ layer was washed with distd. water (3×), dried over $\mathrm{Na}_{2} \mathrm{SO}_{4}$, and concentrated to dryness. The residue on short boiling with ethanol (3.5 mL) formed white flakes of S39. $\mathrm{BF}_{4}^{-}$, which were collected and washed with cold ethanol: yield $467 \mathrm{mg}\left(6 \%\right.$ rel. $\mathrm{C}_{6} \mathrm{D}_{5}-\mathrm{CD}_{2}-$ $\left.\mathrm{CO}_{2} \mathrm{H}\right)$ : mp 241.5-243 ${ }^{\circ} \mathrm{C} ;{ }^{1} \mathrm{H}$ NMR $\left(\mathrm{CD}_{2} \mathrm{Cl}_{2}\right) \delta 2.86$ and 3.36 (2 quasi-t, $2+2 \mathrm{CH}_{2} \mathrm{~N}^{+}$), 3.71 (m, $4 \mathrm{CH}_{2} \mathrm{O}$ ), 7.76 (s, $2 \mathrm{NCH}=$ ), no aromatic resonances. Although S39 offered a very convenient opportunity of purification, it was not further analyzed because its following hydrolysis product is the labeled form of the known ${ }^{\mathrm{S} 35}$ phenylmalonaldehyde (S44). 
The vinamidinium (S39) tetrafluoroborate (467 mg, $1.23 \mathrm{mmol}$ ) in ethyleneglycol (6 mL) and conc. aqueous $\mathrm{NaOH}\left(50 \%, 3.3 \mathrm{~mL}\right.$ ) was stirred at $+63{ }^{\circ} \mathrm{C}$ for $2.5 \mathrm{~h}$, then poured onto ice and extracted with $\mathrm{Et}_{2} \mathrm{O}$, which was discarded. The aqueous layer (containing S43) was cooled in ice and acidified by the dropwise addition of conc. $\mathrm{HCl}$, then extracted with $\mathrm{Et}_{2} \mathrm{O}(3 \times)$. These combined $\mathrm{Et}_{2} \mathrm{O}$ extracts were washed with distd. water $(3 \times)$, dried over $\mathrm{Na}_{2} \mathrm{SO}_{4}$, concentrated to dryness, and dried in vacuo over $\mathrm{KOH}$, yielding $159 \mathrm{mg}$ (84\%) of S44: ${ }^{1} \mathrm{H} \mathrm{NMR}^{70}$ $\left(\mathrm{CDCl}_{3}\right) \delta 8.55(\mathrm{~s}, \mathrm{OCH}=)$, but no aromatic resonances.

(4-Methyl-1-bicyclo[2.2.2]octyl)acetic Acid $^{\text {S51 }}$ (S45). 4-Methoxy-1-methylbicyclo[2.2.2]octane (S61, 13.3 g, $86.2 \mathrm{mmol}$ ) was added dropwise with stirring to an ice-cooled mixture of conc. $\mathrm{H}_{2} \mathrm{SO}_{4}(25 \mathrm{~mL})$ and $\mathrm{BF}_{3} \cdot \mathrm{OEt}_{2}(2.0$ $\mathrm{mL}) .{ }^{\mathrm{S} 52}$ Keeping the internal temperature at below $+10^{\circ} \mathrm{C}$, 1,1-dichloroethene $(8.00 \mathrm{~mL}, 100 \mathrm{mmol})$ was added very slowly in $>1 \mathrm{~h}$, with stirring continued for $2 \mathrm{~h}$ in an ice bath and for $16 \mathrm{~h}$ at room temperature. With cooling in ice, another $4.00 \mathrm{~mL}(50 \mathrm{mmol})$ of $\mathrm{Cl}_{2} \mathrm{C}=\mathrm{CH}_{2}$ was added slowly, and after $22 \mathrm{~h}$ at room temperature this addition was repeated with a third charge. The mixture was poured on ice and extracted with several portions of diethyl ether. Addition of $\mathrm{NaOH}(25 \%$; $30 \mathrm{~mL})$ to the combined $\mathrm{Et}_{2} \mathrm{O}$ extracts caused precipitation of the weakly soluble sodium salt of S45, which may be dissolved by dilution. The sodium salt or its solution was washed with $\mathrm{Et}_{2} \mathrm{O}$, then acidified with aqueous $\mathrm{HCl}$ to afford the acid S45: yield $3.90 \mathrm{~g}(25 \%) ; \mathrm{mp} 81.5-83.5{ }^{\circ} \mathrm{C}$ (ref S51: 83-84 ${ }^{\circ} \mathrm{C}$ ); ${ }^{1} \mathrm{H}$ NMR $\left(\mathrm{CDCl}_{3}\right) \delta 0.78\left(\mathrm{~s}, \mathrm{CH}_{3}\right), 1.45$ (pseudo-d, $6 \mathrm{CH}_{2}$ ), 2.09 (s, $\left.\mathrm{CH}_{2}-\alpha\right), 10.0$ (br s, $\mathrm{CO}_{2} \mathrm{H}$ ).

The $\mathrm{Et}_{2} \mathrm{O}$ phases, containing the nonacidic side products $\mathbf{S 6 2}$ and $\mathbf{S 6 3}$, were concentrated to dryness and crystallized from pentane at low temperature, depositing up to 66\% of 1-chloro-4-methylbicyclo[2.2.2]octane (S62): mp 74.5-77 ${ }^{\circ} \mathrm{C}$ (ref S51: $\left.76-77^{\circ} \mathrm{C}\right) ;{ }^{1} \mathrm{H}$ NMR $\left(\mathrm{CDCl}_{3}\right) \delta 0.77\left(\mathrm{~s}, \mathrm{CH}_{3}\right), 1.51$ and 2.03 (2 pseudo-t, $\left.3+3 \mathrm{CH}_{2}\right)$. The mother liquor furnished colorless needles of 4-methylbicyclo[2.2.2]octan-1-ol (S63): mp 98-101 ${ }^{\circ} \mathrm{C}$ (ref S53: $102-103{ }^{\circ} \mathrm{C}$; $\operatorname{ref}$ S54: 101-102 $\left.{ }^{\circ} \mathrm{C}\right)$; ${ }^{1} \mathrm{H}$ NMR $\left(\mathrm{CDCl}_{3}\right) \delta 0.79$ (s, $\left.\mathrm{CH}_{3}\right), 1.19$ (s, OH), 1.56 (pseudo-s, 6 $\mathrm{CH}_{2}$ ), differing from the data given in ref S53. - The crude mixture of $\mathbf{S 6 2}$ and $\mathbf{S 6 3}$ may be recycled in the reaction with $\mathrm{Cl}_{2} \mathrm{C}=\mathrm{CH}_{2}$ to give $\mathbf{S} \mathbf{4 5}$ as described above.

$\mathrm{N}$-[2-(4-Methyl-1-bicyclo[2.2.2]octyl)-3-phenylimino-1-ethen-1-yl]morpholine (S47). Anhydrous diisopropylamine (2.82 mL, $20.0 \mathrm{mmol})$ in anhydrous THF $(10 \mathrm{~mL})$ under dry $\mathrm{N}_{2}$ gas was cooled in ice. The internal temperature was kept at below $+9{ }^{\circ} \mathrm{C}$ with stirring during the dropwise addition of $n$-butyllithium $(20.0 \mathrm{mmol}$ in $12.5 \mathrm{~mL}$ of hexane), further stirring of this LDA solution for $30 \mathrm{~min}$, and during the dropwise addition of a THF solution (20 mL) of (4-methyl-1-bicyclo[2.2.2]octyl)acetic acid (S45, $1.82 \mathrm{~g}, 10.0 \mathrm{mmol})$. After $1 \mathrm{~h}$ at room temperature, all volatile components were distilled off under 0.01 Torr. The solid residue was vented with dry $\mathrm{N}_{2}$ gas, then dissolved in anhydrous THF $(20 \mathrm{~mL})$, and cooled to $-70{ }^{\circ} \mathrm{C}$. $N$-(Methoxymethylene)morpholinium methyl sulfate $^{69}$ (S38, $30 \mathrm{mmol}$ ) was added dropwise. The mixture was warmed up slowly to room temperature, stirred for $16 \mathrm{~h}$, poured onto an excess of $2 \mathrm{M} \mathrm{NaOH}$ containing ice, and stirred for $30 \mathrm{~min}$ at ice temperature. Extraction with diethyl ether and concentration of the washed and dried $\left(\mathrm{Na}_{2} \mathrm{SO}_{4}\right)$ extracts afforded the air-labile, pale yellow enamine S47: yield $1.76 \mathrm{~g}$ (75\%); bp 105-110 ${ }^{\circ} \mathrm{C}$ (bath temp.)/0.001 Torr; mp 29.5-31 ${ }^{\circ} \mathrm{C} ;{ }^{\mathrm{s} 42} \mathrm{IR}$ (film) 2920, 2855, 1652, 1452, 1381, 1213, 1205, 1122, 1021, 941, and $868 \mathrm{~cm}^{-1}$; UV-vis (dioxane) $\lambda_{\max } 224 \mathrm{~nm}$ (lg $\varepsilon=3.93)$, sh 285 (1.87); ${ }^{1} \mathrm{H}$ NMR $\left(\mathrm{CDCl}_{3}\right) \delta 0.77$ (s, $\left.\mathrm{CH}_{3}\right), 1.41$ (pseudo-s, 6 bicyclo- $\left.\mathrm{CH}_{2}\right), 2.72\left(\mathrm{~m}, 2 \mathrm{CH}_{2} \mathrm{~N}\right.$ ), 3.70 (m, $2 \mathrm{CH}_{2} \mathrm{O}$ ), 4.38 (d, ${ }^{3} \mathrm{~J}=14.7 \mathrm{~Hz}$, olefin. 2-H, no deuterium!), 5.63 (d, ${ }^{3} J=14.7 \mathrm{~Hz}$, olefin. 1-H); Anal. 
Calcd for $\mathrm{C}_{15} \mathrm{H}_{25} \mathrm{NO}$ (235.4): C, 76.55; H, 10.71; N, 5.95. Found: ${ }^{\mathrm{S} 42}$ C, 76.59; H, 10.71; N, 5.95.

(4-Methyl-1-bicyclo[2.2.2]octyl)malonaldehyde (S48). The enamine $\mathbf{S 4 7}$ (1.76 g, $7.50 \mathrm{mmol})$ in dry $\mathrm{CH}_{2} \mathrm{Cl}_{2}$ $(10 \mathrm{~mL})$ was added dropwise to a stirred suspension of $N$-(chloromethylene)morpholinium chloride ${ }^{70}$ (S40, 10 $\mathrm{mmol})$ in dry $\mathrm{CH}_{2} \mathrm{Cl}_{2}(10 \mathrm{~mL})$, cooled in ice. The mixture was stirred for $30 \mathrm{~min}$, kept tightly closed in a refrigerator for $16 \mathrm{~h}$, thereafter poured onto ice, stirred for $2 \mathrm{~h}$ in an icebath, and alkalized with $2 \mathrm{M} \mathrm{NaOH}$. Basic and neutral products were extracted into diethyl ether and discarded. The aqueous layer was acidified and extracted with several portions of diethyl ether, which were combined, washed until neutral, dried briefly over $\mathrm{Na}_{2} \mathrm{SO}_{4}$, and concentrated to leave pure S48 as a pale yellow oil: yield $280 \mathrm{mg}(19 \%) ;{ }^{1} \mathrm{H}$ NMR $\left(\mathrm{CDCl}_{3}\right) \delta 0.80\left(\mathrm{~s}, \mathrm{CH}_{3}\right), 1.50$ (pseudo-s, $3 \mathrm{CH}_{2}$ ), 1.59 (pseudo-s, $3 \mathrm{CH}_{2}$ ), 8.38 (s, $2 \mathrm{CHO}$ ), 14.2 (br, $\mathrm{OH}$ ). The constitution of S48 was confirmed by conversion to vinamidine $\mathbf{1 3 H}$ with $91 \%$ yield.

\section{Almost Unimpeded $N$-Aryl Rotation in $7 \mathrm{Ni}$ and $8 \mathrm{Ni}$}

A striking illustration of frozen $N$-aryl rotation has been published ${ }^{18}$ for $\mathbf{1 8 N i}$ with $N$-(o-methylphenyl) groups that cannot rotate past the vicinal $\mathrm{R}^{1}=\mathrm{R}^{3}=\mathrm{CH}_{3}$ substituents, while their torsional motion through $\varphi=90^{\circ}$ should still be fast. As a consequence, five $p$-hydrogen, ten $m$-hydrogen, four $o$-methyl, four $1,3-\mathrm{CH}_{3}$, and further split signals were observed ${ }^{18}$ at $+31{ }^{\circ} \mathrm{C}$, pointing to the presence of at least two (out of four) diastereomers. In contrast, the $N$-(m-methylphenyl) groups in $\mathbf{1 7 N i}$ exhibited only one ${ }^{1} \mathrm{H}$ NMR resonance at $+34{ }^{\circ} \mathrm{C}$ for each constitutionally different proton (especially $\left.o-\mathrm{H} \neq o^{\prime}-\mathrm{H}\right)^{18}$ and thus are capable of fast $180^{\circ} N$-aryl jumps past 1- $\mathrm{CH}_{3}$ or 3- $\mathrm{CH}_{3}$. Clearly, the same $\mathrm{N}$ - $(\mathrm{m}$-methylphenyl) groups present in $7 \mathrm{Ni}$ should rotate even faster past the adjacent $\mathrm{R}^{1}=\mathrm{R}^{3}=\mathrm{H}$ instead of $\mathrm{CH}_{3}$. Indeed, we could repeat and confirm the observations ${ }^{12, \mathrm{S5}, \mathrm{S} 7}$ of one ${ }^{1} \mathrm{H}$ NMR resonance per proton species in $7 \mathrm{Ni}$ below $-40^{\circ} \mathrm{C}$ and of a common two-proton signal for $o-\mathrm{H}$ and $o^{\prime}-\mathrm{H}$ above that temperature (Table S8). The latter phenomenon is unexpected for two constitutionally nonequivalent protons with slightly different $\Delta \rho_{\mathrm{DFT}}$ values (and hence, contact shifts). Thus the phenomenon cannot be caused by the postulated ${ }^{12, S 5, S 7}$ hindered $N$-aryl rotation in $\mathbf{7 N i}$, and it is not easily assessed due to the narrow temperature range. But with the related bis(chelate) $8 \mathbf{N i}\left(\mathrm{R}^{3}=\mathrm{R}^{1}=\mathrm{H}, \mathrm{R}^{2}=\mathrm{R}^{\alpha}=\mathrm{Ph}\right)$ we could trace the $o-\mathrm{H} / o^{\prime}-\mathrm{H}$ splitting from -61 to $-10^{\circ} \mathrm{C}$, whereupon it became clear that conversion of the signal pair to an apparent single absorption was caused not by an unplausible “coalescence” but by $\Delta \delta^{\mathrm{OBS}}$ decreasing much faster than $1 / T$ (Table S9), combined with a large linewidth (comparable to $\Delta \delta^{\mathrm{OBS}}$ ) that thwarted the $o-\mathrm{H} / o^{\prime}-\mathrm{H}$ differentiation upon warming of $\mathbf{7 N i}$ and $\mathbf{8 N i}$. The phenomenon may now be ascribed to temperature-dependent population changes in a rapidly equilibrating ensemble of $N$-aryl conformational combinations with metal-centered pseudocontact shift differences larger than $\Delta \delta^{\mathrm{MPC}} \approx 23.7 \mathrm{ppm}$ for $o-\mathrm{H} / o^{\prime}-\mathrm{H}$ (Table S2, entries S2.12-S2.13). This explanation requires fast $\mathrm{N}$-aryl rotation with mobile equilibria between conformations having small but non-zero energy differences, in analogy with the conditions for the well known Isotopic Perturbation Method. ${ }^{\text {S55 }}$ 


\section{Tables S4-S46 of the NMR Shifts at Varied Temperatures}

Table S4. ${ }^{1} \mathrm{H}$ NMR Parameters (in ppm) $\delta^{\mathrm{DIA}}, \delta^{\mathrm{OBS}}, \delta^{\mathrm{PARA}}, \delta^{\mathrm{MCD}}$, and $\vartheta^{\mathrm{CON}} \approx \vartheta^{\mathrm{C}+\mathrm{L}}$ of the Bis(chelate) $6 \mathrm{Co}^{\text {in } \mathrm{Cl}_{2} \mathrm{CD}-\mathrm{CDCl}} \mathrm{Cr}_{2}$ or $\mathrm{CDCl} 3$ Solution as a Function of the Temperature

\begin{tabular}{|c|c|c|c|c|c|c|c|c|c|c|c|c|}
\hline \multirow{2}{*}{$\begin{array}{l}\text { nucleus } \\
\text { (line no.) }\end{array}$} & \multirow{2}{*}{$\begin{array}{l}\mathbf{6 H} \\
\delta^{\mathrm{DIA}}\end{array}$} & \multirow[t]{2}{*}{ 6Co } & \multicolumn{10}{|c|}{ temperature $\left[{ }^{\circ} \mathrm{C}\right]$} \\
\hline & & & $-36.0^{a}$ & $+19.5^{a}$ & $+26.8^{a}$ & $+28.0^{a}$ & +29.0 & $+43.5^{a}$ & +59.0 & $+65.3^{a}$ & +93.0 & +122.0 \\
\hline \multirow[t]{3}{*}{$\mathrm{H}\left(\alpha^{\prime}\right)$} & 7.60 & $\delta^{\mathrm{OBS}}$ & - & +491.2 & - & +466.7 & - & - & - & - & - & - \\
\hline & & $\delta^{\mathrm{MCD}}$ & - & +21.02 & - & +20.30 & - & - & - & - & - & - \\
\hline & & $\vartheta^{\mathrm{CON}}$ & - & +454.36 & - & +443.51 & - & - & - & - & - & - \\
\hline \multirow[t]{2}{*}{$N-m-\mathrm{CH}_{3}$} & 2.30 & $\delta^{\mathrm{OBS}}$ & -9.88 & -7.54 & -7.20 & -7.20 & -6.92 & -6.70 & -6.10 & -6.20 & -5.61 & -5.00 \\
\hline & & $\delta^{\mathrm{MCD}}$ & -3.82 & -2.95 & -2.86 & -2.85 & -2.83 & -2.68 & -2.53 & -2.47 & -2.25 & -2.06 \\
\hline (line 39) & & $\vartheta^{\mathrm{CON}}$ & -6.65 & -6.77 & -6.69 & -6.73 & -6.48 & -6.72 & -6.55 & -6.85 & -6.95 & -6.95 \\
\hline \multirow[t]{3}{*}{$N-p-\mathrm{H}$} & 6.66 & $\delta^{\mathrm{OBS}}$ & -27.90 & -20.8 & -20.3 & -20.1 & -18.8 & $\begin{array}{l}-18.8 \\
\end{array}$ & -16.93 & $\begin{array}{l}-17.0 \\
\end{array}$ & -15.0 & $\begin{array}{l}-13.3 \\
\end{array}$ \\
\hline & & $\delta^{\text {PARA }}$ & -34.56 & -27.46 & -26.96 & -26.76 & -25.47 & -25.46 & -23.59 & -23.66 & -21.66 & -19.96 \\
\hline & & $\delta^{\mathrm{MCD}}$ & -5.16 & -3.98 & -3.86 & -3.84 & -3.83 & -3.61 & -3.41 & -3.34 & -3.04 & -2.78 \\
\hline \multirow{2}{*}{$N-O-\mathrm{H}$} & & $\delta^{\mathrm{MCD}}$ & - & -19.02 & -18.46 & -18.37 & -18.30 & -17.29 & -16.33 & -15.97 & -14.54 & -13.30 \\
\hline & & $\vartheta^{\mathrm{CON}}$ & - & -20.76 & -26.67 & -26.47 & -27.34 & -23.88 & -25.00 & -24.87 & -25.21 & -22.49 \\
\hline \multirow[t]{3}{*}{$\mathrm{H}(\alpha)$} & 5.03 & $\delta^{\mathrm{OBS}}$ & -85.20 & -69.0 & -67.0 & -67.1 & $-65.2^{b}$ & $\begin{array}{l}-64.7 \\
\end{array}$ & -59.4 & -59.5 & -53.8 & -49.5 \\
\hline & & $\delta^{\text {PARA }}$ & -90.23 & -74.03 & -72.03 & -72.13 & -70.23 & -69.73 & -64.43 & -64.53 & -58.83 & -54.53 \\
\hline & & $\delta^{\mathrm{MCD}}$ & +35.73 & +27.55 & +26.74 & +26.61 & +26.51 & +25.05 & +23.65 & +23.13 & +21.07 & +19.26 \\
\hline (line 23) & & $\vartheta^{\mathrm{CON}}$ & -100.26 & +99.78 & -99.43 & -99.80 & -98.10 & -100.73 & -98.19 & -99.57 & -98.18 & -97.86 \\
\hline $1000 /$ (tem & erature & K) & 4.216 & 3.416 & 3.333 & 3.320 & 3.309 & 3.158 & 3.010 & 2.954 & 2.731 & 2.530 \\
\hline
\end{tabular}

${ }^{a} \mathrm{In} \mathrm{CDCl}_{3} \cdot{ }^{b} \pm 2 \mathrm{ppm}$. 
Table S5. ${ }^{13} \mathrm{C}$ NMR Parameters (in ppm) $\delta^{\mathrm{DIA}}, \delta^{\mathrm{OBS}}, \delta^{\mathrm{PARA}}, \delta^{\mathrm{MCD}}$, and $\vartheta^{\mathrm{CON}} \approx \vartheta^{\mathrm{C}+\mathrm{L}}$ of the Bis(chelate) $6 \mathrm{Co}$ in $\mathrm{Cl}_{2} \mathrm{CD}-\mathrm{CDCl}_{2}$ Solution as a Function of the Temperature

\begin{tabular}{|c|c|c|c|c|c|}
\hline \multirow{2}{*}{$\begin{array}{l}\text { nucleus } \\
\text { (line no.) }\end{array}$} & \multirow{2}{*}{$\begin{array}{l}\mathbf{6 H} \\
\delta^{\mathrm{DIA}}\end{array}$} & \multirow[t]{2}{*}{ 6Co } & \multicolumn{3}{|c|}{ temperature $\left[{ }^{\circ} \mathrm{C}\right]$} \\
\hline & & & +34.0 & $+65.0^{a}$ & +101.0 \\
\hline \multirow[t]{3}{*}{$\mathrm{N}$-o-C } & $116.0^{b}$ & $\delta^{\mathrm{OBS}}$ & $+611.5^{c}$ & $+561.4^{c}$ & $+518.2^{c}$ \\
\hline & & $\delta^{\text {PARA }}$ & +495.5 & +445.4 & +402.2 \\
\hline & & & -18.99 & -16.92 & -15.01 \\
\hline (line 45) & & $\vartheta^{\mathrm{CON}}$ & +530.38 & +524.69 & +523.89 \\
\hline \multirow[t]{4}{*}{$N-i-\mathrm{C}$} & $146.7^{d}$ & $\delta^{\mathrm{OBS}}$ & +374.1 & $+352.1^{e}$ & $+331.9^{e}$ \\
\hline & & $\delta^{\text {PARA }}$ & +227.4 & +205.4 & +185.2 \\
\hline & & $\delta^{\mathrm{MCD}}$ & -29.05 & -25.88 & -22.96 \\
\hline & & $\vartheta^{\mathrm{CON}}$ & +264.37 & +262.48 & +261.38 \\
\hline \multirow[t]{4}{*}{$N-p-C$} & $125.3^{f}$ & $\delta^{\mathrm{OBS}}$ & $+276.5^{g}$ & $+263.0^{h}$ & $+250.7^{g}$ \\
\hline & & $\delta^{\text {PARA }}$ & +151.2 & +137.7 & +125.4 \\
\hline & & $\delta^{\mathrm{MCD}}$ & -6.35 & -5.66 & -5.02 \\
\hline & & $\vartheta^{\mathrm{CON}}$ & +162.42 & +162.70 & +163.77 \\
\hline \multirow[t]{4}{*}{$N-m-C$} & $138.9^{i}$ & $\delta^{\mathrm{OBS}}$ & $+58.8^{j}$ & $+64.7^{k}$ & $+71.0^{j}$ \\
\hline & & $\delta^{\text {PARA }}$ & -80.1 & -74.2 & -67.9 \\
\hline & & $\delta^{\mathrm{MCD}}$ & -8.05 & -7.18 & -6.36 \\
\hline & & $\vartheta^{\mathrm{CON}}$ & -74.27 & -76.07 & -77.27 \\
\hline \multirow[t]{3}{*}{$\mathrm{N}-\mathrm{m}-\mathrm{CH}_{3}$} & $21.4^{l}$ & $\delta^{\mathrm{OBS}}$ & $+50.0^{j}$ & $+47.1^{m}$ & $+44.9^{j}$ \\
\hline & & $\delta^{\text {PARA }}$ & +28.6 & +25.7 & +23.5 \\
\hline & & $\delta^{\mathrm{MCD}}$ & -3.69 & -3.29 & -2.92 \\
\hline (line 17) & & $\vartheta^{\mathrm{CON}}$ & +33.29 & +32.90 & +33.17 \\
\hline \multicolumn{3}{|c|}{ 1000/(temperature in K) } & 3.255 & 2.957 & 2.672 \\
\hline
\end{tabular}

${ }^{a}{ }^{1} \mathrm{H}$ coupled. $\quad{ }^{b} \mathrm{~d},{ }^{1} J_{\mathrm{CH}}=157 \mathrm{~Hz} . \quad{ }^{c} \pm 2 \mathrm{ppm} . \quad{ }^{d} \mathrm{t},{ }^{2} J_{\mathrm{CH}}=7.5 \mathrm{~Hz} . \quad{ }^{e} \pm 3$ ppm. ${ }^{f}$ d, ${ }^{1} J_{\mathrm{CH}}=156 \mathrm{~Hz} .{ }^{g} \pm 1 \mathrm{ppm} .{ }^{h} \mathrm{~d},{ }^{1} J_{\mathrm{CH}} \approx 150 \mathrm{~Hz} .{ }^{i} \mathrm{t},{ }^{2} J_{\mathrm{CH}}=6.5 \mathrm{~Hz}$. ${ }^{j} \pm 0.5 \mathrm{ppm} .{ }^{k}$ Narrow singlet. ${ }^{l} \mathrm{q},{ }^{1} J_{\mathrm{CH}}=126 \mathrm{~Hz} .{ }^{m} \mathrm{q},{ }^{1} J_{\mathrm{CH}} \approx 110 \mathrm{~Hz}$. 
Table S6. ${ }^{1} \mathrm{H}$ NMR Parameters (in ppm) $\delta^{\mathrm{DIA}}, \delta^{\mathrm{OBS}}, \delta^{\mathrm{PARA}}, \delta^{\mathrm{MCD}}$, and $\vartheta^{\mathrm{CON}} \approx \vartheta^{\mathrm{C}+\mathrm{L}}$ of the Bis(chelate) $\mathbf{6 N i}$ in $\mathrm{Cl}_{2} \mathrm{CD}-\mathrm{CDCl}_{2}$ (or other) Solution as a Function of the Temperature

\begin{tabular}{|c|c|c|c|c|c|c|c|c|c|c|c|c|c|c|c|c|c|c|c|c|}
\hline \multirow{2}{*}{$\begin{array}{l}\text { nucleus } \\
\text { (line no.) }\end{array}$} & \multirow{2}{*}{$\begin{array}{l}\mathbf{6 H} \\
\delta^{\mathrm{DIA}} \\
\end{array}$} & \multirow[t]{2}{*}{$6 \mathrm{Ni}$} & \multicolumn{18}{|c|}{ temperature $\left[{ }^{\circ} \mathrm{C}\right]$} \\
\hline & & & $-84.0^{a}$ & $-72.5^{a}$ & $-64.0^{b}$ & $-63.0^{a}$ & -56.5 & $-52.0^{c}$ & -47.0 & $-36.0^{b}$ & $-31.0^{c}$ & -24.5 & $+19.5^{b}$ & +27.0 & $+28.0^{b}$ & $+28.0^{a}$ & $+28.0^{c}$ & +81.5 & $+93.0^{c}$ & +123.0 \\
\hline \multirow[t]{3}{*}{$\mathrm{H}\left(\alpha^{\prime}\right)$} & 7.60 & $\delta^{\mathrm{OBS}}$ & $+539.7^{d}$ & $+517.5^{d}$ & - & $+494.4^{d}$ & $+479.2^{d}$ & - & $+459.1^{e}$ & $+435.9^{e}$ & $+434.5^{e}$ & $+422.5^{e}$ & $e+370.4$ & $+355.7^{e}$ & $+355.6^{e}$ & $+355.4^{e}$ & $e+355.9^{e}$ & $+303.5^{e}$ & $+294.7^{e}$ & $+273.4^{e}$ \\
\hline & & $\delta^{\text {PARA }}$ & +532.1 & +509.9 & - & +486.8 & +471.6 & - & +451.5 & +428.3 & +426.9 & +414.9 & +362.80 & $0+348.1$ & +348.0 & +347.8 & +348.3 & +295.9 & +287.1 & +265.8 \\
\hline & & $\delta^{\mathrm{MCD}}$ & -24.39 & -22.59 & - & -21.29 & -20.48 & - & -19.39 & -18.26 & -17.79 & -17.21 & $1-14.08$ & $3-13.65$ & -13.60 & -13.60 & $0 \quad-13.60$ & -11.17 & -10.76 & -9.81 \\
\hline (line 7) & & $\vartheta^{\mathrm{CON}}$ & +353.31 & +358.63 & - & +358.39 & +357.83 & - & +357.43 & +355.45 & +361.42 & $2+360.62$ & $2+370.18$ & $8+364.42$ & $2+365.48$ & +365.28 & $8+365.78$ & +365.50 & $0+366.03$ & $3+366.43$ \\
\hline \multirow[t]{3}{*}{$N-m-\mathrm{CH}_{3}$} & 2.30 & $\delta^{\mathrm{OBS}}$ & -6.58 & -6.23 & -5.77 & -5.87 & -5.37 & -5.53 & -5.08 & -4.88 & -4.93 & -4.58 & -3.85 & -3.60 & -3.67 & -3.62 & -3.68 & -2.80 & -2.67 & -2.27 \\
\hline & & $\delta^{\text {PARA }}$ & -8.88 & -8.53 & -8.07 & -8.17 & -7.67 & -7.83 & -7.38 & -7.18 & -7.23 & -6.88 & -6.15 & -5.90 & -5.97 & -5.92 & -5.98 & -5.10 & -4.97 & -4.57 \\
\hline & & $\delta^{\mathrm{MCD}}$ & +3.48 & +3.22 & $2+3.05$ & +3.04 & +2.92 & +2.85 & +2.77 & +2.60 & +2.54 & +2.45 & +2.01 & +1.95 & +1.94 & +1.94 & +1.94 & +1.59 & +1.53 & +1.40 \\
\hline (line 40) & & $\vartheta^{\mathrm{CON}}$ & -7.85 & -7.92 & -7.81 & -7.90 & -7.70 & -7.92 & -7.70 & -7.79 & -7.94 & -7.79 & -8.01 & -7.91 & -7.99 & -7.94 & -8.00 & -7.97 & -7.99 & -7.94 \\
\hline \multirow[t]{4}{*}{$N-O-\mathrm{H}$} & 6.66 & $\delta^{\mathrm{OBS}}$ & -17.6 & -16.3 & -15.3 & -15.3 & - & -14.0 & -12.2 & -12.5 & -12.5 & -11.0 & -9.83 & -8.77 & -9.22 & -9.40 & -9.15 & -6.55 & -6.22 & -5.10 \\
\hline & & $\delta^{\text {PARA }}$ & -24.26 & -22.96 & -21.96 & -21.96 & - & -20.66 & -18.86 & -19.16 & -19.16 & $5-17.66$ & $6-16.49$ & -15.43 & -15.88 & -16.06 & $\begin{array}{ll}6 & -15.81\end{array}$ & -13.21 & $1-12.88$ & -11.76 \\
\hline & & $\delta^{\mathrm{MCD}}$ & +23.76 & +22.01 & $1+20.87$ & +20.74 & - & +19.43 & +18.89 & +17.79 & +17.33 & $3+16.77$ & $7+13.72$ & $2+13.30$ & +13.25 & +13.25 & $5+13.25$ & +10.88 & $8+10.48$ & +9.55 \\
\hline & & $\vartheta^{\mathrm{CON}}$ & -30.49 & -30.29 & -30.06 & -30.12 & - & -29.76 & -28.65 & -29.41 & -29.66 & $5-28.73$ & $3-29.67$ & $7 \quad-28.94$ & -29.44 & -29.62 & $2-29.37$ & -28.68 & $3-28.71$ & -28.34 \\
\hline \multirow[t]{3}{*}{$N-p-\mathrm{H}$} & 6.66 & $\delta^{\mathrm{OBS}}$ & -24.9 & -23.5 & -22.2 & -22.2 & -20.0 & -20.4 & -19.0 & -18.1 & -18.3 & -17.1 & -14.46 & $\begin{array}{ll}5 & -13.4\end{array}$ & -13.7 & -13.7 & -13.5 & -10.5 & -10.0 & -8.63 \\
\hline & & $\delta^{\mathrm{PARA}}$ & -31.56 & -30.16 & -28.86 & -28.86 & -26.66 & -27.06 & -25.66 & -24.76 & -24.96 & $5-23.76$ & $\begin{array}{ll}6 & -21.12\end{array}$ & -20.06 & -20.36 & -20.36 & -20.16 & -17.16 & -16.66 & -15.29 \\
\hline & & $\delta^{\mathrm{MCD}}$ & +4.82 & +4.46 & $5+4.23$ & +4.20 & +4.04 & +3.94 & +3.83 & +3.61 & +3.51 & +3.40 & +2.78 & +2.70 & +2.69 & +2.69 & +2.69 & +2.21 & +2.12 & +1.94 \\
\hline (line 77) & & $\vartheta^{\mathrm{CON}}$ & -23.10 & -23.32 & -23.23 & -23.32 & -22.33 & -23.01 & -22.38 & -22.58 & -23.14 & $4-22.67$ & $\begin{array}{ll}7 & -23.48\end{array}$ & 3 -22.92 & -23.29 & -23.29 & $9-23.09$ & -23.05 & $5 \quad-23.08$ & -22.90 \\
\hline \multirow[t]{3}{*}{$\mathrm{H}(\alpha)$} & 5.03 & $\delta^{\mathrm{OBS}}$ & -197.5 & -185.0 & - & -177.4 & -168.1 & - & -159.3 & -149.0 & -150.4 & -143.7 & -123.8 & -118.6 & -118.8 & -118.5 & -120.0 & -99.1 & -96.1 & -86.9 \\
\hline & & $\delta^{\text {PARA }}$ & -202.53 & -190.03 & - & -182.43 & -173.13 & - & -164.33 & -154.03 & -155.43 & $3-148.73$ & $3-128.83$ & $3-123.63$ & -123.83 & -123.53 & $3-125.03$ & -104.13 & $3-101.13$ & -91.93 \\
\hline & & $\delta^{\mathrm{MCD}}$ & -31.52 & -29.20 & - & -27.51 & -26.46 & - & -25.06 & -23.60 & -22.99 & -22.24 & $4-18.20$ & -17.64 & -17.57 & -17.57 & $\begin{array}{ll}7 & -17.57\end{array}$ & -14.44 & $4-13.90$ & -12.67 \\
\hline (line 23) & & $\vartheta^{\mathrm{CON}}$ & -108.57 & -108.32 & - & -109.27 & -106.65 & - & -105.71 & -103.82 & -107.64 & $4-105.56$ & $6-108.67$ & $7-106.77$ & -107.40 & -107.09 & $9-108.61$ & -106.75 & $5-107.19$ & -105.37 \\
\hline 1000/(tem & nperatu & Ire in $\mathrm{K}$ ) & 5.285 & 4.983 & 4.780 & 4.757 & 4.615 & 4.521 & 4.421 & 4.216 & 4.129 & 4.021 & 3.416 & 3.331 & 3.320 & 3.320 & 3.320 & 2.819 & 2.731 & 2.524 \\
\hline
\end{tabular}

${ }^{a}$ In $\mathrm{CS}_{2} .{ }^{b}$ In $\mathrm{CDCl}_{3} .{ }^{c}$ In toluene. ${ }^{d} \pm 3 \mathrm{ppm} .{ }^{e} \pm 2 \mathrm{ppm}$. 
Table S7. ${ }^{13} \mathrm{C}$ NMR Parameters (in ppm) $\delta^{\mathrm{DIA}}, \delta^{\mathrm{OBS}}, \delta^{\mathrm{PARA}}, \delta^{\mathrm{MCD}}$, and $\vartheta^{\mathrm{CON}} \approx \vartheta^{\mathrm{C}+\mathrm{L}}$ of the Bis(chelate) $\mathbf{6 N i}$ in $\mathrm{Cl}_{2} \mathrm{CD}-\mathrm{CDCl}_{2}$ Solution as a Function of the Temperature

\begin{tabular}{|c|c|c|c|c|c|c|c|}
\hline \multirow{2}{*}{$\begin{array}{l}\text { nucleus } \\
\text { (line no.) }\end{array}$} & \multirow{2}{*}{$\begin{array}{l}\mathbf{6 H} \\
\delta^{\text {DIA }}\end{array}$} & \multirow[t]{2}{*}{$6 \mathrm{Ni}$} & \multicolumn{5}{|c|}{ temperature $\left[{ }^{\circ} \mathrm{C}\right]$} \\
\hline & & & $-31.0^{a}$ & +27.0 & +34.0 & $+65.0^{b}$ & +101.0 \\
\hline \multirow[t]{3}{*}{$\mathrm{C}(2)$} & $96.3^{c}$ & $\delta^{\mathrm{OBS}}$ & $+720.0^{d}$ & +607.7 & $+588.2^{d}$ & $+541.0^{e}$ & $+499.2^{d}$ \\
\hline & & $\delta^{\text {PARA }}$ & +623.7 & +511.4 & +491.9 & +444.7 & +402.9 \\
\hline & & $\delta^{\mathrm{MCD}}$ & -54.50 & -41.82 & -40.67 & -36.23 & -32.13 \\
\hline (line 3) & & $9^{\mathrm{CON}}$ & +551.21 & +557.31 & +549.01 & +545.81 & +546.27 \\
\hline \multirow[t]{3}{*}{$\mathrm{N}-\mathrm{O}-\mathrm{C}$} & $116.0^{f}$ & $\delta^{\mathrm{OBS}}$ & $+685.7^{g}$ & +573.6 & $+565.2^{g}$ & $+522.9^{g}$ & $+485.8^{g}$ \\
\hline & & $\delta^{\text {PARA }}$ & +569.7 & +457.6 & +449.2 & +406.9 & +369.8 \\
\hline & & $\delta^{\mathrm{MCD}}$ & +17.61 & +13.51 & +13.14 & +11.70 & +10.38 \\
\hline (line 5) & & $\vartheta^{\mathrm{CON}}$ & +448.71 & +447.37 & +449.52 & +448.51 & +451.33 \\
\hline \multirow[t]{3}{*}{$N-i-C$} & $146.7^{h}$ & $\delta^{\mathrm{OBS}}$ & +498.9 & +418.9 & +418.0 & $+392.0^{i}$ & +369.8 \\
\hline & & $\delta^{\text {PARA }}$ & +352.2 & +272.2 & +271.3 & +245.3 & +223.1 \\
\hline & & $\delta^{\mathrm{MCD}}$ & +28.09 & +21.55 & +20.96 & +18.67 & +16.56 \\
\hline (line 47) & & $\vartheta^{\mathrm{CON}}$ & +263.42 & +252.50 & +258.07 & +257.20 & +259.36 \\
\hline \multirow[t]{3}{*}{$N-p-\mathrm{C}$} & $125.3^{j}$ & $\delta^{\mathrm{OBS}}$ & +312.3 & $+276.9^{j}$ & +273.8 & $+260.0^{k}$ & +248.1 \\
\hline & & $\delta^{\text {PARA }}$ & +187.0 & +151.6 & +148.5 & +134.7 & +122.8 \\
\hline & & $\delta^{\mathrm{MCD}}$ & +6.01 & +4.62 & +4.49 & +4.00 & +3.55 \\
\hline (line 14) & & $\vartheta^{\mathrm{CON}}$ & +147.10 & +148.07 & +148.46 & +148.33 & +149.75 \\
\hline \multirow[t]{3}{*}{$N-m-\mathrm{C}$} & $138.9^{l}$ & $\delta^{\mathrm{OBS}}$ & $+41.2^{m}$ & $+57.1^{n}$ & $+60.0^{m}$ & $+67.1^{i}$ & $+73.9^{m}$ \\
\hline & & $\delta^{\text {PARA }}$ & -97.7 & -81.8 & -78.9 & -71.8 & -65.0 \\
\hline & & $\delta^{\mathrm{MCD}}$ & +7.65 & -5.87 & +5.71 & +5.08 & +4.51 \\
\hline (line 22) & & $\vartheta^{\mathrm{CON}}$ & -85.62 & -88.32 & -87.22 & -87.26 & -87.28 \\
\hline \multirow[t]{3}{*}{$\mathrm{N}-\mathrm{m}-\mathrm{CH}_{3}$} & $21.4^{\circ}$ & $\delta^{\mathrm{OBS}}$ & $+65.1^{m}$ & $+56.6^{n}$ & $+55.7^{m}$ & $+52.2^{\circ}$ & $+49.4^{m}$ \\
\hline & & $\delta^{\text {PARA }}$ & +43.7 & +35.2 & +34.3 & +30.8 & +28.0 \\
\hline & & $\delta^{\mathrm{MCD}}$ & +3.42 & +2.63 & +2.55 & +2.28 & +2.02 \\
\hline (line 17) & & $\vartheta^{\mathrm{CON}}$ & +32.73 & +32.81 & +32.73 & +32.37 & +32.63 \\
\hline \multirow[t]{3}{*}{$\overline{C(1,3)}$} & $148.6^{p}$ & $\delta^{\mathrm{OBS}}$ & $-557.0^{g}$ & -403.3 & $-388.9^{g}$ & $-331.9^{g}$ & $-280.2^{g}$ \\
\hline & & $\delta^{\text {PARA }}$ & -705.6 & -551.9 & -537.5 & -480.5 & -428.8 \\
\hline & & $\delta^{\mathrm{MCD}}$ & -56.19 & -43.11 & -41.93 & -37.35 & -33.12 \\
\hline (line 27) & & $\vartheta^{\mathrm{CON}}$ & -527.81 & -512.54 & -510.87 & -502.93 & -496.86 \\
\hline \multicolumn{3}{|c|}{ 1000/(temperature in K) } & 4.129 & 3.331 & 3.255 & 2.957 & 2.672 \\
\hline
\end{tabular}


Table S8. ${ }^{1} \mathrm{H}$ NMR Parameters (in ppm) $\delta^{\mathrm{DIA}}, \delta^{\mathrm{OBS}}, \delta^{\mathrm{PARA}}, \delta^{\mathrm{MCD}}$, and $\vartheta^{\mathrm{CON}} \approx \vartheta^{\mathrm{C}+\mathrm{L}}$ of the Bis(chelate) $7 \mathrm{Ni}$ in $\mathrm{Cl}_{2} \mathrm{CD}-\mathrm{CDCl}{ }_{2}$ (or other) Solution as a Function of the Temperature

\begin{tabular}{|c|c|c|c|c|c|c|c|c|c|c|c|c|c|c|c|c|}
\hline \multirow{2}{*}{$\begin{array}{l}\text { nucleus } \\
\text { (line no.) }\end{array}$} & \multirow{2}{*}{$\begin{array}{l}7 \mathbf{H} \\
\delta^{\text {DIA }}\end{array}$} & \multirow[t]{2}{*}{$7 \mathrm{Ni}$} & \multicolumn{14}{|c|}{ temperature $\left[{ }^{\circ} \mathrm{C}\right]$} \\
\hline & & & -72.5 & -63.5 & $-63.5^{a}$ & $-52.0^{b}$ & $-36.0^{b}$ & $-36.0^{a}$ & -18.0 & +28.0 & $+28.0^{a}$ & $+28.0^{C}$ & $+28.0^{b}$ & +80.0 & $+94.0^{b}$ & +129.0 \\
\hline \multirow[t]{3}{*}{$\overline{\mathrm{H}\left(\alpha^{\prime}\right)}$} & 7.55 & $\delta^{\mathrm{OBS}}$ & +519.2 & +496.2 & +498.4 & +455.9 & +444.0 & +436.0 & - & +357.3 & - & +355.6 & +356.1 & +307.1 & +296.7 & +270.3 \\
\hline & & ARA & +511.65 & +488.65 & +490.85 & +448.35 & +436.45 & +428.45 & - & +349.75 & - & +348.05 & +348.55 & +299.55 & +289.15 & +262.75 \\
\hline & & $\delta^{\mathrm{MCD}}$ & -22.59 & -21.35 & -21.35 & -19.95 & -18.26 & -18.26 & - & -13.60 & - & -13.60 & -13.60 & -11.23 & -10.72 & -9.63 \\
\hline (line 7) & & $\vartheta^{\mathrm{CON}}$ & +359.81 & +358.88 & +360.43 & +347.61 & +361.94 & +355.57 & - & +367.25 & - & +365.53 & +366.04 & +368.35 & +369.51 & +367.63 \\
\hline \multirow[t]{4}{*}{$\overline{N-m-\mathrm{H}}$} & 6.95 & $\delta^{\mathrm{OBS}}$ & +37.3 & +35.1 & +35.4 & +33.3 & +31.3 & +31.5 & +30.7 & +26.9 & +26.9 & +26.6 & +26.7 & +24.0 & +23.3 & +21.8 \\
\hline & & $\delta^{\text {PARA }}$ & +30.35 & +28.15 & +28.45 & +26.35 & +24.35 & +24.55 & +23.75 & +19.95 & +19.95 & +19.65 & +19.75 & +17.05 & +16.35 & +14.85 \\
\hline & & $\delta^{\mathrm{MCD}}$ & +5.52 & +5.22 & +5.22 & +4.87 & +4.46 & +4.46 & +4.07 & +3.32 & +3.32 & +3.32 & +3.32 & +2.74 & +2.62 & +2.35 \\
\hline & & $\vartheta^{\mathrm{CON}}$ & +16.72 & +16.14 & +16.35 & +15.94 & +15.83 & +15.99 & +16.85 & +16.81 & +16.81 & +16.50 & +16.60 & +16.96 & +16.92 & +16.87 \\
\hline \multirow[t]{3}{*}{$N-m-\mathrm{CH}_{3}$} & 2.32 & $\delta^{\mathrm{OBS}}$ & -6.28 & -5.77 & -5.63 & -5.30 & -4.83 & -4.75 & -4.62 & -3.82 & -3.63 & -3.60 & -3.67 & -2.97 & -2.70 & -2.35 \\
\hline & & $\delta^{\text {PARA }}$ & -8.60 & -8.09 & -7.95 & -7.62 & -7.15 & -7.07 & -6.94 & -6.14 & -5 & -5.92 & -5.99 & -5.29 & -5.02 & -4.67 \\
\hline & & $\delta^{\mathrm{MCD}}$ & +3.22 & +3.05 & +3.05 & +2.85 & +2.60 & +2.60 & +2.38 & +1.94 & +1 & +1.94 & +1.94 & +1.60 & +1.53 & +1.37 \\
\hline (line 40) & & $\vartheta^{\mathrm{CON}}$ & -7.96 & -7.84 & -7.74 & -7.77 & -7.76 & -7.70 & -7.98 & -8.17 & -7.97 & -7.94 & -8.01 & -8.17 & -8.07 & -8.16 \\
\hline \multirow[t]{4}{*}{$N-o-\mathrm{H}^{d}$} & 6.95 & $\delta^{\mathrm{OBS}}$ & -14.8 & -14.0 & -14.3 & -12.2 & -11.5 & -12.8 & -11.5 & -9.28 & -9.33 & -9.50 & -9.13 & -6.98 & -6.43 & -5.40 \\
\hline & & $\delta^{\text {PARA }}$ & -21.75 & -20.95 & -21.25 & -19.15 & -18.45 & -19.75 & -18.45 & -16.23 & -16.28 & -16.45 & -16.08 & -13.93 & -13.38 & -12.35 \\
\hline & & $\delta^{\mathrm{MCD}}$ & +22.01 & +20.80 & +20.80 & +19.43 & +17.79 & +17.79 & +16 . & +13.25 & +13 & +13.25 & +13.25 & +10.94 & +10.45 & +9.39 \\
\hline & & $\vartheta^{\mathrm{CON}}$ & -29.47 & -29.38 & -29.59 & -28.64 & -28.85 & -29.88 & -29.70 & -29.79 & -29.84 & -30.01 & -29.64 & -29.48 & -29.36 & -29.34 \\
\hline \multirow[t]{4}{*}{$N-O-\mathrm{H}^{d}$} & 6.95 & $\delta^{\mathrm{OBS}}$ & - & - & -16.3 & -16.1 & -13.7 & -12.8 & -11.5 & -9.28 & -9.33 & -9.50 & -9.13 & -6.98 & -6.43 & -5.40 \\
\hline & & $\delta^{\text {PARA }}$ & - & - & -23.25 & -23.05 & -20.65 & -19.75 & -18.45 & -16.23 & -16.28 & -16.45 & -16.08 & -13.93 & -13.38 & -12.35 \\
\hline & & $\delta^{\mathrm{MCD}}$ & - & - & +20.80 & +19.43 & +17.79 & +17.79 & +16.24 & +13.25 & +13.2 & +13.25 & +13.25 & +10.94 & +10.45 & +9.39 \\
\hline & & $\vartheta^{\mathrm{CON}}$ & - & - & -31.00 & -31.53 & -30.60 & -29.88 & -29.70 & -29.79 & -29.84 & -30.01 & -29.64 & -29.48 & -29.36 & -29.34 \\
\hline \multirow[t]{3}{*}{$\overline{N-p-\mathrm{H}}$} & 6.95 & $\delta^{\mathrm{OBS}}$ & -22.9 & -21.3 & -21.8 & -20.4 & -18.5 & -18.1 & -17.1 & -13.8 & -13.60 & -13.7 & -13.6 & -10.7 & -10.1 & -8.78 \\
\hline & & $\delta^{\text {PARA }}$ & -29.85 & -28.25 & -28.75 & -27.35 & -25.45 & -25.05 & -24.05 & -20.75 & -20.55 & -20.65 & -20.55 & -17.65 & -17.05 & -15.73 \\
\hline & & $\delta^{\mathrm{MCD}}$ & +4.46 & +4.22 & +4.22 & +3.94 & +3.61 & +3.61 & +3.29 & +2.69 & +2.69 & +2.69 & +2.69 & +2.22 & +2.12 & +1.90 \\
\hline (line 77) & & $\vartheta^{\mathrm{CON}}$ & -23.11 & -22.85 & -23.20 & -23.23 & -23.13 & -22.81 & -23.41 & -23.69 & -23.48 & -23.59 & -23.48 & -23.55 & -23.62 & -23.80 \\
\hline \multirow[t]{3}{*}{$\mathrm{H}(\alpha)$} & 5.07 & $\delta^{\mathrm{OBS}}$ & -180.5 & -173.8 & -175.2 & -168.5 & -153.5 & $\begin{array}{l}-150.3 \\
\end{array}$ & -142.4 & -119.3 & -120.2 & -120.3 & -120.7 & -99.6 & -96.9 & -85.7 \\
\hline & & $\delta^{\text {PARA }}$ & -185.57 & -178.87 & -180.27 & -173.57 & -158.57 & -155.37 & -147.47 & -124.37 & -125.27 & -125.37 & -125.77 & -104.67 & -101.97 & -90.77 \\
\hline & & $\delta^{\mathrm{MCD}}$ & -29.20 & -27.60 & -27.60 & -25.78 & -23.60 & -23.60 & -21.54 & -17.57 & -17.57 & -17.57 & -17.57 & -14.51 & -13.86 & -12.45 \\
\hline (line 2 & & $\vartheta^{\mathrm{CON}}$ & -105.31 & -106.45 & -107.43 & -109.70 & -107.43 & -104.88 & -107.84 & -107.94 & -108.85 & -108.95 & -109.36 & -106.86 & -108.57 & -105.7 \\
\hline 1000/(ter & & e in $\mathrm{K}$ ) & 4.983 & 4.769 & 4.769 & 4.521 & 4.216 & 4.216 & 3.918 & 3.320 & 3.320 & 3.320 & 3.320 & 2.831 & 2.723 & 2.486 \\
\hline
\end{tabular}

${ }^{a}$ In $\mathrm{CDCl}_{3 .}{ }^{b}$ In toluene. ${ }^{c}$ In $\mathrm{CS}_{2} .{ }^{d}$ Linewidth ca. 2 ppm. 
Table S9. ${ }^{1} \mathrm{H}$ NMR Parameters (in ppm) $\delta^{\mathrm{DIA}}, \delta^{\mathrm{OBS}}, \delta^{\mathrm{PARA}}, \delta^{\mathrm{MCD}}$, and $\vartheta^{\mathrm{CON}} \approx \vartheta^{\mathrm{C}+\mathrm{L}}$ of the Bis(chelate) 8Ni in $\mathrm{Cl}_{2} \mathrm{CD}-\mathrm{CDCl}{ }_{2}$ (or CDCl ) Solution as a Function of the Temperature

\begin{tabular}{|c|c|c|c|c|c|c|c|c|c|c|c|c|c|c|c|}
\hline \multirow{2}{*}{$\begin{array}{l}\text { nucleus } \\
\text { (line no.) }\end{array}$} & \multirow{2}{*}{$\begin{array}{l}\mathbf{8 H} \\
\delta^{\text {DIA }}\end{array}$} & \multirow[t]{2}{*}{$8 \mathrm{Ni}$} & \multicolumn{13}{|c|}{ temperature $\left[{ }^{\circ} \mathrm{C}\right]$} \\
\hline & & & -61.0 & $-61.0^{a}$ & $-60.0^{a}$ & -39.0 & $-39.0^{a}$ & -19.0 & $-19.0^{a}$ & -10.0 & $-10.0^{a}$ & $+26.0^{a}$ & +27.0 & +80.0 & +120.0 \\
\hline \multirow[t]{4}{*}{$\mathrm{H}\left(\alpha^{\prime}\right)$} & 7.55 & $\delta^{\mathrm{OBS}}$ & & & & & & & & & & +379.7 & & & \\
\hline & & $\delta^{\text {PARA }}$ & & & & & & & & & & +372.15 & & & \\
\hline & & $\delta^{\mathrm{MCD}}$ & & & & & & & & & & -13.71 & & & \\
\hline & & $\vartheta^{\mathrm{CON}}$ & & & & & & & & & & +387.41 & & & \\
\hline \multirow[t]{4}{*}{$N-m-\mathrm{H}$} & 7.05 & $\delta^{\mathrm{OBS}}$ & +34.1 & +34.4 & - & +31.8 & +32.1 & +29.9 & +30.3 & +28.9 & +29.3 & +26.9 & +26.7 & +23.9 & +22.1 \\
\hline & & $\delta^{\text {PARA }}$ & +27.05 & +27.35 & - & +24.75 & +25.05 & +22.85 & +23.25 & +21.85 & +22.25 & +19.85 & +19.65 & +16.85 & +15.05 \\
\hline & & $\delta^{\mathrm{MCD}}$ & +5.14 & +5.14 & - & +4.53 & +4.53 & +4.09 & +4.09 & +3.92 & +3.92 & +3.35 & +3.34 & +2.74 & +2.42 \\
\hline & & $\vartheta^{\mathrm{CON}}$ & +15.60 & +15.82 & - & +15.89 & +16.12 & +16.00 & +16.34 & +15.84 & +16.19 & +16.57 & +16.43 & +16.72 & +16.67 \\
\hline $\mathrm{H}(\delta)$ & 7.27 & $\delta^{\mathrm{OBS}}$ & +10.6 & +10.7 & - & +10.5 & +10.5 & +10.3 & +10.4 & +10.2 & +10.3 & +10.0 & +10.0 & +9.58 & +9.32 \\
\hline \multirow{2}{*}{ (m) } & & $\delta^{\text {PARA }}$ & +3.33 & +3.43 & - & +3.23 & +3.23 & +3.03 & +3.13 & +2.93 & +3.03 & +2.73 & +2.73 & +2.31 & +2.05 \\
\hline & & $\delta^{\mathrm{MCD}}$ & -4.38 & -4.38 & - & -3.86 & -3.86 & -3.49 & -3.49 & -3.34 & -3.34 & -2.85 & -2.84 & -2.34 & -2.06 \\
\hline (line 32) & & $\vartheta^{\mathrm{CON}}$ & +5.49 & +5.56 & - & +5.57 & +5.57 & +5.56 & +5.64 & +5.54 & +5.63 & +5.61 & +5.61 & +5.51 & +5.42 \\
\hline \multirow[t]{3}{*}{$N-m-\mathrm{CH}_{3}$} & 2.32 & $\delta^{\text {OBS }}$ & -5.32 & -5.43 & -5.42 & -4.80 & -4.90 & -4.38 & -4.48 & -4.17 & -4.28 & -3.70 & -3.60 & -2.85 & -2.35 \\
\hline & & $\delta^{\text {PARA }}$ & -7.64 & -7.75 & -7.74 & -7.12 & -7.22 & -6.70 & -6.80 & -6.49 & -6.60 & -6.02 & -5.92 & -5.17 & -4.67 \\
\hline & & $\delta^{\mathrm{MCD}}$ & +3.00 & +3.00 & +2.98 & +2.65 & +2.65 & +2.39 & +2.39 & +2.29 & +2.29 & +1.96 & +1.95 & +1.60 & +1.41 \\
\hline (line 40) & & $\vartheta^{\mathrm{CON}}$ & -7.58 & -7.65 & -7.67 & -7.68 & -7.75 & -7.75 & -7.84 & -7.75 & -7.85 & -8.01 & -7.93 & -8.03 & -8.02 \\
\hline $\mathrm{H}(\varepsilon)$ & 7.27 & $\delta^{\mathrm{OBS}}$ & -13.9 & -14.1 & -13.9 & -11.8 & -11.8 & -10.0 & -10.1 & -9.20 & -9.25 & -7.10 & $-7.10^{b}$ & $-4.53^{b}$ & $-3.05^{b}$ \\
\hline \multirow[t]{2}{*}{$(p)$} & & $\delta^{\text {PARA }}$ & -21.17 & -21.37 & -21.17 & -19.07 & -19.07 & -17.27 & -17.37 & -16.47 & -16.52 & -14.37 & -14.37 & -11.80 & -10.32 \\
\hline & & $\delta^{\mathrm{MCD}}$ & -3.52 & -3.52 & -3.50 & -3.10 & -3.10 & -2.80 & -2.80 & -2.68 & -2.68 & -2.29 & -2.28 & -1.88 & -1.65 \\
\hline (line 42) & & $\vartheta^{\mathrm{CON}}$ & -12.57 & -12.71 & -12.64 & -12.55 & -12.55 & -12.34 & -12.43 & -12.18 & -12.22 & -12.13 & -12.18 & -11.76 & -11.43 \\
\hline 1000/(tem & iperat & re in $\mathrm{K}$ ) & 4.713 & 4.713 & 4.690 & 4.270 & 4.270 & 3.934 & 3.934 & 3.799 & 3.799 & 3.342 & 3.331 & 2.831 & 2.543 \\
\hline
\end{tabular}

${ }^{a}$ In $\mathrm{CDCl}_{3} \cdot{ }^{b} \mathrm{t},{ }^{3} \mathrm{~J}_{\mathrm{HH}} \approx 7 \mathrm{~Hz}$. 
Table S9 (cont' d). ${ }^{1} \mathrm{H}$ NMR Parameters (in ppm) $\delta^{\mathrm{DIA}}, \delta^{\mathrm{OBS}}, \delta^{\mathrm{PARA}}, \delta^{\mathrm{MCD}}$, and $\vartheta^{\mathrm{CON}} \approx \vartheta^{\mathrm{C}+\mathrm{L}}$ of the Bis(chelate) 8Ni in $\mathrm{Cl}{ }_{2} \mathrm{CD}-\mathrm{CDCl}{ }_{2}\left(\right.$ or $\mathrm{CDCl}{ }_{3}$ ) Solution as a Function of the Temperature

\begin{tabular}{|c|c|c|c|c|c|c|c|c|c|c|c|c|c|c|c|}
\hline \multirow{2}{*}{$\begin{array}{l}\text { nucleus } \\
\text { (line no.) }\end{array}$} & \multirow{2}{*}{$\begin{array}{l}\mathbf{8 H} \\
\delta^{\text {DIA }}\end{array}$} & \multirow[t]{2}{*}{$8 \mathrm{Ni}$} & \multicolumn{13}{|c|}{ temperature $\left[{ }^{\circ} \mathrm{C}\right]$} \\
\hline & & & -61.0 & $-61.0^{a}$ & $-60.0^{a}$ & -39.0 & $-39.0^{a}$ & -19.0 & $-19.0^{a}$ & -10.0 & $-10.0^{a}$ & $+26.0^{a}$ & +27.0 & +80.0 & +120.0 \\
\hline \multirow[t]{4}{*}{$N-O-\mathrm{H}^{c}$} & 7.05 & $\delta^{\mathrm{OBS}}$ & - & -13.6 & -13.7 & -11.8 & -12.9 & -10.8 & -12.0 & -10.5 & -11.6 & -10.2 & -9.80 & -7.33 & -5.52 \\
\hline & & $\delta^{\text {PARA }}$ & - & -20.65 & -20.75 & -18.85 & -19.95 & -17.85 & -19.05 & -17.55 & -18.65 & -17.25 & -16.85 & -14.38 & -12.57 \\
\hline & & $\delta^{\mathrm{MCD}}$ & - & +20.49 & +20.37 & +18.08 & +18.08 & +16.32 & +16.32 & +15.63 & +15.63 & +13.35 & +13.30 & +10.94 & +9.64 \\
\hline & & $\vartheta^{\mathrm{CON}}$ & - & -29.29 & -29.42 & -29.02 & -29.89 & -29.14 & -30.17 & -29.30 & -30.27 & -30.73 & -30.37 & -30.01 & -29.30 \\
\hline \multirow[t]{4}{*}{$N-O-\mathrm{H}^{c}$} & 7.05 & $\delta^{\mathrm{OBS}}$ & - & -17.7 & -17.7 & -15.7 & -15.4 & -13.6 & -13.3 & -12.3 & -12.4 & -10.2 & -9.80 & -7.33 & -5.52 \\
\hline & & $\delta^{\text {PARA }}$ & - & -24.75 & -24.75 & -22.75 & -22.45 & -20.65 & -20.35 & -19.35 & -19.45 & -17.25 & -16.85 & -14.38 & -12.57 \\
\hline & & $\delta^{\mathrm{MCD}}$ & - & +20.49 & +20.37 & +18.08 & +18.08 & +16.32 & +16.32 & +15.63 & +15.63 & +13.35 & +13.30 & +10.94 & +9.64 \\
\hline & & $\vartheta^{\mathrm{CON}}$ & - & -32.21 & -32.28 & -32.09 & -31.85 & -31.53 & -31.28 & -30.89 & -30.98 & -30.73 & -30.37 & -30.01 & -29.30 \\
\hline $\mathrm{H}(\gamma)$ & 7.27 & $\delta^{\mathrm{OBS}}$ & -19.35 & -19.2 & -19.1 & -16.5 & -16.4 & -14.2 & $\begin{array}{l}-14.2 \\
\end{array}$ & -13.1 & $\begin{array}{l}-13.2 \\
\end{array}$ & -10.6 & $\begin{array}{l}-10.6 \\
\end{array}$ & -7.40 & -5.62 \\
\hline & & $\delta^{\text {PARA }}$ & -26.62 & -26.47 & -26.37 & -23.77 & -23.67 & -21.47 & -21.47 & -20.37 & -20.47 & -17.87 & -17.87 & -14.67 & -12.89 \\
\hline & & $\delta^{\mathrm{MCD}}$ & -11.18 & -11.18 & -11.11 & -9.86 & -9.86 & -8.90 & -8.90 & -8.52 & -8.52 & -7.28 & -7.25 & -5.97 & -5.26 \\
\hline (line 41) & & $\vartheta^{\mathrm{CON}}$ & -11.00 & -10.89 & -10.92 & -10.93 & -10.85 & -10.72 & -10.72 & -10.46 & -10.55 & -10.63 & -10.69 & -10.32 & -10.07 \\
\hline \multirow[t]{3}{*}{$N-p-\mathrm{H}$} & 7.05 & $\delta^{\mathrm{OBS}}$ & -21.1 & -21.2 & -21.1 & -18.8 & -18.9 & -16.8 & -17.1 & -15.9 & -16.1 & -13.8 & -13.7 & -10.7 & -8.88 \\
\hline & & $\delta^{\text {PARA }}$ & -28.15 & -28.25 & -28.15 & -25.85 & -25.95 & -23.85 & -24.15 & -22.95 & -23.15 & -20.85 & -20.75 & -17.75 & -15.93 \\
\hline & & $\delta^{\mathrm{MCD}}$ & +4.15 & +4.15 & +4.13 & +3.66 & +3.66 & +3.31 & +3.31 & +3.17 & +3.17 & +2.71 & +2.70 & +2.22 & +1.95 \\
\hline (line 77) & & $\vartheta^{\mathrm{CON}}$ & -23.00 & -23.07 & -23.09 & -23.20 & -23.27 & -23.17 & -23.42 & -23.07 & -23.24 & -23.65 & -23.62 & -23.67 & -23.60 \\
\hline $1000 /$ (ten & ratu & n K) & 4.713 & 4.713 & 4.690 & 4.270 & 4.270 & 3.934 & 3.934 & 3.799 & 3.799 & 3.342 & 3.331 & 2.831 & 2.543 \\
\hline
\end{tabular}

${ }^{a} \mathrm{In}^{\mathrm{CDCl}_{3} .}{ }^{c}$ Linewidth ca. $2 \mathrm{ppm}$. 
Table S10. ${ }^{1} \mathrm{H}$ NMR Parameters (in ppm) $\delta^{\mathrm{DIA}}, \delta^{\mathrm{OBS}}, \delta^{\mathrm{PARA}}, \delta^{\mathrm{MCD}}$, and $\vartheta^{\mathrm{CON}} \approx \vartheta^{\mathrm{C}+\mathrm{L}}$ of the Bis(chelate) $9 \mathrm{Ni}$ in $\mathrm{Cl}{ }_{2} \mathrm{CD}-\mathrm{CDCl}{ }_{2}$ (or other) Solution as a Function of the Temperature

\begin{tabular}{|c|c|c|c|c|c|c|c|c|c|c|c|c|}
\hline \multirow{2}{*}{$\begin{array}{l}\text { nucleus } \\
\text { (line no.) }\end{array}$} & \multirow{2}{*}{$\begin{array}{l}\mathbf{9 H} \\
\delta^{\text {DIA }}\end{array}$} & \multirow[t]{2}{*}{$9 \mathrm{Ni}$} & \multicolumn{10}{|c|}{ temperature $\left[{ }^{\circ} \mathrm{C}\right]$} \\
\hline & & & +51.0 & +85.5 & +106.0 & +112.0 & +116.0 & $+119.0^{a}$ & +129.0 & +134.0 & +142.0 & $+160.0^{b}$ \\
\hline \multirow[t]{4}{*}{$\mathrm{H}\left(\alpha^{\prime}\right)$} & 7.62 & $\delta^{\text {OBS }}$ & $+344.2^{c}$ & +310.2 & & & & & & & & \\
\hline & & $\delta^{\text {PARA }}$ & +336.58 & +302.58 & & & & & & & & \\
\hline & & $\delta^{\mathrm{MCD}}$ & -12.44 & -11.03 & & & & & & & & \\
\hline & & $\vartheta^{\mathrm{CON}}$ & +379.71 & +377.48 & & & & & & & & \\
\hline \multirow[t]{3}{*}{$\mathrm{H}(\beta)$} & 2.02 & $\delta^{\mathrm{OBS}}$ & - & - & +68.7 & +67.9 & +66.7 & - & +64.0 & - & +62.3 & - \\
\hline & & $\delta^{\text {PARA }}$ & - & - & +66.68 & +65.88 & +64.68 & - & +61.98 & - & +60.28 & - \\
\hline & & $\delta^{\mathrm{MCD}}$ & - & - & -7.18 & -7.05 & -6.97 & - & -6.70 & - & -6.46 & - \\
\hline (line 15) & & $\vartheta^{\mathrm{CON}}$ & - & - & +93.99 & +94.27 & +93.57 & - & +92.70 & - & +92.99 & - \\
\hline \multirow[t]{3}{*}{$N-m-\mathrm{H}$} & 7.17 & $\delta^{\mathrm{OBS}}$ & - & +24.5 & +23.4 & +23.2 & +22.9 & +22.8 & +22.3 & +22.3 & +21.8 & +21.2 \\
\hline & & $\delta^{\text {PARA }}$ & - & +17.33 & +16.23 & +16.03 & +15.73 & +15.63 & +15.13 & +15.13 & +14.63 & +14.03 \\
\hline & & $\delta^{\mathrm{MCD}}$ & - & +2.69 & +2.52 & +2.48 & +2.45 & +2.42 & +2.35 & +2.32 & +2.27 & +2.16 \\
\hline (line 18) & & $\vartheta^{\mathrm{CON}}$ & - & +17.62 & +17.44 & +17.52 & +17.35 & +17.38 & +17.24 & +17.50 & +17.22 & +17.26 \\
\hline \multirow[t]{3}{*}{$N-p-\mathrm{H}$} & 7.17 & $\delta^{\mathrm{OBS}}$ & - & -11.9 & $\begin{array}{l}-10.8 \\
\end{array}$ & - & -10.5 & - & -9.75 & -9.67 & -9.23 & - \\
\hline & & $\delta^{\text {PARA }}$ & - & -19.07 & -17.97 & - & -17.67 & - & -16.92 & -16.84 & -16.40 & - \\
\hline & & $\delta^{\mathrm{MCD}}$ & - & +2.18 & +2.04 & - & +1.98 & - & +1.90 & +1.88 & +1.83 & - \\
\hline (line 78) & & $\vartheta^{\mathrm{CON}}$ & - & -25.58 & -25.46 & - & -25.66 & - & -25.40 & -25.57 & -25.40 & - \\
\hline \multirow[t]{4}{*}{$\mathrm{N}-\mathrm{O}-\mathrm{H}$} & 7.17 & $\delta^{\mathrm{OBS}}$ & - & -8.58 & -7.62 & - & -7.22 & - & -6.58 & -6.58 & -6.33 & -5.50 \\
\hline & & $\delta^{\text {PARA }}$ & - & -15.75 & -14.79 & - & -14.39 & - & -13.75 & -13.75 & -13.50 & -12.67 \\
\hline & & $\delta^{\mathrm{MCD}}$ & - & +10.74 & +10.06 & - & +9.75 & - & +9.39 & +9.25 & +9.04 & +8.61 \\
\hline & & $\vartheta^{\mathrm{CON}}$ & - & -31.89 & -31.62 & - & -31.53 & - & -31.23 & -31.43 & -31.41 & -30.93 \\
\hline \multicolumn{3}{|c|}{ 1000/(temperature in K) } & 3.085 & 2.788 & 2.637 & 2.596 & 2.569 & 2.550 & 2.486 & 2.456 & 2.408 & 2.308 \\
\hline
\end{tabular}

\footnotetext{
${ }^{a}$ In chlorobenzene. ${ }^{b}$ In 1,2-dichlorobenzene. ${ }^{c} \pm>3$ ppm.
} 
Table S11. ${ }^{1} \mathrm{H}$ NMR Parameters (in ppm) $\delta^{\mathrm{DIA}}, \delta^{\mathrm{OBS}}, \delta^{\mathrm{PARA}}, \delta^{\mathrm{MCD}}$, and $\vartheta^{\mathrm{CON}} \approx \vartheta^{\mathrm{C}+\mathrm{L}}$ of the Bis(chelate) $10 \mathrm{Co}$ in $\mathrm{Cl}_{2} \mathrm{CD}-\mathrm{CDCl}_{2}$ Solution as a Function of the Temperature

\begin{tabular}{|c|c|c|c|c|c|c|c|c|}
\hline \multirow{2}{*}{$\begin{array}{l}\text { nucleus } \\
\text { (line no.) }\end{array}$} & \multirow{2}{*}{$\begin{array}{r}10 \mathrm{H} \\
\delta^{\text {DIA }}\end{array}$} & \multirow[t]{2}{*}{ 10Co } & \multicolumn{6}{|c|}{ temperature $\left[{ }^{\circ} \mathrm{C}\right]$} \\
\hline & & & -50.0 & -16.0 & +25.0 & +53.0 & +78.0 & +106.0 \\
\hline \multirow[t]{4}{*}{$\mathrm{H}(\alpha)$} & 7.55 & $\delta^{\mathrm{OBS}}$ & - & - & - & $+436.4^{a}$ & $+401.6^{a}$ & - \\
\hline & & $\delta^{\text {PARA }}$ & - & - & - & +428.85 & +394.05 & - \\
\hline & & $\delta^{\mathrm{MCD}}$ & - & - & - & +18.44 & +16.88 & - \\
\hline & & $\vartheta^{\mathrm{CON}}$ & - & - & - & +449.25 & +444.50 & - \\
\hline $\mathrm{H}(\beta)$ & 2.02 & $\delta^{\mathrm{OBS}}$ & - & $+114.0^{b}$ & $+97.6^{b}$ & $+89.4^{b}$ & +83.3 & $+78.2^{b}$ \\
\hline \multirow[t]{2}{*}{ (Me) } & & $\delta^{\text {PARA }}$ & - & +111.98 & +95.58 & +87.38 & +81.28 & +76.18 \\
\hline & & $\delta^{\mathrm{MCD}}$ & - & +17.28 & +14.41 & +12.93 & +11.84 & +10.82 \\
\hline (line 16) & & $\vartheta^{\mathrm{CON}}$ & - & +81.73 & +81.22 & +81.49 & +81.83 & +83.17 \\
\hline \multirow[t]{3}{*}{$N-p-\mathrm{CH}_{3}$} & 2.33 & $\delta^{\mathrm{OBS}}$ & +33.2 & +29.6 & +26.0 & +23.9 & +22.2 & +20.7 \\
\hline & & $\delta^{\text {PARA }}$ & +30.87 & +27.27 & +23.67 & +21.57 & +19.87 & +18.37 \\
\hline & & $\delta^{\mathrm{MCD}}$ & -3.98 & -3.33 & -2.78 & -2.50 & -2.29 & -2.09 \\
\hline (line 54) & & $\vartheta^{\mathrm{CON}}$ & +26.10 & +26.41 & +26.47 & +26.34 & +26.11 & +26.03 \\
\hline \multirow[t]{3}{*}{$N-m-\mathrm{H}$} & 7.02 & $\delta^{\mathrm{OBS}}$ & +24.3 & +22.1 & +20.2 & +18.8 & +17.9 & +17.1 \\
\hline & & $\delta^{\text {PARA }}$ & +17.28 & +15.08 & +13.18 & +11.78 & +10.88 & +10.08 \\
\hline & & $\delta^{\mathrm{MCD}}$ & -6.91 & -5.79 & -4.83 & -4.33 & -3.97 & -3.62 \\
\hline (line 18) & & $\vartheta^{\mathrm{CON}}$ & +18.12 & +18.01 & +18.02 & +17.64 & +17.50 & +17.44 \\
\hline 1000/(tem & iperatı & Ire in $\mathrm{K}$ ) & 4.480 & 3. 888 & 3.353 & 3.066 & 2.847 & 2.637 \\
\hline
\end{tabular}

${ }^{a} \pm>5$ ppm. ${ }^{b} \pm 2$ ppm. 
Table S12. ${ }^{13} \mathrm{C}$ NMR Parameters (in ppm) $\delta^{\mathrm{DIA}}, \delta^{\mathrm{OBS}}, \delta^{\mathrm{PARA}}, \delta^{\mathrm{MCD}}$, and $\vartheta^{\mathrm{CON}} \approx \vartheta^{\mathrm{C}+\mathrm{L}}$ of the Bis(chelate) 10Co in $\mathrm{Cl}_{2} \mathrm{CD}-\mathrm{CDCl}_{2}$ Solution as a Function of the Temperature

\begin{tabular}{|c|c|c|c|c|c|c|}
\hline \multirow{2}{*}{$\begin{array}{l}\text { nucleus } \\
\text { (line no.) }\end{array}$} & \multirow{2}{*}{$\begin{array}{l}\mathbf{1 0 H} \\
\delta^{\mathrm{DIA}}\end{array}$} & \multirow[t]{2}{*}{$10 \mathrm{Co}$} & \multicolumn{4}{|c|}{ temperature $\left[{ }^{\circ} \mathrm{C}\right]$} \\
\hline & & & -38.0 & -17.0 & $+31.5^{a}$ & +90.0 \\
\hline \multirow[t]{3}{*}{$N-O-C$} & 117.6 & $\delta^{\mathrm{OBS}}$ & +782.5 & +727.8 & +628.5 & +545.2 \\
\hline & & $\delta^{\text {PARA }}$ & +664.9 & +610.2 & +510.9 & +427.6 \\
\hline & & $\delta^{\mathrm{MCD}}$ & -26.39 & -23.72 & -19.18 & -15.55 \\
\hline (line 44) & & $\vartheta^{\mathrm{CON}}$ & +545.61 & +545.00 & +542.00 & +540.11 \\
\hline \multirow[t]{4}{*}{$N-i-C$} & 144.4 & $\delta^{\mathrm{OBS}}$ & +412.5 & +386.5 & +345.3 & +311.0 \\
\hline & & $\delta^{\text {PARA }}$ & +268.1 & +242.1 & +200.9 & +166.6 \\
\hline & & $\delta^{\mathrm{MCD}}$ & -40.37 & -36.28 & -29.34 & -23.78 \\
\hline & & $\vartheta^{\mathrm{CON}}$ & +243.46 & +239.33 & +235.42 & +232.03 \\
\hline \multirow[t]{3}{*}{$N-p-C$} & 132.3 & $\delta^{\mathrm{OBS}}$ & +353.5 & +335.9 & $+304.7^{b}$ & +277.4 \\
\hline & & $\delta^{\text {PARA }}$ & +221.2 & +203.6 & +172.4 & +145.1 \\
\hline & & $\delta^{\mathrm{MCD}}$ & -8.83 & -7.93 & -6.42 & -5.20 \\
\hline (line 51) & & $\vartheta^{\mathrm{CON}}$ & +181.55 & +181.86 & +182.84 & +183.18 \\
\hline \multirow[t]{4}{*}{$N-m-\mathrm{C}$} & 129.7 & $\delta^{\mathrm{OBS}}$ & +8.50 & +17.9 & $+35.4^{c}$ & +49.7 \\
\hline & & $\delta^{\text {PARA }}$ & -121.2 & -111.8 & -94.3 & +80.0 \\
\hline & & $\delta^{\mathrm{MCD}}$ & -11.19 & -10.06 & -8.13 & -6.59 \\
\hline & & $\vartheta^{\mathrm{CON}}$ & -86.83 & -87.47 & -88.10 & -89.47 \\
\hline \multirow[t]{3}{*}{$N-p-\mathrm{CH}_{3}$} & 20.8 & $\delta^{\mathrm{OBS}}$ & -61.8 & -55.4 & $-43.0^{d}$ & -33.0 \\
\hline & & $\delta^{\text {PARA }}$ & -82.6 & -76.2 & -63.8 & -53.8 \\
\hline & & $\delta^{\mathrm{MCD}}$ & -4.31 & -3.87 & -3.13 & -2.54 \\
\hline (line 21) & & $\vartheta^{\mathrm{CON}}$ & -61.79 & -62.18 & -62.03 & -62.48 \\
\hline \multirow[t]{3}{*}{$\mathrm{C}(\alpha)$} & 20.8 & $\delta^{\mathrm{OBS}}$ & -239.3 & -220.5 & -185.7 & -155.0 \\
\hline & & $\delta^{\text {PARA }}$ & -260.1 & -241.3 & -206.5 & -175.8 \\
\hline & & $\delta^{\mathrm{MCD}}$ & +27.16 & +24.41 & +19.74 & +16.00 \\
\hline (line 25) & & $\vartheta^{\mathrm{CON}}$ & -226.73 & -228.44 & -231.33 & -233.77 \\
\hline \multicolumn{3}{|c|}{ 1000/(temperature in K) } & 4.252 & 3.903 & 3.282 & 2.753 \\
\hline
\end{tabular}

${ }^{a}{ }^{1} \mathrm{H}$ coupled. ${ }^{b}$ Singlet. ${ }^{c} \mathrm{~d},{ }^{1} J_{\mathrm{CH}}=140 \mathrm{~Hz} .{ }^{d} \mathrm{q},{ }^{1} J_{\mathrm{CH}}=122.1 \mathrm{~Hz}$. 
Table S13. ${ }^{13} \mathrm{C}$ NMR Parameters (in ppm) $\delta^{\text {DIA }}, \delta^{\mathrm{OBS}}$, $\delta^{\mathrm{PARA}}, \delta^{\mathrm{MCD}}$, and $\vartheta^{\mathrm{CON}} \approx \vartheta^{\mathrm{C}+\mathrm{L}}$ of the Bis(chelate) $10 \mathrm{Ni}$ in $\mathrm{Cl}_{2} \mathrm{CD}-\mathrm{CDCl}_{2}$ Solution as a Function of the Temperature

\begin{tabular}{|c|c|c|c|c|}
\hline \multirow{2}{*}{$\begin{array}{l}\text { nucleus } \\
\text { (line no.) }\end{array}$} & \multirow{2}{*}{$\begin{array}{l}\mathbf{1 0 H} \\
\delta^{\mathrm{DIA}}\end{array}$} & \multirow[t]{2}{*}{$10 \mathrm{Ni}$} & \multicolumn{2}{|c|}{ temperature $\left[{ }^{\circ} \mathrm{C}\right]$} \\
\hline & & & -43.0 & $+32.5^{a}$ \\
\hline \multirow[t]{3}{*}{$N-o-C$} & \multirow[t]{3}{*}{117.6} & $\delta^{\mathrm{OBS}}$ & +737.8 & +589.1 \\
\hline & & $\delta^{\text {PARA }}$ & +620.2 & +471.5 \\
\hline & & $\delta^{\mathrm{MCD}}$ & +18.77 & +13.22 \\
\hline \multicolumn{2}{|l|}{ (line 4) } & $\vartheta^{\mathrm{CON}}$ & +464.60 & +470.13 \\
\hline \multirow[t]{4}{*}{$N-i-C$} & \multirow[t]{4}{*}{144.4} & $\delta^{\mathrm{OBS}}$ & +461.0 & $+380.7^{b}$ \\
\hline & & $\delta^{\text {PARA }}$ & +316.6 & +236.3 \\
\hline & & $\delta^{\mathrm{MCD}}$ & +29.94 & +21.08 \\
\hline & & $\vartheta^{\mathrm{CON}}$ & +221.44 & +220.78 \\
\hline \multirow[t]{4}{*}{$N-p-C$} & \multirow[t]{4}{*}{132.3} & $\delta^{\mathrm{OBS}}$ & +351.4 & $+298.7^{b}$ \\
\hline & & $\delta^{\text {PARA }}$ & +219.1 & +166.4 \\
\hline & & $\delta^{\mathrm{MCD}}$ & +6.41 & +4.51 \\
\hline & & $\vartheta^{\mathrm{CON}}$ & +164.30 & +166.07 \\
\hline \multirow[t]{4}{*}{$N-m-C$} & \multirow[t]{4}{*}{129.7} & $\delta^{\mathrm{OBS}}$ & +13.6 & $+42.0^{c}$ \\
\hline & & $\delta^{\text {PARA }}$ & -116.1 & -87.7 \\
\hline & & $\delta^{\mathrm{MCD}}$ & +8.15 & +5.74 \\
\hline & & $\vartheta^{\mathrm{CON}}$ & -95.98 & -95.86 \\
\hline \multirow[t]{3}{*}{$N-p-\mathrm{CH}_{3}$} & \multirow[t]{3}{*}{20.8} & $\delta^{\mathrm{OBS}}$ & -56.0 & $-37.4^{d}$ \\
\hline & & $\delta^{\text {PARA }}$ & -76.8 & -58.2 \\
\hline & & $\delta^{\mathrm{MCD}}$ & +3.09 & +2.17 \\
\hline \multicolumn{2}{|l|}{ (line 21) } & $\vartheta^{\mathrm{CON}}$ & -61.71 & -61.93 \\
\hline \multirow[t]{4}{*}{$C(1,3)$} & \multirow[t]{4}{*}{149.6} & $\delta^{\mathrm{OBS}}$ & - & -520.4 \\
\hline & & $\delta^{\text {PARA }}$ & - & -670.0 \\
\hline & & $\delta^{\mathrm{MCD}}$ & - & -42.18 \\
\hline & & $\vartheta^{\mathrm{CON}}$ & - & -644.05 \\
\hline \multicolumn{3}{|c|}{ 1000/(temperature in K) } & 4.344 & 3.271 \\
\hline
\end{tabular}

${ }^{a}{ }^{1} \mathrm{H}$ coupled. ${ }^{b}$ Singlet. ${ }^{c} \mathrm{~d},{ }^{1} J_{\mathrm{CH}}=159 \mathrm{~Hz} .{ }^{d} \mathrm{q},{ }^{1} J_{\mathrm{CH}}=128 \mathrm{~Hz}$. 
Table S14. ${ }^{1} \mathrm{H}$ NMR Parameters (in ppm) $\delta^{\mathrm{DIA}}, \delta^{\mathrm{OBS}}, \delta^{\mathrm{PARA}}, \delta^{\mathrm{MCD}}$, and $\vartheta^{\mathrm{CON}} \approx \vartheta^{\mathrm{C}+\mathrm{L}}$ of the Bis(chelate) $11 \mathrm{Co}$ in $\mathrm{Cl}_{2} \mathrm{CD}-\mathrm{CDCl}_{2}$ Solution as a Function of the Temperature

\begin{tabular}{|c|c|c|c|c|c|c|c|c|}
\hline \multirow{2}{*}{$\begin{array}{l}\text { nucleus } \\
\text { (line no.) }\end{array}$} & \multirow{2}{*}{$\begin{array}{l}11 \mathrm{H} \\
\delta^{\mathrm{DIA}}\end{array}$} & \multirow[t]{2}{*}{ 11Co } & \multicolumn{6}{|c|}{ temperature $\left[{ }^{\circ} \mathrm{C}\right]$} \\
\hline & & & -9.0 & +26.0 & +53.0 & +76.5 & +104.0 & +135.0 \\
\hline \multirow[t]{4}{*}{$\mathrm{H}\left(\alpha^{\prime}\right)$} & 7.85 & $\delta^{\mathrm{OBS}}$ & +549.3 & +486.5 & +444.6 & +415.5 & - & - \\
\hline & & $\delta^{\text {PARA }}$ & +541.45 & +478.65 & +436.75 & +407.65 & - & - \\
\hline & & $\delta^{\mathrm{MCD}}$ & +23.83 & +20.46 & +18.44 & +16.97 & - & - \\
\hline & & $\vartheta^{\mathrm{CON}}$ & +458.91 & +460.03 & +457.90 & +458.46 & - & - \\
\hline \multirow[t]{3}{*}{$N-m-\mathrm{H}$} & 7.17 & $\delta^{\mathrm{OBS}}$ & +20.7 & +19.2 & +18.2 & +17.4 & +16.6 & +16.0 \\
\hline & & $\delta^{\text {PARA }}$ & +13.53 & +12.03 & +11.03 & +10.23 & +9.43 & +8.83 \\
\hline & & $\delta^{\mathrm{MCD}}$ & -5.60 & -4.81 & -4.33 & -3.99 & -3.64 & -3.32 \\
\hline (line 55) & & $\vartheta^{\mathrm{CON}}$ & +16.96 & +16.90 & +16.81 & +16.68 & +16.55 & +16.65 \\
\hline $\mathrm{H}(\gamma)$ & 1.25 & $\delta^{\mathrm{OBS}}$ & +14.68 & +12.60 & +11.63 & +10.93 & +10.33 & +9.50 \\
\hline \multirow[t]{2}{*}{ (tert-Bu) } & & $\delta^{\text {PARA }}$ & +13.43 & +11.35 & +10.38 & +9.68 & +9.08 & +8.25 \\
\hline & & $\delta^{\mathrm{MCD}}$ & +11.08 & +9.52 & +8.58 & +7.89 & +7.22 & +6.58 \\
\hline (line 72) & & $\vartheta^{\mathrm{CON}}$ & +2.08 & +1.84 & +1.98 & +2.10 & +2.36 & +2.29 \\
\hline \multirow[t]{3}{*}{$N-p-\mathrm{H}$} & 7.17 & $\delta^{\mathrm{OBS}}$ & -26.23 & -22.3 & -20.0 & -18.3 & -16.7 & -14.9 \\
\hline & & $\delta^{\text {PARA }}$ & -33.40 & -29.47 & -27.17 & -25.47 & -23.87 & -22.07 \\
\hline & & $\delta^{\mathrm{MCD}}$ & -4.51 & -3.87 & -3.49 & -3.21 & -2.94 & -2.68 \\
\hline (line 78) & & $\vartheta^{\mathrm{CON}}$ & -25.61 & -25.70 & -25.92 & -26.12 & -26.50 & -26.57 \\
\hline \multicolumn{3}{|c|}{$1000 /$ (temperature in $\mathrm{K}$ ) } & 3.785 & 3.342 & 3.066 & 2.860 & 2.651 & 2.450 \\
\hline
\end{tabular}


Table S15. ${ }^{13} \mathrm{C}$ NMR Parameters (in ppm) $\delta^{\mathrm{DIA}}, \delta^{\mathrm{OBS}}, \delta^{\mathrm{PARA}}, \delta^{\mathrm{MCD}}$, and $\vartheta^{\mathrm{CON}} \approx \vartheta^{\mathrm{C}+\mathrm{L}}$ of the Bis(chelate) $11 \mathrm{Co}$ in $\mathrm{Cl}_{2} \mathrm{CD}-\mathrm{CDCl}_{2}$ Solution as a Function of the Temperature

\begin{tabular}{|c|c|c|c|c|c|}
\hline \multirow{2}{*}{$\begin{array}{l}\text { nucleus } \\
\text { (line no.) }\end{array}$} & \multirow{2}{*}{$\begin{array}{r}\mathbf{1 1 H} \\
\delta^{\mathrm{DIA}} \\
\end{array}$} & \multirow[t]{2}{*}{ 11Co } & \multicolumn{3}{|c|}{ temperature $\left[{ }^{\circ} \mathrm{C}\right]$} \\
\hline & & & -49.0 & $-19.0^{a}$ & +34.0 \\
\hline \multirow[t]{3}{*}{$N-o-C$} & \multirow[t]{3}{*}{117.9} & $\delta^{\mathrm{OBS}}$ & +839.3 & +743.3 & +632.6 \\
\hline & & $\delta^{\text {PARA }}$ & +721.4 & +625.4 & +514.7 \\
\hline & & $\delta^{\mathrm{MCD}}$ & -28.04 & -23.95 & -18.99 \\
\hline \multicolumn{2}{|l|}{ (line 43) } & $\vartheta^{\mathrm{CON}}$ & +563.84 & +553.91 & +550.17 \\
\hline \multirow[t]{3}{*}{$N-i-\mathrm{C}$} & \multirow[t]{3}{*}{147.0} & $\delta^{\mathrm{OBS}}$ & +437.1 & +400.4 & +359.2 \\
\hline & & $\delta^{\mathrm{PARA}}$ & +290.1 & +253.4 & +212.2 \\
\hline & & $\delta^{\mathrm{MCD}}$ & -42.88 & -36.64 & -29.05 \\
\hline \multicolumn{2}{|l|}{ (line 48) } & $\vartheta^{\mathrm{CON}}$ & +250.52 & +247.41 & +248.70 \\
\hline \multirow[t]{3}{*}{$N-p-\mathrm{C}$} & \multirow[t]{3}{*}{122.9} & $\delta^{\mathrm{OBS}}$ & +346.5 & $+319.5^{b}$ & +286.8 \\
\hline & & $\delta^{\text {PARA }}$ & +223.6 & +196.6 & +163.9 \\
\hline & & $\delta^{\mathrm{MCD}}$ & -9.38 & -8.01 & -6.35 \\
\hline \multicolumn{2}{|l|}{ (line 52) } & $\vartheta^{\mathrm{CON}}$ & +175.28 & +174.54 & +175.51 \\
\hline \multirow{4}{*}{$\begin{array}{l}\mathrm{C}(\beta) \\
(\text { tert-Bu) }\end{array}$} & \multirow[t]{4}{*}{31.2} & $\delta^{\mathrm{OBS}}$ & +275.6 & +245.3 & +209.9 \\
\hline & & $\delta^{\mathrm{PARA}}$ & +244.4 & +214.1 & +178.7 \\
\hline & & $\delta^{\mathrm{MCD}}$ & +16.98 & +14.51 & +11.51 \\
\hline & & $\vartheta^{\mathrm{CON}}$ & +171.10 & +170.25 & +172.36 \\
\hline \multirow[t]{4}{*}{$N-m-C$} & \multirow[t]{4}{*}{129.1} & $\delta^{\mathrm{OBS}}$ & +16.1 & $+28.3^{c}$ & +44.2 \\
\hline & & $\delta^{\text {PARA }}$ & -113.0 & -100.8 & -84.9 \\
\hline & & $\delta^{\mathrm{MCD}}$ & -11.89 & -10.16 & -8.05 \\
\hline & & $\vartheta^{\mathrm{CON}}$ & -76.07 & -77.32 & -79.22 \\
\hline \multirow[t]{3}{*}{$\mathrm{C}(\alpha)$} & \multirow[t]{3}{*}{33.0} & $\delta^{\mathrm{OBS}}$ & -222.9 & -192.6 & -154.8 \\
\hline & & $\delta^{\text {PARA }}$ & -255.9 & -225.6 & -187.8 \\
\hline & & $\delta^{\mathrm{MCD}}$ & +28.86 & +24.65 & +19.55 \\
\hline \multicolumn{2}{|l|}{ (line 25) } & $\vartheta^{\mathrm{CON}}$ & -214.24 & -213.47 & -213.75 \\
\hline \multicolumn{3}{|c|}{$1000 /$ (temperature in K) } & 4.460 & 3.934 & 3.255 \\
\hline
\end{tabular}

${ }^{a}{ }^{1} \mathrm{H}$ coupled. ${ }^{b} \mathrm{~d},{ }^{1} J_{\mathrm{CH}} \approx 123 \mathrm{~Hz} .{ }^{c} \mathrm{~d},{ }^{1} J_{\mathrm{CH}} \approx 110 \mathrm{~Hz}$. 
Table S16. ${ }^{1} \mathrm{H}$ NMR Parameters (in ppm) $\delta^{\mathrm{DIA}}, \delta^{\mathrm{OBS}}, \delta^{\mathrm{PARA}}, \delta^{\mathrm{MCD}}$, and $\vartheta^{\mathrm{CON}} \approx \vartheta^{\mathrm{C}+\mathrm{L}}$ of the Bis(chelate) $\mathbf{1 1 N i}$ in $\mathrm{Cl}_{2} \mathrm{CD}-\mathrm{CDCl}_{2}$ Solution as a Function of the Temperature

\begin{tabular}{|c|c|c|c|c|c|c|c|c|c|}
\hline \multirow{2}{*}{$\begin{array}{l}\text { nucleus } \\
\text { (line no.) }\end{array}$} & \multirow{2}{*}{$\begin{array}{l}\mathbf{1 1 H} \\
\delta^{\text {DIA }}\end{array}$} & \multirow[t]{2}{*}{$11 \mathrm{Ni}$} & \multicolumn{7}{|c|}{ temperature $\left[{ }^{\circ} \mathrm{C}\right]$} \\
\hline & & & -42.0 & -10.0 & +26.0 & +53.0 & +76.5 & +104.0 & +135.0 \\
\hline \multirow[t]{3}{*}{$\mathrm{H}\left(\alpha^{\prime}\right)$} & 7.85 & $\delta^{\mathrm{OBS}}$ & $+480.7^{a}$ & $+428.3^{a}$ & $+378.3^{a}$ & $+348.1^{a}$ & $+325.9^{a}$ & $+302.6^{a}$ & $+279.8^{a}$ \\
\hline & & $\delta^{\text {PARA }}$ & +472.85 & +420.45 & +370.45 & +340.25 & +318.05 & +294.75 & +271.95 \\
\hline & & $\delta^{\mathrm{MCD}}$ & -18.86 & -16.04 & -13.71 & -12.35 & -11.36 & -10.39 & -9.47 \\
\hline (line 6) & & $\vartheta^{\mathrm{CON}}$ & +381.49 & +385.52 & +385.70 & +385.96 & +386.56 & +386.24 & +385.49 \\
\hline \multirow[t]{3}{*}{$N-m-\mathrm{H}$} & 7.17 & $\delta^{\mathrm{OBS}}$ & +33.5 & +30.4 & +27.3 & +25.7 & +24.5 & +23.1 & +21.93 \\
\hline & & $\delta^{\text {PARA }}$ & +26.33 & +23.23 & +20.13 & +18.53 & +17.33 & +15.93 & +14.76 \\
\hline & & $\delta^{\mathrm{MCD}}$ & +4.61 & +3.92 & +3.35 & +3.02 & +2.78 & +2.54 & +2.31 \\
\hline (line 18) & & $\vartheta^{\mathrm{CON}}$ & +16.85 & +17.06 & +16.85 & +16.98 & +17.08 & +16.95 & +17.05 \\
\hline $\mathrm{H}(\gamma)$ & 1.25 & $\delta^{\mathrm{OBS}}$ & -2.33 & -1.82 & -1.48 & -1.07 & -0.97 & -0.84 & -0.74 \\
\hline \multirow[t]{2}{*}{ (tert-Bu) } & & $\delta^{\text {PARA }}$ & -3.58 & -3.07 & -2.73 & -2.32 & -2.22 & -2.09 & -1.99 \\
\hline & & $\delta^{\mathrm{MCD}}$ & -8.74 & -7.44 & -6.35 & -5.73 & -5.27 & -4.82 & -4.39 \\
\hline (line 71) & & $\vartheta^{\mathrm{CON}}$ & +4.01 & +3.86 & +3.64 & +3.73 & +3.58 & +3.45 & +3.29 \\
\hline \multirow[t]{3}{*}{$N-O-H$} & 7.17 & $\delta^{\mathrm{OBS}}$ & -16.3 & -13.9 & -11.5 & -10.0 & -8.90 & -7.92 & -6.92 \\
\hline & & $\delta^{\text {PARA }}$ & -23.47 & -21.07 & -18.67 & -17.17 & -16.07 & -15.09 & -14.09 \\
\hline & & $\delta^{\mathrm{MCD}}$ & +18.37 & +15.63 & +13.35 & +12.03 & +11.07 & +10.12 & +9.23 \\
\hline (line 57) & & $\vartheta^{\mathrm{CON}}$ & -32.46 & -32.41 & -32.15 & -31.96 & -31.85 & -31.91 & -31.94 \\
\hline \multirow[t]{3}{*}{$N-p-\mathrm{H}$} & 7.17 & $\delta^{\mathrm{OBS}}$ & -21.0 & -18.1 & -14.9 & -13.5 & -12.1 & -10.73 & -9.50 \\
\hline & & $\delta^{\text {PARA }}$ & -28.17 & -25.27 & -22.07 & -20.67 & -19.27 & -17.90 & -16.67 \\
\hline & & $\delta^{\mathrm{MCD}}$ & +3.72 & +3.17 & +2.71 & +2.44 & +2.24 & +2.05 & +1.87 \\
\hline (line 78) & & $\vartheta^{\mathrm{CON}}$ & -24.75 & -25.12 & -24.88 & -25.30 & -25.25 & -25.25 & -25.40 \\
\hline 1000/(tem & peratu & in $K$ ) & 4.325 & 3.799 & 3.342 & 3.066 & 2.860 & 2.651 & 2.450 \\
\hline
\end{tabular}

\footnotetext{
${ }^{a} \pm 5 \mathrm{ppm}$.
} 
Table S17. ${ }^{13} \mathrm{C}$ NMR Parameters (in ppm) $\delta^{\mathrm{DIA}}, \delta^{\mathrm{OBS}}, \delta^{\mathrm{PARA}}, \delta^{\mathrm{MCD}}$, and $\vartheta^{\mathrm{CON}} \approx \vartheta^{\mathrm{C}+\mathrm{L}}$ of the Bis(chelate) $11 \mathrm{Ni}$ in $\mathrm{Cl}_{2} \mathrm{CD}-$ $\mathrm{CDCl}_{2}$ or $\mathrm{CDCl}_{3}$ Solution as a Function of the Temperature

\begin{tabular}{|c|c|c|c|c|c|c|c|c|c|c|}
\hline \multirow{2}{*}{$\begin{array}{l}\text { nucleus } \\
\text { (line no.) }\end{array}$} & \multirow{2}{*}{$\begin{array}{l}\mathbf{1 1 H} \\
\delta^{\mathrm{DIA}}\end{array}$} & \multirow[t]{2}{*}{$11 \mathrm{Ni}$} & \multicolumn{8}{|c|}{ temperature $\left[{ }^{\circ} \mathrm{C}\right]$} \\
\hline & & & -49.0 & $-44.0^{a}$ & $-23.0^{a}$ & $-19.0^{b}$ & +34.0 & +36.0 & $+36.0^{a}$ & +50.0 \\
\hline \multirow[t]{3}{*}{$\mathrm{C}(2)$} & 114.8 & $\delta^{\mathrm{OBS}}$ & +981.1 & - & - & +876.6 & +747.5 & +746.1 & - & - \\
\hline & & $\delta^{\text {PARA }}$ & +866.3 & - & - & +761.8 & +632.7 & +631.3 & - & - \\
\hline & & $\delta^{\mathrm{MCD}}$ & -60.07 & - & - & -51.31 & -40.67 & -40.35 & - & - \\
\hline (line 1) & & $\vartheta^{\mathrm{CON}}$ & +696.96 & - & - & +693.60 & +694.16 & +696.90 & - & - \\
\hline \multirow[t]{3}{*}{$\mathrm{N}-\mathrm{O}-\mathrm{C}$} & 117.9 & $\delta^{\mathrm{OBS}}$ & $+763.9^{c}$ & $+746.3^{c}$ & $+697.0^{c}$ & $+684.2^{c}$ & $+589.1^{c}$ & $+587.6^{c}$ & $+587.3^{c}$ & $+567.0^{c}$ \\
\hline & & $\delta^{\text {PARA }}$ & +646.0 & +628.4 & +579.1 & +566.3 & +471.2 & +469.7 & +469.4 & +449.1 \\
\hline & & $\delta^{\mathrm{MCD}}$ & +19.41 & +18.87 & +16.91 & +16.58 & +13.14 & +13.04 & +13.04 & +12.36 \\
\hline (line 4) & & $\vartheta^{\mathrm{CON}}$ & +471.42 & +468.8 & +472.02 & +468.93 & +472.2 & +473.83 & +473.52 & $\begin{array}{r}+473.67 \\
\end{array}$ \\
\hline \multirow[t]{3}{*}{$N-i-\mathrm{C}$} & 147.0 & $\delta^{\mathrm{OBS}}$ & $+504.3^{c}$ & $+486.4^{c}$ & $+458.9^{c}$ & $+457.7^{c}$ & $+405.0^{c}$ & $+404.7^{c}$ & $+401.6^{c}$ & $+391.6^{c}$ \\
\hline & & $\delta^{\text {PARA }}$ & +357.3 & +339.4 & +311.9 & +310.7 & +258.0 & +257.7 & +254.6 & +244.6 \\
\hline & & $\delta^{\mathrm{MCD}}$ & +30.96 & +30.11 & +26.97 & +26.44 & +20.96 & +20.8 & +20.8 & +19.71 \\
\hline (line 49) & & $\vartheta^{\mathrm{CON}}$ & +245.52 & +237.89 & +239.23 & +242.48 & +244.36 & +245.81 & +242.59 & +243.90 \\
\hline \multirow[t]{3}{*}{$N-p-\mathrm{C}$} & 122.9 & $\delta^{\mathrm{OBS}}$ & +334.1 & +329.8 & +312.9 & $+308.9^{d}$ & +278.7 & +278.4 & +279.0 & +271.7 \\
\hline & & $\delta^{\text {PARA }}$ & +211.2 & +206.9 & +190.0 & +186.0 & +155.8 & +155.5 & +156.1 & +148.8 \\
\hline & & $\delta^{\mathrm{MCD}}$ & +6.63 & +6.45 & +5.78 & +5.66 & +4.49 & +4.45 & +4.45 & +4.22 \\
\hline (line 13) & & $\vartheta^{\mathrm{CON}}$ & +153.91 & +154.17 & +154.67 & +153.83 & +155.98 & +156.72 & +157.35 & +156.80 \\
\hline $\mathrm{C}(\beta)$ & 31.2 & $\delta^{\mathrm{OBS}}$ & +252.9 & +251.4 & +232.6 & $+225.7^{e}$ & +193.2 & +192.9 & $+194.4^{c}$ & +187.5 \\
\hline \multirow[t]{2}{*}{ (tert-Bu) } & & $\delta^{\text {PARA }}$ & +221.7 & +220.2 & +201.4 & +194.5 & +162.0 & +161.7 & +163.2 & +156.3 \\
\hline & & $\delta^{\mathrm{MCD}}$ & -11.32 & -11.01 & -9.86 & -9.67 & -7.66 & -7.60 & -7.60 & -7.21 \\
\hline (line 11) & & $\vartheta^{\mathrm{CON}}$ & +175.31 & +177.83 & +177.37 & +174.16 & +174.90 & +175.67 & +177.22 & +177.33 \\
\hline \multirow[t]{3}{*}{$N-m-C$} & 129.1 & $\delta^{\mathrm{OBS}}$ & +23.0 & $+25.9^{c}$ & +32.1 & $+35.1^{d}$ & +50.3 & +50.6 & $+50.9^{c}$ & +53.6 \\
\hline & & $\delta^{\text {PARA }}$ & -106.1 & -103.2 & -97.0 & -94.0 & -78.8 & -78.5 & -78.2 & -75.5 \\
\hline & & $\delta^{\mathrm{MCD}}$ & +8.43 & +8.20 & +7.34 & +7.20 & +5.71 & +5.66 & +5.66 & +5.37 \\
\hline (line 22) & & $\vartheta^{\mathrm{CON}}$ & -86.17 & -85.68 & -87.61 & -86.33 & -87.12 & -87.33 & -87.01 & -87.71 \\
\hline \multirow[t]{3}{*}{$\mathrm{C}(\alpha)$} & 33.0 & $\delta^{\mathrm{OBS}}$ & -285.0 & $-280.8^{c}$ & -254.7 & -244.7 & -196.6 & -192.8 & $-196.9^{c}$ & -187.5 \\
\hline & & $\delta^{\text {PARA }}$ & -318.0 & -313.8 & -287.7 & -277.7 & -229.6 & -225.8 & -229.9 & -220.5 \\
\hline & & $\delta^{\mathrm{MCD}}$ & -19.11 & -18.59 & -16.65 & -16.32 & -12.94 & -12.84 & -12.84 & -12.17 \\
\hline (line 25) & & $\vartheta^{\mathrm{CON}}$ & -224.87 & -227.06 & -227.57 & -222.96 & -223.35 & -220.97 & -225.22 & -225.95 \\
\hline \multirow[t]{3}{*}{$C(1,3)$} & 147.0 & $\delta^{\mathrm{OBS}}$ & -735.1 & -711.5 & -636.1 & $\begin{array}{l}-615.8 \\
\end{array}$ & -476.1 & -471.4 & -474.6 & -446.9 \\
\hline & & $\delta^{\text {PARA }}$ & -882.1 & -858.5 & -783.1 & -762.8 & -623.1 & -618.4 & -621.6 & -593.9 \\
\hline & & $\delta^{\mathrm{MCD}}$ & -61.93 & -60.22 & -53.95 & -52.89 & -41.93 & -41.6 & -41.6 & -39.43 \\
\hline (line 28) & & $\vartheta^{\mathrm{CON}}$ & -617.06 & -613.98 & -612.19 & -605.56 & -599.12 & -598.48 & -601.80 & -601.35 \\
\hline $1000 /$ (tem & iperature & in $\mathrm{K}$ ) & 4.460 & 4.363 & 3.997 & 3.934 & 3.255 & 3.234 & 3.234 & 3.094 \\
\hline
\end{tabular}

${ }^{a}$ In $\mathrm{CDCl}_{3} .{ }^{b}{ }^{1} \mathrm{H}$ coupled. ${ }^{c}$ Broad. ${ }^{d} \mathrm{~d},{ }^{1} J_{\mathrm{CH}}=159 \mathrm{~Hz} .{ }^{e} \mathrm{q},{ }^{1} J_{\mathrm{CH}}=122 \mathrm{~Hz}$. 
Table S18. ${ }^{1} \mathrm{H}$ NMR Parameters (in ppm) $\delta^{\mathrm{DIA}}, \delta^{\mathrm{OBS}}, \delta^{\mathrm{PARA}}, \delta^{\mathrm{MCD}}$, and $\vartheta^{\mathrm{CON}} \approx \vartheta^{\mathrm{C}+\mathrm{L}}$ of the Bis(chelate) $12 \mathrm{Co}$ in $\mathrm{Cl}_{2} \mathrm{CD}-\mathrm{CDCl}_{2}$ Solution as a Function of the Temperature

\begin{tabular}{|c|c|c|c|c|c|c|c|c|c|c|}
\hline \multirow{2}{*}{$\begin{array}{l}\text { nucleus } \\
\text { (line no.) }\end{array}$} & \multirow{2}{*}{$\begin{array}{l}\mathbf{1 2 H} \\
\delta^{\mathrm{DIA}}\end{array}$} & \multirow[t]{2}{*}{ 12Co } & \multicolumn{8}{|c|}{ temperature $\left[{ }^{\circ} \mathrm{C}\right]$} \\
\hline & & & -50.0 & -24.0 & -1.0 & +25.0 & +49.5 & +77.0 & +104.0 & +138.0 \\
\hline \multirow[t]{4}{*}{$\mathrm{H}\left(\alpha^{\prime}\right)$} & 7.80 & $\delta^{\mathrm{OBS}}$ & - & - & - & - & - & - & +383.5 & - \\
\hline & & $\delta^{\text {PARA }}$ & - & - & - & - & - & - & +375.7 & - \\
\hline & & $\delta^{\mathrm{MCD}}$ & - & - & - & - & - & - & +15.52 & - \\
\hline & & $\vartheta^{\mathrm{CON}}$ & - & - & - & - & - & - & +455.91 & - \\
\hline \multirow[t]{3}{*}{$N-m-\mathrm{H}$} & 7.20 & $\delta^{\mathrm{OBS}}$ & $+22.9^{a}$ & $+21.1^{a}$ & $+19.8^{a}$ & +18.8 & +18.0 & +17.4 & +16.6 & +15.7 \\
\hline & & $\delta^{\text {PARA }}$ & +15.7 & +13.9 & +12.6 & +11.6 & +10.8 & +10.2 & ++9.40 & +8.50 \\
\hline & & $\delta^{\mathrm{MCD}}$ & -6.91 & -6.02 & -5.39 & -4.83 & -4.39 & -3.98 & -3.64 & -3.29 \\
\hline (line 55) & & $\vartheta^{\mathrm{CON}}$ & +16.94 & +16.66 & +16.44 & +16.44 & +16.45 & +16.66 & +16.51 & +16.27 \\
\hline $\mathrm{H}(\delta)$ & 2.05 & $\delta^{\mathrm{OBS}}$ & +7.22 & +6.55 & +6.12 & +5.81 & +5.37 & +5.20 & +4.92 & +4.77 \\
\hline \multirow[t]{3}{*}{ (tert-H) } & & $\delta^{\text {PARA }}$ & +5.17 & +4.50 & +4.07 & +3.76 & +3.32 & +3.15 & +2.87 & +2.72 \\
\hline & & $\delta^{\mathrm{MCD}}$ & +5.99 & +5.21 & +4.67 & +4.18 & +3.80 & +3.45 & +3.16 & +2.85 \\
\hline & & $\vartheta^{\mathrm{CON}}$ & -0.61 & -0.60 & -0.55 & -0.42 & -0.52 & -0.35 & -0.36 & -0.19 \\
\hline $\mathrm{H}(\varepsilon)$ & 1.80 & $\delta^{\mathrm{OBS}}$ & +5.83 & +5.48 & +5.08 & +4.83 & +4.62 & +4.35 & +4.22 & +3.98 \\
\hline \multirow[t]{3}{*}{ (ax) } & & $\delta^{\text {PARA }}$ & +4.03 & +3.68 & +3.28 & +3.03 & +2.82 & +2.55 & +2.42 & +2.18 \\
\hline & & $\delta^{\mathrm{MCD}}$ & +6.42 & +5.59 & +5.01 & +4.48 & +4.08 & +3.70 & +3.39 & +3.06 \\
\hline & & $\vartheta^{\mathrm{CON}}$ & -1.79 & -1.60 & -1.58 & -1.46 & -1.36 & -1.35 & -1.22 & -1.22 \\
\hline $\mathrm{H}(\varepsilon)$ & 1.80 & $\delta^{\mathrm{OBS}}$ & +5.83 & +5.48 & +5.08 & +4.83 & +4.62 & +4.35 & +4.22 & +3.98 \\
\hline \multirow[t]{3}{*}{ (eq) } & & $\delta^{\text {PARA }}$ & +4.03 & +3.68 & +3.28 & +3.03 & +2.82 & +2.55 & +2.42 & +2.18 \\
\hline & & $\delta^{\mathrm{MCD}}$ & +4.79 & +4.17 & +3.74 & +3.35 & +3.04 & +2.76 & +2.53 & +2.28 \\
\hline & & $\vartheta^{\mathrm{CON}}$ & -0.57 & -0.41 & -0.42 & -0.32 & -0.24 & -0.24 & -0.13 & -0.14 \\
\hline \multirow[t]{4}{*}{$\mathrm{H}(\gamma)$} & 1.80 & $\delta^{\mathrm{OBS}}$ & +11.4 & +10.3 & +9.50 & +8.90 & +8.45 & +8.10 & +7.68 & +7.22 \\
\hline & & $\delta^{\text {PARA }}$ & +9.60 & +8.50 & +7.70 & +7.10 & +6.65 & +6.30 & +5.88 & +5.42 \\
\hline & & $\delta^{\mathrm{MCD}}$ & +15.33 & +13.35 & +11.96 & +10.71 & +9.73 & +8.82 & +8.08 & +7.31 \\
\hline & & $\vartheta^{\mathrm{CON}}$ & -4.29 & -4.05 & -3.90 & -3.61 & -3.33 & -2.97 & -2.79 & -2.60 \\
\hline \multirow[t]{3}{*}{$N-p-\mathrm{H}$} & 7.20 & $\delta^{\mathrm{OBS}}$ & $-30.30^{a}$ & $-25.88^{a}$ & $-22.84^{a}$ & -20.53 & -19.00 & -18.00 & -16.40 & -14.50 \\
\hline & & $\delta^{\mathrm{PARA}}$ & -37.50 & -33.08 & -30.04 & -27.73 & -26.20 & -25.20 & -23.60 & -21.70 \\
\hline & & $\delta^{\mathrm{MCD}}$ & -5.57 & -4.85 & -4.35 & -3.89 & -3.53 & -3.21 & -2.94 & -2.65 \\
\hline (line 78) & & $\vartheta^{\mathrm{CON}}$ & -23.92 & -23.61 & -23.47 & -23.86 & -24.54 & -25.85 & -26.16 & -26.28 \\
\hline $1000 /$ (tem & peratu & in $\mathrm{K}$ ) & 4.480 & 4.013 & 3.674 & 3.353 & 3.099 & 2.856 & 2.651 & 2.432 \\
\hline
\end{tabular}

${ }^{a}$ Broad. 
Table S19. ${ }^{13} \mathrm{C}$ NMR Parameters (in ppm) $\delta^{\mathrm{DIA}}, \delta^{\mathrm{OBS}}, \delta^{\mathrm{PARA}}, \delta^{\mathrm{MCD}}$, and $\vartheta^{\mathrm{CON}} \approx \vartheta^{\mathrm{C}+\mathrm{L}}$ of the Bis(chelate) 12Co in $\mathrm{Cl}_{2} \mathrm{CD}-\mathrm{CDCl}_{2}$ Solution as a Function of the Temperature

\begin{tabular}{|c|c|c|c|c|c|}
\hline \multirow{2}{*}{$\begin{array}{l}\text { nucleus } \\
\text { (line no.) }\end{array}$} & \multirow{2}{*}{$\begin{array}{c}\mathbf{1 2 H} \\
\delta^{\text {DIA }}\end{array}$} & \multirow[t]{2}{*}{ 12Co } & \multicolumn{3}{|c|}{ temperature $\left[{ }^{\circ} \mathrm{C}\right]$} \\
\hline & & & -41.0 & $+32.0^{a}$ & +89.0 \\
\hline \multirow[t]{3}{*}{$N-o-C$} & 117.9 & $\overline{\delta^{\mathrm{OBS}}}$ & +813.0 & +639.0 & +554.6 \\
\hline & & $\delta^{\text {PARA }}$ & +695.1 & +521.1 & +436.7 \\
\hline & & $\delta^{\mathrm{MCD}}$ & -26.82 & -19.14 & -15.60 \\
\hline (line 43) & & $\vartheta^{\mathrm{CON}}$ & +562.52 & +553.30 & +549.74 \\
\hline \multirow[t]{3}{*}{$N-i-C$} & 147.1 & $\delta^{\mathrm{OBS}}$ & +433.7 & +366.0 & +331.4 \\
\hline & & $\delta^{\text {PARA }}$ & +286.6 & +218.9 & +184.3 \\
\hline & & $\delta^{\mathrm{MCD}}$ & -41.03 & -29.28 & -23.86 \\
\hline (line 48) & & $\vartheta^{\mathrm{CON}}$ & +255.28 & +254.18 & +253.00 \\
\hline \multirow[t]{3}{*}{$N-p-\mathrm{C}$} & 122.8 & $\delta^{\mathrm{OBS}}$ & +338.3 & $+287.9^{b}$ & +263.6 \\
\hline & & $\delta^{\text {PARA }}$ & +215.5 & +165.1 & +140.8 \\
\hline & & $\delta^{\mathrm{MCD}}$ & -8.97 & -6.40 & -5.22 \\
\hline (line 52) & & $\vartheta^{\mathrm{CON}}$ & +174.91 & +175.65 & +177.47 \\
\hline \multirow[t]{3}{*}{$\mathrm{C}(\beta)$} & 42.9 & $\delta^{\mathrm{OBS}}$ & +272.5 & +219.9 & +193.3 \\
\hline & & $\delta^{\text {PARA }}$ & +229.6 & +177.0 & +150.4 \\
\hline & & $\delta^{\mathrm{MCD}}$ & +16.25 & +11.60 & +9.45 \\
\hline (line 12) & & $9^{\mathrm{CON}}$ & $\begin{array}{r}+166.24 \\
\end{array}$ & $\begin{array}{r}+169.40 \\
\end{array}$ & +171.32 \\
\hline $\mathrm{C}(\gamma)$ & 28.8 & $\delta^{\mathrm{OBS}}$ & +65.0 & $+56.7^{c}$ & +52.4 \\
\hline \multirow[t]{2}{*}{ (CH) } & & $\delta^{\text {PARA }}$ & +36.2 & +27.9 & +23.6 \\
\hline & & $\delta^{\mathrm{MCD}}$ & +8.21 & +5.86 & +4.78 \\
\hline (line 67) & & $\vartheta^{\mathrm{CON}}$ & +21.81 & +22.57 & +22.88 \\
\hline \multirow[t]{3}{*}{$\mathrm{C}(\delta)$} & 36.6 & $\delta^{\mathrm{OBS}}$ & +44.0 & $+42.1^{d}$ & +41.2 \\
\hline & & $\delta^{\text {PARA }}$ & +7.4 & +5.5 & +4.6 \\
\hline & & $\delta^{\mathrm{MCD}}$ & +6.72 & +4.80 & +3.91 \\
\hline (line 73) & & $\vartheta^{\mathrm{CON}}$ & +0.53 & +0.72 & +0.84 \\
\hline \multirow[t]{4}{*}{$N-m-\mathrm{C}$} & 129.1 & $\delta^{\mathrm{OBS}}$ & +22.8 & $+45.0^{e}$ & +54.9 \\
\hline & & $\delta^{\text {PARA }}$ & -106.3 & -84.1 & -74.2 \\
\hline & & $\delta^{\mathrm{MCD}}$ & -11.37 & -8.12 & -6.61 \\
\hline & & $\vartheta^{\mathrm{CON}}$ & -73.97 & -77.82 & -82.15 \\
\hline \multirow[t]{3}{*}{$\mathrm{C}(\alpha)$} & 34.4 & $\delta^{\mathrm{OBS}}$ & -213.0 & -156.6 & -129.0 \\
\hline & & $\delta^{\text {PARA }}$ & -247.4 & -191.0 & -163.4 \\
\hline & & $\delta^{\mathrm{MCD}}$ & +27.61 & +19.70 & +16.05 \\
\hline (line 25) & & $\vartheta^{\mathrm{CON}}$ & -214.28 & -215.79 & -218.12 \\
\hline \multicolumn{3}{|l|}{$1000 /$ te } & 4.307 & 3.277 & 2.761 \\
\hline
\end{tabular}

${ }^{a}{ }^{1} \mathrm{H}$ coupled. ${ }^{b} \mathrm{~d},{ }^{1} J_{\mathrm{CH}}=144 \mathrm{~Hz} .{ }^{c} \mathrm{~d},{ }^{1} J_{\mathrm{CH}}=123 \mathrm{~Hz} .{ }^{d} \mathrm{t},{ }^{1} J_{\mathrm{CH}}=123 \mathrm{~Hz} .{ }^{e} \mathrm{~d},{ }^{1} J_{\mathrm{CH}} \approx 140 \mathrm{~Hz}$. 
Table S20. ${ }^{1} \mathrm{H}$ NMR Parameters (in ppm) $\delta^{\mathrm{DIA}}, \delta^{\mathrm{OBS}}, \delta^{\mathrm{PARA}}, \delta^{\mathrm{MCD}}$, and $\vartheta^{\mathrm{CON}} \approx \vartheta^{\mathrm{C}+\mathrm{L}}$ of the Bis(chelate) $12 \mathrm{Ni}$ in $\mathrm{Cl}_{2} \mathrm{CD}-$ $\mathrm{CDCl}_{2}$ Solution as a Function of the Temperature

\begin{tabular}{|c|c|c|c|c|c|c|c|c|c|c|}
\hline \multirow{2}{*}{$\begin{array}{l}\text { nucleus } \\
\text { (line no.) }\end{array}$} & \multirow{2}{*}{$\begin{array}{l}\mathbf{1 2 H} \\
\delta^{\text {DIA }}\end{array}$} & \multirow[t]{2}{*}{$12 \mathrm{Ni}$} & \multicolumn{8}{|c|}{ temperature $\left[{ }^{\circ} \mathrm{C}\right]$} \\
\hline & & & -50.0 & -24.0 & -1.0 & +25.0 & +50.0 & +77.0 & +104.0 & +138.0 \\
\hline \multirow[t]{3}{*}{$\mathrm{H}\left(\alpha^{\prime}\right)$} & 7.80 & $\delta^{\mathrm{OBS}}$ & +502.8 & +457.0 & +417.5 & +381.7 & +355.7 & +326.9 & +305.9 & +281.0 \\
\hline & & $\delta^{\text {PARA }}$ & +495.0 & +449.2 & +409.7 & +373.9 & +347.9 & +319.1 & +298.1 & +273.2 \\
\hline & & $\delta^{\mathrm{MCD}}$ & -19.72 & -17.17 & -15.39 & -13.76 & -12.49 & -11.34 & -10.39 & -9.39 \\
\hline (line 6) & & $\vartheta^{\mathrm{CON}}$ & +385.52 & +390.00 & +388.28 & +387.92 & +390.86 & +388.33 & +390.48 & +389.93 \\
\hline \multirow[t]{3}{*}{$N-m-\mathrm{H}$} & 7.20 & $\delta^{\mathrm{OBS}}$ & +34.9 & +31.8 & +29.5 & +27.6 & +25.9 & +24.5 & +23.2 & +21.8 \\
\hline & & $\delta^{\text {PARA }}$ & +27.70 & +24.6 & +22.3 & +20.4 & +18.70 & +17.30 & +16.00 & +14.60 \\
\hline & & $\delta^{\mathrm{MCD}}$ & +4.82 & +4.19 & +3.76 & +3.36 & +3.05 & +2.77 & +2.54 & +2.29 \\
\hline (line 18) & & $\vartheta^{\mathrm{CON}}$ & +17.14 & +17.06 & +16.93 & +17.05 & +16.97 & +17.07 & +17.04 & +16.98 \\
\hline $\mathrm{H}(\delta)$ & 2.05 & $\delta^{\mathrm{OBS}}$ & +3.65 & +3.33 & +3.30 & +3.18 & +3.10 & +3.03 & +3.00 & +2.83 \\
\hline \multirow[t]{3}{*}{$($ tert-H) } & & $\delta^{\text {PARA }}$ & +1.60 & +1.28 & +1.25 & +1.13 & +1.05 & +0.98 & +0.95 & +0.78 \\
\hline & & $\delta^{\mathrm{MCD}}$ & -4.01 & -3.50 & -3.13 & -2.80 & -2.54 & -2.31 & -2.12 & -1.91 \\
\hline & & $\vartheta^{\mathrm{CON}}$ & +4.21 & +3.99 & +4.00 & +3.93 & +3.90 & +3.87 & +3.88 & +3.71 \\
\hline $\mathrm{H}(\varepsilon)$ & 1.80 & $\delta^{\mathrm{OBS}}$ & -1.82 & -1.45 & -1.12 & -0.93 & -0.73 & -0.47 & -0.35 & +0.03 \\
\hline \multirow[t]{3}{*}{$(a x)$} & & $\delta^{\text {PARA }}$ & -3.62 & -3.25 & -2.92 & -2.73 & -2.53 & -2.27 & -2.15 & -1.77 \\
\hline & & $\delta^{\mathrm{MCD}}$ & -4.31 & -3.75 & -3.36 & -3.00 & -2.73 & -2.48 & -2.27 & -2.05 \\
\hline & & $\vartheta^{\mathrm{CON}}$ & +0.51 & +0.42 & +0.40 & +0.27 & +0.21 & +0.24 & +0.15 & +0.39 \\
\hline $\mathrm{H}(\varepsilon)$ & 1.80 & $\delta^{\mathrm{OBS}}$ & -1.82 & -1.45 & -1.12 & -0.93 & -0.73 & -0.47 & -0.35 & +0.03 \\
\hline \multirow[t]{3}{*}{ (eq) } & & $\delta^{\text {PARA }}$ & -3.62 & -3.25 & -2.92 & -2.73 & -2.53 & -2.27 & -2.15 & -1.77 \\
\hline & & $\delta^{\mathrm{MCD}}$ & -3.21 & -2.80 & -2.51 & -2.24 & -2.03 & -1.85 & -1.69 & -1.53 \\
\hline & & $\vartheta^{\mathrm{CON}}$ & -0.31 & -0.38 & -0.38 & -0.49 & -0.54 & -0.50 & -0.58 & -0.33 \\
\hline \multirow[t]{3}{*}{$\mathrm{H}(\gamma)$} & 1.80 & $\delta^{\mathrm{OBS}}$ & -10.30 & -8.95 & -7.87 & -6.98 & -6.25 & -5.57 & -4.93 & -4.28 \\
\hline & & $\delta^{\text {PARA }}$ & -12.10 & -10.75 & -9.67 & -8.78 & -8.05 & -7.37 & -6.73 & -6.08 \\
\hline & & $\delta^{\mathrm{MCD}}$ & -10.24 & -8.92 & -7.99 & -7.15 & -6.48 & -5.89 & -5.40 & -4.88 \\
\hline (line 74) & & $\vartheta^{\mathrm{CON}}$ & -1.39 & -1.53 & -1.53 & -1.63 & -1.70 & -1.74 & -1.69 & -1.66 \\
\hline \multirow[t]{3}{*}{$N-O-H$} & 7.20 & $\delta^{\mathrm{OBS}}$ & -16.4 & -14.8 & -13.1 & -11.3 & -10.1 & -8.88 & -7.72 & -6.30 \\
\hline & & $\delta^{\text {PARA }}$ & -23.6 & -22.0 & -20.3 & -18.5 & -17.3 & -16.08 & -14.92 & -13.50 \\
\hline & & $\delta^{\mathrm{MCD}}$ & +19.21 & +16.72 & +14.99 & +13.41 & +12.16 & +11.05 & +10.12 & +9.15 \\
\hline (line 57) & & $\vartheta^{\mathrm{CON}}$ & -32.07 & -32.38 & -32.24 & -31.93 & -31.96 & -31.88 & -31.70 & -31.25 \\
\hline \multirow[t]{3}{*}{$N-p-\mathrm{H}$} & 7.20 & $\delta^{\mathrm{OBS}}$ & -22.0 & -19.2 & -17.2 & -15.0 & -13.4 & -11.88 & -10.60 & -9.12 \\
\hline & & $\delta^{\text {PARA }}$ & -29.2 & -26.4 & -24.4 & -22.2 & -20.6 & -19.08 & -17.80 & -16.32 \\
\hline & & $\delta^{\mathrm{MCD}}$ & +3.89 & +3.39 & +3.04 & +2.72 & +2.47 & +2.24 & +2.05 & +1.85 \\
\hline (line 78) & & $\vartheta^{\mathrm{CON}}$ & -24.79 & -24.91 & -25.06 & -24.93 & -25.02 & -25.05 & -25.13 & -25.08 \\
\hline \multicolumn{3}{|c|}{ 1000/(temperature in K) } & 4.480 & 4.013 & 3.674 & 3.353 & 3.094 & 2.856 & 2.651 & 2.432 \\
\hline
\end{tabular}


Table S21. ${ }^{13} \mathrm{C}$ NMR Parameters (in ppm) $\delta^{\mathrm{DIA}}, \delta^{\mathrm{OBS}}, \delta^{\mathrm{PARA}} \delta^{\mathrm{MCD}}$, and $\vartheta^{\mathrm{CON}} \approx \vartheta^{\mathrm{C}+\mathrm{L}}$ of the Bis(chelate) $\mathbf{1 2 N i}$ in $\mathrm{Cl}_{2} \mathrm{CD}-\mathrm{CDCl}_{2}$ Solution as a Function of the Temperature

\begin{tabular}{|c|c|c|c|c|c|}
\hline \multirow{2}{*}{$\begin{array}{l}\text { nucleus } \\
\text { (line no.) }\end{array}$} & \multirow{2}{*}{$\begin{array}{l}\mathbf{1 2 H} \\
\delta^{\text {DIA }}\end{array}$} & \multirow[t]{2}{*}{$12 \mathrm{Ni}$} & \multicolumn{3}{|c|}{ temperature $\left[{ }^{\circ} \mathrm{C}\right]$} \\
\hline & & & -45.0 & $+32.0^{a}$ & +89.0 \\
\hline \multirow[t]{3}{*}{$\mathrm{C}(2)$} & 115.0 & $\delta^{\mathrm{OBS}}$ & $+959.0^{b}$ & $+749.0^{b}$ & +648.0 \\
\hline & & $\delta^{\text {PARA }}$ & +844.0 & +634.0 & +533.0 \\
\hline & & $\delta^{\mathrm{MCD}}$ & -58.74 & -40.99 & -33.39 \\
\hline (line 1) & & $\vartheta^{\mathrm{CON}}$ & +691.30 & +691.30 & +688.41 \\
\hline \multirow[t]{3}{*}{$N-O-C$} & 117.9 & $\delta^{\mathrm{OBS}}$ & +753.5 & $+594.0^{C}$ & +518.9 \\
\hline & & $\delta^{\text {PARA }}$ & +635.6 & +476.1 & +401.0 \\
\hline & & $\delta^{\mathrm{MCD}}$ & +18.98 & +13.24 & +10.79 \\
\hline (line 4) & & $\vartheta^{\mathrm{CON}}$ & +472.19 & +474.04 & +474.28 \\
\hline \multirow[t]{3}{*}{$N-i-\mathrm{C}$} & 147.1 & $\delta^{\mathrm{OBS}}$ & +502.8 & $+411.9^{d}$ & +372.0 \\
\hline & & $\delta^{\text {PARA }}$ & +355.7 & +264.8 & +224.9 \\
\hline & & $\delta^{\mathrm{MCD}}$ & +30.27 & +21.13 & +17.21 \\
\hline (line 49) & & $\vartheta^{\mathrm{CON}}$ & +249.20 & +249.56 & +252.44 \\
\hline \multirow[t]{3}{*}{$N-p-\mathrm{C}$} & 122.8 & $\delta^{\mathrm{OBS}}$ & +330.5 & $+280.2^{e}$ & +255.9 \\
\hline & & $\delta^{\text {PARA }}$ & +207.7 & +157.4 & +133.1 \\
\hline & & $\delta^{\mathrm{MCD}}$ & +6.48 & +4.52 & +3.68 \\
\hline (line 13) & & $\vartheta^{\mathrm{CON}}$ & +154.09 & +156.57 & +157.30 \\
\hline \multirow[t]{3}{*}{$\mathrm{C}(\beta)$} & 42.9 & $\delta^{\mathrm{OBS}}$ & +259.6 & $+206.3^{f}$ & +179.6 \\
\hline & & $\delta^{\text {PARA }}$ & +216.7 & +163.4 & +136.7 \\
\hline & & $\delta^{\mathrm{MCD}}$ & -11.07 & -7.72 & -6.29 \\
\hline (line 11) & & $\vartheta^{\mathrm{CON}}$ & +174.42 & +175.26 & +173.80 \\
\hline $\mathrm{C}(\gamma)$ & 28.8 & $\delta^{\mathrm{OBS}}$ & +52.7 & $+47.3^{g}$ & +44.8 \\
\hline \multirow[t]{2}{*}{ (CH) } & & $\delta^{\text {PARA }}$ & +23.9 & +18.5 & +16.0 \\
\hline & & $\delta^{\mathrm{MCD}}$ & -5.61 & -3.92 & -3.19 \\
\hline (line 66) & & $\vartheta^{\mathrm{CON}}$ & +22.60 & +22.96 & +23.32 \\
\hline \multirow{3}{*}{$\mathrm{C}(\delta)$} & 36.6 & $\delta^{\mathrm{OBS}}$ & +32.1 & $+33.3^{h}$ & +34.5 \\
\hline & & $\delta^{\text {PARA }}$ & -4.50 & -3.30 & -2.10 \\
\hline & & $\delta^{\mathrm{MCD}}$ & -4.60 & -3.21 & -2.61 \\
\hline (line 73) & & $\vartheta^{\mathrm{CON}}$ & +0.07 & -0.09 & +0.62 \\
\hline \multirow[t]{3}{*}{$N-m-\mathrm{C}$} & 129.1 & $\delta^{\mathrm{OBS}}$ & $+25.4^{c}$ & $+49.7^{i}$ & +62.1 \\
\hline & & $\delta^{\text {PARA }}$ & -103.7 & -79.4 & -67.0 \\
\hline & & $\delta^{\mathrm{MCD}}$ & +8.24 & +5.75 & +4.69 \\
\hline (line 22) & & $\vartheta^{\mathrm{CON}}$ & -85.72 & -87.21 & -87.13 \\
\hline \multirow[t]{3}{*}{$\mathrm{C}(\alpha)$} & 34.4 & $\delta^{\mathrm{OBS}}$ & -280.5 & $-199.6^{d}$ & -160.2 \\
\hline & & $\delta^{\text {PARA }}$ & -314.9 & -234.0 & -194.6 \\
\hline & & $\delta^{\mathrm{MCD}}$ & -18.69 & -13.04 & -10.62 \\
\hline (line 25) & & $\vartheta^{\mathrm{CON}}$ & -226.83 & -226.30 & -223.61 \\
\hline \multirow[t]{3}{*}{$\mathrm{C}(1,3)$} & 147.1 & $\delta^{\mathrm{OBS}}$ & -702.4 & $-473.7^{d}$ & -366.3 \\
\hline & & $\delta^{\text {PARA }}$ & -849.5 & -620.8 & -513.4 \\
\hline & & $\delta^{\mathrm{MCD}}$ & -60.56 & -42.26 & -34.42 \\
\hline (line 28) & & $\vartheta^{\mathrm{CON}}$ & -604.15 & -592.52 & -582.17 \\
\hline \multicolumn{3}{|c|}{ 1000/(temperature in K) } & 4.382 & 3.277 & 2.761 \\
\hline
\end{tabular}

${ }^{a}{ }^{1}$ H coupled. ${ }^{b} \pm>3$ ppm. ${ }^{c}$ Broad. ${ }^{d}$ Narrow singlet. ${ }^{e}$ d, ${ }^{1} J_{\mathrm{CH}}=163 \mathrm{~Hz}$.

${ }^{f} \mathrm{t},{ }^{1} J_{\mathrm{CH}}=124 \mathrm{~Hz} .{ }^{g} \mathrm{~d},{ }^{1} J_{\mathrm{CH}}=131 \mathrm{~Hz} .{ }^{h} \mathrm{t},{ }^{1} J_{\mathrm{CH}}=126 \mathrm{~Hz} .{ }^{i} \mathrm{~d},{ }^{1} J_{\mathrm{CH}}=156 \mathrm{~Hz}$. 
Table S22. ${ }^{1} \mathrm{H}$ NMR Parameters (in ppm) $\delta^{\mathrm{DIA}}, \delta^{\mathrm{OBS}}, \delta^{\mathrm{PARA}}, \delta^{\mathrm{MCD}}$, and $\vartheta^{\mathrm{CON}} \approx \vartheta^{\mathrm{C}+\mathrm{L}}$ of the Bis(chelate) $13 \mathrm{Co}$ in $\mathrm{Cl}_{2} \mathrm{CD}-\mathrm{CDCl}_{2}$ Solution as a Function of the Temperature

\begin{tabular}{|c|c|c|c|c|c|c|c|c|}
\hline \multirow{2}{*}{$\begin{array}{l}\text { nucleus } \\
\text { (line no.) }\end{array}$} & \multirow{2}{*}{$\begin{array}{r}13 \mathrm{H} \\
\delta^{\mathrm{DIA}}\end{array}$} & \multirow[t]{2}{*}{ 13Co } & \multicolumn{6}{|c|}{ temperature $\left[{ }^{\circ} \mathrm{C}\right]$} \\
\hline & & & -53.5 & -28.5 & -1.0 & +25.0 & +62.0 & +100.0 \\
\hline \multirow[t]{3}{*}{$N-m-\mathrm{H}$} & 7.27 & $\delta^{\mathrm{OBS}}$ & +23.2 & +21.6 & +20.1 & +19.0 & +17.8 & +16.66 \\
\hline & & $\delta^{\text {PARA }}$ & +15.93 & +14.33 & +12.83 & +11.73 & +10.53 & +9.39 \\
\hline & & $\delta^{\mathrm{MCD}}$ & -7.05 & -6.16 & -5.39 & -4.83 & -4.19 & -3.69 \\
\hline (line 55) & & $\vartheta^{\mathrm{CON}}$ & +16.94 & +16.82 & +16.65 & +16.57 & +16.56 & +16.38 \\
\hline \multirow[t]{4}{*}{$\mathrm{H}(\delta)$} & 1.52 & $\delta^{\mathrm{OBS}}$ & +9.17 & +8.30 & +7.47 & +7.02 & +6.45 & +6.01 \\
\hline & & $\delta^{\text {PARA }}$ & +7.65 & +6.78 & +5.95 & +5.50 & +4.93 & +4.49 \\
\hline & & $\delta^{\mathrm{MCD}}$ & +6.63 & +5.78 & +5.07 & +4.53 & +3.94 & +3.47 \\
\hline & & $\vartheta^{\mathrm{CON}}$ & +0.76 & +0.82 & +0.80 & +0.97 & +1.11 & +1.28 \\
\hline $\mathrm{H}(\zeta)$ & 0.83 & $\delta^{\mathrm{OBS}}$ & +4.50 & +3.95 & +3.60 & +3.30 & +3.08 & +2.88 \\
\hline \multirow[t]{2}{*}{$(\mathrm{Me})$} & & $\delta^{\text {PARA }}$ & +3.67 & +3.12 & +2.77 & +2.47 & +2.25 & +2.05 \\
\hline & & $\delta^{\mathrm{MCD}}$ & +3.90 & +3.41 & +2.99 & +2.67 & +2.32 & +2.04 \\
\hline (line 36) & & $\vartheta^{\mathrm{CON}}$ & -0.17 & -0.23 & -0.20 & -0.20 & -0.08 & +0.01 \\
\hline \multirow[t]{4}{*}{$\mathrm{H}(\gamma)$} & 1.70 & $\delta^{\mathrm{OBS}}$ & $+11.46^{a}$ & $+10.70^{a}$ & $+9.30^{a}$ & $+8.60^{a}$ & $+7.80^{a}$ & $+7.12^{a}$ \\
\hline & & $\delta^{\text {PARA }}$ & +9.76 & +9.00 & +7.60 & +6.90 & +6.10 & +5.42 \\
\hline & & $\delta^{\mathrm{MCD}}$ & +15.64 & +13.65 & +11.96 & +10.71 & +9.30 & +8.18 \\
\hline & & $\vartheta^{\mathrm{CON}}$ & -4.33 & -3.82 & -3.99 & -3.81 & -3.60 & -3.46 \\
\hline \multirow[t]{3}{*}{$N-p-\mathrm{H}$} & 7.03 & $\delta^{\mathrm{OBS}}$ & -31.6 & -27.8 & -24.3 & -21.9 & -19.3 & -16.66 \\
\hline & & $\delta^{\text {PARA }}$ & -38.63 & -34.83 & -31.33 & -28.93 & -26.33 & -23.69 \\
\hline & & $\delta^{\mathrm{MCD}}$ & -5.68 & -4.96 & -4.35 & -3.89 & -3.38 & -2.97 \\
\hline (line 78) & & $\vartheta^{\mathrm{CON}}$ & -24.29 & -24.53 & -24.65 & -25.06 & -25.82 & -25.95 \\
\hline $1000 /$ (tem & iperatu & e in $K$ ) & 4.552 & 4.087 & 3.674 & 3.353 & 2.983 & 2.680 \\
\hline
\end{tabular}

a Broad. 
Table S23. ${ }^{13} \mathrm{C}$ NMR Parameters (in ppm) $\delta^{\mathrm{DIA}}, \delta^{\mathrm{OBS}}, \delta^{\mathrm{PARA}}, \delta^{\mathrm{MCD}}$, and $\vartheta^{\mathrm{CON}} \approx \vartheta^{\mathrm{C}+\mathrm{L}}$ of the Bis(chelate) $\mathbf{1 3 C o}$ in $\mathrm{Cl}_{2} \mathrm{CD}-\mathrm{CDCl}_{2}$ Solution as a Function of the Temperature

\begin{tabular}{|c|c|c|c|c|}
\hline \multirow{2}{*}{$\begin{array}{l}\text { nucleus } \\
\text { (line no.) }\end{array}$} & \multirow{2}{*}{$\begin{array}{c}\mathbf{1 3 H} \\
\delta^{\text {DIA }}\end{array}$} & \multirow[t]{2}{*}{ 13Co } & \multicolumn{2}{|c|}{ temperature $\left[{ }^{\circ} \mathrm{C}\right]$} \\
\hline & & & -44.0 & $+31.0^{a}$ \\
\hline \multirow[t]{3}{*}{$\mathrm{N}-\mathrm{O}-\mathrm{C}$} & 117.9 & $\delta^{\mathrm{OBS}}$ & +822.0 & +642.0 \\
\hline & & $\delta^{\text {PARA }}$ & +704.1 & +524.1 \\
\hline & & $\delta^{\mathrm{MCD}}$ & -27.27 & -19.22 \\
\hline (line 43) & & $\vartheta^{\mathrm{CON}}$ & +562.51 & +554.62 \\
\hline \multirow[t]{3}{*}{$N-i-\mathrm{C}$} & 147.1 & $\delta^{\mathrm{OBS}}$ & +433.0 & +364.0 \\
\hline & & $\delta^{\text {PARA }}$ & +285.9 & +216.9 \\
\hline & & $\delta^{\mathrm{MCD}}$ & -41.70 & -29.40 \\
\hline (line 48) & & $\vartheta^{\mathrm{CON}}$ & +251.97 & +251.42 \\
\hline \multirow[t]{3}{*}{$N-p-\mathrm{C}$} & 122.9 & $\delta^{\mathrm{OBS}}$ & +344.0 & $+289.1^{b}$ \\
\hline & & $\delta^{\text {PARA }}$ & +221.1 & +166.2 \\
\hline & & $\delta^{\mathrm{MCD}}$ & -9.12 & -6.43 \\
\hline (line 52) & & $\vartheta^{\mathrm{CON}}$ & +177.07 & +176.22 \\
\hline \multirow[t]{3}{*}{$\mathrm{C}(\beta)$} & 32.5 & $\delta^{\mathrm{OBS}}$ & +264.0 & +208.0 \\
\hline & & $\delta^{\text {PARA }}$ & +231.5 & +175.5 \\
\hline & & $\delta^{\mathrm{MCD}}$ & +16.52 & +11.64 \\
\hline (line 12) & & $\vartheta^{\mathrm{CON}}$ & +165.35 & +167.27 \\
\hline \multirow{3}{*}{$\mathrm{C}(\gamma)$} & 33.6 & $\delta^{\mathrm{OBS}}$ & +67.2 & $+59.1^{c}$ \\
\hline & & $\delta^{\text {PARA }}$ & +33.6 & +25.5 \\
\hline & & $\delta^{\mathrm{MCD}}$ & +8.35 & +5.88 \\
\hline (line 68) & & $\vartheta^{\mathrm{CON}}$ & +19.42 & +20.02 \\
\hline $\mathrm{C}(\varepsilon)$ & 28.2 & $\delta^{\mathrm{OBS}}$ & +33.6 & $+32.1^{d}$ \\
\hline \multirow[t]{3}{*}{ (Me) } & & $\delta^{\text {PARA }}$ & +5.40 & +3.90 \\
\hline & & $\delta^{\mathrm{MCD}}$ & +4.32 & +3.05 \\
\hline & & $\vartheta^{\mathrm{CON}}$ & +0.83 & +0.87 \\
\hline \multirow[t]{4}{*}{$\mathrm{C}(\delta)$} & 27.8 & $\delta^{\mathrm{OBS}}$ & +33.6 & $+32.1^{e}$ \\
\hline & & $\delta^{\text {PARA }}$ & +5.80 & +4.30 \\
\hline & & $\delta^{\mathrm{MCD}}$ & +7.68 & +5.41 \\
\hline & & $\vartheta^{\mathrm{CON}}$ & -1.44 & -1.13 \\
\hline \multirow[t]{4}{*}{$N-m-C$} & 129.1 & $\delta^{\mathrm{OBS}}$ & +17.2 & $+44.1^{f}$ \\
\hline & & $\delta^{\text {PARA }}$ & -111.9 & -85.0 \\
\hline & & $\delta^{\mathrm{MCD}}$ & -11.56 & -8.15 \\
\hline & & $\vartheta^{\mathrm{CON}}$ & -77.17 & -78.45 \\
\hline \multirow[t]{3}{*}{$\mathrm{C}(\alpha)$} & 32.9 & $\delta^{\mathrm{OBS}}$ & -226.0 & $-163.5^{e}$ \\
\hline & & $\delta^{\text {PARA }}$ & -258.9 & -196.4 \\
\hline & & $\delta^{\mathrm{MCD}}$ & +28.06 & +19.78 \\
\hline (line 25) & & $\vartheta^{\mathrm{CON}}$ & -220.71 & -220.68 \\
\hline \multicolumn{3}{|c|}{ 1000/(temperature in K) } & 4.363 & 3.287 \\
\hline
\end{tabular}

${ }^{a}{ }^{1} \mathrm{H}$ coupled. ${ }^{b} \mathrm{~d},{ }^{1} J_{\mathrm{CH}}>128 \mathrm{~Hz} .{ }^{c} \mathrm{t},{ }^{1} J_{\mathrm{CH}}=131 \mathrm{~Hz} .{ }^{d} \mathrm{~m},{ }^{1} J_{\mathrm{CH}} \approx 122 \mathrm{~Hz} .{ }^{e}$ Narrow singlet. ${ }^{f} \mathrm{~d},{ }^{1} J_{\mathrm{CH}}=140 \mathrm{~Hz}$. 
Table S24. ${ }^{1} \mathrm{H}$ NMR Parameters (in ppm) $\delta^{\mathrm{DIA}}, \delta^{\mathrm{OBS}}, \delta^{\mathrm{PARA}}, \delta^{\mathrm{MCD}}$, and $\vartheta^{\mathrm{CON}} \approx \vartheta^{\mathrm{C}+\mathrm{L}}$ of the Bis(chelate) 13Ni in $\mathrm{Cl}_{2} \mathrm{CD}-\mathrm{CDCl}_{2}$ Solution as a Function of the Temperature

\begin{tabular}{|c|c|c|c|c|c|c|c|c|c|c|}
\hline \multirow{2}{*}{$\begin{array}{l}\text { nucleus } \\
\text { (line no.) }\end{array}$} & \multirow{2}{*}{$\begin{array}{l}\mathbf{1 3 H} \\
\delta^{\text {DIA }} \\
\end{array}$} & \multirow[t]{2}{*}{$13 N i$} & \multicolumn{8}{|c|}{ temperature $\left[{ }^{\circ} \mathrm{C}\right]$} \\
\hline & & & -49.0 & -27.0 & $-8.0^{a}$ & +24.0 & +50.0 & +75.0 & +109.5 & 135.0 \\
\hline \multirow[t]{3}{*}{$\mathrm{H}(\alpha)$} & 7.77 & $\delta^{\mathrm{OBS}}$ & +503.1 & +461.8 & +424.3 & +379.0 & +351.6 & +326.7 & +297.8 & +282.1 \\
\hline & & $\delta^{\text {PARA }}$ & +495.33 & +454.03 & +416.53 & +371.23 & +343.83 & +318.93 & +290.03 & +274.33 \\
\hline & & $\delta^{\mathrm{MCD}}$ & -19.61 & -17.43 & -15.89 & -13.82 & -12.49 & -11.42 & -10.21 & -9.47 \\
\hline (line 6) & & $\vartheta^{\mathrm{CON}}$ & +387.41 & +389.51 & +384.83 & +384.02 & +386.45 & +386.00 & +385.58 & +388.75 \\
\hline \multirow[t]{3}{*}{$N-m-\mathrm{H}$} & 7.27 & $\delta^{\mathrm{OBS}}$ & +34.4 & +32.4 & +30.0 & +27.6 & +25.9 & +24.5 & +22.9 & +22.0 \\
\hline & & $\delta^{\mathrm{PARA}}$ & +27.13 & +25.13 & +22.73 & +20.33 & +18.63 & +17.23 & +15.63 & +14.73 \\
\hline & & $\delta^{\mathrm{MCD}}$ & +4.79 & +4.26 & +3.88 & +3.38 & +3.05 & +2.79 & +2.50 & +2.31 \\
\hline (line 18) & & $\vartheta^{\mathrm{CON}}$ & +16.81 & +17.24 & +16.77 & +16.91 & +16.90 & +16.87 & +16.87 & +17.01 \\
\hline \multirow[t]{3}{*}{$\mathrm{H}(\delta)$} & 1.52 & $\delta^{\mathrm{OBS}}$ & -0.01 & +0.01 & +0.23 & +0.42 & +0.55 & +0.65 & +0.73 & +0.87 \\
\hline & & $\delta^{\text {PARA }}$ & -1.53 & -1.51 & -1.29 & -1.10 & -0.97 & -0.87 & -0.79 & -0.65 \\
\hline & & $\delta^{\mathrm{MCD}}$ & -4.32 & -3.84 & -3.50 & -3.05 & -2.75 & -2.52 & -2.25 & -2.09 \\
\hline (line 34) & & $\vartheta^{\mathrm{CON}}$ & +2.10 & +1.93 & +1.97 & +1.94 & +1.93 & +1.93 & +1.88 & +1.97 \\
\hline $\mathrm{H}(\zeta)$ & 0.83 & $\delta^{\mathrm{OBS}}$ & -1.43 & -1.32 & -1.02 & -0.87 & -0.55 & -0.47 & -0.37 & -0.28 \\
\hline \multirow[t]{2}{*}{ (Me) } & & $\delta^{\text {PARA }}$ & -2.26 & -2.15 & -1.85 & -1.70 & -1.38 & -1.30 & -1.20 & -1.11 \\
\hline & & $\delta^{\mathrm{MCD}}$ & -2.55 & -2.27 & -2.07 & -1.80 & -1.62 & -1.49 & -1.33 & -1.23 \\
\hline (line 35) & & $\vartheta^{\mathrm{CON}}$ & +0.22 & +0.10 & +0.19 & +0.10 & +0.26 & +0.22 & +0.16 & +0.17 \\
\hline \multirow[t]{3}{*}{$\mathrm{H}(\gamma)$} & 1.70 & $\delta^{\mathrm{OBS}}$ & -10.60 & -9.40 & -8.30 & -7.10 & -6.33 & -5.60 & -5.00 & -4.50 \\
\hline & & $\delta^{\text {PARA }}$ & -12.30 & -11.10 & -10.00 & -8.80 & -8.03 & -7.30 & -6.70 & -6.20 \\
\hline & & $\delta^{\mathrm{MCD}}$ & -10.18 & -9.05 & -8.25 & -7.18 & -6.48 & -5.93 & -5.30 & -4.92 \\
\hline (line 74) & & $\vartheta^{\mathrm{CON}}$ & -1.59 & -1.69 & -1.56 & -1.62 & -1.68 & -1.60 & -1.79 & -1.76 \\
\hline \multirow[t]{3}{*}{$N-O-H$} & 7.03 & $\delta^{\mathrm{OBS}}$ & -17.5 & -15.3 & -13.3 & -11.5 & -10.0 & -9.30 & -7.60 & -6.90 \\
\hline & & $\delta^{\text {PARA }}$ & -24.53 & -22.33 & -20.33 & -18.53 & -17.03 & -16.33 & -14.63 & -13.93 \\
\hline & & $\delta^{\mathrm{MCD}}$ & +19.10 & +16.98 & +15.48 & +13.46 & +12.16 & +11.13 & +9.95 & +9.23 \\
\hline (line 57) & & $\vartheta^{\mathrm{CON}}$ & -32.83 & -32.48 & -31.87 & -31.91 & -31.66 & -32.08 & -31.57 & -31.72 \\
\hline \multirow[t]{3}{*}{$N-p-\mathrm{H}$} & 7.03 & $\delta^{\mathrm{OBS}}$ & -22.4 & -20.0 & -17.7 & -15.3 & -13.3 & -12.1 & -10.4 & -9.50 \\
\hline & & $\delta^{\text {PARA }}$ & -29.43 & -27.03 & -24.73 & -22.33 & -20.33 & -19.13 & -17.43 & -16.53 \\
\hline & & $\delta^{\mathrm{MCD}}$ & +3.87 & +3.44 & +3.14 & +2.73 & +2.47 & +2.26 & +2.02 & +1.87 \\
\hline (line 78) & & $\vartheta^{\mathrm{CON}}$ & -25.05 & -25.18 & -24.80 & -24.99 & -24.72 & -24.99 & -24.97 & -25.20 \\
\hline \multicolumn{3}{|c|}{ 1000/(temperature in K) } & 4.460 & 4.062 & 3.771 & 3.365 & 3.094 & 2.872 & 2.613 & 2.450 \\
\hline
\end{tabular}


Table S25. ${ }^{13} \mathrm{C}$ NMR Parameters (in ppm) $\delta^{\mathrm{DIA}}, \delta^{\mathrm{OBS}}, \delta^{\mathrm{PARA}}, \delta^{\mathrm{MCD}}$, and $\vartheta^{\mathrm{CON}} \approx \vartheta^{\mathrm{C}+\mathrm{L}}$ of the Bis(chelate) $\mathbf{1 3 N i}$ in $\mathrm{Cl}_{2} \mathrm{CD}-\mathrm{CDCl}_{2}$ Solution as a Function of the Temperature

\begin{tabular}{|c|c|c|c|c|c|}
\hline \multirow{2}{*}{$\begin{array}{l}\text { nucleus } \\
\text { (line no.) }\end{array}$} & \multirow{2}{*}{$\begin{array}{c}\text { 13H } \\
\delta^{\text {DIA }}\end{array}$} & \multirow[t]{2}{*}{$13 N i$} & \multicolumn{3}{|c|}{ temperature $\left[{ }^{\circ} \mathrm{C}\right]$} \\
\hline & & & -46.0 & -22.0 & $+33.0^{a}$ \\
\hline \multirow[t]{3}{*}{$\mathrm{C}(2)$} & 114.0 & $\delta^{\mathrm{OBS}}$ & +954.0 & +878.6 & +746.1 \\
\hline & & $\delta^{\text {PARA }}$ & +840.0 & +764.6 & +632.1 \\
\hline & & $\delta^{\mathrm{MCD}}$ & -59.07 & -52.07 & -40.83 \\
\hline (line 1) & & $\vartheta^{\mathrm{CON}}$ & +685.47 & +688.42 & +691.45 \\
\hline \multirow[t]{3}{*}{$\mathrm{N}-\mathrm{O}-\mathrm{C}$} & 117.9 & $\delta^{\mathrm{OBS}}$ & +750.6 & +694.2 & +593.7 \\
\hline & & $\delta^{\text {PARA }}$ & +632.7 & +576.3 & +475.8 \\
\hline & & $\delta^{\mathrm{MCD}}$ & +19.08 & +16.82 & +13.19 \\
\hline (line 4) & & $\vartheta^{\mathrm{CON}}$ & +467.83 & +471.61 & +475.34 \\
\hline \multirow[t]{3}{*}{$N-i-C$} & 147.1 & $\delta^{\mathrm{OBS}}$ & +498.9 & +466.1 & +409.2 \\
\hline & & $\delta^{\text {PARA }}$ & +351.8 & +319.0 & +262.1 \\
\hline & & $\delta^{\mathrm{MCD}}$ & +30.44 & +26.84 & +21.04 \\
\hline (line 49) & & $\vartheta^{\mathrm{CON}}$ & +245.01 & +246.28 & +247.69 \\
\hline \multirow[t]{3}{*}{$N-p-C$} & 122.9 & $\delta^{\mathrm{OBS}}$ & +330.8 & +312.3 & $+279.9^{b}$ \\
\hline & & $\delta^{\text {PARA }}$ & +207.9 & +189.4 & +157.0 \\
\hline & & $\delta^{\mathrm{MCD}}$ & +6.52 & +5.75 & +4.51 \\
\hline (line 13) & & $\vartheta^{\mathrm{CON}}$ & +153.54 & +154.81 & +156.69 \\
\hline \multirow[t]{3}{*}{$\mathrm{C}(\beta)$} & 32.5 & $\delta^{\mathrm{OBS}}$ & +245.3 & +226.9 & $+192.9^{c}$ \\
\hline & & $\delta^{\text {PARA }}$ & +212.8 & +194.4 & +160.4 \\
\hline & & $\delta^{\mathrm{MCD}}$ & -11.13 & -9.81 & -7.69 \\
\hline (line 11) & & $\vartheta^{\mathrm{CON}}$ & +170.73 & +172.14 & +172.72 \\
\hline \multirow[t]{3}{*}{$\mathrm{C}(\gamma)$} & 33.6 & $\delta^{\text {OBS }}$ & +53.9 & +52.4 & $+49.4^{c}$ \\
\hline & & $\delta^{\text {PARA }}$ & +20.3 & +18.8 & +15.8 \\
\hline & & $\delta^{\mathrm{MCD}}$ & -5.64 & -4.97 & -3.90 \\
\hline (line 68) & & $\vartheta^{\mathrm{CON}}$ & +19.78 & +20.04 & +20.24 \\
\hline $\mathrm{C}(\varepsilon)$ & 28.2 & $\delta^{\mathrm{OBS}}$ & +23.6 & +24.2 & $+24.8^{d}$ \\
\hline \multirow[t]{3}{*}{ (Me) } & & $\delta^{\text {PARA }}$ & -4.60 & -4.00 & -3.40 \\
\hline & & $\delta^{\mathrm{MCD}}$ & -2.93 & -2.59 & -2.03 \\
\hline & & $\vartheta^{\mathrm{CON}}$ & -1.27 & -1.19 & -1.41 \\
\hline \multirow[t]{4}{*}{$\mathrm{C}(\delta)$} & 27.8 & $\delta^{\mathrm{OBS}}$ & +19.4 & +20.3 & +21.8 \\
\hline & & $\delta^{\text {PARA }}$ & -8.40 & -7.50 & -6.00 \\
\hline & & $\delta^{\mathrm{MCD}}$ & -5.19 & -4.57 & -3.59 \\
\hline & & $\vartheta^{\mathrm{CON}}$ & -2.45 & -2.47 & -2.48 \\
\hline \multirow[t]{3}{*}{$N-m-\mathrm{C}$} & 129.1 & $\delta^{\text {OBS }}$ & +25.5 & +33.3 & $+49.7^{b}$ \\
\hline & & $\delta^{\text {PARA }}$ & -103.7 & -95.9 & -79.5 \\
\hline & & $\delta^{\mathrm{MCD}}$ & +8.29 & +7.31 & +5.73 \\
\hline (line 22) & & $\vartheta^{\mathrm{CON}}$ & -85.38 & -87.00 & -87.58 \\
\hline \multirow[t]{3}{*}{$\mathrm{C}(\alpha)$} & 32.9 & $\delta^{\mathrm{OBS}}$ & -286.2 & -256.9 & $-204.8^{e}$ \\
\hline & & $\delta^{\text {PARA }}$ & -319.1 & -289.8 & -237.7 \\
\hline & & $\delta^{\mathrm{MCD}}$ & -18.79 & -16.57 & -12.99 \\
\hline (line 25) & & $\vartheta^{\mathrm{CON}}$ & -228.96 & -230.32 & -230.89 \\
\hline \multirow[t]{3}{*}{$\mathrm{C}(1,3)$} & 147.5 & $\delta^{\text {OBS }}$ & -703.9 & -621.2 & $-475.2^{e}$ \\
\hline & & $\delta^{\text {PARA }}$ & -851.4 & -768.7 & -622.7 \\
\hline & & $\delta^{\mathrm{MCD}}$ & -60.89 & -53.68 & -42.09 \\
\hline (line 28) & & $\vartheta^{\mathrm{CON}}$ & -602.69 & -602.73 & -596.58 \\
\hline \multicolumn{3}{|c|}{ 1000/(temperature in K) } & 4.401 & 3.981 & 3.266 \\
\hline
\end{tabular}

${ }^{a}{ }^{1} \mathrm{H}$ coupled. ${ }^{b} \mathrm{~d},{ }^{1} J_{\mathrm{CH}}=159 \mathrm{~Hz} .{ }^{c} \mathrm{t},{ }^{1} J_{\mathrm{CH}}=128.2 \mathrm{~Hz} .{ }^{d} \mathrm{q},{ }^{1} J_{\mathrm{CH}}=123 \mathrm{~Hz} .{ }^{e}$ Narrow singlet. 
Table S26. ${ }^{1} \mathrm{H}$ NMR Parameters (in ppm) $\delta^{\mathrm{DIA}}, \delta^{\mathrm{OBS}}, \delta^{\mathrm{PARA}}, \delta^{\mathrm{MCD}}$, and $\vartheta^{\mathrm{CON}} \approx \vartheta^{\mathrm{C}+\mathrm{L}}$ of the Bis(chelate) 14Ni in $\mathrm{Cl}_{2} \mathrm{CD}-\mathrm{CDCl}_{2}$ Solution as a Function of the Temperature

\begin{tabular}{|c|c|c|c|c|c|c|c|c|c|}
\hline \multirow{2}{*}{$\begin{array}{l}\text { nucleus } \\
\text { (line no.) }\end{array}$} & \multirow{2}{*}{$\begin{array}{l}14 \mathrm{H} \\
\delta^{\mathrm{DIA}}\end{array}$} & \multirow[t]{2}{*}{$14 \mathrm{Ni}$} & \multicolumn{7}{|c|}{ temperature $\left[{ }^{\circ} \mathrm{C}\right]$} \\
\hline & & & -62.0 & -32.0 & -18.0 & -3.5 & +27.5 & +29.5 & +55.0 \\
\hline \multirow[t]{3}{*}{$\mathrm{N}-\mathrm{CH}_{3}$} & 2.95 & $\delta^{\mathrm{OBS}}$ & +367.7 & +321.2 & +303.2 & +287.8 & +259.2 & +258.3 & +238.8 \\
\hline & & $\delta^{\text {PARA }}$ & +364.75 & +318.25 & +300.25 & +284.85 & +256.25 & +255.35 & +235.85 \\
\hline & & $\delta^{\mathrm{MCD}}$ & +25.58 & +21.62 & +20.15 & +18.81 & +16.47 & +16.34 & +14.82 \\
\hline (line 9) & & $\vartheta^{\mathrm{CON}}$ & +240.38 & +240.09 & +239.87 & +240.77 & +241.95 & +242.78 & +243.43 \\
\hline \multirow[t]{3}{*}{$\mathrm{H}\left(\beta^{\prime}\right)$} & 1.78 & $\delta^{\mathrm{OBS}}$ & -78.6 & -68.3 & -64.8 & -61.0 & -54.4 & -54.1 & -49.5 \\
\hline & & $\delta^{\text {PARA }}$ & -80.38 & -70.08 & -66.58 & -62.78 & -56.18 & -55.88 & -51.28 \\
\hline & & $\delta^{\mathrm{MCD}}$ & -8.46 & -7.15 & -6.66 & -6.22 & -5.45 & -5.40 & -4.90 \\
\hline (line 59) & & $\vartheta^{\mathrm{CON}}$ & -50.97 & -50.94 & -51.31 & -51.19 & -51.19 & -51.27 & -51.08 \\
\hline \multirow[t]{3}{*}{$\mathrm{H}(\alpha)$} & 4.37 & $\delta^{\mathrm{OBS}}$ & -179.2 & -154.8 & -146.6 & - & -122.3 & -122.2 & -112.0 \\
\hline & & $\delta^{\text {PARA }}$ & -183.57 & -159.17 & -150.97 & - & -126.67 & -126.57 & -116.37 \\
\hline & & $\delta^{\mathrm{MCD}}$ & -27.35 & -23.11 & -21.54 & - & -17.61 & -17.47 & -15.84 \\
\hline (line 63) & & $\vartheta^{\mathrm{CON}}$ & -110.72 & -110.12 & -110.84 & - & -110.05 & -110.82 & -110.71 \\
\hline \multicolumn{3}{|c|}{ 1000/(temperature in K) } & 4.735 & 4.146 & 3.918 & 3.708 & 3.326 & 3.304 & 3.047 \\
\hline
\end{tabular}


Table S27. ${ }^{1} \mathrm{H}$ NMR Parameters (in ppm) $\delta^{\mathrm{DIA}}, \delta^{\mathrm{OBS}}, \delta^{\mathrm{PARA}}, \delta^{\mathrm{MCD}}$, and $\vartheta^{\mathrm{CON}} \approx \vartheta^{\mathrm{C}+\mathrm{L}}$ of the Bis(chelate) 15Co in $\mathrm{Cl}_{2} \mathrm{CD}-\mathrm{CDCl}_{2}$ Solution as a Function of the Temperature

\begin{tabular}{|c|c|c|c|c|c|c|c|c|c|}
\hline \multirow{2}{*}{$\begin{array}{l}\text { nucleus } \\
\text { (line no.) }\end{array}$} & \multirow{2}{*}{$\begin{array}{r}15 \mathbf{H} \\
\delta^{\text {DIA }}\end{array}$} & \multirow[t]{2}{*}{ 15Co } & \multicolumn{7}{|c|}{ temperature $\left[{ }^{\circ} \mathrm{C}\right]$} \\
\hline & & & -30.0 & -13.0 & +30.5 & +58.0 & +87.0 & +112.0 & +134.0 \\
\hline \multirow[t]{4}{*}{$N-m-\mathrm{H}$} & 7.00 & $\delta^{\mathrm{OBS}}$ & +18.7 & +18.3 & 16.8 & +16.1 & +15.5 & +14.8 & +14.5 \\
\hline & & $\delta^{\text {PARA }}$ & +11.70 & +11.30 & +9.80 & +9.10 & +8.50 & +7.80 & +7.50 \\
\hline & & $\delta^{\mathrm{MCD}}$ & -6.20 & -5.70 & -4.72 & -4.25 & -3.85 & -3.56 & -3.33 \\
\hline & & $\vartheta^{\mathrm{CON}}$ & +14.61 & +14.85 & +14.80 & +14.84 & +14.93 & +14.68 & +14.80 \\
\hline \multirow[t]{4}{*}{$N-p-\mathrm{H}$} & 7.00 & $\delta^{\mathrm{OBS}}$ & -36.1 & -34.3 & -27.6 & -25.2 & -22.6 & -20.4 & -19.2 \\
\hline & & $\delta^{\text {PARA }}$ & -43.10 & -41.30 & -34.60 & -32.20 & -29.60 & -27.40 & -26.20 \\
\hline & & $\delta^{\mathrm{MCD}}$ & -5.00 & -4.59 & -3.80 & -3.43 & -3.10 & -2.86 & -2.68 \\
\hline & & $\vartheta^{\mathrm{CON}}$ & -31.10 & -32.05 & -31.39 & -31.98 & -32.03 & -31.72 & -32.13 \\
\hline \multirow[t]{4}{*}{$\mathrm{H}\left(\beta^{\prime}\right)$} & 1.93 & $\delta^{\mathrm{OBS}}$ & -51.9 & -49.0 & -41.4 & -38.1 & -35.0 & -32.1 & -30.2 \\
\hline & & $\delta^{\text {PARA }}$ & -53.83 & -50.93 & -43.33 & -40.03 & -36.93 & -34.03 & -32.13 \\
\hline & & $\delta^{\mathrm{MCD}}$ & +10.61 & +9.76 & +8.08 & +7.28 & +6.58 & +6.08 & +5.70 \\
\hline & & $\vartheta^{\mathrm{CON}}$ & -52.59 & -52.99 & -52.39 & -52.58 & -52.60 & -51.85 & -51.69 \\
\hline \multirow[t]{3}{*}{$\mathrm{H}(\alpha)$} & 4.75 & $\delta^{\mathrm{OBS}}$ & $-85.3^{a}$ & -80.6 & -69.5 & -65.0 & -59.6 & -55.4 & -53.1 \\
\hline & & $\delta^{\text {PARA }}$ & -90.05 & -85.35 & -74.25 & -69.75 & -64.35 & -60.15 & -57.85 \\
\hline & & $\delta^{\mathrm{MCD}}$ & +34.63 & +31.84 & +26.35 & +23.74 & +21.48 & +19.85 & +18.60 \\
\hline (line 23) & & $\vartheta^{\mathrm{CON}}$ & -101.75 & -102.32 & -102.52 & -103.90 & -103.75 & -103.41 & -104.46 \\
\hline $1000 /$ (tem & rature & K) & 4.112 & 3.843 & 3.293 & 3.019 & 2.776 & 2.596 & 2.456 \\
\hline
\end{tabular}

a \pm 3 ppm. 
Table S28. ${ }^{13} \mathrm{C}$ NMR Parameters (in ppm) $\delta^{\mathrm{DIA}}, \delta^{\mathrm{OBS}}, \delta^{\mathrm{PARA}}, \delta^{\mathrm{MCD}}$, and $\vartheta^{\mathrm{CON}} \approx \vartheta^{\mathrm{C}+\mathrm{L}}$ of the Bis(chelate) $15 \mathrm{Co}$ in $\mathrm{Cl}_{2} \mathrm{CD}-\mathrm{CDCl}_{2}$ Solution as a Function of the Temperature

\begin{tabular}{|c|c|c|c|c|c|}
\hline \multirow[t]{2}{*}{ nucleus } & \multirow{2}{*}{$\begin{array}{l}\mathbf{1 5 H} \\
\delta^{\mathrm{DIA}}\end{array}$} & \multirow[t]{2}{*}{ 15Co } & \multicolumn{3}{|c|}{ temperature $\left[{ }^{\circ} \mathrm{C}\right]$} \\
\hline & & & $-42.0^{a}$ & -10.0 & $+33.0^{b}$ \\
\hline \multirow[t]{4}{*}{$\mathrm{C}\left(\alpha^{\prime}\right)$} & 20.72 & $\delta^{\mathrm{OBS}}$ & $+1162.0^{c}$ & - & $+885.7^{d}$ \\
\hline & & $\delta^{\text {PARA }}$ & +1141.28 & - & +864.98 \\
\hline & & $\delta^{\mathrm{MCD}}$ & +19.09 & - & +13.49 \\
\hline & & $\vartheta^{\mathrm{CON}}$ & +870.64 & - & +874.92 \\
\hline \multirow[t]{3}{*}{$N-O-C$} & 122.34 & $\delta^{\mathrm{OBS}}$ & +755.0 & +678.6 & $+599.7^{e}$ \\
\hline & & $\delta^{\text {PARA }}$ & +632.66 & +556.26 & +477.36 \\
\hline & & $\delta^{\mathrm{MCD}}$ & -26.97 & -22.94 & -19.07 \\
\hline (line 46) & & $\vartheta^{\mathrm{CON}}$ & +511.77 & +511.56 & +510.09 \\
\hline \multirow[t]{4}{*}{$N-i-C$} & 145.51 & $\delta^{\mathrm{OBS}}$ & +314.4 & +299.0 & +281.1 \\
\hline & & $\delta^{\text {PARA }}$ & +168.89 & +153.49 & +135.59 \\
\hline & & $\delta^{\mathrm{MCD}}$ & -41.25 & -35.09 & -29.17 \\
\hline & & $\vartheta^{\mathrm{CON}}$ & +163.03 & +166.56 & +169.29 \\
\hline \multirow[t]{4}{*}{$N-p-C$} & 122.95 & $\delta^{\mathrm{OBS}}$ & +353.8 & +327.1 & $+299.7^{f}$ \\
\hline & & $\delta^{\text {PARA }}$ & +230.85 & +204.15 & +176.75 \\
\hline & & $\delta^{\mathrm{MCD}}$ & -9.02 & -7.67 & -6.38 \\
\hline & & $\vartheta^{\mathrm{CON}}$ & +186.10 & +187.09 & +188.17 \\
\hline \multirow[t]{3}{*}{$N-m-\mathrm{C}$} & 128.52 & $\delta^{\mathrm{OBS}}$ & $-32.1^{g}$ & -13.0 & $+6.70^{h}$ \\
\hline & & $\delta^{\text {PARA }}$ & -160.62 & -141.52 & -121.82 \\
\hline & & $\delta^{\mathrm{MCD}}$ & -11.44 & -9.73 & -8.09 \\
\hline (line 64) & & $\vartheta^{\mathrm{CON}}$ & -115.74 & -116.40 & -116.86 \\
\hline \multicolumn{3}{|c|}{ 1000/(temperature in K) } & 4.325 & 3.799 & 3.266 \\
\hline
\end{tabular}


Table S29. ${ }^{1} \mathrm{H}$ NMR Parameters (in ppm) $\delta^{\mathrm{DIA}}, \delta^{\mathrm{OBS}}, \delta^{\mathrm{PARA}}, \delta^{\mathrm{MCD}}$, and $\vartheta^{\mathrm{CON}} \approx \vartheta^{\mathrm{C}+\mathrm{L}}$ of the Bis(chelate) $15 \mathrm{Ni}$ in $\mathrm{Cl}_{2} \mathrm{CD}-\mathrm{CDCl}{ }_{2}$ Solution as a Function of the Temperature

\begin{tabular}{|c|c|c|c|c|c|c|c|c|c|c|c|c|c|}
\hline \multirow{2}{*}{$\begin{array}{l}\text { nucleus } \\
\text { (line no.) }\end{array}$} & \multirow{2}{*}{$\begin{array}{l}\mathbf{1 5 H} \\
\delta^{\text {DIA }}\end{array}$} & \multirow[t]{2}{*}{$15 \mathrm{Ni}$} & \multicolumn{11}{|c|}{ temperature $\left[{ }^{\circ} \mathrm{C}\right]$} \\
\hline & & & -45.5 & -29.5 & -6.0 & $+26.0^{a}$ & +27.0 & +42.0 & +51.0 & +76.0 & +85.0 & +112.0 & +134.0 \\
\hline \multirow[t]{3}{*}{$N-m-\mathrm{H}$} & 7.00 & $\delta^{\mathrm{OBS}}$ & +34.5 & +32.6 & - & +27.7 & +27.6 & +26.6 & - & +24.7 & +24.2 & +22.9 & +22.2 \\
\hline & & $\delta^{\text {PARA }}$ & +27.50 & +25.60 & - & +20.70 & +20.60 & +19.60 & - & +17.70 & +17.2 & +15.9 & +15.2 \\
\hline & & $\delta^{\mathrm{MCD}}$ & +4.70 & +4.31 & - & +3.35 & +3.34 & +3.14 & - & +2.78 & +2.70 & +2.48 & +2.32 \\
\hline (line 18) & & $\vartheta^{\mathrm{CON}}$ & +17.42 & +17.41 & - & +17.42 & +17.39 & +17.41 & - & +17.48 & +17.43 & +17.35 & +17.60 \\
\hline \multirow[t]{4}{*}{$N-O-H$} & 7.00 & $\delta^{\mathrm{OBS}}$ & -19.4 & -17.7 & -16.2 & -14.1 & -14.0 & $\begin{array}{l}-13.1 \\
\end{array}$ & - & -11.00 & -11.10 & -9.65 & -8.80 \\
\hline & & $\delta^{\text {PARA }}$ & -26.40 & -24.7 & -23.2 & -21.1 & -21.0 & -20.1 & - & -18.00 & -18.10 & -16.65 & -15.80 \\
\hline & & $\delta^{\mathrm{MCD}}$ & +18.73 & +17.20 & +15.34 & +13.35 & +13.30 & +12.54 & - & +11.09 & +10.76 & +9.87 & +9.25 \\
\hline & & $\vartheta^{\mathrm{CON}}$ & -34.49 & -34.26 & -34.55 & -34.59 & -34.55 & -34.52 & - & -34.09 & -34.69 & -34.29 & -34.23 \\
\hline \multirow[t]{4}{*}{$N-p-\mathrm{H}$} & 7.00 & $\delta^{\mathrm{OBS}}$ & -27.2 & -25.2 & -22.4 & -19.6 & -19.5 & -18.3 & - & -15.9 & -15.5 & -13.9 & -12.8 \\
\hline & & $\delta^{\text {PARA }}$ & -34.20 & -32.20 & -29.40 & -26.60 & -26.50 & -25.30 & - & -22.90 & -22.50 & -20.90 & -19.8 \\
\hline & & $\delta^{\mathrm{MCD}}$ & +3.80 & +3.49 & +3.11 & +2.71 & +2.70 & +2.54 & - & +2.25 & +2.18 & +2.00 & +1.88 \\
\hline & & $\vartheta^{\mathrm{CON}}$ & -29.03 & -29.18 & -29.15 & -29.42 & -29.41 & -29.45 & - & -29.47 & -29.67 & -29.60 & -29.62 \\
\hline \multirow[t]{3}{*}{$\mathrm{H}\left(\beta^{\prime}\right)$} & 1.93 & $\delta^{\mathrm{OBS}}$ & -66.8 & -62.4 & - & -49.2 & -49.5 & -46.80 & -44.4 & -41.5 & -40.70 & -37.2 & -35.0 \\
\hline & & $\delta^{\text {PARA }}$ & -68.73 & -64.33 & - & -51.13 & -51.43 & -48.73 & -46.33 & -43.43 & -42.63 & -39.13 & -36.93 \\
\hline & & $\delta^{\mathrm{MCD}}$ & -7.69 & -7.06 & - & -5.48 & -5.46 & -5.15 & -4.97 & -4.55 & -4.42 & -4.05 & -3.80 \\
\hline (line 58) & & $\vartheta^{\mathrm{CON}}$ & -46.64 & -46.84 & - & -45.83 & -46.31 & -46.1 & -44.99 & -45.56 & -45.93 & -45.34 & -45.27 \\
\hline \multirow[t]{3}{*}{$\mathrm{H}(\alpha)$} & 4.75 & $\delta^{\mathrm{OBS}}$ & - & - & - & - & -113.3 & - & -104.2 & - & - & -85.2 & -81.0 \\
\hline & & $\delta^{\text {PARA }}$ & - & - & - & - & -118.05 & - & -108.95 & - & - & -89.95 & -85.75 \\
\hline & & $\delta^{\mathrm{MCD}}$ & - & - & - & - & -17.64 & - & -16.08 & - & - & -13.10 & -12.27 \\
\hline (line 23) & & $\vartheta^{\mathrm{CON}}$ & - & - & - & - & -101.15 & - & -101.04 & - & - & -99.34 & -100.40 \\
\hline 1000/(tem & peratur & in $\mathrm{K}$ ) & 4.392 & 4.103 & 3.743 & 3.342 & 3.331 & 3.173 & 3.085 & 2.864 & 2.792 & 2.596 & 2.456 \\
\hline
\end{tabular}

\footnotetext{
${ }^{a}$ In $\mathrm{CDCl}_{3}$.
} 
Table S30. ${ }^{13} \mathrm{C}$ NMR Parameters (in ppm) $\delta^{\mathrm{DIA}}, \delta^{\mathrm{OBS}}, \delta^{\mathrm{PARA}}, \delta^{\mathrm{MCD}}$, and $\vartheta^{\mathrm{CON}} \approx$ $\vartheta^{\mathrm{C}+\mathrm{L}}$ of the Bis(chelate) $\mathbf{1 5 N i}$ in $\mathrm{CDCl}_{3}$ Solution as a Function of the Temperature

\begin{tabular}{|c|c|c|c|c|c|}
\hline \multirow{2}{*}{$\begin{array}{l}\text { nucleus } \\
\text { (line no.) }\end{array}$} & \multirow{2}{*}{$\begin{array}{l}\mathbf{1 5 H} \\
\delta^{\text {DIA }}\end{array}$} & \multirow[t]{2}{*}{$15 \mathrm{Ni}$} & \multicolumn{3}{|c|}{ temperature $\left[{ }^{\circ} \mathrm{C}\right]$} \\
\hline & & & $-42.0^{a}$ & $-23.0^{b}$ & +34.0 \\
\hline \multirow[t]{3}{*}{$\mathrm{C}(\alpha)$} & \multirow[t]{4}{*}{20.72} & $\delta^{\mathrm{OBS}}$ & $+859.0^{c}$ & $+800.0^{c}$ & +656.1 \\
\hline & & $\delta^{\text {PARA }}$ & +838.28 & +779.28 & +635.38 \\
\hline & & $\delta^{\mathrm{MCD}}$ & -12.74 & -11.54 & -8.97 \\
\hline (line 2) & & $\vartheta^{\mathrm{CON}}$ & +660.26 & +663.97 & +664.24 \\
\hline \multirow[t]{3}{*}{$\mathrm{C}(2)$} & \multirow[t]{4}{*}{97.27} & $\delta^{\mathrm{OBS}}$ & $+758.7^{d}$ & $+700.0^{c}$ & +587.0 \\
\hline & & $\delta^{\text {PARA }}$ & +661.43 & +602.73 & +489.73 \\
\hline & & $\delta^{\mathrm{MCD}}$ & -57.78 & -52.33 & -40.67 \\
\hline (line 3) & & $\vartheta^{\mathrm{CON}}$ & +557.99 & +549.99 & +546.78 \\
\hline \multirow[t]{3}{*}{$N-O-C$} & \multirow[t]{4}{*}{122.34} & $\delta^{\mathrm{OBS}}$ & +737.5 & +692.0 & +584.6 \\
\hline & & $\delta^{\text {PARA }}$ & +615.16 & +569.66 & +462.26 \\
\hline & & $\delta^{\mathrm{MCD}}$ & +18.67 & +16.91 & +13.14 \\
\hline (line 4) & & $\vartheta^{\mathrm{CON}}$ & +462.78 & +464.09 & +462.99 \\
\hline \multirow[t]{4}{*}{$N-i-C$} & \multirow[t]{4}{*}{145.51} & $\delta^{\mathrm{OBS}}$ & +418.6 & +407.1 & +358.1 \\
\hline & & $\delta^{\text {PARA }}$ & +273.09 & +261.59 & +212.59 \\
\hline & & $\delta^{\mathrm{MCD}}$ & +29.78 & +26.97 & +20.96 \\
\hline & & $\vartheta^{\mathrm{CON}}$ & +188.77 & +196.99 & +197.55 \\
\hline \multirow[t]{4}{*}{$N-p-\mathrm{C}$} & \multirow[t]{4}{*}{122.95} & $\delta^{\mathrm{OBS}}$ & +343.5 & $+329.3^{e}$ & +291.4 \\
\hline & & $\delta^{\text {PARA }}$ & +220.55 & +206.35 & +168.45 \\
\hline & & $\delta^{\mathrm{MCD}}$ & +6.38 & +5.78 & +4.49 \\
\hline & & $\vartheta^{\mathrm{CON}}$ & +166.16 & +168.4 & +169.02 \\
\hline \multirow[t]{3}{*}{$N-m-C$} & \multirow[t]{4}{*}{128.52} & $\delta^{\mathrm{OBS}}$ & -4.20 & $+3.94^{e}$ & +26.7 \\
\hline & & $\delta^{\text {PARA }}$ & -132.72 & -124.58 & -101.82 \\
\hline & & $\delta^{\mathrm{MCD}}$ & +8.11 & +7.34 & +5.71 \\
\hline (line 63) & & $\vartheta^{\mathrm{CON}}$ & -109.26 & -110.76 & -110.85 \\
\hline \multirow[t]{3}{*}{$\mathrm{C}(1,3)$} & \multirow[t]{3}{*}{159.03} & $\delta^{\mathrm{OBS}}$ & -718.4 & -648.2 & -482.7 \\
\hline & & $\delta^{\text {PARA }}$ & -877.43 & -807.23 & -641.73 \\
\hline & & $\delta^{\mathrm{MCD}}$ & -59.57 & -53.95 & -41.93 \\
\hline (line 29) & & $\vartheta^{\mathrm{CON}}$ & -634.53 & -632.45 & -618.32 \\
\hline \multicolumn{3}{|c|}{$1000 /$ (temperature in K) } & 4.325 & 3.997 & 3.255 \\
\hline
\end{tabular}

${ }^{a}$ In $\mathrm{Cl}_{2} \mathrm{CD}-\mathrm{CDCl}_{2} .{ }^{b}{ }^{1} \mathrm{H}$ coupled. ${ }^{c} \pm 3 \mathrm{ppm} .{ }^{d} \pm 7 \mathrm{ppm} .{ }^{e} \mathrm{~d},{ }^{1} J_{\mathrm{CH}}=159 \mathrm{~Hz}$. 
Table S31. ${ }^{1} \mathrm{H}$ NMR Parameters (in ppm) $\delta^{\mathrm{DIA}}, \delta^{\mathrm{OBS}}, \delta^{\mathrm{PARA}}, \delta^{\mathrm{MCD}}$, and $\vartheta^{\mathrm{CON}} \approx \vartheta^{\mathrm{C}+\mathrm{L}}$ of the Bis(chelate) $16 \mathrm{Ni}$ in $\mathrm{Cl}_{2} \mathrm{CD}-\mathrm{CDCl}_{2}$ Solution as a Function of the Temperature

\begin{tabular}{|c|c|c|c|c|c|c|c|c|}
\hline \multirow{2}{*}{$\begin{array}{l}\text { nucleus } \\
\text { (line no.) }\end{array}$} & \multirow{2}{*}{$\begin{array}{l}16 \mathbf{H} \\
\delta^{\text {DIA }} \\
\end{array}$} & \multirow[t]{2}{*}{$16 \mathrm{Ni}$} & \multicolumn{6}{|c|}{ temperature $\left[{ }^{\circ} \mathrm{C}\right]$} \\
\hline & & & -62.3 & -39.0 & -21.3 & +27.0 & +62.8 & +100.3 \\
\hline \multirow[t]{3}{*}{$\mathrm{N}-\mathrm{m}-\mathrm{CH}_{3}$} & 2.25 & $\delta^{\mathrm{OBS}}$ & -8.33 & -7.33 & -6.63 & -5.30 & -4.57 & -3.88 \\
\hline & & $\delta^{\text {PARA }}$ & -10.58 & -9.58 & -8.88 & -7.55 & -6.82 & -6.13 \\
\hline & & $\delta^{\mathrm{MCD}}$ & +3.02 & +2.65 & +2.42 & +1.95 & +1.70 & +1.50 \\
\hline (line 76) & & $\vartheta^{\mathrm{CON}}$ & -9.63 & -9.61 & -9.55 & -9.57 & -9.61 & -9.56 \\
\hline \multirow[t]{4}{*}{$N-O-\mathrm{H}$} & 6.47 & $\delta^{\mathrm{OBS}}$ & -20.6 & -18.6 & -16.9 & -13.6 & -11.52 & -9.78 \\
\hline & & $\delta^{\text {PARA }}$ & -27.07 & -25.07 & -23.37 & -20.07 & -17.99 & -16.25 \\
\hline & & $\delta^{\mathrm{MCD}}$ & +20.65 & +18.08 & +16.50 & +13.30 & +11.61 & +10.24 \\
\hline & & $\vartheta^{\mathrm{CON}}$ & -33.77 & -33.91 & -33.70 & -33.62 & -33.38 & -33.20 \\
\hline \multirow[t]{3}{*}{$N-p-\mathrm{H}$} & 6.55 & $\delta^{\mathrm{OBS}}$ & -29.4 & -26.3 & -23.8 & -19.0 & -16.4 & -14.05 \\
\hline & & $\delta^{\text {PARA }}$ & -35.95 & -32.85 & -30.35 & -25.55 & -22.95 & -20.60 \\
\hline & & $\delta^{\mathrm{MCD}}$ & +4.19 & +3.66 & +3.34 & +2.70 & +2.35 & +2.08 \\
\hline (line 79) & & $\vartheta^{\mathrm{CON}}$ & -28.41 & -28.70 & -28.48 & -28.45 & -28.53 & -28.42 \\
\hline \multirow[t]{3}{*}{$\mathrm{H}\left(\beta^{\prime}\right)$} & 1.92 & $\delta^{\mathrm{OBS}}$ & -73.0 & -65.2 & -59.7 & -49.3 & -43.2 & -37.9 \\
\hline & & $\delta^{\text {PARA }}$ & -74.92 & -67.12 & -61.62 & -51.22 & -45.12 & -39.82 \\
\hline & & $\delta^{\mathrm{MCD}}$ & -8.48 & -7.42 & -6.77 & -5.46 & -4.77 & -4.20 \\
\hline (line 58) & & $\vartheta^{\mathrm{CON}}$ & -47.02 & -46.92 & -46.36 & -46.10 & -45.50 & -44.64 \\
\hline \multirow[t]{3}{*}{$\mathrm{H}(\alpha)$} & 4.68 & $\delta^{\mathrm{OBS}}$ & -171.5 & -152.2 & -141.1 & -114.9 & -101.2 & - \\
\hline & & $\delta^{\text {PARA }}$ & -176.18 & -156.88 & -145.78 & -119.58 & -105.88 & - \\
\hline & & $\delta^{\mathrm{MCD}}$ & -27.4 & -23.98 & -21.89 & -17.64 & -15.4 & - \\
\hline (line 23) & & $\vartheta^{\mathrm{CON}}$ & -105.30 & -104.44 & -104.72 & -102.69 & -102.01 & - \\
\hline 1000/(tem & seratu & in $\mathrm{K}$ ) & 4.742 & 4.270 & 3.970 & 3.331 & 2.976 & 2.677 \\
\hline
\end{tabular}


Table S32. ${ }^{1} \mathrm{H}$ NMR Parameters (in ppm) $\delta^{\mathrm{DIA}}, \delta^{\mathrm{OBS}}, \delta^{\mathrm{PARA}}, \delta^{\mathrm{MCD}}$, and $\vartheta^{\mathrm{CON}} \approx \vartheta^{\mathrm{C}+\mathrm{L}}$ of the Bis(chelate) $19 C o$ in $\left[D_{8}\right]$ Toluene Solution as a Function of the Temperature

\begin{tabular}{|c|c|c|c|c|c|c|c|c|}
\hline \multirow[t]{2}{*}{ nucleus } & \multirow{2}{*}{$\begin{array}{l}19 \mathbf{H} \\
\delta^{\text {DIA }}\end{array}$} & \multirow[t]{2}{*}{ 19Co } & \multicolumn{6}{|c|}{ temperature $\left[{ }^{\circ} \mathrm{C}\right]$} \\
\hline & & & -53.5 & -28.5 & -1.0 & +25.0 & +62.0 & +100.0 \\
\hline \multirow[t]{4}{*}{$N-m-\mathrm{H}$} & 7.08 & $\delta^{\mathrm{OBS}}$ & +21.7 & +20.6 & +19.3 & +18.2 & +17.0 & +15.9 \\
\hline & & $\delta^{\text {PARA }}$ & +14.62 & +13.52 & +12.22 & +11.12 & +9.92 & +8.82 \\
\hline & & $\delta^{\mathrm{MCD}}$ & -7.05 & -6.16 & -5.39 & -4.83 & -4.19 & -3.69 \\
\hline & & $\vartheta^{\mathrm{CON}}$ & +15.98 & +16.16 & +16.09 & +15.96 & +15.87 & +15.67 \\
\hline \multirow[t]{4}{*}{$\mathrm{H}\left(\gamma^{\prime}\right)$} & 1.08 & $\delta^{\mathrm{OBS}}$ & +9.71 & +9.00 & +8.14 & +7.82 & +6.98 & +6.61 \\
\hline & & $\delta^{\text {PARA }}$ & +8.63 & +7.92 & +7.06 & +6.74 & +5.90 & +5.53 \\
\hline & & $\delta^{\mathrm{MCD}}$ & +8.03 & +7.01 & +6.14 & +5.50 & +4.77 & +4.20 \\
\hline & & $\vartheta^{\mathrm{CON}}$ & +0.44 & +0.75 & +0.84 & +1.24 & +1.27 & +1.66 \\
\hline \multirow[t]{3}{*}{$N-p-\mathrm{H}$} & 7.08 & $\delta^{\mathrm{OBS}}$ & -54.4 & -48.1 & -41.8 & -37.5 & -32.3 & -27.9 \\
\hline & & $\delta^{\text {PARA }}$ & -61.48 & -55.18 & -48.88 & -44.58 & -39.38 & -34.98 \\
\hline & & $\delta^{\mathrm{MCD}}$ & -5.68 & -4.96 & -4.35 & -3.89 & -3.38 & -2.97 \\
\hline (line 82) & & $\vartheta^{\mathrm{CON}}$ & -41.14 & -41.24 & -40.68 & -40.72 & -40.50 & -40.08 \\
\hline \multirow[t]{4}{*}{$\mathrm{H}(\alpha)$} & 5.62 & $\delta^{\mathrm{OBS}}$ & -119.8 & -106.6 & -93.7 & -86.0 & -75.0 & -64.6 \\
\hline & & $\delta^{\text {PARA }}$ & -125.42 & -112.22 & -99.32 & -91.62 & -80.62 & -70.22 \\
\hline & & $\delta^{\mathrm{MCD}}$ & +39.36 & +34.36 & +30.11 & +26.94 & +23.40 & +20.60 \\
\hline & & $\vartheta^{\mathrm{CON}}$ & -121.48 & -120.36 & -118.23 & -118.64 & -117.00 & -113.74 \\
\hline $1000 /$ (ter & Ipelat & re in $\mathrm{K}$ ) & 4.552 & 4.087 & 3.674 & 3.353 & 2.983 & 2.680 \\
\hline
\end{tabular}


Table S33. ${ }^{13} \mathrm{C}$ NMR Parameters (in ppm) $\delta^{\mathrm{DIA}}, \delta^{\mathrm{OBS}}, \delta^{\mathrm{PARA}}, \delta^{\mathrm{MCD}}$, and $\vartheta^{\mathrm{CON}} \approx \vartheta^{\mathrm{C}+\mathrm{L}}$ of the Bis(chelate) 19Co in $\left[D_{8}\right]$ Toluene Solution as a Function of the Temperature

\begin{tabular}{|c|c|c|c|c|c|c|c|}
\hline \multirow{2}{*}{$\begin{array}{l}\text { nucleus } \\
\text { (line no.) }\end{array}$} & \multirow{2}{*}{$\begin{array}{c}\mathbf{1 9 H} \\
\delta^{\mathrm{DIA}}\end{array}$} & \multirow[t]{2}{*}{ 19Co } & \multicolumn{5}{|c|}{ temperature $\left[{ }^{\circ} \mathrm{C}\right]$} \\
\hline & & & -45.0 & $-36.0^{a}$ & -18.0 & $+2.0^{a}$ & $+32.0^{b}$ \\
\hline \multirow[t]{3}{*}{$N-O-C$} & 119.3 & $\delta^{\mathrm{OBS}}$ & $+783.0^{c}$ & +757.2 & +714.5 & +668.0 & +620.5 \\
\hline & & $\delta^{\text {PARA }}$ & +663.7 & +637.9 & +595.2 & +548.7 & +501.2 \\
\hline & & $\delta^{\mathrm{MCD}}$ & -27.42 & -26.12 & -23.84 & -21.72 & -19.14 \\
\hline (line 45) & & $\vartheta^{\mathrm{CON}}$ & +529.24 & +528.54 & +530.13 & +526.77 & +532.92 \\
\hline \multirow[t]{3}{*}{$N-p-\mathrm{C}$} & 122.7 & $\delta^{\mathrm{OBS}}$ & $+423.5^{d}$ & +408.6 & +390.5 & +367.0 & $+346.5^{e}$ \\
\hline & & $\delta^{\text {PARA }}$ & +300.8 & +285.9 & +267.8 & +244.3 & +223.8 \\
\hline & & $\delta^{\mathrm{MCD}}$ & -9.17 & -8.73 & -7.97 & -7.26 & -6.40 \\
\hline (line 50) & & $\vartheta^{\mathrm{CON}}$ & +237.37 & +234.52 & +236.17 & +232.32 & +235.77 \\
\hline \multirow[t]{3}{*}{$\mathrm{H}\left(\beta^{\prime}\right)$} & 27.9 & $\delta^{\mathrm{OBS}}$ & -77.5 & -73.3 & -66.0 & -57.5 & -48.0 \\
\hline & & $\delta^{\text {PARA }}$ & -105.4 & -101.2 & -93.9 & -85.4 & -75.9 \\
\hline & & $\delta^{\mathrm{MCD}}$ & +8.48 & +8.07 & +7.37 & +6.71 & +5.92 \\
\hline (line 61) & & $\vartheta^{\mathrm{CON}}$ & -87.20 & -86.98 & -86.72 & -85.07 & -83.80 \\
\hline \multirow[t]{3}{*}{$N-m-C$} & 128.1 & $\delta^{\mathrm{OBS}}$ & $-98.5^{f}$ & -89.0 & -73.6 & -57.5 & $-40.0^{g}$ \\
\hline & & $\delta^{\text {PARA }}$ & -226.6 & -217.1 & -201.7 & -185.6 & -168.1 \\
\hline & & $\delta^{\mathrm{MCD}}$ & -11.63 & -11.07 & -10.11 & -9.21 & -8.12 \\
\hline (line 24) & & $\vartheta^{\mathrm{CON}}$ & -164.62 & -163.99 & -164.08 & -162.90 & -163.85 \\
\hline \multicolumn{3}{|c|}{ 1000/(temperature in K) } & 4.382 & 4.216 & 3.918 & 3.634 & 3.277 \\
\hline
\end{tabular}

${ }^{a}$ In $\mathrm{CDCl}_{3} .{ }^{b}{ }^{1} \mathrm{H}$ coupled. ${ }^{c} \pm 6 \mathrm{ppm} .{ }^{d} \pm 2 \mathrm{ppm}$. ${ }^{e}$ broadened d, ${ }^{1} J_{\mathrm{CH}} \approx 160 \mathrm{~Hz} .{ }^{f} \pm 1.5 \mathrm{ppm}$. $g$ Sharp d, ${ }^{1} J_{\mathrm{CH}}=149 \mathrm{~Hz}$. 
Table S34. ${ }^{1} \mathrm{H}$ NMR Parameters (in ppm) $\delta^{\mathrm{DIA}}, \delta^{\mathrm{OBS}}, \delta^{\mathrm{PARA}}, \delta^{\mathrm{MCD}}$, and $\vartheta^{\mathrm{CON}} \approx \vartheta^{\mathrm{C}+\mathrm{L}}$ of the Bis(chelate) 19Ni in $\mathrm{Cl}_{2} \mathrm{CD}-\mathrm{CDCl}_{2}$ Solution as a Function of the Temperature

\begin{tabular}{|c|c|c|c|c|c|c|c|c|c|}
\hline \multirow{2}{*}{$\begin{array}{l}\text { nucleus } \\
\text { (line no.) }\end{array}$} & \multirow{2}{*}{$\begin{array}{c}\mathbf{1 9 H} \\
\delta^{\mathrm{DIA}}\end{array}$} & \multirow[t]{2}{*}{$19 \mathrm{Ni}$} & \multicolumn{7}{|c|}{ temperature $\left[{ }^{\circ} \mathrm{C}\right]$} \\
\hline & & & -60.5 & -48.0 & -39.5 & -20.0 & +27.5 & +57.0 & +81.5 \\
\hline \multirow[t]{4}{*}{$N-m-\mathrm{H}$} & 7.08 & $\delta^{\mathrm{OBS}}$ & +38.3 & +36.3 & +35.2 & +32.7 & +28.5 & +26.9 & +25.3 \\
\hline & & $\delta^{\text {PARA }}$ & +31.22 & +29.22 & +28.12 & +25.62 & +21.42 & +19.82 & +18.22 \\
\hline & & $\delta^{\mathrm{MCD}}$ & +5.12 & +4.76 & +4.55 & +4.11 & +3.33 & +2.97 & +2.73 \\
\hline & & $\vartheta^{\mathrm{CON}}$ & +18.63 & +18.48 & +18.49 & +18.27 & +18.25 & +18.67 & +18.44 \\
\hline \multirow[t]{4}{*}{$\mathrm{H}\left(\gamma^{\prime}\right)$} & 1.08 & $\delta^{\mathrm{OBS}}$ & +2.47 & +2.45 & +2.43 & +2.30 & +2.17 & +2.15 & +2.08 \\
\hline & & $\delta^{\text {PARA }}$ & +1.39 & +1.37 & +1.35 & +1.22 & +1.09 & +1.07 & +1.00 \\
\hline & & $\delta^{\mathrm{MCD}}$ & -5.56 & -5.17 & -4.94 & -4.46 & -3.61 & -3.23 & -2.96 \\
\hline & & $\vartheta^{\mathrm{CON}}$ & +4.96 & +4.94 & +4.93 & +4.83 & +4.75 & +4.76 & +4.72 \\
\hline \multirow[t]{3}{*}{$N-o-\mathrm{H}$} & 6.65 & $\delta^{\mathrm{OBS}}$ & -31.6 & -29.5 & -28.4 & -25.5 & -20.8 & - & -16.7 \\
\hline & & $\delta^{\text {PARA }}$ & -38.25 & -36.15 & -35.05 & -32.15 & -27.45 & - & -23.35 \\
\hline & & $\delta^{\mathrm{MCD}}$ & +20.43 & +19.00 & +18.13 & +16.40 & +13.27 & - & +10.88 \\
\hline (line 83) & & $\vartheta^{\mathrm{CON}}$ & -41.88 & -41.67 & -41.70 & -41.25 & -41.09 & - & -40.75 \\
\hline \multirow[t]{3}{*}{$N-p-\mathrm{H}$} & 7.08 & $\delta^{\mathrm{OBS}}$ & -42.8 & -40.0 & -38.3 & -35.0 & -28.4 & -25.2 & -22.9 \\
\hline & & $\delta^{\text {PARA }}$ & -49.88 & -47.08 & -45.38 & -42.08 & -35.48 & -32.28 & -29.98 \\
\hline & & $\delta^{\mathrm{MCD}}$ & +4.14 & +3.85 & +3.67 & +3.32 & +2.69 & +2.40 & +2.21 \\
\hline (line 81) & & $\vartheta^{\mathrm{CON}}$ & -38.56 & -38.49 & -38.47 & -38.58 & -38.52 & -38.43 & -38.31 \\
\hline \multirow[t]{3}{*}{$\mathrm{H}(\alpha)$} & 5.62 & $\delta^{\mathrm{OBS}}$ & -171.7 & -157.8 & -151.7 & -138.2 & -114.2 & -103.0 & -95.1 \\
\hline & & $\delta^{\text {PARA }}$ & -177.32 & -163.42 & -157.32 & -143.82 & -119.82 & -108.62 & -100.72 \\
\hline & & $\delta^{\mathrm{MCD}}$ & -27.10 & -25.20 & -24.05 & -21.75 & -17.61 & -15.73 & -14.44 \\
\hline (line 23) & & $\vartheta^{\mathrm{CON}}$ & -107.22 & -104.45 & -104.51 & -103.72 & -103.14 & -102.93 & -102.70 \\
\hline $1000 /$ ten & nperatı & re in $\mathrm{K}$ ) & 4.701 & 4.440 & 4.279 & 3.949 & 3.326 & 3.028 & 2.819 \\
\hline
\end{tabular}


Table S35. ${ }^{13} \mathrm{C}$ NMR Parameters (in ppm) $\delta^{\mathrm{DIA}}, \delta^{\mathrm{OBS}}, \delta^{\mathrm{PARA}}, \delta^{\mathrm{MCD}}$, and $\vartheta^{\mathrm{CON}} \approx \vartheta^{\mathrm{C}+\mathrm{L}}$ of the Bis(chelate) $19 \mathrm{Ni}$ in $\left[\mathrm{D}_{8}\right]$ Toluene Solution as a Function of the Temperature

\begin{tabular}{|c|c|c|c|c|c|c|}
\hline \multirow{2}{*}{$\begin{array}{l}\text { nucleus } \\
\text { (line no.) }\end{array}$} & \multirow{2}{*}{$\begin{array}{l}\text { 19H } \\
\delta^{\text {DIA }}\end{array}$} & \multirow[t]{2}{*}{$19 \mathrm{Ni}$} & \multicolumn{4}{|c|}{ temperature $\left[{ }^{\circ} \mathrm{C}\right]$} \\
\hline & & & -45.0 & $-35.5^{a}$ & -20.0 & $+31.5^{b}$ \\
\hline \multirow[t]{4}{*}{$C\left(\alpha^{\prime}\right)$} & 36.3 & $\delta^{\mathrm{OBS}}$ & - & - & +1082.0 & $+906.0^{c}$ \\
\hline & & $\delta^{\text {PARA }}$ & - & - & +1045.7 & +869.7 \\
\hline & & $\delta^{\mathrm{MCD}}$ & - & - & -11.37 & -9.06 \\
\hline & & $\vartheta^{\mathrm{CON}}$ & - & - & +898.16 & +898.52 \\
\hline \multirow[t]{3}{*}{$N-\mathrm{o}-\mathrm{C}$} & 119.3 & $\delta^{\mathrm{OBS}}$ & +806.5 & +781.0 & +739.4 & $+637.0^{c}$ \\
\hline & & $\delta^{\text {PARA }}$ & +687.2 & +661.7 & +620.1 & +517.7 \\
\hline & & $\delta^{\mathrm{MCD}}$ & +18.98 & +18.03 & +16.66 & +13.27 \\
\hline (line 46) & & $\vartheta^{\mathrm{CON}}$ & +511.71 & +513.43 & +512.72 & +515.77 \\
\hline \multirow[t]{4}{*}{$\mathrm{C}(2)$} & 105.4 & $\delta^{\mathrm{OBS}}$ & +784.0 & - & +718.0 & $+616.0^{c}$ \\
\hline & & $\delta^{\text {PARA }}$ & +678.6 & - & +612.6 & +510.6 \\
\hline & & $\delta^{\mathrm{MCD}}$ & -58.74 & - & -51.56 & -41.07 \\
\hline & & $\vartheta^{\mathrm{CON}}$ & +564.64 & - & +564.31 & $\begin{array}{r}+564.08 \\
\end{array}$ \\
\hline \multirow[t]{3}{*}{$N-p-\mathrm{C}$} & 122.7 & $\delta^{\mathrm{OBS}}$ & +421.3 & +405.5 & +391.3 & $+347.3^{d}$ \\
\hline & & $\delta^{\text {PARA }}$ & +298.6 & +282.8 & +268.6 & +224.6 \\
\hline & & $\delta^{\mathrm{MCD}}$ & +6.48 & +6.16 & +5.69 & +4.53 \\
\hline (line 10) & & $\vartheta^{\mathrm{CON}}$ & +223.70 & +220.66 & +223.39 & +225.02 \\
\hline \multirow[t]{3}{*}{$\mathrm{H}\left(\beta^{\prime}\right)$} & 27.9 & $\delta^{\mathrm{OBS}}$ & -53.9 & -51.5 & -46.0 & $-32.7^{e}$ \\
\hline & & $\delta^{\text {PARA }}$ & -81.8 & -79.4 & -73.9 & -60.6 \\
\hline & & $\delta^{\mathrm{MCD}}$ & -5.58 & -5.30 & -4.90 & -3.90 \\
\hline (line 60) & & $\vartheta^{\mathrm{CON}}$ & -58.37 & -59.11 & -58.63 & -57.97 \\
\hline \multirow[t]{3}{*}{$N-m-\mathrm{C}$} & 128.1 & $\delta^{\mathrm{OBS}}$ & -69.8 & -58.0 & -49.5 & $-20.0^{f}$ \\
\hline & & $\delta^{\text {PARA }}$ & -197.9 & -186.1 & -177.6 & -148.1 \\
\hline & & $\delta^{\mathrm{MCD}}$ & +8.24 & +7.83 & +7.24 & +5.76 \\
\hline (line 65) & & $\vartheta^{\mathrm{CON}}$ & -157.86 & -154.69 & -157.05 & -157.32 \\
\hline \multirow[t]{3}{*}{$\mathrm{C}(1,3)$} & 150.8 & $\delta^{\mathrm{OBS}}$ & $-863.5^{g}$ & $-826.0^{h}$ & $\begin{array}{l}-758.1 \\
\end{array}$ & $-597.3^{i}$ \\
\hline & & $\delta^{\text {PARA }}$ & -1014.3 & -976.8 & -908.9 & -748.1 \\
\hline & & $\delta^{\mathrm{MCD}}$ & -60.56 & -57.52 & -53.15 & -42.34 \\
\hline (line 31) & & $\vartheta^{\mathrm{CON}}$ & -730.35 & -733.26 & -727.1 & -721.62 \\
\hline \multicolumn{3}{|c|}{ 1000/(temperature in K) } & 4.382 & 4.207 & 3.949 & 3.282 \\
\hline
\end{tabular}

${ }^{a}$ In $\mathrm{Cl}_{2} \mathrm{CD}-\mathrm{CDCl}_{2} .{ }^{b}{ }^{1} \mathrm{H}$ coupled. ${ }^{c}$ Broad. ${ }^{d}$ d, ${ }^{1} J_{\mathrm{CH}}=156 \mathrm{~Hz} .{ }^{e} \mathrm{q},{ }^{1} J_{\mathrm{CH}}=126 \mathrm{~Hz}$. ${ }^{f} \mathrm{~d},{ }^{1} J_{\mathrm{CH}}=153 \mathrm{~Hz} .{ }^{g} \pm 2 \mathrm{ppm} .{ }^{h} \pm 10 \mathrm{ppm} .{ }^{i}$ Narrow singlet. 
Table S36. ${ }^{1} \mathrm{H}$ NMR Parameters (in ppm) $\delta^{\mathrm{DIA}}, \delta^{\mathrm{OBS}}, \delta^{\mathrm{PARA}}, \delta^{\mathrm{MCD}}$, and $\vartheta^{\mathrm{CON}} \approx \vartheta^{\mathrm{C}+\mathrm{L}}$ of the Bis(chelate) 20Ni in $\mathrm{Cl}_{2} \mathrm{CD}-\mathrm{CDCl}{ }_{2}$ Solution as a Function of the Temperature

\begin{tabular}{|c|c|c|c|c|c|c|c|c|c|c|c|c|}
\hline \multirow[t]{2}{*}{ nucleus } & \multirow{2}{*}{$\begin{array}{l}\mathbf{2 0 Z n} \\
\delta^{\text {DIA }}\end{array}$} & \multirow[t]{2}{*}{$20 \mathrm{Ni}$} & \multicolumn{10}{|c|}{ temperature $\left[{ }^{\circ} \mathrm{C}\right]$} \\
\hline & & & -68.0 & $-56.0^{a}$ & -37.5 & $-36.0^{a}$ & -24.0 & $+27.0^{a}$ & +27.0 & +55.0 & +92.5 & +118.0 \\
\hline \multirow[t]{4}{*}{$\mathrm{H}\left(\alpha^{\prime}\right)$} & 7.20 & $\delta^{\mathrm{OBS}}$ & - & - & +510.2 & - & +481.4 & - & +392.5 & +356.7 & +319.0 & +299.2 \\
\hline & & $\delta^{\text {PARA }}$ & - & - & +503.00 & - & +474.2 & - & +385.30 & +349.50 & +311.80 & +292.00 \\
\hline & & $\delta^{\mathrm{MCD}}$ & - & - & -18.41 & - & -17.17 & - & -13.65 & -12.26 & -10.78 & -9.95 \\
\hline & & $\vartheta^{\mathrm{CON}}$ & - & - & +412.40 & - & +410.90 & - & +401.90 & +398.42 & +395.86 & +396.39 \\
\hline \multirow[t]{4}{*}{$N-m-\mathrm{H}(1)$} & 6.80 & $\delta^{\mathrm{OBS}}$ & +40.4 & +38.7 & +35.1 & +35.5 & +33.9 & +29.1 & +29.1 & +27.2 & +24.8 & +23.6 \\
\hline & & $\delta^{\text {PARA }}$ & +33.60 & +31.90 & +28.30 & +28.70 & +27.10 & +22.30 & +22.30 & +20.40 & +18.00 & +16.80 \\
\hline & & $\delta^{\mathrm{MCD}}$ & +5.36 & +4.99 & +4.50 & +4.46 & +4.19 & +3.34 & +3.34 & +3.00 & +2.63 & +2.43 \\
\hline & & $\vartheta^{\mathrm{CON}}$ & +19.44 & +19.61 & +18.83 & +19.29 & +19.15 & +19.10 & +19.10 & +19.17 & +18.86 & +18.86 \\
\hline \multirow[t]{4}{*}{$N-m-\mathrm{H}(1)$} & 6.80 & $\delta^{\mathrm{OBS}}$ & +38.6 & +36.7 & +34.0 & +34.1 & +32.8 & +28.4 & +28.6 & +26.8 & +24.8 & +23.6 \\
\hline & & $\delta^{\text {PARA }}$ & +31.80 & +29.90 & +27.20 & +27.30 & +26.00 & +21.60 & +21.80 & +20.00 & +18.00 & +16.80 \\
\hline & & $\delta^{\mathrm{MCD}}$ & +5.36 & +4.99 & +4.50 & +4.46 & +4.19 & +3.34 & +3.34 & +3.00 & +2.63 & +2.43 \\
\hline & & $\vartheta^{\mathrm{CON}}$ & +18.20 & +18.16 & +17.96 & +18.18 & +18.23 & +18.40 & +18.60 & +18.73 & +18.86 & +18.86 \\
\hline \multirow[t]{4}{*}{$N-m-\mathrm{H}(2)$} & 6.80 & $\delta^{\mathrm{OBS}}$ & +39.0 & +37.2 & +34.0 & +34.1 & +32.8 & +28.2 & +28.3 & +26.5 & +24.2 & +23.0 \\
\hline & & $\delta^{\text {PARA }}$ & +32.20 & +30.40 & +27.2 & +27.3 & +26.0 & +21.4 & +21.50 & +19.70 & +17.40 & +16.20 \\
\hline & & $\delta^{\mathrm{MCD}}$ & +5.36 & +4.99 & +4.50 & +4.46 & +4.19 & +3.34 & +3.34 & +3.00 & +2.63 & +2.43 \\
\hline & & $\vartheta^{\mathrm{CON}}$ & +18.48 & +18.52 & +17.96 & +18.18 & +18.23 & +18.20 & +18.30 & +18.40 & +18.12 & +18.07 \\
\hline \multirow[t]{4}{*}{$\mathrm{H}\left(\gamma^{\prime}\right)$} & 0.95 & $\delta^{\mathrm{OBS}}$ & +3.17 & - & +2.92 & - & +2.83 & - & +2.57 & +2.50 & +2.37 & +2.23 \\
\hline & & $\delta^{\text {PARA }}$ & +2.22 & - & +1.97 & - & +1.88 & - & +1.62 & +1.55 & +1.42 & +1.28 \\
\hline & & $\delta^{\mathrm{MCD}}$ & -4.05 & - & -3.39 & - & -3.16 & - & -2.52 & -2.26 & -1.99 & -1.83 \\
\hline & & $\vartheta^{\mathrm{CON}}$ & +4.32 & - & +4.24 & - & +4.22 & - & +4.17 & +4.20 & +4.18 & +4.09 \\
\hline \multirow[t]{4}{*}{$N-p-\mathrm{H}(1)$} & 6.80 & $\delta^{\mathrm{OBS}}$ & -23.5 & -22.0 & -19.7 & -19.7 & -18.6 & -14.8 & -14.9 & -13.1 & -11.2 & -10.0 \\
\hline & & $\delta^{\text {PARA }}$ & -30.30 & -28.80 & -26.50 & -26.50 & -25.40 & -21.60 & -21.70 & -19.90 & -18.00 & -16.80 \\
\hline & & $\delta^{\mathrm{MCD}}$ & +4.34 & +4.03 & +3.64 & +3.61 & +3.39 & +2.70 & +2.70 & +2.42 & +2.13 & +1.97 \\
\hline & & $\vartheta^{\mathrm{CON}}$ & -23.85 & -23.93 & -23.84 & -23.96 & -24.08 & -24.48 & -24.58 & -24.58 & -24.70 & -24.63 \\
\hline \multicolumn{3}{|c|}{ 1000/(temperature in K) } & 4.873 & 4.604 & 4.243 & 4.216 & 4.013 & 3.331 & 3.331 & 3.047 & 2.734 & 2.556 \\
\hline
\end{tabular}

${ }^{a}$ In $L$-(-)-(1-phenylethyl)amine. 
Table S36 (cont'd). ${ }^{1} \mathrm{H}$ NMR Parameters (in ppm) $\delta^{\mathrm{DIA}}, \delta^{\mathrm{OBS}}, \delta^{\mathrm{PARA}}, \delta^{\mathrm{MCD}}$, and $\vartheta^{\mathrm{CON}} \approx \vartheta^{\mathrm{C}+\mathrm{L}}$ of the Bis(chelate) 20Ni in Cl ${ }_{2} \mathrm{CD}-\mathrm{CDCl}{ }_{2}$ Solution as a Function of the Temperature

\begin{tabular}{|c|c|c|c|c|c|c|c|c|c|c|c|c|}
\hline \multirow{2}{*}{$\begin{array}{l}\text { nucleus } \\
\text { (line no.) }\end{array}$} & \multirow{2}{*}{$\begin{array}{l}\text { 20Zn } \\
\delta^{\text {DIA }} \\
\end{array}$} & \multirow[t]{2}{*}{$20 \mathrm{Ni}$} & \multicolumn{10}{|c|}{ temperature $\left[{ }^{\circ} \mathrm{C}\right]$} \\
\hline & & & -68.0 & $-56.0^{a}$ & -37.5 & $-36.0^{a}$ & -24.0 & $+27.0^{a}$ & +27.0 & +55.0 & +92.5 & +118.0 \\
\hline \multirow[t]{4}{*}{$N-\mathrm{O}-\mathrm{H}(2)$} & 6.27 & $\delta^{\mathrm{OBS}}$ & -22.4 & -20.2 & -17.6 & -17.7 & -16.5 & -12.1 & -12.3 & -10.5 & -8.67 & -7.50 \\
\hline & & $\delta^{\text {PARA }}$ & -28.67 & -26.47 & -23.87 & -23.97 & -22.77 & -18.37 & -18.57 & -16.77 & -14.94 & -13.77 \\
\hline & & $\delta^{\mathrm{MCD}}$ & +21.39 & +19.89 & +17.93 & +17.79 & +16.72 & +13.30 & +13.30 & +11.94 & +10.50 & +9.70 \\
\hline & & $\vartheta^{\mathrm{CON}}$ & -34.47 & -33.79 & -33.06 & -33.24 & -33.03 & -31.90 & -32.10 & -31.62 & -31.22 & -30.81 \\
\hline \multirow[t]{4}{*}{$N-O-\mathrm{H}(1)$} & 6.27 & $\delta^{\mathrm{OBS}}$ & -31.2 & - & -24.8 & - & -24.0 & -18.9 & -19.1 & -17.1 & -16.4 & -14.50 \\
\hline & & $\delta^{\text {PARA }}$ & -37.47 & - & -31.07 & - & -30.27 & -25.17 & -25.37 & -23.37 & -22.67 & -20.77 \\
\hline & & $\delta^{\mathrm{MCD}}$ & +21.39 & - & +17.93 & - & +16.72 & +13.30 & +13.30 & +11.94 & +10.50 & +9.70 \\
\hline & & $\vartheta^{\mathrm{CON}}$ & -40.53 & - & -38.76 & - & -39.30 & -38.75 & -38.96 & -38.89 & -40.70 & -39.99 \\
\hline \multirow[t]{4}{*}{$N-O-\mathrm{H}(1)$} & 6.27 & $\delta^{\mathrm{OBS}}$ & -40.0 & - & -32.1 & - & -30.1 & -23.0 & -22.9 & -20.0 & -16.4 & -14.5 \\
\hline & & $\delta^{\text {PARA }}$ & -46.27 & - & -38.37 & - & -36.37 & -29.27 & -29.17 & -26.27 & -22.67 & -20.77 \\
\hline & & $\delta^{\mathrm{MCD}}$ & +21.39 & - & +17.93 & - & +16.72 & +13.30 & +13.30 & +11.94 & +10.50 & +9.70 \\
\hline & & $\vartheta^{\mathrm{CON}}$ & -46.59 & - & -44.53 & - & -44.40 & -42.88 & -42.78 & -42.08 & -40.70 & -39.99 \\
\hline \multirow[t]{4}{*}{$N-p-\mathrm{H}(1)$} & 6.80 & $\delta^{\mathrm{OBS}}$ & -48.9 & -46.1 & -40.1 & -40.5 & -37.8 & -29.9 & -29.8 & -26.6 & -23.1 & -20.7 \\
\hline & & $\delta^{\text {PARA }}$ & -55.70 & -52.90 & -46.90 & -47.30 & -44.60 & -36.70 & -36.60 & -33.40 & -29.90 & -27.50 \\
\hline & & $\delta^{\mathrm{MCD}}$ & +4.34 & +4.03 & +3.64 & +3.61 & +3.39 & +2.70 & +2.70 & +2.42 & +2.13 & +1.97 \\
\hline & & $\vartheta^{\mathrm{CON}}$ & -41.34 & -41.50 & -39.97 & -40.52 & -40.13 & -39.69 & -39.59 & -39.45 & -39.30 & -38.68 \\
\hline \multirow[t]{3}{*}{$\mathrm{H}(\alpha)$} & 4.77 & $\delta^{\mathrm{OBS}}$ & -158.9 & -152.2 & -134.2 & -136.8 & -128.5 & -106.8 & -106.3 & -96.5 & -85.3 & -79.2 \\
\hline & & $\delta^{\text {PARA }}$ & -163.67 & -156.97 & -138.97 & -141.57 & -133.27 & -111.57 & -111.07 & -101.27 & -90.07 & -83.97 \\
\hline & & $\delta^{\mathrm{MCD}}$ & -28.38 & -26.39 & -23.79 & -23.60 & -22.19 & -17.64 & -17.64 & -15.84 & -13.93 & -12.86 \\
\hline (line 62) & & $\vartheta^{\mathrm{CON}}$ & -93.16 & -95.18 & -91.10 & -93.90 & -92.89 & -94.62 & -94.12 & -94.08 & -93.44 & -93.34 \\
\hline 1000/(tem & erature i & $\mathrm{K})$ & 4.873 & 4.604 & 4.243 & 4.216 & 4.013 & 3.331 & 3.331 & 3.047 & 2.734 & 2.556 \\
\hline
\end{tabular}

${ }^{a}$ In $L$-(-)-(1-phenylethyl)amine. 
Table S37. ${ }^{1} \mathrm{H}$ NMR Parameters (in ppm) $\delta^{\mathrm{DIA}}, \delta^{\mathrm{OBS}}, \delta^{\mathrm{PARA}}, \delta^{\mathrm{MCD}}$, and $\vartheta^{\mathrm{CON}} \approx \vartheta^{\mathrm{C}+\mathrm{L}}$ of the Bis(chelate) 21Ni in $\mathrm{CDCl}_{3}$ Solution as a Function of the Temperature

\begin{tabular}{|c|c|c|c|c|c|c|c|c|c|}
\hline \multirow{2}{*}{$\begin{array}{l}\text { nucleus } \\
\text { (line no.) }\end{array}$} & \multirow{2}{*}{$\begin{array}{l}\mathbf{2 1 H} \\
\delta^{\text {DIA }}\end{array}$} & \multirow[t]{2}{*}{$21 \mathrm{Ni}$} & \multicolumn{7}{|c|}{ temperature $\left[{ }^{\circ} \mathrm{C}\right]$} \\
\hline & & & -61.0 & -49.0 & -30.5 & +27.0 & +30.5 & +55.0 & +71.8 \\
\hline \multirow[t]{3}{*}{$\mathrm{N}-\mathrm{CH}_{3}$} & 2.98 & $\delta^{\mathrm{OBS}}$ & +370.0 & +350.0 & +323.8 & +262.4 & +258.9 & +239.1 & +227.5 \\
\hline & & $\delta^{\text {PARA }}$ & +367.02 & +347.02 & +320.82 & +259.42 & +255.92 & +236.12 & +224.52 \\
\hline & & $\delta^{\mathrm{MCD}}$ & +25.42 & +23.70 & +21.45 & +16.50 & +16.27 & +14.82 & +13.96 \\
\hline (line 9) & & $\vartheta^{\mathrm{CON}}$ & +243.24 & +243.25 & +243.82 & +244.71 & +244.23 & +243.73 & +243.77 \\
\hline $\mathrm{H}(\delta)$ & 7.08 & $\delta^{\mathrm{OBS}}$ & +8.20 & +8.20 & +8.20 & - & +8.07 & +8.00 & +7.98 \\
\hline \multirow[t]{3}{*}{$(m)$} & & $\delta^{\text {PARA }}$ & +1.12 & +1.12 & +1.12 & - & +0.99 & +0.92 & +0.90 \\
\hline & & $\delta^{\mathrm{MCD}}$ & -4.38 & -4.08 & -3.69 & - & -2.80 & -2.55 & -2.40 \\
\hline & & $\vartheta^{\mathrm{CON}}$ & +3.92 & +3.91 & +3.92 & - & +3.86 & +3.82 & +3.83 \\
\hline $\mathrm{H}(\varepsilon)$ & 7.08 & $\delta^{\mathrm{OBS}}$ & +1.07 & +1.47 & +1.98 & - & +3.00 & +3.50 & +3.70 \\
\hline \multirow[t]{3}{*}{$(p)$} & & $\delta^{\text {PARA }}$ & -6.01 & -5.61 & -5.10 & - & -4.08 & -3.58 & -3.38 \\
\hline & & $\delta^{\mathrm{MCD}}$ & -3.52 & -3.28 & -2.97 & - & -2.25 & -2.05 & -1.93 \\
\hline & & $\vartheta^{\mathrm{CON}}$ & -1.77 & -1.75 & -1.74 & - & -1.86 & -1.68 & -1.68 \\
\hline $\mathrm{H}(\gamma)$ & 7.08 & $\delta^{\mathrm{OBS}}$ & -9.42 & -8.47 & -6.87 & - & -3.58 & -2.70 & -2.05 \\
\hline \multirow[t]{3}{*}{$(o)$} & & $\delta^{\text {PARA }}$ & -16.50 & -15.55 & -13.95 & - & -10.66 & -9.78 & -9.13 \\
\hline & & $\delta^{\mathrm{MCD}}$ & -11.18 & -10.42 & -9.43 & - & -7.15 & -6.51 & -6.14 \\
\hline & & $\vartheta^{\mathrm{CON}}$ & -3.79 & -3.86 & -3.68 & - & -3.57 & -3.60 & -3.47 \\
\hline \multirow[t]{3}{*}{$\mathrm{H}\left(\beta^{\prime}\right)$} & 1.55 & $\delta^{\mathrm{OBS}}$ & -78.3 & -74.2 & -67.7 & -54.2 & -52.9 & -48.7 & -46.1 \\
\hline & & $\delta^{\text {PARA }}$ & -79.85 & -75.75 & -69.25 & -55.75 & -54.45 & -50.25 & -47.65 \\
\hline & & $\delta^{\mathrm{MCD}}$ & -8.41 & -7.84 & -7.09 & -5.46 & -5.38 & -4.90 & -4.62 \\
\hline (line 59) & & $\vartheta^{\mathrm{CON}}$ & -50.87 & -51.09 & -50.62 & -50.66 & -50.01 & -49.94 & -49.82 \\
\hline $1000 /(\mathrm{t}$ & & in $\mathrm{K}$ ) & 4.713 & 4.460 & 4.120 & 3.331 & 3.293 & 3.047 & 2.899 \\
\hline
\end{tabular}


Table S38. ${ }^{1} \mathrm{H}$ NMR Parameters (in ppm) $\delta^{\mathrm{DIA}}, \delta^{\mathrm{OBS}}, \delta^{\mathrm{PARA}}, \delta^{\mathrm{MCD}}$, and $\vartheta^{\mathrm{CON}} \approx \vartheta^{\mathrm{C}+\mathrm{L}}$ of the Bis(chelate) 22Ni in $\mathrm{Cl}_{2} \mathrm{CD}-\mathrm{CDCl}_{2}$ Solution as a Function of the Temperature

\begin{tabular}{|c|c|c|c|c|c|c|c|}
\hline \multirow{2}{*}{$\begin{array}{l}\text { nucleus } \\
\text { (line no.) }\end{array}$} & \multirow{2}{*}{$\begin{array}{c}22 \mathrm{H} \\
\delta^{\text {DIA }}\end{array}$} & \multirow[t]{2}{*}{$22 \mathrm{Ni}$} & \multicolumn{5}{|c|}{ temperature $\left[{ }^{\circ} \mathrm{C}\right]$} \\
\hline & & & -63.0 & -40.0 & -21.3 & +27.0 & +64.0 \\
\hline $\mathrm{H}(\delta)$ & 7.22 & $\delta^{\mathrm{OBS}}$ & +8.57 & +8.42 & +8.28 & +8.10 & +7.98 \\
\hline \multirow[t]{3}{*}{$(m)$} & & $\delta^{\text {PARA }}$ & +1.35 & +1.20 & +1.06 & +0.88 & +0.76 \\
\hline & & $\delta^{\mathrm{MCD}}$ & -4.43 & -3.88 & -3.53 & -2.84 & -2.47 \\
\hline & & $\vartheta^{\mathrm{CON}}$ & +4.08 & +3.98 & +3.88 & +3.75 & +3.66 \\
\hline $\mathrm{H}(\varepsilon)$ & 7.22 & $\delta^{\mathrm{OBS}}$ & - & - & +2.73 & +3.57 & +3.93 \\
\hline \multirow[t]{2}{*}{ (p) } & & $\delta^{\text {PARA }}$ & - & - & -4.49 & -3.65 & -3.29 \\
\hline & & $\delta^{\mathrm{MCD}}$ & - & - & -2.83 & -2.28 & -1.99 \\
\hline (line 37) & & $\vartheta^{\mathrm{CON}}$ & - & - & -1.40 & -1.38 & -1.48 \\
\hline \multirow[t]{4}{*}{$\mathrm{H}(\gamma)$} & 7.22 & $\delta^{\mathrm{OBS}}$ & -7.73 & -5.93 & -4.80 & -2.70 & -1.67 \\
\hline & & $\delta^{\text {PARA }}$ & -14.95 & -13.15 & -12.02 & -9.92 & -8.89 \\
\hline & & $\delta^{\mathrm{MCD}}$ & -11.31 & -9.91 & -9.00 & -7.25 & -6.31 \\
\hline & & $\vartheta^{\mathrm{CON}}$ & -2.57 & -2.53 & -2.55 & -2.69 & -2.92 \\
\hline \multirow[t]{4}{*}{$N-m-\mathrm{CH}_{3}$} & 2.25 & $\delta^{\mathrm{OBS}}$ & -8.82 & -7.97 & -7.30 & -5.90 & -5.10 \\
\hline & & $\delta^{\text {PARA }}$ & -11.07 & -10.22 & -9.55 & -8.15 & -7.35 \\
\hline & & $\delta^{\mathrm{MCD}}$ & +3.04 & +2.66 & +2.42 & +1.95 & +1.69 \\
\hline & & $\vartheta^{\mathrm{CON}}$ & -9.95 & -10.08 & -10.11 & -10.17 & -10.23 \\
\hline \multirow[t]{3}{*}{$N-o-\mathrm{H}$} & 6.53 & $\delta^{\mathrm{OBS}}$ & -24.7 & -21.6 & -19.3 & -15.5 & -13.3 \\
\hline & & $\delta^{\text {PARA }}$ & -31.23 & -28.13 & -25.83 & -22.03 & -19.83 \\
\hline & & $\delta^{\mathrm{MCD}}$ & +20.74 & +18.18 & +16.50 & +13.30 & +11.56 \\
\hline (line 20) & & $\vartheta^{\mathrm{CON}}$ & -36.66 & -36.24 & -35.78 & -35.59 & -35.52 \\
\hline \multirow[t]{4}{*}{$N-p-\mathrm{H}$} & 6.53 & $\delta^{\mathrm{OBS}}$ & -30.6 & -27.5 & -25.2 & -20.4 & -17.7 \\
\hline & & $\delta^{\text {PARA }}$ & -37.13 & -34.03 & -31.73 & -26.93 & -24.23 \\
\hline & & $\delta^{\mathrm{MCD}}$ & +4.20 & +3.68 & +3.34 & +2.70 & +2.34 \\
\hline & & $\vartheta^{\mathrm{CON}}$ & -29.16 & -29.51 & -29.65 & -29.84 & -30.07 \\
\hline \multirow[t]{3}{*}{$\mathrm{H}\left(\beta^{\prime}\right)$} & 1.68 & $\delta^{\mathrm{OBS}}$ & -70.8 & -63.7 & -58.6 & -48.3 & -42.5 \\
\hline & & $\delta^{\text {PARA }}$ & -72.48 & -65.38 & -60.28 & -49.98 & -44.18 \\
\hline & & $\delta^{\mathrm{MCD}}$ & -8.51 & -7.46 & -6.77 & -5.46 & -4.74 \\
\hline (line 58) & & $\vartheta^{\mathrm{CON}}$ & -45.12 & -45.33 & -45.23 & -44.85 & -44.62 \\
\hline \multicolumn{3}{|c|}{ 1000/(temperature in K) } & 4.757 & 4.288 & 3.970 & 3.331 & 2.966 \\
\hline
\end{tabular}


Table S39. ${ }^{1} \mathrm{H}$ NMR Parameters (in ppm) $\delta^{\mathrm{DIA}}, \delta^{\mathrm{OBS}}, \delta^{\mathrm{PARA}}, \delta^{\mathrm{MCD}}$, and $\vartheta^{\mathrm{CON}} \approx \vartheta^{\mathrm{C}+\mathrm{L}}$ of the Bis(chelate) $23 \mathrm{Ni}$ in $\mathrm{Cl}_{2} \mathrm{CD}-\mathrm{CDCl} \mathrm{CD}_{2}$ Solution as a Function of the Temperature

\begin{tabular}{|c|c|c|c|c|c|c|c|c|c|c|c|c|}
\hline \multirow{2}{*}{$\begin{array}{l}\text { nucleus } \\
\text { (line no.) }\end{array}$} & \multirow{2}{*}{$\begin{array}{l}\mathbf{2 3 H} \\
\delta^{\text {DIA }}\end{array}$} & \multirow[t]{2}{*}{$23 \mathrm{Ni}$} & \multicolumn{10}{|c|}{ temperature $\left[{ }^{\circ} \mathrm{C}\right]$} \\
\hline & & & -39.0 & -32.0 & -21.0 & -8.0 & +8.0 & +26.0 & +26.0 & +57.0 & +79.0 & +98.0 \\
\hline$N-m-\mathrm{H}$ & 7.00 & $\begin{array}{l}\delta^{\text {OBS }} \\
\delta^{\text {PARA }} \\
\delta^{\text {MCD }} \\
\vartheta^{\text {CON }}\end{array}$ & $\begin{array}{r}+33.6 \\
+26.60 \\
+4.53 \\
+17.34 \\
\end{array}$ & $\begin{array}{r}+32.5 \\
+25.50 \\
+4.37 \\
+17.10 \\
\end{array}$ & $\begin{array}{r}+31.6 \\
+24.60 \\
+4.13 \\
+17.32 \\
\end{array}$ & $\begin{array}{r}+29.8 \\
+22.80 \\
+3.88 \\
+16.84 \\
\end{array}$ & $\begin{array}{r}+29.0 \\
+22.00 \\
+3.61 \\
+17.35 \\
\end{array}$ & $\begin{array}{r}+27.7 \\
+20.70 \\
+3.35 \\
+17.42 \\
\end{array}$ & $\begin{array}{r}+27.7 \\
+20.70 \\
+3.35 \\
+17.42 \\
\end{array}$ & $\begin{array}{r}+25.7 \\
+18.70 \\
+2.97 \\
+17.43 \\
\end{array}$ & $\begin{array}{r}+24.7 \\
+17.70 \\
+2.75 \\
+17.67\end{array}$ & $\begin{array}{r}+23.8 \\
+16.80 \\
+2.59 \\
+17.70 \\
\end{array}$ \\
\hline $\begin{array}{l}\mathrm{H}(\delta) \\
(m)\end{array}$ & 7.22 & $\begin{array}{l}\delta^{\text {OBS }} \\
\delta^{\text {PARA }} \\
\delta^{\text {MCD }} \\
\vartheta^{\text {CON }}\end{array}$ & $\begin{array}{l}+8.70 \\
+1.48 \\
-3.86 \\
+4.20 \\
\end{array}$ & $\begin{array}{l}+8.70 \\
+1.48 \\
-3.72 \\
+4.21 \\
\end{array}$ & $\begin{array}{l}+8.67 \\
+1.45 \\
-3.52 \\
+4.21\end{array}$ & $\begin{array}{l}+8.53 \\
+1.31 \\
-3.31 \\
+4.11 \\
\end{array}$ & $\begin{array}{l}+8.55 \\
+1.33 \\
-3.08 \\
+4.16 \\
\end{array}$ & $\begin{array}{l}+8.47 \\
+1.25 \\
-2.85 \\
+4.12\end{array}$ & $\begin{array}{r}+8.28 \\
+1.06 \\
-2.85 \\
+3.93 \\
\end{array}$ & $\begin{array}{l}+8.28 \\
+1.06 \\
-2.53 \\
+3.98 \\
\end{array}$ & $\begin{array}{l}+8.27 \\
+1.05 \\
-2.35 \\
+4.01 \\
\end{array}$ & $\begin{array}{c}+8.17 \\
+0.95 \\
-2.20 \\
+3.93 \\
\end{array}$ \\
\hline $\begin{array}{l}\mathrm{H}(\varepsilon) \\
(p)\end{array}$ & 7.22 & $\begin{array}{l}\delta^{\text {OBS }} \\
\delta^{\text {PARA }} \\
\delta^{\text {MCD }} \\
\vartheta^{\text {CON }}\end{array}$ & $\begin{array}{l}+2.60 \\
-4.62 \\
-3.10 \\
-1.19\end{array}$ & $\begin{array}{l}+2.85 \\
-4.37 \\
-2.99 \\
-1.12\end{array}$ & $\begin{array}{l}+3.05 \\
-4.17 \\
-2.83 \\
-1.13\end{array}$ & $\begin{array}{l}+3.30 \\
-3.92 \\
-2.66 \\
-1.12\end{array}$ & $\begin{array}{l}- \\
- \\
- \\
-\end{array}$ & $\begin{array}{l}+3.68 \\
-3.54 \\
-2.29 \\
-1.25\end{array}$ & $\begin{array}{l}+3.67^{a} \\
-3.55 \\
-2.29 \\
-1.26\end{array}$ & $\begin{array}{l}+4.08 \\
-3.14 \\
-2.04 \\
-1.22\end{array}$ & $\begin{array}{l}+4.22 \\
-3.00 \\
-1.88 \\
-1.32\end{array}$ & $\begin{array}{l}+4.33 \\
-2.89 \\
-1.77 \\
-1.39\end{array}$ \\
\hline $\begin{array}{l}\mathrm{H}(\gamma) \\
(o) \\
\text { (line 38) }\end{array}$ & 7.22 & $\begin{array}{l}\delta^{\text {OBS }} \\
\delta^{\text {PARA }} \\
\delta^{\text {MCD }} \\
\vartheta^{\text {CON }}\end{array}$ & $\begin{array}{r}-5.43 \\
-12.65 \\
-9.86 \\
-2.19 \\
\end{array}$ & $\begin{array}{r}-4.78 \\
-12.00 \\
-9.50 \\
-2.02 \\
\end{array}$ & $\begin{array}{r}-4.32 \\
-11.54 \\
-8.99 \\
-2.16 \\
\end{array}$ & $\begin{array}{r}-3.43 \\
-10.65 \\
-8.44 \\
-1.96 \\
\end{array}$ & $\begin{array}{l}- \\
- \\
- \\
-\end{array}$ & $\begin{array}{l}-2.42 \\
-9.64 \\
-7.28 \\
-2.37\end{array}$ & $\begin{array}{l}-2.43 \\
-9.65 \\
-7.28 \\
-2.38\end{array}$ & $\begin{array}{l}-1.52 \\
-8.74 \\
-6.47 \\
-2.52\end{array}$ & $\begin{array}{l}-0.97 \\
-8.19 \\
-5.99 \\
-2.60\end{array}$ & $\begin{array}{l}-0.58 \\
-7.80 \\
-5.63 \\
-2.71\end{array}$ \\
\hline$N-\mathrm{O}-\mathrm{H}$ & 7.00 & $\begin{array}{l}\delta^{\text {OBS }} \\
\delta^{\text {PARA }} \\
\delta^{\text {MCD }} \\
\vartheta^{\text {CON }}\end{array}$ & $\begin{array}{l}-21.0 \\
-28.00 \\
+18.08 \\
-36.21\end{array}$ & $\begin{array}{l}-20.0 \\
-27.00 \\
+17.42 \\
-35.95\end{array}$ & $\begin{array}{l}-19.4 \\
-26.40 \\
+16.48 \\
-36.29\end{array}$ & $\begin{array}{l}-17.8 \\
-24.80 \\
+15.48 \\
-35.85 \\
\end{array}$ & $\begin{array}{l}-16.7 \\
-23.70 \\
+14.40 \\
-35.96 \\
\end{array}$ & $\begin{array}{l}- \\
- \\
- \\
-\end{array}$ & $\begin{array}{l}-15.7 \\
-22.70 \\
+13.35 \\
-36.20\end{array}$ & $\begin{array}{l}- \\
- \\
- \\
-\end{array}$ & $\begin{array}{l}-12.6 \\
-19.60 \\
+10.98 \\
-36.14\end{array}$ & $\begin{array}{l}-11.5 \\
-18.50 \\
+10.31 \\
-35.89\end{array}$ \\
\hline$N-p-\mathrm{H}$ & 7.00 & $\begin{array}{l}\delta^{\text {OBS }} \\
\delta^{\text {PARA }} \\
\delta^{\text {MCD }} \\
\vartheta^{\text {CON }} \\
\end{array}$ & $\begin{array}{r}-28.1 \\
-35.10 \\
+3.66 \\
-30.47 \\
\end{array}$ & $\begin{array}{r}-26.7 \\
-33.70 \\
+3.53 \\
-30.13 \\
\end{array}$ & $\begin{array}{l}-25.7 \\
-32.70 \\
+3.34 \\
-30.50 \\
\end{array}$ & $\begin{array}{r}-23.4 \\
-30.40 \\
+3.14 \\
-29.85 \\
\end{array}$ & $\begin{array}{r}-22.2 \\
-29.20 \\
+2.92 \\
-30.31 \\
\end{array}$ & $\begin{array}{r}-20.8 \\
-27.80 \\
+2.71 \\
-30.63 \\
\end{array}$ & $\begin{array}{r}-20.9 \\
-27.90 \\
+2.71 \\
-30.73 \\
\end{array}$ & $\begin{array}{r}-18.4 \\
-25.40 \\
+2.40 \\
-30.81 \\
\end{array}$ & $\begin{array}{r}-17.0 \\
-24.00 \\
+2.23 \\
-30.99 \\
\end{array}$ & $\begin{array}{r}-15.8 \\
-22.80 \\
+2.09 \\
-31.00 \\
\end{array}$ \\
\hline (line 58) & 1.68 & $\begin{array}{l}\delta^{\text {OBS }} \\
\delta^{\text {PARA }} \\
\delta^{\mathrm{MCD}} \\
\oint^{\mathrm{CON}} \\
\end{array}$ & $\begin{array}{r}-63.2 \\
-64.88 \\
-7.42 \\
-45.16 \\
\end{array}$ & $\begin{array}{r}-60.4 \\
-62.08 \\
-7.15 \\
-44.46 \\
\end{array}$ & $\begin{array}{r}-58.4 \\
-60.08 \\
-6.76 \\
-45.12 \\
\end{array}$ & $\begin{array}{r}-53.40 \\
-55.08 \\
-6.35 \\
-43.36 \\
\end{array}$ & $\begin{array}{l}- \\
- \\
- \\
- \\
\end{array}$ & $\begin{array}{r}-48.2 \\
-49.88 \\
-5.48 \\
-44.58 \\
\end{array}$ & $\begin{array}{r}-48.3 \\
-49.98 \\
-5.48 \\
-44.68 \\
\end{array}$ & $\begin{array}{r}-43.4 \\
-45.08 \\
-4.87 \\
-44.56 \\
\end{array}$ & $\begin{array}{r}-40.7 \\
-42.38 \\
-4.51 \\
-44.76 \\
\end{array}$ & $\begin{array}{r}-38.2 \\
-39.88 \\
-4.23 \\
-44.40 \\
\end{array}$ \\
\hline 1000/(tem) & rature & K) & 4.270 & 4.146 & 3.965 & 3.771 & 3.556 & 3.342 & 3.342 & 3.028 & 2.839 & 2.694 \\
\hline
\end{tabular}

${ }^{a} \mathrm{t},{ }^{3} \mathrm{~J}_{\mathrm{HH}} \approx 7 \mathrm{~Hz}$. 
Table S40. ${ }^{1} \mathrm{H}$ NMR Parameters (in ppm) $\delta^{\mathrm{DIA}}, \delta^{\mathrm{OBS}}, \delta^{\mathrm{PARA}}, \delta^{\mathrm{MCD}}$, and $\vartheta^{\mathrm{CON}} \approx \vartheta^{\mathrm{C}+\mathrm{L}}$ of the Bis(chelate) 24Ni in $\mathrm{Cl}_{2} \mathrm{CD}-\mathrm{CDCl}_{2}$ Solution as a Function of the Temperature

\begin{tabular}{|c|c|c|c|c|c|c|c|c|c|}
\hline \multirow{2}{*}{$\begin{array}{l}\text { nucleus } \\
\text { (line no.) }\end{array}$} & \multirow{2}{*}{$\begin{array}{c}\mathbf{2 4 H} \\
\delta^{\text {DIA }} \\
\end{array}$} & \multirow[t]{2}{*}{$24 \mathrm{Ni}$} & \multicolumn{7}{|c|}{ temperature $\left[{ }^{\circ} \mathrm{C}\right]$} \\
\hline & & & -60.5 & -41.5 & -26.0 & -18.0 & +26.0 & +60.0 & +90.0 \\
\hline \multirow[t]{3}{*}{$N-m-\mathrm{H}$} & 6.97 & $\delta^{\mathrm{OBS}}$ & +36.5 & +33.6 & +32.0 & +31.4 & +27.7 & +25.5 & +24.0 \\
\hline & & $\delta^{\text {PARA }}$ & +29.53 & +26.63 & +25.03 & +24.43 & +20.73 & +18.53 & +17.03 \\
\hline & & $\delta^{\mathrm{MCD}}$ & +5.12 & +4.60 & +4.24 & +4.07 & +3.35 & +2.94 & +2.65 \\
\hline (line 18) & & $\vartheta^{\mathrm{CON}}$ & +17.42 & +17.13 & +17.25 & +17.43 & +17.45 & +17.43 & +17.52 \\
\hline $\mathrm{H}(\delta)$ & 7.05 & $\delta^{\mathrm{OBS}}$ & +8.82 & +8.70 & +8.60 & +8.57 & +8.35 & +8.17 & +8.05 \\
\hline \multirow[t]{3}{*}{$(m)$} & & $\delta^{\text {PARA }}$ & +1.77 & +1.65 & +1.55 & +1.52 & +1.30 & +1.12 & +1.00 \\
\hline & & $\delta^{\mathrm{MCD}}$ & -4.37 & -3.92 & -3.61 & -3.47 & -2.85 & -2.51 & -2.26 \\
\hline & & $\vartheta^{\mathrm{CON}}$ & +4.38 & +4.33 & +4.28 & +4.27 & +4.17 & +4.05 & +3.98 \\
\hline $\mathrm{H}(\zeta)$ & 2.33 & $\delta^{\mathrm{OBS}}$ & +2.87 & +2.85 & +2.84 & +2.83 & +2.77 & +2.70 & +2.67 \\
\hline \multirow[t]{3}{*}{$(p-\mathrm{Me})$} & & $\delta^{\text {PARA }}$ & +0.54 & +0.52 & +0.51 & +0.50 & +0.44 & +0.37 & +0.34 \\
\hline & & $\delta^{\mathrm{MCD}}$ & -2.47 & -2.22 & -2.04 & -1.96 & -1.62 & -1.42 & -1.28 \\
\hline & & $\vartheta^{\mathrm{CON}}$ & +2.15 & +2.13 & +2.12 & +2.11 & +2.06 & +2.00 & +1.97 \\
\hline $\mathrm{H}(\gamma)$ & 7.05 & $\delta^{\mathrm{OBS}}$ & -7.20 & -5.60 & -4.78 & -4.37 & -2.60 & -1.33 & -0.58 \\
\hline \multirow[t]{2}{*}{$(o)$} & & $\delta^{\text {PARA }}$ & -14.25 & -12.65 & -11.83 & -11.42 & -9.65 & -8.38 & -7.63 \\
\hline & & $\delta^{\mathrm{MCD}}$ & -11.14 & -9.99 & -9.21 & -8.86 & -7.28 & -6.40 & -5.77 \\
\hline (line 38) & & $\vartheta^{\mathrm{CON}}$ & -2.22 & -2.06 & -2.17 & -2.20 & -2.38 & -2.22 & -2.26 \\
\hline \multirow[t]{3}{*}{$N-O-\mathrm{H}$} & 6.97 & $\delta^{\mathrm{OBS}}$ & -23.4 & -21.4 & -19.7 & -19.0 & -15.6 & -13.6 & -12.0 \\
\hline & & $\delta^{\text {PARA }}$ & -30.37 & -28.37 & -26.67 & -25.97 & -22.57 & -20.57 & -18.97 \\
\hline & & $\delta^{\mathrm{MCD}}$ & +20.43 & +18.32 & +16.89 & +16.24 & +13.35 & +11.73 & +10.58 \\
\hline (line 20) & & $\vartheta^{\mathrm{CON}}$ & -36.26 & -36.31 & -36.14 & -36.14 & -36.07 & -36.11 & -36.02 \\
\hline \multirow[t]{3}{*}{$N-p-\mathrm{H}$} & 6.97 & $\delta^{\mathrm{OBS}}$ & -31.3 & -28.2 & -26.2 & -25.2 & -21.0 & -18.1 & -16.2 \\
\hline & & $\delta^{\text {PARA }}$ & -38.27 & -35.17 & -33.17 & -32.17 & -27.97 & -25.07 & -23.17 \\
\hline & & $\delta^{\mathrm{MCD}}$ & +4.14 & +3.71 & +3.42 & +3.29 & +2.71 & +2.38 & +2.15 \\
\hline (line 80) & & $\vartheta^{\mathrm{CON}}$ & -30.27 & -30.23 & -30.36 & -30.37 & -30.80 & -30.69 & -30.85 \\
\hline \multirow[t]{3}{*}{$\mathrm{H}\left(\beta^{\prime}\right)$} & 1.70 & $\delta^{\mathrm{OBS}}$ & -69.7 & -63.5 & -58.1 & -57.0 & -48.3 & -43.1 & -39.0 \\
\hline & & $\delta^{\text {PARA }}$ & -71.40 & -65.20 & -59.80 & -58.70 & -50.00 & -44.80 & -40.70 \\
\hline & & $\delta^{\mathrm{MCD}}$ & -8.38 & -7.52 & -6.93 & -6.66 & -5.48 & -4.81 & -4.34 \\
\hline (line 58) & & $\vartheta^{\mathrm{CON}}$ & -44.98 & -44.85 & -43.85 & -44.56 & -44.70 & -44.71 & -44.31 \\
\hline $1000 /$ (tem & iperatu & e in $K$ ) & 4.701 & 4.316 & 4.045 & 3.918 & 3.342 & 3.001 & 2.753 \\
\hline
\end{tabular}


Table S41. ${ }^{13} \mathrm{C}$ NMR Parameters (in ppm) $\delta^{\mathrm{DIA}}, \delta^{\mathrm{OBS}}, \delta^{\mathrm{PARA}}, \delta^{\mathrm{MCD}}$, and $\vartheta^{\mathrm{CON}} \approx \vartheta^{\mathrm{C}+\mathrm{L}}$ of the Bis(chelate) $24 \mathrm{Ni}$ in $\mathrm{Cl}_{2} \mathrm{CD}-\mathrm{CDCl}_{2}$ Solution as a Function of the Temperature

\begin{tabular}{|c|c|c|c|c|c|c|}
\hline \multirow{2}{*}{$\begin{array}{l}\text { nucleus } \\
\text { (line no.) }\end{array}$} & \multirow{2}{*}{$\begin{array}{l}\mathbf{2 4 H} \\
\delta^{\text {DIA }}\end{array}$} & \multirow[t]{2}{*}{$24 \mathrm{Ni}$} & \multicolumn{4}{|c|}{ temperature $\left[{ }^{\circ} \mathrm{C}\right]$} \\
\hline & & & -48.0 & $-23.0^{a}$ & $+31.0^{b}$ & +33.5 \\
\hline \multirow[t]{4}{*}{$C(2)$} & 109.4 & $\delta^{\mathrm{OBS}}$ & +939.3 & +860.0 & $+721.5^{c}$ & +713.6 \\
\hline & & $\delta^{\text {PARA }}$ & +829.9 & +750.6 & +612.1 & +604.2 \\
\hline & & $\delta^{\mathrm{MCD}}$ & -59.74 & -52.33 & -41.16 & -40.75 \\
\hline & & $9^{\mathrm{CON}}$ & +672.30 & +674.14 & +666.85 & +663.78 \\
\hline \multirow[t]{3}{*}{$\mathrm{C}\left(\alpha^{\prime}\right)$} & 20.0 & $\delta^{\text {OBS }}$ & +887.5 & +805.0 & $+663.4^{d}$ & +656.1 \\
\hline & & $\delta^{\text {PARA }}$ & +867.5 & +785.0 & +643.4 & +636.1 \\
\hline & & $\delta^{\mathrm{MCD}}$ & -13.17 & -11.54 & -9.08 & -8.99 \\
\hline (line 2) & & $\vartheta^{\mathrm{CON}}$ & +665.53 & $\begin{array}{r}+668.77 \\
\end{array}$ & +666.05 & +663.92 \\
\hline \multirow[t]{3}{*}{$N-O-\mathrm{C}$} & 122.8 & $\delta^{\text {OBS }}$ & +773.3 & +706.0 & $+599.0^{e}$ & +595.8 \\
\hline & & $\delta^{\text {PARA }}$ & +650.5 & $\begin{array}{l}+583.2 \\
\end{array}$ & +476.2 & +473.0 \\
\hline & & $\delta^{\mathrm{MCD}}$ & +19.30 & +16.91 & +13.30 & $\begin{array}{l}+13.16 \\
\end{array}$ \\
\hline (line 4) & & $9^{\mathrm{CON}}$ & +477.0 & +475.46 & $\begin{array}{r}+472.54 \\
\end{array}$ & $\begin{array}{r}+473.26 \\
\end{array}$ \\
\hline $\mathrm{C}(\beta)$ & 129.0 & $\delta^{\mathrm{OBS}}$ & +526.6 & +487.6 & $+418.2^{f}$ & +414.4 \\
\hline \multirow[t]{2}{*}{ (o) } & & $\delta^{\text {PARA }}$ & +397.6 & +358.6 & +289.2 & +285.4 \\
\hline & & $\delta^{\mathrm{MCD}}$ & -11.26 & -9.87 & -7.76 & -7.68 \\
\hline (line 8) & & $\vartheta^{\mathrm{CON}}$ & +308.98 & +309.36 & +303.14 & +301.64 \\
\hline \multirow[t]{3}{*}{$N-i-C$} & 145.5 & $\delta^{\text {OBS }}$ & +381.9 & +361.0 & $+322.6^{g}$ & +320.5 \\
\hline & & $\delta^{\text {PARA }}$ & +236.4 & +215.5 & +177.1 & +175.0 \\
\hline & & $\delta^{\mathrm{MCD}}$ & +30.79 & +26.97 & +21.21 & +21.00 \\
\hline (line 53) & & $\vartheta^{\mathrm{CON}}$ & +155.38 & $\begin{array}{r}+158.29 \\
\end{array}$ & +159.13 & +158.49 \\
\hline \multirow[t]{3}{*}{$N-p-\mathrm{C}$} & 123.0 & $\delta^{\text {OBS }}$ & +360.7 & +339.5 & $+301.6^{h}$ & +299.3 \\
\hline & & $\delta^{\text {PARA }}$ & +237.7 & +216.5 & +178.6 & +176.3 \\
\hline & & $\delta^{\mathrm{MCD}}$ & $\begin{array}{r}+6.59 \\
\end{array}$ & $\begin{array}{r}+5.78 \\
+\end{array}$ & +4.54 & +4.50 \\
\hline (line 52) & & $9^{\mathrm{CON}}$ & +174.65 & +176.92 & +177.68 & +176.82 \\
\hline $\mathrm{C}(\gamma)$ & 131.8 & $\delta^{\mathrm{OBS}}$ & +157.2 & +154.7 & $+149.5^{f}$ & +149.0 \\
\hline \multirow[t]{3}{*}{ (m) } & & $\delta^{\text {PARA }}$ & +25.4 & +22.9 & +17.7 & +17.2 \\
\hline & & $\delta^{\mathrm{MCD}}$ & -5.97 & -5.23 & -4.11 & -4.07 \\
\hline & & $\vartheta^{\mathrm{CON}}$ & +23.71 & +23.62 & +22.27 & +21.89 \\
\hline $\mathrm{C}(\delta)$ & 135.7 & $\delta^{\mathrm{OBS}}$ & +142.0 & +142.0 & $+140.6^{g}$ & +140.2 \\
\hline \multirow[t]{2}{*}{$(p)$} & & $\delta^{\text {PARA }}$ & +6.30 & +6.30 & +4.90 & +4.50 \\
\hline & & $\delta^{\mathrm{MCD}}$ & -4.89 & -4.29 & -3.37 & -3.34 \\
\hline (line 70) & & $\vartheta^{\mathrm{CON}}$ & +8.46 & +8.89 & +8.44 & +8.07 \\
\hline \multirow{3}{*}{$\begin{array}{l}\mathrm{C}(\varepsilon) \\
(p-\mathrm{Me})\end{array}$} & 21.2 & $\delta^{\mathrm{OBS}}$ & +13.3 & +14.2 & $+15.4^{i}$ & +15.5 \\
\hline & & $\delta^{\text {PARA }}$ & -7.90 & -7.00 & -5.80 & -5.70 \\
\hline & & $\delta^{\mathrm{MCD}}$ & -2.82 & -2.47 & -1.94 & -1.92 \\
\hline (line 75) & & $\vartheta^{\mathrm{CON}}$ & -3.84 & -3.80 & -3.94 & -3.89 \\
\hline \multirow[t]{3}{*}{$N-m-C$} & 128.6 & $\delta^{\mathrm{OBS}}$ & -15.1 & -3.07 & $+19.5^{j}$ & +20.9 \\
\hline & & $\delta^{\text {PARA }}$ & -143.7 & -131.67 & -109.1 & -107.7 \\
\hline & & $\delta^{\mathrm{MCD}}$ & +8.38 & +7.34 & +5.78 & +5.72 \\
\hline \multicolumn{2}{|l|}{ (line 64) } & $\vartheta^{\mathrm{CON}}$ & -114.93 & -116.72 & -117.27 & -116.73 \\
\hline \multirow{3}{*}{$\begin{array}{l}\mathrm{C}(\alpha) \\
\text { (ipso-C) }\end{array}$} & 138.7 & $\delta^{\mathrm{OBS}}$ & $-234.1^{k}$ & $-196.0^{l}$ & $-130.8^{g}$ & -127.5 \\
\hline & & $\delta^{\text {PARA }}$ & -372.8 & -334.7 & -269.5 & -266.2 \\
\hline & & $\delta^{\mathrm{MCD}}$ & -19.74 & -17.29 & -13.60 & -13.46 \\
\hline (line 26) & & $\vartheta^{\mathrm{CON}}$ & -266.81 & -266.50 & -261.23 & -260.11 \\
\hline $\mathrm{C}(1,3)$ & 159.3 & $\delta^{\text {OBS }}$ & -757.8 & -663.0 & $-505.2^{g}$ & -498.6 \\
\hline & & $\delta^{\text {PARA }}$ & -917.1 & -822.3 & -664.5 & -657.9 \\
\hline & & $\delta^{\mathrm{MCD}}$ & -61.58 & -53.95 & -42.43 & -42.01 \\
\hline (line 30) & & $\vartheta^{\mathrm{CON}}$ & -646.52 & -645.11 & -635.02 & -633.87 \\
\hline $1000 /$ (ten & rature & & 4.440 & 3.997 & 3.287 & 3.261 \\
\hline
\end{tabular}

${ }^{a}$ In $\mathrm{CDCl}_{3} .{ }^{b}{ }^{1} \mathrm{H}$ coupled. ${ }^{c}$ Broad. ${ }^{d}$ Very broad. ${ }^{e}$ Pseudo-d. ${ }^{f} \mathrm{~d},{ }^{1} J_{\mathrm{CH}}=153 \mathrm{~Hz} .{ }^{g}$ Narrow singlet. ${ }^{h} \mathrm{~d},{ }^{1} J_{\mathrm{CH}}=158 \mathrm{~Hz} .{ }^{i} \mathrm{q},{ }^{1} J_{\mathrm{CH}}=126 \mathrm{~Hz} .{ }^{j}$ Sharp d, ${ }^{1} J_{\mathrm{CH}}=158 \mathrm{~Hz} .{ }^{k} \pm>3 \mathrm{ppm} .{ }^{l} \pm 2 \mathrm{ppm}$. 
Table S42. ${ }^{1} \mathrm{H}$ NMR Parameters (in ppm) $\delta^{\mathrm{DIA}}, \delta^{\mathrm{OBS}}, \delta^{\mathrm{PARA}}, \delta^{\mathrm{MCD}}$, and $\vartheta^{\mathrm{CON}} \approx \vartheta^{\mathrm{C}+\mathrm{L}}$ of the Bis(chelate) 25Ni in $\mathrm{CS}_{2}$ Solution as a Function of the Temperature

\begin{tabular}{|c|c|c|c|c|c|c|c|c|c|c|}
\hline \multirow{2}{*}{$\begin{array}{l}\text { nucleus } \\
\text { (line no.) }\end{array}$} & \multirow{2}{*}{$\begin{array}{l}25 \mathbf{H} \\
\delta^{\text {DIA }}\end{array}$} & \multirow[t]{2}{*}{$25 \mathrm{Ni}$} & \multicolumn{8}{|c|}{ temperature $\left[{ }^{\circ} \mathrm{C}\right]$} \\
\hline & & & -63.7 & -50.5 & -35.7 & -18.0 & +30.0 & +30.2 & +60.0 & +69.0 \\
\hline \multirow[t]{3}{*}{$N-m-\mathrm{H}$} & 6.97 & $\delta^{\mathrm{OBS}}$ & +37.3 & +35.4 & +33.7 & +31.7 & +27.9 & +27.9 & +26.0 & +25.5 \\
\hline & & $\delta^{\text {PARA }}$ & +30.33 & +28.43 & +26.73 & +24.73 & +20.93 & +20.93 & +19.03 & +18.53 \\
\hline & & $\delta^{\mathrm{MCD}}$ & +5.22 & +4.83 & +4.46 & +4.07 & +3.30 & +3.29 & +2.94 & +2.85 \\
\hline (line 69) & & $\vartheta^{\mathrm{CON}}$ & +17.65 & +17.63 & +17.75 & +17.69 & +17.94 & +17.96 & +17.99 & +18.01 \\
\hline $\mathrm{H}(\delta)$ & 6.97 & $\delta^{\mathrm{OBS}}$ & +10.7 & +10.5 & +10.4 & +10.2 & +9.70 & +9.67 & +9.42 & +9.35 \\
\hline \multirow[t]{2}{*}{$(m)$} & & $\delta^{\text {PARA }}$ & +3.73 & +3.53 & +3.43 & +3.23 & +2.73 & +2.70 & +2.45 & +2.38 \\
\hline & & $\delta^{\mathrm{MCD}}$ & -4.45 & -4.12 & -3.80 & -3.47 & -2.81 & -2.81 & -2.51 & -2.43 \\
\hline (line 32) & & $\vartheta^{\mathrm{CON}}$ & +5.75 & +5.71 & +5.76 & +5.74 & +5.63 & +5.61 & +5.54 & +5.52 \\
\hline $\mathrm{H}(\zeta)$ & 2.13 & $\delta^{\mathrm{OBS}}$ & +0.90 & +1.03 & +1.13 & +1.27 & +1.47 & +1.45 & +1.57 & +1.57 \\
\hline \multirow[t]{2}{*}{$(p-\mathrm{Me})$} & & $\delta^{\text {PARA }}$ & -1.23 & -1.10 & -1.00 & -0.86 & -0.66 & -0.68 & -0.56 & -0.56 \\
\hline & & $\delta^{\mathrm{MCD}}$ & -2.52 & -2.33 & -2.15 & -1.96 & -1.59 & -1.59 & -1.42 & -1.37 \\
\hline (line 56) & & $\vartheta^{\mathrm{CON}}$ & +0.91 & +0.92 & +0.92 & +0.95 & +0.95 & +0.92 & +0.96 & +0.93 \\
\hline $\mathrm{H}(\delta)$ & 2.20 & $\delta^{\mathrm{OBS}}$ & -3.15 & -2.85 & -2.48 & -2.13 & -1.45 & -1.45 & -1.17 & -1.07 \\
\hline \multirow[t]{3}{*}{ (o-Me) } & & $\delta^{\text {PARA }}$ & -5.35 & -5.05 & -4.68 & -4.33 & -3.65 & -3.65 & -3.37 & -3.27 \\
\hline & & $\delta^{\mathrm{MCD}}$ & -8.16 & -7.55 & -6.96 & -6.36 & -5.15 & -5.14 & -4.59 & -4.45 \\
\hline & & $\vartheta^{\mathrm{CON}}$ & +1.97 & +1.87 & +1.81 & +1.74 & +1.52 & +1.52 & +1.37 & +1.35 \\
\hline \multirow[t]{4}{*}{$N-O-\mathrm{H}$} & 6.97 & $\delta^{\mathrm{OBS}}$ & -21.5 & -19.7 & -18.7 & -17.4 & -13.8 & -13.8 & -12.3 & -11.7 \\
\hline & & $\delta^{\text {PARA }}$ & -28.47 & -26.67 & -25.67 & -24.37 & -20.77 & -20.77 & -19.27 & -18.67 \\
\hline & & $\delta^{\mathrm{MCD}}$ & +20.83 & +19.27 & +17.76 & +16.24 & +13.14 & +13.13 & +11.73 & +11.36 \\
\hline & & $\vartheta^{\mathrm{CON}}$ & -34.66 & -34.33 & -34.62 & -34.77 & -34.50 & -34.51 & -34.66 & -34.48 \\
\hline \multirow[t]{3}{*}{$N-p-\mathrm{H}$} & 6.97 & $\delta^{\mathrm{OBS}}$ & -32.1 & -29.9 & -27.9 & -25.6 & -20.8 & -21.1 & -18.5 & -17.9 \\
\hline & & $\delta^{\text {PARA }}$ & -39.07 & -36.87 & -34.87 & -32.57 & -27.77 & -28.07 & -25.47 & -24.87 \\
\hline & & $\delta^{\mathrm{MCD}}$ & +4.22 & +3.91 & +3.60 & +3.29 & +2.66 & +2.66 & +2.38 & +2.30 \\
\hline (line 80) & & $\vartheta^{\mathrm{CON}}$ & -30.44 & -30.47 & -30.66 & -30.71 & -30.96 & -31.29 & -31.14 & -31.20 \\
\hline \multirow[t]{3}{*}{$\mathrm{H}\left(\beta^{\prime}\right)$} & 1.58 & $\delta^{\mathrm{OBS}}$ & -76.7 & -72.1 & -67.5 & -62.0 & -51.9 & -52.0 & -46.8 & -45.5 \\
\hline & & $\delta^{\text {PARA }}$ & -78.28 & -73.68 & -69.08 & -63.58 & -53.48 & -53.58 & -48.38 & -47.08 \\
\hline & & $\delta^{\mathrm{MCD}}$ & -8.55 & -7.91 & -7.29 & -6.66 & -5.39 & -5.39 & -4.81 & -4.66 \\
\hline (line 59) & & $\vartheta^{\mathrm{CON}}$ & -49.02 & -49.15 & -49.25 & -48.74 & -48.93 & -49.06 & -48.71 & -48.71 \\
\hline $1000 /$ (tem & iperatu & in $K$ ) & 4.773 & 4.490 & 4.211 & 3.918 & 3.298 & 3.296 & 3.001 & 2.922 \\
\hline
\end{tabular}


Table S43. ${ }^{1} \mathrm{H}$ NMR Parameters (in ppm) $\delta^{\mathrm{DIA}}, \delta^{\mathrm{OBS}}, \delta^{\mathrm{PARA}}, \delta^{\mathrm{MCD}}$, and $\vartheta^{\mathrm{CON}} \approx \vartheta^{\mathrm{C}+\mathrm{L}}$ of the Bis(chelate) 26Ni in $\mathrm{Cl}_{2} \mathrm{CD}-\mathrm{CDCl}_{2}$ Solution as a Function of the Temperature

\begin{tabular}{|c|c|c|c|c|c|c|c|c|c|c|}
\hline \multirow{2}{*}{$\begin{array}{l}\text { nucleus } \\
\text { (line no.) }\end{array}$} & \multirow{2}{*}{$\begin{array}{l}\mathbf{2 6 H} \\
\delta^{\mathrm{DIA}}\end{array}$} & \multirow[t]{2}{*}{$26 \mathrm{Ni}$} & \multicolumn{8}{|c|}{ temperature $\left[{ }^{\circ} \mathrm{C}\right]$} \\
\hline & & & -62.5 & -50.0 & -38.3 & -20.5 & -12.5 & +27.0 & +72.7 & 104.5 \\
\hline \multirow[t]{3}{*}{$N-m-\mathrm{H}$} & 6.92 & $\delta^{\mathrm{OBS}}$ & +37.0 & +35.0 & +33.9 & +32.0 & +31.2 & +27.9 & +25.1 & +23.5 \\
\hline & & $\delta^{\text {PARA }}$ & +30.08 & +28.08 & +26.98 & +25.08 & +24.28 & +20.98 & +18.18 & +16.58 \\
\hline & & $\delta^{\mathrm{MCD}}$ & +5.19 & +4.82 & +4.52 & +4.12 & +3.97 & +3.34 & +2.81 & +2.53 \\
\hline (line 69) & & $\vartheta^{\mathrm{CON}}$ & +17.60 & +17.42 & +17.71 & +17.77 & +17.77 & +17.77 & +17.84 & +17.80 \\
\hline $\mathrm{H}(\varepsilon)$ & 6.92 & $\delta^{\mathrm{OBS}}$ & +2.00 & +2.28 & +2.48 & +2.80 & +2.97 & +3.45 & +3.87 & +4.07 \\
\hline \multirow[t]{2}{*}{$(p)$} & & $\delta^{\text {PARA }}$ & -4.92 & -4.64 & -4.44 & -4.12 & -3.95 & -3.47 & -3.05 & -2.85 \\
\hline & & $\delta^{\mathrm{MCD}}$ & -3.55 & -3.30 & -3.09 & -2.82 & -2.71 & -2.28 & -1.93 & -1.74 \\
\hline (line 37) & & $\vartheta^{\mathrm{CON}}$ & -0.97 & -1.00 & -1.06 & -1.10 & -1.08 & -1.20 & -1.31 & -1.41 \\
\hline $\mathrm{H}(\varepsilon)$ & 2.28 & $\delta^{\mathrm{OBS}}$ & -0.63 & -0.43 & -0.30 & -0.10 & +0.01 & +0.33 & +0.60 & +0.72 \\
\hline \multirow[t]{3}{*}{$\left(m-\mathrm{CH}_{3}\right)$} & & $\delta^{\text {PARA }}$ & -2.91 & -2.71 & -2.58 & -2.38 & -2.27 & -1.95 & -1.68 & -1.56 \\
\hline & & $\delta^{\mathrm{MCD}}$ & -2.99 & -2.78 & -2.61 & -2.38 & -2.29 & -1.92 & -1.62 & -1.46 \\
\hline & & $\vartheta^{\mathrm{CON}}$ & +0.06 & +0.05 & +0.02 & -0.00 & +0.02 & -0.03 & -0.07 & -0.12 \\
\hline $\mathrm{H}(\gamma)$ & 6.92 & $\delta^{\mathrm{OBS}}$ & -7.27 & -6.23 & -5.53 & -4.62 & -4.20 & -2.67 & -1.32 & -0.68 \\
\hline \multirow[t]{2}{*}{$(o)$} & & $\delta^{\text {PARA }}$ & -14.19 & -13.15 & -12.45 & -11.54 & -11.12 & -9.59 & -8.24 & -7.60 \\
\hline & & $\delta^{\mathrm{MCD}}$ & -11.28 & -10.48 & -9.82 & -8.97 & -8.62 & -7.25 & -6.12 & -5.51 \\
\hline (line 38) & & $\vartheta^{\mathrm{CON}}$ & -2.06 & -2.00 & -2.07 & -2.18 & -2.18 & -2.35 & -2.46 & -2.65 \\
\hline \multirow[t]{3}{*}{$N-O-\mathrm{H}$} & 6.92 & $\delta^{\mathrm{OBS}}$ & -23.5 & -22.1 & -21.2 & -19.3 & -18.6 & -15.7 & -12.8 & -11.4 \\
\hline & & $\delta^{\text {PARA }}$ & -30.42 & -29.02 & -28.12 & -26.22 & -25.52 & -22.62 & -19.72 & -18.32 \\
\hline & & $\delta^{\mathrm{MCD}}$ & +20.68 & +19.21 & +18.01 & +16.44 & +15.81 & +13.30 & +11.22 & +10.11 \\
\hline (line 20) & & $\vartheta^{\mathrm{CON}}$ & -36.13 & -36.13 & -36.36 & -36.17 & -36.16 & -36.18 & -35.91 & -36.03 \\
\hline \multirow[t]{3}{*}{$N-p-\mathrm{H}$} & 6.92 & $\delta^{\mathrm{OBS}}$ & -31.4 & -29.4 & -28.3 & -25.8 & -24.8 & -21.0 & -17.3 & -15.5 \\
\hline & & $\delta^{\text {PARA }}$ & -38.32 & -36.32 & -35.22 & -32.72 & -31.72 & -27.92 & -24.22 & -22.42 \\
\hline & & $\delta^{\mathrm{MCD}}$ & +4.19 & +3.89 & +3.65 & +3.33 & +3.21 & +2.70 & +2.27 & +2.05 \\
\hline (line 80) & & $\vartheta^{\mathrm{CON}}$ & -30.06 & -30.12 & -30.64 & -30.57 & -30.55 & -30.84 & -30.75 & -31.01 \\
\hline \multirow[t]{3}{*}{$\mathrm{H}\left(\beta^{\prime}\right)$} & 1.68 & $\delta^{\mathrm{OBS}}$ & -71.9 & -67.5 & -64.0 & -59.4 & -57.3 & -49.0 & -41.6 & -37.9 \\
\hline & & $\delta^{\text {PARA }}$ & -73.58 & -69.18 & -65.68 & -61.08 & -58.98 & -50.68 & -43.28 & -39.58 \\
\hline & & $\delta^{\mathrm{MCD}}$ & -8.49 & -7.88 & -7.39 & -6.75 & -6.49 & -5.46 & -4.60 & -4.15 \\
\hline (line 58) & & $\vartheta^{\mathrm{CON}}$ & -46.02 & -45.91 & -45.95 & -46.07 & -45.92 & -45.56 & -44.89 & -44.91 \\
\hline 1000/(tem & iperatu & in $K$ ) & 4.746 & 4.480 & 4.257 & 3.957 & 3.836 & 3.331 & 2.891 & 2.648 \\
\hline
\end{tabular}


Table S44. ${ }^{1} \mathrm{H}$ NMR Parameters (in ppm) $\delta^{\mathrm{DIA}}, \delta^{\mathrm{OBS}}, \delta^{\mathrm{PARA}}, \delta^{\mathrm{MCD}}$, and $\vartheta^{\mathrm{CON}} \approx \vartheta^{\mathrm{C}+\mathrm{L}}$ of the Bis(chelate) $\mathbf{2 7 N i}$ in $\mathrm{Cl}_{2} \mathrm{CD}-\mathrm{CDCl}_{2}$ Solution as a Function of the Temperature

\begin{tabular}{|c|c|c|c|c|c|c|c|c|}
\hline \multirow[t]{2}{*}{ nucleus } & \multirow{2}{*}{$\begin{array}{l}\mathbf{2 7 H} \\
\delta^{\text {DIA }} \\
\end{array}$} & \multirow[t]{2}{*}{$27 \mathrm{Ni}$} & \multicolumn{6}{|c|}{ temperature $\left[{ }^{\circ} \mathrm{C}\right]$} \\
\hline & & & -64.0 & -45.5 & -23.0 & +25.5 & +83.0 & +101.5 \\
\hline \multirow[t]{3}{*}{$N-m-\mathrm{H}$} & 7.02 & $\delta^{\mathrm{OBS}}$ & +37.9 & +35.1 & +32.6 & +28.6 & +25.0 & +24.0 \\
\hline & & $\delta^{\text {PARA }}$ & +30.88 & +28.08 & +25.58 & +21.58 & +17.98 & +16.98 \\
\hline & & $\delta^{\mathrm{MCD}}$ & +5.23 & +4.70 & +4.17 & +3.36 & +2.72 & +2.56 \\
\hline (line 69) & & $\vartheta^{\mathrm{CON}}$ & +18.00 & +17.87 & +17.97 & +18.27 & +18.24 & +18.13 \\
\hline $\mathrm{H}(\varepsilon)$ & 7.02 & $\delta^{\mathrm{OBS}}$ & +2.00 & +2.65 & +3.05 & +3.70 & +4.15 & - \\
\hline \multirow{2}{*}{$(p)$} & & $\delta^{\text {PARA }}$ & -5.02 & -4.37 & -3.97 & -3.32 & -2.87 & - \\
\hline & & $\delta^{\mathrm{MCD}}$ & -3.58 & -3.22 & -2.86 & -2.30 & -1.86 & - \\
\hline (line 37) & & $\vartheta^{\mathrm{CON}}$ & -1.01 & -0.88 & -0.93 & -1.02 & -1.21 & - \\
\hline $\mathrm{H}(\varepsilon)$ & 2.17 & $\delta^{\mathrm{OBS}}$ & -0.77 & -0.42 & -0.12 & +0.28 & +0.60 & +0.67 \\
\hline \multirow[t]{3}{*}{$\left(m-\mathrm{CH}_{3}\right)$} & & $\delta^{\text {PARA }}$ & -2.94 & -2.59 & -2.29 & -1.89 & -1.57 & -1.50 \\
\hline & & $\delta^{\mathrm{MCD}}$ & -3.02 & -2.71 & -2.41 & -1.94 & -1.57 & -1.48 \\
\hline & & $\vartheta^{\mathrm{CON}}$ & +0.06 & +0.09 & +0.10 & +0.05 & -0.00 & -0.03 \\
\hline $\mathrm{H}(\delta)$ & 2.23 & $\delta^{\mathrm{OBS}}$ & -4.72 & -3.88 & -3.18 & -2.17 & -1.32 & -1.18 \\
\hline \multirow[t]{3}{*}{$\left(o-\mathrm{CH}_{3}\right)$} & & $\delta^{\text {PARA }}$ & -6.95 & -6.11 & -5.41 & -4.40 & -3.55 & -3.41 \\
\hline & & $\delta^{\mathrm{MCD}}$ & -8.17 & -7.34 & -6.52 & -5.24 & -4.24 & -4.00 \\
\hline & & $\vartheta^{\mathrm{CON}}$ & +0.86 & +0.94 & +0.93 & +0.84 & +0.83 & +0.74 \\
\hline \multirow[t]{4}{*}{$N-O-\mathrm{H}$} & 7.02 & $\delta^{\mathrm{OBS}}$ & -20.6 & -18.9 & -17.0 & -14.2 & -11.0 & -10.4 \\
\hline & & $\delta^{\text {PARA }}$ & -27.62 & -25.92 & -24.02 & -21.22 & -18.02 & -17.42 \\
\hline & & $\delta^{\mathrm{MCD}}$ & +20.87 & +18.73 & +16.64 & +13.38 & +10.83 & +10.20 \\
\hline & & $\vartheta^{\mathrm{CON}}$ & -34.04 & -34.12 & -34.14 & -34.68 & -34.49 & -34.73 \\
\hline \multirow[t]{3}{*}{$N-p-\mathrm{H}$} & 7.02 & $\delta^{\mathrm{OBS}}$ & -31.4 & -28.6 & -25.8 & -21.4 & -16.9 & -15.8 \\
\hline & & $\delta^{\text {PARA }}$ & -38.42 & -35.62 & -32.82 & -28.42 & -23.92 & -22.82 \\
\hline & & $\delta^{\mathrm{MCD}}$ & +4.23 & +3.80 & +3.37 & +2.71 & +2.20 & +2.07 \\
\hline (line 80) & & $\vartheta^{\mathrm{CON}}$ & -29.94 & -30.12 & -30.39 & -31.21 & -31.22 & -31.29 \\
\hline \multirow[t]{3}{*}{$\mathrm{H}\left(\beta^{\prime}\right)$} & 1.55 & $\delta^{\mathrm{OBS}}$ & -78.4 & -71.0 & -64.5 & -53.4 & -43.8 & -41.4 \\
\hline & & $\delta^{\text {PARA }}$ & -79.95 & -72.55 & -66.05 & -54.95 & -45.35 & -42.95 \\
\hline & & $\delta^{\mathrm{MCD}}$ & -8.56 & -7.69 & -6.83 & -5.49 & -4.44 & -4.19 \\
\hline (line 59) & & $\vartheta^{\mathrm{CON}}$ & -50.11 & -49.56 & -49.72 & -49.57 & -48.89 & -48.74 \\
\hline 1000/(tem & iperatu & e in K) & 4.780 & 4.392 & 3.997 & 3.348 & 2.807 & 2.669 \\
\hline
\end{tabular}


Table S45. ${ }^{1} \mathrm{H}$ NMR Parameters (in ppm) $\delta^{\mathrm{DIA}}, \delta^{\mathrm{OBS}}, \delta^{\mathrm{PARA}}, \delta^{\mathrm{MCD}}$, and $\vartheta^{\mathrm{CON}} \approx \vartheta^{\mathrm{C}+\mathrm{L}}$ of the Bis(chelate) $28 \mathrm{Ni}$ in $\mathrm{Cl}_{2} \mathrm{CD}-\mathrm{CDCl}{ }_{2}$ or $\mathrm{CDCl}_{3}$ Solution as a Function of the Temperature

\begin{tabular}{|c|c|c|c|c|c|c|c|c|c|c|c|}
\hline \multirow{2}{*}{$\begin{array}{l}\text { nucleus } \\
\text { (line no.) }\end{array}$} & \multirow{2}{*}{$\begin{array}{c}\mathbf{2 8 H} \\
\delta^{\text {DIA }}\end{array}$} & \multirow[t]{2}{*}{$28 \mathrm{Ni}$} & \multicolumn{9}{|c|}{ temperature $\left[{ }^{\circ} \mathrm{C}\right]$} \\
\hline & & & -70.0 & -57.0 & -44.5 & -24.8 & -11.5 & +28.3 & +64.5 & +97.2 & +118.5 \\
\hline \multirow[t]{3}{*}{$N-m-\mathrm{H}$} & \multirow[t]{4}{*}{7.10} & $\delta^{\mathrm{OBS}}$ & +37.5 & +35.9 & +34.1 & +32.1 & +30.7 & +27.7 & +25.5 & +23.8 & +22.9 \\
\hline & & $\delta^{\text {PARA }}$ & +30.40 & +28.80 & +27.00 & +25.00 & +23.60 & +20.60 & +18.40 & +16.70 & +15.80 \\
\hline & & $\delta^{\mathrm{MCD}}$ & +5.43 & +5.02 & +4.67 & +4.21 & +3.95 & +3.32 & +2.89 & +2.59 & +2.43 \\
\hline (line 18) & & $\vartheta^{\mathrm{CON}}$ & +17.02 & +17.25 & +17.14 & +17.33 & +17.26 & +17.48 & +17.57 & +17.53 & +17.58 \\
\hline $\mathrm{H}(\delta)$ & \multirow[t]{4}{*}{7.20} & $\delta^{\mathrm{OBS}}$ & +9.27 & +9.20 & +9.15 & +9.05 & +8.95 & +8.78 & +8.62 & +8.57 & +8.48 \\
\hline \multirow[t]{2}{*}{$(m)$} & & $\delta^{\text {PARA }}$ & +2.07 & +2.00 & +1.95 & +1.85 & +1.75 & +1.58 & +1.42 & +1.37 & +1.28 \\
\hline & & $\delta^{\mathrm{MCD}}$ & -4.63 & -4.28 & -3.98 & -3.59 & -3.36 & -2.83 & -2.47 & -2.21 & -2.07 \\
\hline (line 19) & & $\vartheta^{\mathrm{CON}}$ & +4.57 & +4.55 & +4.55 & +4.53 & +4.49 & +4.46 & +4.40 & +4.45 & +4.40 \\
\hline \multirow{4}{*}{$\begin{array}{l}\mathrm{H}(\vartheta) \\
\left(m^{\prime}\right)\end{array}$} & \multirow[t]{4}{*}{7.10} & $\delta^{\mathrm{OBS}}$ & +6.53 & +6.53 & +6.58 & $+6.68^{a}$ & +6.67 & $+6.77^{a}$ & $+6.85^{a}$ & $+6.88^{a}$ & $+6.92^{a}$ \\
\hline & & $\delta^{\text {PARA }}$ & -0.57 & -0.57 & -0.52 & -0.42 & -0.43 & -0.33 & -0.25 & -0.22 & -0.18 \\
\hline & & $\delta^{\mathrm{MCD}}$ & -1.37 & -1.26 & -1.17 & -1.06 & -0.99 & -0.83 & -0.73 & -0.65 & -0.61 \\
\hline & & $\vartheta^{\mathrm{CON}}$ & +0.54 & +0.50 & +0.50 & +0.53 & +0.49 & +0.51 & +0.54 & +0.54 & +0.57 \\
\hline \multirow{4}{*}{$\begin{array}{l}\mathrm{H}(l) \\
\left(p^{\prime}\right)\end{array}$} & \multirow[t]{4}{*}{7.20} & $\delta^{\mathrm{OBS}}$ & +6.07 & +6.17 & +6.18 & $+6.28^{a}$ & +6.30 & $+6.40^{a}$ & $+6.50^{a}$ & $+6.55^{a}$ & $+6.57^{a}$ \\
\hline & & $\delta^{\text {PARA }}$ & -1.13 & -1.03 & -1.02 & -0.92 & -0.90 & -0.80 & -0.70 & -0.65 & -0.63 \\
\hline & & $\delta^{\mathrm{MCD}}$ & -1.11 & -1.03 & -0.96 & -0.86 & -0.81 & -0.68 & -0.59 & -0.53 & -0.50 \\
\hline & & $\vartheta^{\mathrm{CON}}$ & -0.01 & -0.00 & -0.05 & -0.05 & -0.08 & -0.12 & -0.12 & -0.15 & -0.17 \\
\hline \multirow{4}{*}{$\begin{array}{l}\mathrm{H}(\eta) \\
\left(o^{\prime}\right)\end{array}$} & \multirow[t]{4}{*}{7.30} & $\delta^{\mathrm{OBS}}$ & +5.37 & +5.50 & $+5.65^{b}$ & $+5.82^{b}$ & +5.88 & $+6.13^{b}$ & $+6.30^{b}$ & $+6.40^{b}$ & $+6.45^{b}$ \\
\hline & & $\delta^{\text {PARA }}$ & -1.93 & -1.80 & -1.65 & -1.48 & -1.42 & -1.17 & -1.00 & -0.90 & -0.85 \\
\hline & & $\delta^{\mathrm{MCD}}$ & -2.64 & -2.44 & -2.27 & -2.05 & -1.92 & -1.61 & -1.41 & -1.26 & -1.18 \\
\hline & & $\vartheta^{\mathrm{CON}}$ & +0.49 & +0.47 & +0.48 & +0.47 & +0.44 & +0.45 & +0.46 & +0.45 & +0.44 \\
\hline \multirow{3}{*}{$\begin{array}{l}\mathrm{H}(\gamma) \\
(o)\end{array}$} & \multirow[t]{4}{*}{7.10} & $\delta^{\mathrm{OBS}}$ & -7.57 & -6.82 & -5.72 & -4.62 & -3.97 & -2.42 & -1.37 & -0.42 & +0.01 \\
\hline & & $\delta^{\text {PARA }}$ & -14.67 & -13.92 & -12.82 & -11.72 & -11.07 & -9.52 & -8.47 & -7.52 & -7.09 \\
\hline & & $\delta^{\mathrm{MCD}}$ & -11.81 & -10.91 & -10.16 & -9.16 & -8.58 & -7.22 & -6.29 & -5.64 & -5.28 \\
\hline (line 38) & & $\vartheta^{\mathrm{CON}}$ & -1.95 & -2.18 & -2.04 & -2.13 & -2.18 & -2.33 & -2.46 & -2.34 & -2.38 \\
\hline \multirow[t]{3}{*}{$N-O-\mathrm{H}$} & \multirow[t]{4}{*}{7.10} & $\delta^{\mathrm{OBS}}$ & -24.6 & -22.8 & -21.5 & -19.8 & -18.7 & -15.7 & -13.5 & -11.7 & -10.5 \\
\hline & & $\delta^{\text {PARA }}$ & -31.70 & -29.90 & -28.60 & -26.90 & -25.80 & -22.80 & -20.60 & -18.80 & -17.60 \\
\hline & & $\delta^{\mathrm{MCD}}$ & +21.66 & +20.01 & +18.63 & +16.79 & +15.74 & +13.23 & +11.54 & +10.34 & +9.68 \\
\hline (line 20) & & $\vartheta^{\mathrm{CON}}$ & -36.39 & -36.21 & -36.25 & -36.42 & -36.48 & -36.45 & -36.42 & -36.22 & -35.86 \\
\hline \multirow[t]{3}{*}{$N-p-\mathrm{H}$} & \multirow[t]{4}{*}{7.10} & $\delta^{\mathrm{OBS}}$ & -32.7 & -30.8 & -28.7 & -26.2 & -24.6 & -20.9 & -18.0 & -16.0 & -14.6 \\
\hline & & $\delta^{\text {PARA }}$ & -39.80 & -37.90 & -35.80 & -33.30 & -31.70 & -28.00 & -25.10 & -23.10 & -21.70 \\
\hline & & $\delta^{\mathrm{MCD}}$ & +4.39 & +4.06 & +3.78 & +3.40 & +3.19 & +2.68 & +2.34 & +2.10 & +1.96 \\
\hline (line 80) & & $\vartheta^{\mathrm{CON}}$ & -30.13 & -30.44 & -30.37 & -30.59 & -30.64 & -31.04 & -31.09 & -31.32 & -31.10 \\
\hline \multirow[t]{3}{*}{$\mathrm{H}\left(\beta^{\prime}\right)$} & \multirow[t]{3}{*}{1.73} & $\delta^{\mathrm{OBS}}$ & -72.7 & -68.7 & -64.3 & -59.1 & -55.6 & -48.3 & -42.6 & -38.5 & -35.9 \\
\hline & & $\delta^{\text {PARA }}$ & -74.43 & -70.43 & -66.03 & -60.83 & -57.33 & -50.03 & -44.33 & -40.23 & -37.63 \\
\hline & & $\delta^{\mathrm{MCD}}$ & -8.89 & -8.21 & -7.65 & -6.89 & -6.46 & -5.43 & -4.74 & -4.24 & -3.97 \\
\hline (line 58) & & $\vartheta^{\mathrm{CON}}$ & -44.69 & -45.14 & -44.81 & -44.96 & -44.67 & -45.12 & -44.87 & -44.73 & -44.24 \\
\hline 1000/(tem & serature & in $\mathrm{K}$ ) & 4.921 & 4.625 & 4.373 & 4.026 & 3.821 & 3.317 & 2.961 & 2.700 & 2.553 \\
\hline
\end{tabular}

${ }^{a} \mathrm{t},{ }^{3} J_{\mathrm{HH}} \approx 7 \mathrm{~Hz} \cdot{ }^{b} \mathrm{~d},{ }^{3} J_{\mathrm{HH}}<8 \mathrm{~Hz}$. 
Table S46. ${ }^{1} \mathrm{H}$ NMR Parameters (in ppm) $\delta^{\mathrm{DIA}}, \delta^{\mathrm{OBS}}, \delta^{\mathrm{PARA}}, \delta^{\mathrm{MCD}}$, and $\vartheta^{\mathrm{CON}} \approx \vartheta^{\mathrm{C}+\mathrm{L}}$ of the Bis(chelate) $29 \mathrm{Ni}$ in $\mathrm{Cl}_{2} \mathrm{CD}-\mathrm{CDCl}{ }_{2}$ Solution as a Function of the Temperature

\begin{tabular}{|c|c|c|c|c|c|c|c|c|c|c|c|}
\hline \multirow[t]{2}{*}{ nucleus } & \multirow{2}{*}{$\begin{array}{l}\mathbf{2 9 H} \\
\delta^{\text {DIA }}\end{array}$} & \multirow[t]{2}{*}{$29 \mathrm{Ni}$} & \multicolumn{9}{|c|}{ temperature $\left[{ }^{\circ} \mathrm{C}\right]$} \\
\hline & & & -62.5 & -38.0 & -20.0 & +9.0 & +26.0 & +55.5 & +59.0 & +62.5 & +103.8 \\
\hline \multirow[t]{4}{*}{$N-m-\mathrm{H}(1)$} & 7.07 & $\delta^{\mathrm{OBS}}$ & +38.72 & +35.30 & +33.23 & +29.63 & +28.28 & +26.28 & +26.00 & +25.83 & - \\
\hline & & $\delta^{\text {PARA }}$ & +31.65 & +28.23 & +26.16 & +22.56 & +21.21 & +19.21 & +18.93 & +18.76 & - \\
\hline & & $\delta^{\mathrm{MCD}}$ & +5.19 & +4.51 & +4.11 & +3.60 & +3.35 & +2.99 & +2.95 & +2.92 & - \\
\hline & & $\vartheta^{\mathrm{CON}}$ & +18.71 & +18.72 & +18.73 & +17.96 & +17.93 & +17.89 & +17.81 & +17.85 & - \\
\hline \multirow[t]{4}{*}{$N-m-\mathrm{H}(1)$} & 7.07 & $\delta^{\mathrm{OBS}}$ & +37.60 & +34.48 & +32.55 & +29.63 & +28.28 & +26.28 & +26.00 & +25.83 & - \\
\hline & & $\delta^{\text {PARA }}$ & +30.53 & +27.41 & +25.48 & +22.56 & +21.21 & +19.21 & +18.93 & +18.76 & - \\
\hline & & $\delta^{\mathrm{MCD}}$ & +5.19 & +4.51 & +4.11 & +3.60 & +3.35 & +2.99 & +2.95 & +2.92 & - \\
\hline & & $\vartheta^{\mathrm{CON}}$ & +17.92 & +18.07 & +18.16 & +17.96 & +17.93 & +17.89 & +17.81 & +17.85 & - \\
\hline \multirow[t]{4}{*}{$N-m-\mathrm{H}(2)$} & 7.07 & $\delta^{\mathrm{OBS}}$ & +36.10 & +33.43 & +31.82 & +29.33 & +28.05 & +26.17 & +25.90 & +25.75 & +23.80 \\
\hline & & $\delta^{\mathrm{PARA}}$ & +29.03 & +26.36 & +24.75 & +22.26 & +20.98 & +19.10 & +18.83 & +18.68 & +16.73 \\
\hline & & $\delta^{\mathrm{MCD}}$ & +5.19 & +4.51 & +4.11 & +3.60 & +3.35 & +2.99 & +2.95 & +2.92 & +2.54 \\
\hline & & $\vartheta^{\mathrm{CON}}$ & +16.86 & +17.25 & +17.54 & +17.67 & +17.70 & +17.77 & +17.70 & +17.76 & +17.95 \\
\hline \multirow{4}{*}{$\begin{array}{l}\mathrm{H}(\delta) \\
(3-\mathrm{H})\end{array}$} & 7.50 & $\delta^{\mathrm{OBS}}$ & +7.88 & +7.98 & +8.00 & +8.02 & +8.02 & +8.00 & +7.97 & +7.98 & - \\
\hline & & $\delta^{\text {PARA }}$ & +0.38 & +0.48 & +0.50 & +0.52 & +0.52 & +0.50 & +0.47 & +0.48 & - \\
\hline & & $\delta^{\mathrm{MCD}}$ & -4.42 & -3.84 & -3.50 & -3.06 & -2.85 & -2.55 & -2.52 & -2.48 & - \\
\hline & & $\vartheta^{\mathrm{CON}}$ & +3.39 & +3.41 & +3.40 & +3.39 & +3.39 & +3.36 & +3.33 & +3.34 & - \\
\hline \multirow{4}{*}{$\begin{array}{l}\mathrm{H}(\zeta) \\
(6-\mathrm{H})\end{array}$} & 7.50 & $\delta^{\mathrm{OBS}}$ & +6.40 & +6.53 & +6.57 & +6.65 & +6.68 & +6.73 & +6.73 & +6.78 & - \\
\hline & & $\delta^{\text {PARA }}$ & -1.10 & -0.97 & -0.93 & -0.85 & -0.82 & -0.77 & -0.77 & -0.72 & - \\
\hline & & $\delta^{\mathrm{MCD}}$ & -2.02 & -1.76 & -1.60 & -1.40 & -1.31 & -1.17 & -1.15 & -1.14 & - \\
\hline & & $\vartheta^{\mathrm{CON}}$ & +0.65 & +0.62 & +0.57 & +0.52 & +0.49 & +0.44 & +0.43 & +0.47 & - \\
\hline \multirow{4}{*}{$\begin{array}{l}\mathrm{H}(\varepsilon) \\
(7-\mathrm{H})\end{array}$} & 7.50 & $\delta^{\mathrm{OBS}}$ & +6.40 & +6.53 & +6.57 & +6.65 & +6.68 & +6.73 & +6.73 & +6.78 & - \\
\hline & & $\delta^{\mathrm{PARA}}$ & -1.10 & -0.97 & -0.93 & -0.85 & -0.82 & -0.77 & -0.77 & -0.72 & - \\
\hline & & $\delta^{\mathrm{MCD}}$ & -2.26 & -1.96 & -1.79 & -1.57 & -1.46 & -1.30 & -1.28 & -1.27 & - \\
\hline & & $\vartheta^{\mathrm{CON}}$ & +0.82 & +0.78 & +0.73 & +0.68 & +0.64 & +0.59 & +0.57 & +0.62 & - \\
\hline \multirow{4}{*}{$\begin{array}{l}\mathrm{H}(\varepsilon) \\
(5-\mathrm{H})\end{array}$} & 7.80 & $\delta^{\mathrm{OBS}}$ & +6.02 & +6.03 & +6.08 & +6.10 & +6.15 & +6.18 & $+6.17^{a}$ & +6.22 & - \\
\hline & & $\delta^{\text {PARA }}$ & -1.78 & -1.77 & -1.72 & -1.70 & -1.65 & -1.62 & -1.63 & -1.58 & - \\
\hline & & $\delta^{\mathrm{MCD}}$ & -2.82 & -2.45 & -2.23 & -1.95 & -1.82 & -1.62 & -1.60 & -1.58 & - \\
\hline & & $\vartheta^{\mathrm{CON}}$ & +0.73 & +0.54 & +0.44 & +0.24 & +0.17 & +0.01 & -0.03 & +0.00 & - \\
\hline \multirow{4}{*}{$\begin{array}{l}\mathrm{H}(\varepsilon) \\
(4-\mathrm{H})\end{array}$} & 8.12 & $\delta^{\mathrm{OBS}}$ & +3.20 & +3.67 & +3.97 & $+4.40^{b}$ & $+4.57^{b}$ & $+4.87^{b}$ & $+4.88^{b}$ & $+4.97^{b}$ & - \\
\hline & & $\delta^{\text {PARA }}$ & -4.92 & -4.45 & -4.15 & -3.72 & -3.55 & -3.25 & -3.24 & -3.15 & - \\
\hline & & $\delta^{\mathrm{MCD}}$ & -3.55 & -3.09 & -2.82 & -2.46 & -2.29 & -2.05 & -2.02 & -2.00 & - \\
\hline & & $\vartheta^{\mathrm{CON}}$ & -0.97 & -1.08 & -1.13 & -1.19 & -1.26 & -1.33 & -1.36 & -1.30 & - \\
\hline \multicolumn{3}{|c|}{ 1000/(temperature in K) } & 4.746 & 4.252 & 3.949 & 3.544 & 3.342 & 3.042 & 3.010 & 2.979 & 2.653 \\
\hline
\end{tabular}

${ }^{a}$ Doublet. ${ }^{b}$ d, ${ }^{3} J_{\mathrm{HH}} \approx 7 \mathrm{~Hz}$. 
Table S46 (cont'd). ${ }^{1} \mathrm{H}$ NMR Parameters (in ppm) $\delta^{\mathrm{DIA}}, \delta^{\mathrm{OBS}}, \delta^{\mathrm{PARA}}, \delta^{\mathrm{MCD}}$, and $\vartheta^{\mathrm{CON}} \approx \vartheta^{\mathrm{C}+\mathrm{L}}$ of the Bis(chelate) 29Ni in $\mathrm{Cl}_{2} \mathrm{CD}-\mathrm{CDCl}_{2}$ Solution as a Function of the Temperature

\begin{tabular}{|c|c|c|c|c|c|c|c|c|c|c|c|}
\hline \multirow{2}{*}{$\begin{array}{l}\text { nucleus } \\
\text { (line no.) }\end{array}$} & \multirow{2}{*}{$\begin{array}{l}\mathbf{2 9 H} \\
\delta^{\text {DIA }}\end{array}$} & \multirow[t]{2}{*}{$29 \mathrm{Ni}$} & \multicolumn{9}{|c|}{ temperature $\left[{ }^{\circ} \mathrm{C}\right]$} \\
\hline & & & -62.5 & -38.0 & -20.0 & +9.0 & +26.0 & +55.5 & +59.0 & +62.5 & +103.8 \\
\hline $\mathrm{H}(\delta)$ & 7.70 & $\delta^{\mathrm{OBS}}$ & $-1.93^{c}$ & $-1.00^{c}$ & $-0.40^{c}$ & $+0.37^{c}$ & $+0.75^{c}$ & $+1.30^{c}$ & - & - & - \\
\hline \multirow[t]{2}{*}{$(8-\mathrm{H})$} & & $\delta^{\text {PARA }}$ & -9.63 & -8.70 & -8.10 & -7.33 & -6.95 & -6.40 & - & - & - \\
\hline & & $\delta^{\mathrm{MCD}}$ & -14.64 & -12.37 & -11.61 & -10.16 & -9.46 & -8.44 & - & - & - \\
\hline (line 33) & & $\vartheta^{\mathrm{CON}}$ & +3.54 & +3.18 & +2.98 & +2.68 & +2.52 & +2.25 & - & - & - \\
\hline $\mathrm{H}(\gamma)$ & 7.50 & $\delta^{\mathrm{OBS}}$ & -8.07 & -6.30 & -5.07 & -3.50 & -2.65 & -1.62 & -1.52 & -1.35 & - \\
\hline \multirow[t]{3}{*}{$(2-\mathrm{H})$} & & $\delta^{\text {PARA }}$ & -15.57 & -13.80 & -12.57 & -11.00 & -10.15 & -9.12 & -9.02 & -8.85 & - \\
\hline & & $\delta^{\mathrm{MCD}}$ & -11.28 & -9.81 & -8.94 & -7.82 & -7.28 & -6.50 & -6.42 & -6.34 & - \\
\hline & & $\vartheta^{\mathrm{CON}}$ & -3.03 & -3.15 & -3.08 & -3.01 & -2.88 & -2.89 & -2.90 & -2.83 & - \\
\hline$N-O-\mathrm{H}$ & 7.07 & $\delta^{\mathrm{OBS}}$ & -19.4 & -17.8 & -16.1 & - & - & - & - & - & - \\
\hline \multirow[t]{3}{*}{ (smaller) } & & $\delta^{\text {PARA }}$ & -26.47 & -24.87 & -23.17 & - & - & - & - & - & - \\
\hline & & $\delta^{\mathrm{MCD}}$ & +20.68 & +17.98 & +16.40 & - & - & - & - & - & - \\
\hline & & $\vartheta^{\mathrm{CON}}$ & -33.33 & -33.82 & -33.62 & - & - & - & - & - & - \\
\hline \multirow{4}{*}{$\begin{array}{l}N-O-H \\
\text { (larger) }\end{array}$} & 7.07 & $\delta^{\mathrm{OBS}}$ & -25.3 & -22.1 & -19.5 & -16.1 & -14.9 & -13.4 & -12.9 & -12.8 & -10.8 \\
\hline & & $\delta^{\text {PARA }}$ & -32.37 & -29.17 & -26.57 & -23.17 & -21.97 & -20.47 & -19.97 & -19.87 & -17.87 \\
\hline & & $\delta^{\mathrm{MCD}}$ & +20.68 & +17.98 & +16.40 & +14.34 & +13.35 & +11.92 & +11.77 & +11.62 & +10.13 \\
\hline & & $\vartheta^{\mathrm{CON}}$ & -37.51 & -37.22 & -36.51 & -35.52 & -35.47 & -35.73 & -35.38 & -35.48 & -35.42 \\
\hline \multirow[t]{4}{*}{$N-p-\mathrm{H}$} & 7.07 & $\delta^{\mathrm{OBS}}$ & -32.1 & -28.4 & -26.2 & -22.8 & -21.2 & -18.6 & -18.3 & -18.1 & -15.5 \\
\hline & & $\delta^{\text {PARA }}$ & -39.17 & -35.47 & -33.27 & -29.87 & -28.27 & -25.67 & -25.37 & -25.17 & -22.57 \\
\hline & & $\delta^{\mathrm{MCD}}$ & +4.19 & +3.64 & +3.32 & +2.91 & +2.71 & +2.42 & +2.39 & +2.36 & +2.05 \\
\hline & & $\vartheta^{\mathrm{CON}}$ & -30.66 & -30.87 & -31.09 & -31.04 & -31.10 & -30.98 & -30.94 & -31.01 & -31.15 \\
\hline \multirow[t]{4}{*}{$\mathrm{H}\left(\beta^{\prime}\right)$} & 1.58 & $\delta^{\mathrm{OBS}}$ & -73.3 & -65.3 & -60.6 & -53.4 & -50.0 & -45.0 & -44.4 & -43.9 & -38.6 \\
\hline & & $\delta^{\text {PARA }}$ & -74.88 & -66.88 & -62.18 & -54.98 & -51.58 & -46.58 & -45.98 & -45.48 & -40.18 \\
\hline & & $\delta^{\mathrm{MCD}}$ & -8.49 & -7.38 & -6.73 & -5.89 & -5.48 & -4.89 & -4.83 & -4.77 & -4.16 \\
\hline & & $\vartheta^{\mathrm{CON}}$ & -46.94 & -46.96 & -47.11 & -46.49 & -46.29 & -45.98 & -45.87 & -45.86 & -45.57 \\
\hline \multicolumn{3}{|c|}{ 1000/(temperature in K) } & 4.746 & 4.252 & 3.949 & 3.544 & 3.342 & 3.042 & 3.010 & 2.979 & 2.653 \\
\hline
\end{tabular}

${ }^{c}$ Broad. 


\section{Appendix: Initializing Preparations}

\section{Scheme S5}

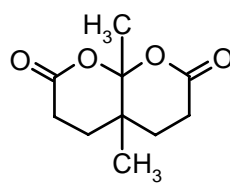

S55
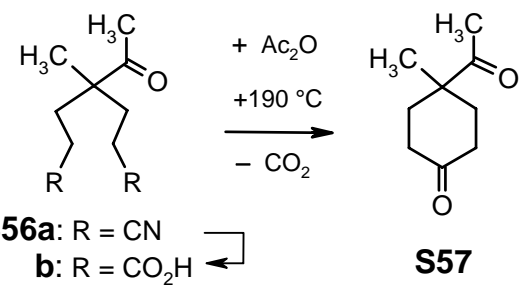

S57
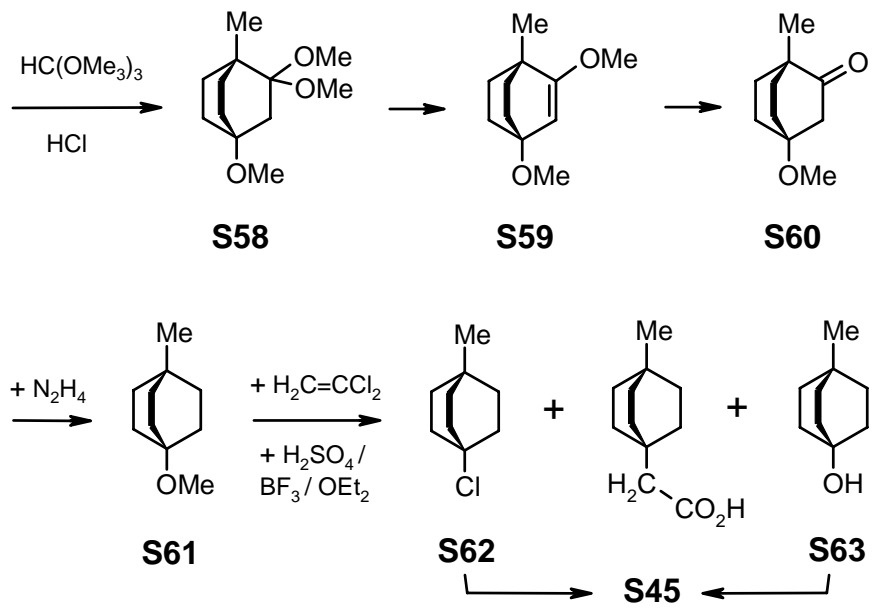

9,10-Dimethyl-1,8-dioxadecahydronaphthalen-2,7-dione (S55). This bicyclic dilactone acetal of the diacid S56b was obtained as a byproduct from insufficiently thermolyzed runs: mp 130-132 ${ }^{\circ} \mathrm{C}$ (benzene); IR (KBr) 1755, $1730 \mathrm{~cm}^{-1}$ (two coupled C=O oscillators); ${ }^{1} \mathrm{H} \mathrm{NMR}\left(\mathrm{CD}_{2} \mathrm{Cl}_{2}\right) \delta 1.22$ (s, 10- $\left.\mathrm{CH}_{3}\right), 1.61$ (s, 9- $\left.\mathrm{CH}_{3}\right), 1.72$ and 1.91 (AB part of $\mathrm{ABHH}^{\prime}$; dt, ${ }^{2} \mathrm{~J}=14.2 \mathrm{~Hz},{ }^{3} \mathrm{~J}=7.5 \mathrm{~Hz}$, diastereotopic $\mathrm{H}$ in the symmetry-equivalent groups

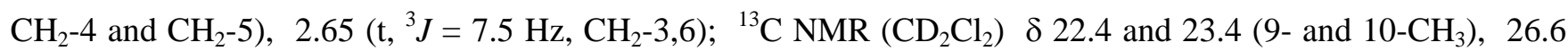
$\left(\mathrm{CH}_{2}-4,5\right), 28.3\left(\mathrm{CH}_{2}-3,6\right), 33.5$ (C-10), 110.3 (C-9), 168.5 (C-2,7); Anal. Calcd for $\mathrm{C}_{10} \mathrm{H}_{14} \mathrm{O}_{4}$ (198.2): C, 60.59; H, 7.12. Found: C, 60.51; H, 7.19. Chem. Abstr.: CAN 500900-75-4 ("no references”). - An oligomeric structure can be dismissed because it would show the IR absorptions of $(Z)$ ester groups and a lower symmetry in its ${ }^{13} \mathrm{C}$ NMR spectrum. The isomeric structure of a monocyclic anhydride of the diacid S56b would have two ${ }^{13} \mathrm{C}$ NMR carbonyl resonances (1:2) instead of only one. As a proof of the carbon chain, the ${ }^{1} \mathrm{H}$ NMR signals and thereafter the crystals (mixed mp not depressed) of the diacid S56b appeared slowly on shaking S55 in $\mathrm{CD}_{2} \mathrm{Cl}_{2}$ with aqueous $2 \mathrm{M} \mathrm{HCl}$.

4-Acetyl-4-methylheptanedioic Acid (S56b). 4-Acetyl-4-methylheptanedinitrile (S56a, $158 \mathrm{~g}, 888 \mathrm{mmol}$ ) was mixed with aqueous $\mathrm{KOH}(1.6 \mathrm{~L}, 2.5 \mathrm{~mol})$ and was heated slowly to keep the strongly exothermic reaction under control. After $3 \mathrm{~h}$ at reflux, the mixture was concentrated to $\sim 50 \%$ and acidified with conc. HCl. The precipitated acid S56b was separated, and the filtrate was extracted with $\mathrm{Et}_{2} \mathrm{O}$ in a perforator for 2 days: Total yield 178 g (93\%); mp 122-124 ${ }^{\circ} \mathrm{C}$ (ref S54: 74\%, mp 122-123 ${ }^{\circ} \mathrm{C}$; ref S56: 63\%, mp $125^{\circ} \mathrm{C}$ ); IR (KBr) 1716,1690 $\mathrm{cm}^{-1} ;{ }^{1} \mathrm{H}$ NMR $\left(\mathrm{CDCl}_{3}\right) \delta 1.16\left(\mathrm{~s}, 4-\mathrm{CH}_{3}\right), 1.85$ and $1.96\left(\mathrm{AB}\right.$ part of $\left.\mathrm{ABH}_{2},{ }^{3} J \approx 7.6 \mathrm{~Hz}, 2 \mathrm{CH}_{2}-3\right), 2.16$ (s, acetyl), $2.29\left(\mathrm{t},{ }^{3} \mathrm{~J}=7.6 \mathrm{~Hz}, 2 \mathrm{CH}_{2}-2\right)$. 
4-Acetyl-4-methylcyclohexanone (S57). The acid S56b (50.0 g, $231 \mathrm{mmol})$, acetanhydride (125 mL), and sodium acetate (1.0 g) were heated slowly with stirring in a distillation apparatus, first at normal pressure up to $170{ }^{\circ} \mathrm{C}$ to remove acetic acid and acetanhydride, then under 12 Torr up to $190{ }^{\circ} \mathrm{C}$ (ref S57: $250{ }^{\circ} \mathrm{C}$ ) bath temperature for decarboxylation. The diketone S57 (22.7 g, 64\%) distilled at 138-140 C/12 Torr (ref S57: 133 ${ }^{\circ} \mathrm{C} / 15$ Torr). - For a sideproduct, see S55.

2,2,4-Trimethoxy-1-methylbicyclo[2.2.2]octane (S58). Hydrogen chloride gas (2.40 g, 65.8 mmol; ref S58: $10.3 \mathrm{~g}$ ) was bubbled into an ice-cold mixture of 4-acetyl-4-methylcyclohexanone (S57, $22.7 \mathrm{~g}, 147 \mathrm{mmol}$ ), trimethyl orthoformate (52.0 g, $490 \mathrm{mmol})$, and anhydrous methanol (160 mL). After $1 \mathrm{~h}$ at reflux, the mixture was concentrated to $\sim 30 \%$, neutralized with sodium methoxide in methanol, diluted with water, and extracted with $\mathrm{Et}_{2} \mathrm{O}$. The combined extracts were washed until neutral, dried over $\mathrm{Na}_{2} \mathrm{SO}_{4}$, and concentrated to yield $27.8 \mathrm{~g}$ (88\%) of the crude acetal S58: ${ }^{1} \mathrm{H}$ NMR $\left(\mathrm{CCl}_{4}\right) \delta 0.91$ (s, 1- $\left.\mathrm{CH}_{3}\right), 1.48\left(\mathrm{~m}, 4 \mathrm{CH}_{2}\right), 1.66\left(\mathrm{~s}, \mathrm{CH}_{2}-3\right), 3.05(\mathrm{~s}, 4-$ $\left.\mathrm{OCH}_{3}\right), 3.18$ (s, 2 2- $\left.-\mathrm{OCH}_{3}\right)$.

Distillation of S58 at 108-115 ${ }^{\circ} \mathrm{C} / 12$ Torr afforded a mixture of S58 and 2,4-dimethoxy-1-methylbicyclo[2.2.2] oct-2-ene (S59). ${ }^{1} \mathrm{H}$ NMR $\left(\mathrm{CCl}_{4}\right)$ of S59: $\delta 1.03$ (s, 1- $\left.\mathrm{CH}_{3}\right), 1.40$ (br s, $\left.4 \mathrm{CH}_{2}\right), 3.23\left(\mathrm{~s}, 4-\mathrm{OCH}_{3}\right), 3.45$ (s, 2- $\mathrm{OCH}_{3}$ ), 4.77 (s, olefin. 3-H). This mixture did not react with 1,1-dichloroethene under the conditions described above for the preparation of $\mathbf{S} 45$.

4-Methoxy-1-methylbicyclo[2.2.2]octan-2-one (S60). This ketone was obtained either by hydrolysis of the preceding mixture S58/S59 with $2 \mathrm{M} \mathrm{HCl}$ (yield 77\%) or by acidic workup ${ }^{\mathrm{S} 58}$ of $\mathbf{S 5 8}$ (omitting the neutralization, 92\%): bp 112-115 ${ }^{\circ} \mathrm{C} / 12$ Torr; ${ }^{1} \mathrm{H}$ NMR $\left(\mathrm{CCl}_{4}\right) \delta 0.86$ (s, 1- $\left.\mathrm{CH}_{3}\right), 1.68$ (pseudo-s, $\left.4 \mathrm{CH}_{2}\right), 2.28\left(\mathrm{~s}, \mathrm{CH}_{2}-3\right), 3.17$ $\left(\mathrm{s}, \mathrm{OCH}_{3}\right)$.

4-Methoxy-1-methylbicyclo[2.2.2]octane $\mathbf{S}^{\mathrm{S59,S60}}$ (S61). The ketone $\mathbf{S 6 0}$ (15.5 g, $92.0 \mathrm{mmol}$ ) and hydrazine hydrate $(99 \%, 30 \mathrm{~mL})^{\mathrm{S} 61}$ were refluxed at $+140{ }^{\circ} \mathrm{C}$ for $2 \mathrm{~h}$. The cooled mixture was diluted with diethylene glycol (90 mL), containing $9.0 \mathrm{~g}$ of solid $\mathrm{KOH}$, then heated in a distillation apparatus to $170{ }^{\circ} \mathrm{C}$ for $1 \mathrm{~h}$ and to 220 ${ }^{\circ} \mathrm{C}$ for $4 \mathrm{~h}$, until the evolution of $\mathrm{N}_{2}$ gas ceased. Residue and distillate were recombined, diluted with distd. water, and extracted with $\mathrm{Et}_{2} \mathrm{O}(3 \times)$. The combined extracts were washed with $2 \mathrm{M} \mathrm{HCl}$, washed until neutral, dried over $\mathrm{Na}_{2} \mathrm{SO}_{4}$, and concentrated to yield $11.6 \mathrm{~g}$ (81\%) of almost pure S61 (ref S59: 20\%; ref S60: 76\%): bp 95$105{ }^{\circ} \mathrm{C} / 46$ Torr; ${ }^{1} \mathrm{H}$ NMR $\left(\mathrm{CCl}_{4}\right) \delta 0.76$ (s, $\left.1-\mathrm{CH}_{3}\right), 1.51$ (s, $\left.6 \mathrm{CH}_{2}\right), 3.03\left(\mathrm{~s}, \mathrm{OCH}_{3}\right)$.

In one run $^{\mathrm{S} 42}$ with a smaller amount of pure (“100\%”) hydrazine hydrate, the crude product contained 4methoxy-1-methylbicyclo[2.2.2] octan-2-one azine (the $=\mathrm{N}-\mathrm{N}=$ derivative of ketone $\mathbf{S 6 0}$ ), a colorless powder weakly soluble in $\mathrm{Et}_{2} \mathrm{O}$ : $\mathrm{mp} 144-145.5{ }^{\circ} \mathrm{C}$; IR (KBr) 2954, 2861, 1645, 1456, 1336, 1114, and $1096 \mathrm{~cm}^{-1}$; ${ }^{1} \mathrm{H}$ $\operatorname{NMR}\left(\mathrm{CDCl}_{3}\right) \delta 1.11$ (s, 2 1- $\left.\mathrm{CH}_{3}\right), 1.69\left(\mathrm{mc}, 6 \mathrm{CH}_{2}\right), 1.83\left(\mathrm{mc}, 2 \mathrm{CH}_{2}\right), 2.30\left(\mathrm{~s}, 2 \mathrm{CH}_{2}\right), 3.23\left(\mathrm{~s}, 2 \mathrm{OCH}_{3}\right) ;{ }^{13} \mathrm{C}$ NMR (CDCl $) \delta 21.6$ (q, 1- $\mathrm{CH}_{3}$ ), 29.1 (t, $\left.\mathrm{CH}_{2}-6 /-7\right), 32.5$ (t, $\left.\mathrm{CH}_{2}-5 /-8\right), 35.7$ (s, C-1), 37.6 (t, $\left.\mathrm{CH}_{2}-3\right), 49.4$ (q, $\mathrm{OCH}_{3}$ ), 74.4 (s, C-4), 166.1 (s, C-2); Anal. Calcd for $\mathrm{C}_{20} \mathrm{H}_{32} \mathrm{~N}_{2} \mathrm{O}_{2}$ (332.5): C, 72.25; H, 9.70; N, 8.43. Found: C, 72.42; H, 9.64; N, 8.55.

1-Chloro-4-methylbicyclo[2.2.2]octane (S62): See S45.

4-Methylbicyclo[2.2.2]octan-1-ol (S63): See S45. 


\section{References}

(4) McGeachin, S. G. Canad. J. Chem. 1968, 46, 1903-1912.

(5) Sheldrick, W. S.; Knorr, R.; Polzer, H. Acta Crystallogr. 1979, B35, 739-741.

(6) Knorr, R.; Zölch, R.; Polborn, K. Heterocycles 1995, 40, 559-576.

(8) Healey, P. C.; Bendall, M. R.; Doddrell, D. M.; Skelton, B. W.; White, A. H. Aust. J. Chem. 1979, 32, 727-735.

(12) Honeybourne, C. L.; Webb, G. A. Mol. Phys. 1969, 17, 17-31.

(14) The $\chi$ values in this paper were calculated in the SI unit system. ${ }^{15,16}$ For comparisons with older literature data, they may be converted to the now obsolete "irrational" $\left(\chi_{\mathrm{ir}}\right)^{16}$ values in the cgs system by the relation $\chi$ $=4 \pi \chi_{\mathrm{ir}}$.

(15) Gerloch, M.; Constable, E. C. Transition Metal Chemistry, VCH: Weinheim, 1994.

(16) Mills, I.; Cvitaš, T.; Homann, K.; Kallay, N.; Kuchitsu, K. Quantities, Units and Symbols in Physical Chemistry, 2nd ed.; Blackwell: Oxford, U.K, 1993. Homann, K.-H.; Hausmann, M. Grössen, Einheiten und Symbole in der Physikalischen Chemie, German ed.; VCH: Weinheim, Germany, 1996.

(17) Method described by Evans, D. F. J. Chem. Soc. 1959, 2003-2005.

(18) Parks, J. E.; Holm, R. H. Inorg. Chem. 1968, 7, 1408-1416.

(22) McGarvey, B. R. Inorg. Chem. 1995, 34, 6000-6007. Specific reference details: (a) p 6005. (b) Figure 4 on p 6005. (c) Eq 2 on p 6000. (d) p 6004. (e) Figure 6 on p 6006. (f) Figure 5 on p 6005.

(27) Gerson, F. Hochauflösende ESR Spektroskopie; Verlag Chemie: Weinheim, 1967. High resolution E.S.R. spectroscopy; Verlag Chemie: Weinheim, 1970.

(30) NMR of Paramagnetic Molecules; La Mar, G. N., Horrocks, W. D., Holm, R. H., Eds.; Academic Press: NewYork, 1973. Specific reference details: (a) p 95. (b) pp 558-559. (c) p 563. (d) Eq 1-53 on p 18 and eq 1-111 on p 39. (e) Eq 14-12 on p 562. (f) Eq 1-30 on p 11. (g) Eq 1-8 on p 6. (h) Eq 3-3 on p 86 and eq 3-17 on p 93. (i) p 88. (j) Eq 14A-6 on p 585.

(31) Carrington, A.; McLachlan, A. D. Introduction to Magnetic Resonance; Harper and Row: NewYork, 1967. Specific reference details: (a) p 81. (b) p 92. (c) p 82. (d) p 222.

(32) In contrast to earlier usage $e^{22,30,35}$ in NMR of paramagnetics, it is now customary to define the chemical shifts $\delta$ as positive in the deshielded (higher frequency) direction and to use SI units.

(35) Kurland, R. J.; McGarvey, B. R. J. Magn. Reson. 1970, 2, 286-301. Specific reference details: (a) Eqs 40 and 42 on p 294. (b) Eq 50 on p 298. (c) Eq 17 on p 291. (d) Eq 53 on p 299. (e) Eqs 41 and 43 on p 294.

(38) Banci, L.; Bertini, I.; Luchinat, C.; Pierattelli, R.; Shokhirev, N. V.; Walker, F. A. J. Am. Chem. Soc. 1998, 120, 8472-8479.

(40) Domaille, P. J. J. Am. Chem. Soc. 1980, 102, 5392-5393.

(41) Domaille, P. J.; Harlow, R. L.; Ittel, S. D.; Peet, W. G. Inorg. Chem. 1983, 22, 3944-3952.

(44) Knorr, R.; Weiss, A.; Polzer, H.; Bischler, E. J. Am. Chem. Soc. 1975, 97, 644-646.

(47) Analyzed from enlarged versions of the diagrams in ref 22 as obtained through the courtesy of Prof. B. 


\section{R. McGarvey.}

(51) Mispelter, J.; Momenteau, M.; Lhoste, J. M. Biol. Magn. Reson. 1993, 12, 299-355.

(52) Eicher, H.; Köhler, F. H.; Cao, R. J. Chem. Phys. 1987, 86, 1829-1835, on p 1829 and p 1833.

(53) Eicher, H.; Köhler, F. H. Chem. Phys. 1988, 128, 297-309, on p 307.

(54) Eq (8) of ref 38.

(57) McConnell, H. M.; Chesnut, D. B. J. Chem. Phys. 1958, 28, 107-117, and cited refs.

(59) Neese, F. J. Chem. Phys. 2001, 115, 11080-11096.

(63) (a) Budzelaar, P. H. M.; van Oort, A. B.; Orpen, A. G. Eur. J. Inorg. Chem. 1998, 1485-1494. (b) Smith, J. M.; Lachicotte, R. J.; Holland, P. L. J. Chem. Soc., Chem. Commun. 2001, 1542-1543. (c) Eckert, N. A.; Smith, J. M.; Lachicotte, R. J.; Holland, P. L. Inorg. Chem. 2004, 43, 3306-3321, with extensive applications.

(69) Knorr, R.; Löw, P.; Hassel, P. Synthesis 1983, 785-786.

(70) Knorr, R.; Löw, P.; Hassel, P.; Bronberger, H. J. Org. Chem. 1984, 49, 1288-1290.

(71) Knorr, R.; Weiß, A. Chem. Ber. 1982, 115, 139-160.

(S1) Golding, R. M.; Stubbs, L. C. J. Magn. Reson. 1980, 40, 115-133.

(S2) Bennett, B.; Raynes, W. T. Magn. Reson. Chem. 1991, 29, 946-953.

(S3) Becconsall, J. K. Mol. Phys. 1968, 15, 129-139.

(S4) Doddrell, D.; Roberts, J. D. J. Am. Chem. Soc. 1970, 92, 4484-4486.

(S5) Molin, Yu. N. Mol. Phys. 1970, 5, 511-514.

(S6) Knorr, R.; Weiß, A. Chem. Ber. 1981, 114, 2104-2115.

(S7) Honeybourne, C. L.; Webb, G. A. Chem. Phys. Lett. 1968, 2, 426-428.

(S8) Gaussian 98, Revision A.11.4, M. J. Frisch, G. W. Trucks, H. B. Schlegel, G. E. Scuseria, M. A. Robb, J. R. Cheeseman, V. G. Zakrzewski, J. A. Montgomery, Jr., R. E. Stratmann, J. C. Burant, S. Dapprich, J. M. Millam, A. D. Daniels, K. N. Kudin, M. C. Strain, O. Farkas, J. Tomasi, V. Barone, M. Cossi, R. Cammi, B. Mennucci, C. Pomelli, C. Adamo, S. Clifford, J. Ochterski, G. A. Petersson, P. Y. Ayala, Q. Cui, K. Morokuma, N. Rega, P. Salvador, J. J. Dannenberg, D. K. Malick, A. D. Rabuck, K. Raghavachari, J. B. Foresman, J. Cioslowski, J. V. Ortiz, A. G. Baboul, B. B. Stefanov, G. Liu, A. Liashenko, P. Piskorz, I. Komaromi, R. Gomperts, R. L. Martin, D. J. Fox, T. Keith, M. A. Al-Laham, C. Y. Peng, A. Nanayakkara, M. Challacombe, P. M. W. Gill, B. Johnson, W. Chen, M. W. Wong, J. L. Andres, C. Gonzalez, M. Head-Gordon, E. S. Replogle, and J. A. Pople, Gaussian, Inc., Pittsburgh PA, 2002.

(S9) Gaussian 03, Revision B.01, M. J. Frisch, G. W. Trucks, H. B. Schlegel, G. E. Scuseria, M. A. Robb, J. R. Cheeseman, J. A. Montgomery, Jr., T. Vreven, K. N. Kudin, J. C. Burant, J. M. Millam, S. S. Iyengar, J. Tomasi, V. Barone, B. Mennucci, M. Cossi, G. Scalmani, N. Rega, G. A. Petersson, H. Nakatsuji, M. Hada, M. Ehara, K. Toyota, R. Fukuda, J. Hasegawa, M. Ishida, T. Nakajima, Y. Honda, O. Kitao, H. Nakai, M. Klene, X. Li, J. E. Knox, H. P. Hratchian, J. B. Cross, C. Adamo, J. Jaramillo, R. Gomperts, R. E. Stratmann, O. Yazyev, A. J. Austin, R. Cammi, C. Pomelli, J. W. Ochterski, P. Y. Ayala, K. Morokuma, G. A. Voth, P. Salvador, J. J. Dannenberg, V. G. Zakrzewski, S. Dapprich, A. D. Daniels, M. C. Strain, O. Farkas, D. K. Malick, A. D. Rabuck, K. Raghavachari, J. B. Foresman, J. V. Ortiz, Q. Cui, A. G. Baboul, S. Clifford, J. Cioslowski, B. B. Stefanov, G. 
Liu, A. Liashenko, P. Piskorz, I. Komaromi, R. L. Martin, D. J. Fox, T. Keith, M. A. Al-Laham, C. Y. Peng, A. Nanayakkara, M. Challacombe, P. M. W. Gill, B. Johnson, W. Chen, M. W. Wong, C. Gonzalez, and J. A. Pople, Gaussian, Inc., Pittsburgh PA, 2003.

(S10) Braden, D. A.; Tyler, D. R. J. Am. Chem. Soc. 1998, 120, 942-947, and cited refs.

(S11) Wachters, A. J. H. J. Chem. Phys. 1970, 52, 1033-1036.

(S12) Hay, P. J. J. Chem. Phys. 1977, 66, 4377-4384.

(S13) Vangberg, T.; Ghosh, A. J. Am. Chem. Soc. 1998, 120, 6227-6230.

(S14) Hoaglin, R. I.; Hirsh, D. H. J. Am. Chem. Soc. 1949, 71, 3468-3472.

(S15) Jutz, C. Adv. Org. Chem. 1976, 9, 225-342.

(S16) Arnold, Z.; Šorm, F. Chem. Listy 1957, 51, 1082-1090; Chem. Abstr. 1957, 51, 13761c.

(S17) Schlosser, M. J. Organomet. Chem. 1967, 8, 9-16.

(S18) Lochmann, L.; Trekoval, J. J. Organomet. Chem. 1987, 326, 1-8.

(S19) Schlosser, M.; Strunk, S. Tetrahedron Lett. 1984, 25, 741-744.

(S20) See ref 70 for citations of the earlier synthetic routes.

(S21) Reichardt, C.; Würthwein, E.-U. Chem. Ber. 1974, 107, 3454-3456.

(S22) Reichardt, C.; Würthwein, E.-U. Synthesis 1973, 604-605.

(S23) Knorr, R.; Weiß, A.; Löw, P.; Räpple, E. Chem. Ber. 1980, 113, 2462-2489.

(S24) DeWolfe, R. H. J. Org. Chem. 1962, 27, 490-493, and cited refs.

(S25) Gill, N. S.; Nyholm, R. S. J. Chem. Soc. 1959, 3997-4007.

(S26) Everett, G. W.; Holm, R. H. J. Am. Chem. Soc. 1965, 87; 2117-2127.

(S27) Our specimen of the tetrabromonickelate ${ }^{\mathrm{S} 25, \mathrm{~S} 26}$ was hygroscopic and had mp $300-303{ }^{\circ} \mathrm{C}$ (dec).

(S28) Rupe, H.; Huber, A. Helv. Chim. Acta 1927, 10, 846-858.

(S29) Keller, R. Helv. Chim. Acta 1937, 20, 436-450.

(S30) Torgova, T. V.; Osipov, O. A.; Kurbatov, V. P.; Belonog, N. A. J. Gen. Chem. USSR 1977, 47, 819821.

(S31) Polzer, H. Doctoral Dissertation, Univ. of Munich: 1975; pp 220-221 (in German).

(S32) Nishida, Y.; Oishi, N.; Kida, S. Inorg. Chim. Acta 1979, 32, 7-10.

(S33) Knorr, R.; Ruf, F.; Högerl, J.; Hilpert, M.; Hassel, P. Chem. Ber. 1985, 118, 4743-4753.

(S34) Honeybourne, C. L.; Webb, G. A. J. Chem. Soc., Chem. Commun. 1968, 739-740.

(S35) Rupe, H.; Knup, E. Helv. Chim. Acta 1927, 10, 299-309.

(S36) Hamer, F. M.; Rathbone, R. J. J. Chem. Soc. 1945, 595-600.

(S37) Klimko, V. T.; Skoldinov, A. P. J. Gen. Chem. USSR 1959, 29, 3987-3989.

(S38) Tsybina, N. M.; Vinokurov, V. G.; Protopopova, T. V.; Skoldinov, A. P. J. Gen. Chem. USSR 1966, 36, 1383-1384.

(S39) Todoriki, R.; Ono, M.; Tamura, S. Heterocycles 1986, 24, 755-769.

(S40) Della, E. W.; Patney, H. K. Aust. J. Chem. 1979, 32, 2243-2248.

(S41) Berger, S. Org. Magn. Reson. 1980, 14, 65-68.

(S42) Nadolny, A. Doctoral Dissertation, University of Munich: 1994 (in German). 
(S43) Honeybourne, C. L.; Webb, G. A. Spectrochim. Acta 1969, 25A, 1075-1080.

(S44) Laitar, D. S.; Mathison, C. J. N.; Davis, W. M.; Sadighi, J. P. Inorg. Chem. 2003, 42, 7354-7356, Supporting Information therein.

(S45) Sabatini, A.; Sacconi, L. J. Am. Chem. Soc. 1964, 86, 17-20. Our specimen (colorless and nonhygroscopic) had mp $293-293.5^{\circ} \mathrm{C}$.

(S46) Wolff, L.; Greulich, R. Justus Liebigs Ann. Chem. 1912, 394, 36-48, on p 43.

(S47) Schlosser, M.; Choi, J. H.; Tagakishi, S. Tetrahedron 1990, 46, 5633-5648.

(S48) Miyashita, M.; Yamaguchi, R.; Yoshikoshi, A. J. Org. Chem. 1985, 49, 2857-2863.

(S49) Creger, P. L. J. Am. Chem. Soc. 1970, 92, 1397-1398.

(S50) Ziegenbein, W.; Franke, W. Chem. Ber. 1957, 90, 2291-2301, on p 2301.

(S51) Kopecký, J.; Šmejkal, J. Coll. Czech. Chem. Commun. 1980, 45, 2965-2970.

(S52) Nilssen, Å.; Carlson, R. Acta Chem. Scand. B 1980, 34, 621-621.

(S53) Holtz, H. D.; Stock, L. M. J. Am. Chem. Soc. 1964, 86, 5183-5188.

(S54) Gray, G. W.; Kelly, S. M. J. Chem. Soc., Perkin Trans. 2 1981, 26-31.

(S55) (a) Saunders, M.; Jaffe, M. H.; Vogel, P. J. Am. Chem. Soc. 1971, 93, 2558-2559. (b) Siehl, H. U. Adv. Phys. Org. Chem. 1987, 23, 63-163.

(S56) Bruson, H. A.; Riener, T. W. J. Am. Chem. Soc. 1942, 64, 2850-2858.

(S57) Colonge, J.; Vuillemet, R. Bull. Soc. Chim. Fr. 1961, 2235-2238.

(S58) Morita, K.; Kobayashi, T. J. Org. Chem. 1966, 31, 229-232.

(S59) Colonge, J.; François, P.; Vuillemet, R. Bull. Soc. Chim. Fr. 1966, 1028-1031.

(S60) Suzuki, Z.; Morita, K. J. Org. Chem. 1967, 32, 31-34.

(S61) Kopecký, J.; Šmejkal, J.; Hanuš, V. Coll. Czech. Chem. Commun. 1981, 46, 1370-1375. 